\title{
O impacto de algumas causas básicas de morte na esperança de vida de residentes em Salvador e São Paulo - 1996
}

\section{André Renê Barboni}

Tese apresentada ao Departamento de Epidemiologia da Faculdade de Saúde Pública da Universidade de São Paulo para obtenção do Título de Doutor.

Área de Concentração: Epidemiologia

Orientadora: Prof?. Dr. ${ }^{2}$ Sabina Léa Davidson Gotlieb

São Paulo

2002 
Autorizo, exclusivamente para fins acadêmicos e científicos, a reprodução total ou parcial desta tese, por processos fotocopiadores.

Assinatura: Pollowi.

Data: 04/O4/ LOal

$$
42098 / 2002 d x
$$


Sem saber que era impossível, foi lá e fez. 


\section{DEDICATÓRIA}

À minha orientadora Professora SABINA por tudo o que fez por mim e pelo exemplo de dedicação ao Ensino e à Saúde Pública. É com muita emoção e carinho que eu lhe dedico este trabalho.

Aos MEUS PAIS, MINHA FAMÍLIA, AMIGOS e todos aqueles que torceram pelo meu sucesso. 


\section{AGRADECIMENTOS}

À Professora MÁRCIA FURQUIM DE ALMEIDA, pelo apoio e orientação que culminaram na definição do tema deste estudo.

A RAFA, VIVI e NATI, pelo tempo que lhes roubei, mas que prometo recompensar.

A SUZI, minha esposa e companheira, pelo apoio e carinho.

A SUANI DE ALMEIDA VASCONCELOS, pela preciosa ajuda nas questões da língua portuguesa.

Aos PROFESSORES DO CURSO DE DOUTORADO, por tudo o que nos ensinaram e pela convivência maravilhosa, apesar de tão curta.

Aos COLEGAS do curso.

Aos amigos e funcionários da UEFS e da FSP/USP.

Aos heróis anônimos, responsáveis pelo desenvolvimento e manutenção dos programas/dados disponibilizados pelo DATASUS.

Aos criadores e mantenedores da Internet, em especial, aos responsáveis pelos sites do DATASUS, IBGE, SEADE, ABEB e portal CAPES.

\section{OBRIGADO!...}




\section{RESUMO}

Barboni $\mathrm{AR}$. $\mathrm{O}$ impacto de algumas causas básicas de morte na esperança de vida de residentes em Salvador e São Paulo - 1996. São Paulo; 2002. [Tese de Doutorado - Faculdade de Saúde Pública da USP].

Objetivo. Avaliar e analisar o impacto de algumas causas básicas de morte na esperança de vida dos residentes nos Municípios de Salvador (BA) e São Paulo (SP), em 1996. Métodos. Trata-se de um estudo ecológico descritivo, utilizando dados oficiais secundários e estimativas. Através de um corte transversal, avaliou-se o impacto de diferentes grupos de causas de óbito na esperança de vida por meio de tábuas de vida de múltiplo decremento. Resultados. As esperanças de vida ao nascer (EVN) para as populaçôes masculinas de ambos os municípios (64,10 anos, em Salvador e 63,39 anos, em São Paulo) ficaram abaixo das EVN das mulheres (70,33 anos, em Salvador e 73,92 anos, em São Paulo). Doenças de caráter transmissível têm uma influência maior nas primeiras idades, as causas externas (CE), principalmente entre os homens, nas idades intermediárias, e, nas idades mais avançadas, destacam-se as doenças do aparelho circulatório (DAC). Na faixa etária economicamente ativa, predominam as DAC seguidas das CE para os homens e, com relação ao sexo feminino, as doenças infecciosas e parasitárias (DIP) em conjunto com as doenças do aparelho respiratório (DAR - provavelmente um fenômeno associado à Aids) assumem um papel significativo na mortalidade das duas capitais para a faixa do adulto jovem e as neoplasias constituem a segunda causa de óbito entre mulheres de 40 anos e mais, permitindo, assim, um diferencial entre os sexos. Por ordem de importância, atuaram, no sexo masculino, as DAC, as CE, as neoplasias, as DAR e, por fim, as DIP, em ambos os municípios estudados. No sexo feminino, a ordenação foi: DAC, as neoplasias, as DAR, as DIP e, por fim, as CE. Conclusão. As disparidades sociais entre as duas capitais interferem, primeiro, em um nível estrutural que vai desde a oferta e qualidade dos serviços oferecidos à população até o nível de informação que estes serviços conseguem gerar. $O$ subregistro de óbitos, na Bahia e no Nordeste, é um bom exemplo de como isso pode prejudicar análises mais detalhadas.

Descritores: Saúde Pública. Esperança de vida. Tábua de vida de múltiplo decremento. Riscos competitivos. Mortalidade. 


\section{SUMMARY}

Barboni AR. The impact of some underlying causes of death in the life expectancy of Salvador and São Paulo populations - 1996. São Paulo; 2002. [Tese de Doutorado - Faculdade de Saúde Pública da USP].

Objective. To evaluate and to analyze the impact of some underlying causes of death in the life expectancy of residents in Salvador (BA) and São Paulo (SP), in 1996. Methods. This is a ecological study, based in official data. By a transversal cut, the impact of different groups of causes of death in life expectancy was evaluated by means of multiple decrement life tables. Results. The male life expectancies at birth (LEB) in both cities (64.10 years, in Salvador, and 63.39 years, in São Paulo) was above the female's LEB (70.33 years, in Salvador, and 73.92, in São Paulo). Communicable diseases have major influence in the first ages, the external causes (EC), especially for men, in the intermediate ages, and, in elderly ages, the cardiovascular diseases (CVD) have distinction. In the active economic ages, CVD was the predominant followed by EC for men. In respect to female, infective and parasitic diseases (IPD) with respiratory diseases (RD - probably an associated Aids phenomena) assume a significant role in the mortality of young adults for the two capitals and the neoplasms constitute the second cause of death for women older than 39 years, this denotes a gender differential. Ranking by importance, the causes of death were for males the CVD, EC, neoplasms, RD and, finally the IPD, in both cities. For females, the sequence was: CVD, neoplasms, RD, IPD and finally the EC. Conclusion. The social disparities among the two capitals interfere, at first, in the structural level, since the public services' offers and quality until the information level that this services can produce. The under-registration of deaths in Bahia and in the Northeast Region is a good example of how this can prejudice a more detailed analysis.

Descriptors: Public health. Life expectancy. Multiple decrement life table. Competitive risks. Mortality. 


\section{LISTA DE TABELAS}

1 - Número de habitantes, segundo sexo e grupo etário, de residentes nos Municípios de Salvador (BA) e São Paulo (SP) em 01/07/1996

2 - Número de óbitos, segundo sexo e grupo etário, de residentes nos Municípios de Salvador (BA) e São Paulo (SP), 1996

3 - Tábua de vida. População residente no Município de Salvador (BA), 1996 (ambos os sexos)

4 - Tábua de vida. População residente no Município de São Paulo (SP), 1996 (ambos os sexos)

5 - Tábua de vida. População masculina residente no Município de Salvador (BA), 1996

6 - Tábua de vida. População masculina residente no Município de São Paulo (SP), 1996

7 - Tábua de vida. População feminina residente no Município de Salvador (BA), 1996

8 - Tábua de vida. População feminina residente no Município de São Paulo (SP), 1996

9 - Esperança de vida ao nascer (em anos), segundo sexo e respectivas diferenças, no Município de São Paulo, em 1950, 1960, 1970 e 1996

10 - Proporção de óbitos segundo sexo e tipo de agravo (capítulos da CID10), Salvador (BA) e São Paulo (SP), 1996

11 - Comparação entre as probabilidades de morte real $\left(q_{X}\right)$ e líquida ( $q_{x}$ ), eliminando as doenças infecciosas e parasitárias como fator de risco de morte, segundo sexo e idade, Municípios de Salvador (BA) e São Paulo (SP), 1996

12 - Comparação entre as probabilidades de sobreviver real ( $p_{o x}$ ) e hipotética ( $\mathrm{p}_{\mathrm{OX}}$.), eliminando as doenças infecciosas e parasitárias como fator de risco de morte, segundo sexo e idade, dos residentes dos Municípios de Salvador (BA) e São Paulo (SP), 1996

13 - Comparação entre as esperanças de vida real $\left(e_{\mathrm{x}}\right)$ e hipotética ( $\mathrm{e}_{\mathrm{x}}$.), eliminando as doenças infecciosas e parasitárias como fator de risco de morte, segundo sexo e idade, dos residentes dos Municípios de Salvador (BA) e São Paulo (SP), 1996

14 - Comparação entre os totais de anos vividos além de $X$ real $\left(T_{X}\right)$ e hipotético $\left(\mathrm{T}_{\mathrm{X}}\right.$ ) (Anos Potenciais de Vida Ganhos - APVG), eliminando as doenças infecciosas e parasitárias como fator de risco de morte, segundo sexo e idade, dos residentes dos Municípios de Salvador (BA) e São Paulo (SP), 1996 
15 - Comparação entre as esperanças de vida real $\left(\mathrm{e}_{\mathrm{x}}\right)$ e hipotética (ex.), eliminando as doenças infecciosas intestinais como fator de risco de morte, segundo sexo e idade, dos residentes dos Municípios de Salvador (BA) e São Paulo (SP), 1996

16 - Comparação entre as esperanças de vida real $\left(e_{X}\right)$ e hipotética ( $\left.e_{X}.\right)$, eliminando as outras doenças bacterianas como fator de risco de morte, segundo sexo e idade, dos residentes dos Municípios de Salvador (BA) e São Paulo (SP), 1996

17 - Comparação entre as esperanças de vida real $\left(e_{X}\right)$ e hipotética ( $\left.e_{X}.\right)$, eliminando as doenças virais como fator de risco de morte, segundo sexo e idade, dos residentes dos Municípios de Salvador (BA) e São Paulo (SP), 1996

18 - Comparação entre as probabilidades de morte real $\left(q_{x}\right)$ e líquida $\left(q_{x}.\right)$, eliminando as neoplasias como fator de risco de morte, segundo sexo e idade, dos residentes dos Municípios de Salvador (BA) e São Paulo (SP), 1996

19 - Comparação entre as probabilidades de sobreviver real ( $\mathrm{p}_{\text {ox }}$ ) e hipotética ( $\mathrm{p}_{\mathrm{OX}}$.), eliminando as neoplasias como fator de risco de morte, segundo sexo e idade, dos residentes dos Municípios de Salvador (BA) e São Paulo (SP), 1996

20 - Comparação entre as esperanças de vida real ( $\left.e_{X}\right)$ e hipotética (e $\left.e_{X} \cdot\right)$, eliminando as neoplasias como fator de risco de morte, segundo sexo e idade, dos residentes dos Municípios de Salvador (BA) e São Paulo (SP), 1996

21 - Comparação entre os totais de anos vividos além de $X$ real $\left(T_{X}\right)$ e hipotético $\left(\mathrm{T}_{\mathrm{X}}\right.$ ) (Anos Potenciais de Vida Ganhos - APVG), eliminando as neoplasias como fator de risco de morte, segundo sexo e idade, dos residentes dos Municípios de Salvador (BA) e São Paulo (SP), 1996

22 - Comparação entre as probabilidades de morte real $\left(\mathrm{q}_{\mathrm{X}}\right)$ e líquida $\left(\mathrm{q}_{\mathrm{X}}\right.$. $)$, eliminando as doenças do aparelho circulatório como fator de risco de morte, segundo sexo e idade, dos residentes dos Municípios de Salvador (BA) e São Paulo (SP), 1996

23 - Comparação entre as probabilidades de sobreviver real (pox) e hipotética (pox.), eliminando as doenças do aparelho circulatório como fator de risco de morte, segundo sexo e idade, dos residentes dos Municípios de Salvador (BA) e São Paulo (SP), 1996

24 - Comparação entre as esperanças de vida real $\left(\mathrm{e}_{\mathrm{X}}\right)$ e hipotética $\left(\mathrm{e}_{\mathrm{X}}\right.$.), eliminando as doenças do aparelho circulatório como fator de risco de morte, segundo sexo e idade, dos residentes dos Municípios de Salvador (BA) e São Paulo (SP), 1996

25 - Comparação entre os totais de anos vividos além de $\mathrm{X}$ real $\left(\mathrm{T}_{\mathrm{X}}\right)$ e hipotético $\left(\mathrm{T}_{\mathrm{X}}\right.$ ) (Anos Potenciais de Vida Ganhos - APVG), eliminando as doenças do aparelho circulatório como fator de risco de morte, segundo sexo e idade, dos residentes dos Municípios de Salvador (BA) e São Paulo (SP), 1996 
26 - Comparação entre as esperanças de vida real $\left(e_{\mathrm{x}}\right)$ e hipotética (ex.), eliminando as doenças isquêmicas do coração como fator de risco de morte, segundo sexo e idade, dos residentes dos Municípios de Salvador (BA) e São Paulo (SP), 1996

27 - Comparação entre as esperanças de vida real $\left(\mathrm{e}_{\mathrm{X}}\right)$ e hipotética (e $\mathrm{e}_{\mathrm{X}}$.), eliminando as doenças cerebrovasculares como fator de risco de morte, segundo sexo e idade, dos residentes dos Municípios de Salvador (BA) e São Paulo (SP), 1996

28 - Comparação entre as probabilidades de morte real $\left(\mathrm{q}_{\mathrm{x}}\right)$ e líquida $\left(\mathrm{q}_{\mathrm{x}}\right.$.), eliminando as doenças do aparelho respiratório como fator de risco de morte, segundo sexo e idade, dos residentes dos Municípios de Salvador (BA) e São Paulo (SP), 1996

29 - Comparação entre as probabilidades de sobreviver real (pox) e hipotética (pox.), eliminando as doenças do aparelho respiratório como fator de risco de morte, segundo sexo e idade, dos residentes dos Municípios de Salvador (BA) e São Paulo (SP), 1996

30 - Comparação entre as esperanças de vida real $\left(e_{\mathrm{X}}\right)$ e hipotética ( $\mathrm{e}_{\mathrm{X}}$.), eliminando as doenças do aparelho respiratório como fator de risco de morte, segundo sexo e idade, dos residentes dos Municípios de Salvador (BA) e São Paulo (SP), 1996

31 - Comparação entre os totais $d$ anos vividos além de $X$ real $\left(T_{X}\right)$ e hipotético $\left(\mathrm{T}_{\mathrm{X}}\right.$ ) (Anos Potenciais de Vida Ganhos - APVG), eliminando as doenças do aparelho respiratório como fator de risco de morte, segundo sexo e idade, dos residentes dos Municípios de Salvador (BA) e São Paulo (SP), 1996

32 - Comparação entre as probabilidades de morte real $\left(q_{X}\right)$ e líquida $\left(q_{X}.\right)$, eliminando as causas externas como fator de risco de morte, segundo sexo e idade, dos residentes dos Municípios de Salvador (BA) e São Paulo (SP), 1996

33 - Comparação entre as probabilidades de sobreviver real ( $\mathrm{p}_{\mathrm{ox}}$ ) e hipotética (pox.), eliminando as causas externas como fator de risco de morte, segundo sexo e idade, dos residentes dos Municípios de Salvador (BA) e São Paulo (SP), 1996

34 - Comparação entre as esperanças de vida real $\left(\mathrm{e}_{\mathrm{X}}\right)$ e hipotética $\left(\mathrm{e}_{\mathrm{X}}.\right)$, eliminando as causas externas como fator de risco de morte, segundo sexo e idade, dos residentes dos Municípios de Salvador (BA) e São Paulo (SP), 1996

35 - Comparação entre os totais de anos vividos além de $\mathrm{X}$ real $\left(\mathrm{T}_{\mathrm{X}}\right)$ e hipotético $\left(\mathrm{T}_{\mathrm{X}}\right.$ ) (Anos Potenciais de Vida Ganhos - APVG), eliminando as causas externas como fator de risco de morte, segundo sexo e idade, dos residentes dos Municípios de Salvador (BA) e São Paulo (SP), 1996

36 - Comparação entre as esperanças de vida real ( $\left.e_{\mathrm{X}}\right)$ e hipotética (ex.), eliminando os acidentes de transporte como fator de risco de morte, segundo sexo e idade, dos residentes dos Municípios de Salvador (BA) e São Paulo (SP), 1996 
37 - Comparação entre as esperanças de vida real $\left(e_{\mathrm{x}}\right)$ e hipotética (e $\mathrm{e}_{\mathrm{X}}$ ), eliminando as agressões como fator de risco de morte, segundo sexo e idade, dos residentes dos Municípios de Salvador (BA) e São Paulo (SP), 1996

38 - Diferenças relativas (\%) entre as probabilidade real e líquida de morte, segundo faixas etárias e grupos de morte eliminados (capítulos da CID-10), para residentes nos Municípios de Salvador (BA) e São Paulo (SP), em 1996 (Sexo masculino)

39 - Diferenças relativas (\%) entre as probabilidade real e líquida de morte, segundo faixas etárias e grupos de morte eliminados (capítulos da CID-10), para residentes nos Municípios de Salvador (BA) e São Paulo (SP), em 1996 (Sexo feminino)

40 - Probabilidade de sobreviver (\%), segundo sexo, faixas etárias e grupos de causas de morte eliminados (capítulos da CID-10), para residentes nos Municípios de Salvador (BA) e São Paulo (SP), em 1996

41 - Número de anos ganhos na esperança de vida ao nascer, segundo sexo e grupos de causas de morte eliminados (capítulos da CID-10), para residentes nos Municípios de Salvador (BA) e São Paulo (SP), em 1996 


\section{LISTA DAS FIGURAS}

1 - Pirâmides populacionais, segundo sexo e faixa etária (\%). Municípios de Salvador e São Paulo, 1996

2 - Distribuição proporcional (\%) dos óbitos por doenças infecciosas e parasitárias, segundo sexo e faixa etária. Municípios de Salvador e São Paulo, 1996

3 - Distribuição proporcional (\%) dos óbitos por doenças infecciosas e parasitárias, segundo sexo e faixa etária. Município de São Paulo, 1970 e 1996

4 - Proporção de população atendida por "condições mínimas de água, esgoto e lixo", respectivamente, nos Estados da Bahia e São Paulo de acordo com dados do Censo Populacional do IBGE de 1991

5 - Distribuição proporcional (\%) dos óbitos por doenças infecciosas e intestinais, segundo sexo e faixa etária. Municípios de Salvador e São Paulo, 1996

6 - Distribuição proporcional (\%) dos óbitos por outras doenças bacterianas, segundo sexo e faixa etária. Municípios de Salvador e São Paulo, 1996

7 - Distribuição proporcional (\%) dos óbitos por doenças virais, segundo sexo e faixa etária. Municípios de Salvador e São Paulo, 1996

8 - Coeficiente de mortalidade (100.000 habitantes) por doenças infecciosas e parasitárias, segundo subgrupos de causa (CID10-BR) e sexo. Municípios de Salvador e São Paulo, 1996

9 - Coeficiente de mortalidade (100.000 habitantes) por doenças infecciosas e parasitárias, segundo subgrupos de causa (CID10-BR) e sexo, eliminando-se doenças pelo vírus da imunodeficiência humana HIV. Municípios de Salvador e São Paulo, 1996

10 - Distribuição proporcional (\%) dos óbitos por neoplasias, segundo sexo e faixa etária. Municípios de Salvador e São Paulo, 1996

11 - Coeficiente de mortalidade (100.000 habitantes) por neoplasias, segundo localizações anatômicas mais freqüentes e sexo. Municípios de Salvador e São Paulo, 1996

12 - Coeficiente de mortalidade (100.000 habitantes) por doenças do aparelho circulatório, segundo subgrupos de causa (CID10-BR) e sexo. Municípios de Salvador e São Paulo, 1996

13 - Distribuição proporcional (\%) dos óbitos por doenças do aparelho circulatório, segundo sexo e faixa etária. Municípios de Salvador e São Paulo, 1996

14 - Distribuição proporcional (\%) dos óbitos por doenças isquêmicas do coração, segundo sexo e faixa etária. Municípios de Salvador e São Paulo, 1996 
15 - Distribuição proporcional (\%) dos óbitos por doenças cerebrovasculares, segundo sexo e faixa etária. Municípios de Salvador e São Paulo, 1996

16 - Coeficiente de mortalidade (100.000 habitantes) por doenças do aparelho respiratório, segundo subgrupos de causa (CID10-BR) e sexo. Municípios de Salvador e São Paulo, 1996

17 - Distribuição proporcional (\%) dos óbitos por doenças do aparelho respiratório, segundo sexo e faixa etária. Municípios de Salvador e São Paulo, 1996

18 - Distribuição proporcional (\%) dos óbitos por causas externas, segundo sexo e faixa etária. Municípios de Salvador e São Paulo, 1996

19 - Coeficiente de mortalidade (100.000 habitantes) por causas externas, segundo subgrupos de causa (CID10-BR) e sexo. Municípios de Salvador e São Paulo, 1996

20 - Distribuição proporcional (\%) dos óbitos por acidentes de transporte. Municípios de Salvador e São Paulo, 1996

21 - Distribuição proporcional (\%) dos óbitos por agressões, segundo sexo e faixa etária. Municípios de Salvador e São Paulo, 1996

22 - Proporção de óbitos por capítulo da CID-10 e sexo. Municípios de Salvador e São Paulo, 1996 


\section{ABREVIATURAS, SIGLAS E SÍMBOLOS}

$a^{\prime}$

$a^{\prime}$

Aids Síndrome da imunodeficiência adquirida (Acquired Immunodeficiency Syndrome)

APVG Anos potenciais de vida ganhos

APVP Anos potenciais de vida perdidos

CID Classificação internacional de doenças

DALE Disability-Adjusted Life Expectancy

DALY Disability-Adjusted Life Years

D $_{\mathbf{i}} \quad$ Óbitos totais na idade $\mathrm{i}$

$\mathbf{D}_{\mathrm{ij}} \quad$ Óbitos ocorridos na idade i pela causa $\mathrm{j}$, ou grupo de causas $\mathrm{j}$

D $_{\mathrm{i} . j} \quad$ Óbitos totais na idade $\mathrm{i}$, excluindo os óbitos da causa eliminada, ou grupo de causas eliminadas, $\mathrm{j}$

Do Declaração de óbito

dx $\quad$ Número de mortes no intervalo etário $(x, x+n)$

EV Esperança de vida

EVN Esperança de vida ao nascer

ex Esperança de vida observada na idade $x$

ex. Esperança de vida hipotética

FIBGE Fundação Instituto Brasileiro de Geografia e Estatística

HALE Health-Adjusted Life Expectancy

HALY Health-Adjusted Life Year

HIV Vírus da imunodeficiência humana (Human Immunodeficiency Virus)

IBGE Instituto Brasileiro de Geografia e Estatística

IDH Índice de desenvolvimento humano

Ix $\quad$ Número de sobreviventes que iniciaram $\mathrm{a}$ idade $\mathrm{x}$

$\mathbf{M}_{\mathbf{i}} \quad$ Coeficiente de mortalidade na idade i

$\mathbf{M}_{\mathrm{ij}} \quad$ Coeficiente de mortalidade específico pela causa $\mathrm{j}$, ou grupo de causas $\mathrm{j}$, na idade $\mathrm{i}$

MS Ministério da Saúde

$\mathbf{N}_{\mathbf{i}} \quad$ Intervalo de classe para o grupo etário considerado

nLx Número de anos vividos no intervalo etário $(x, x+n)$

„OX Óbitos ocorridos no intervalo etário $(\mathrm{x}, \mathrm{x}+\mathrm{n})$ 
${ }_{n} P_{\mathbf{X}} \quad$ População estimada no intervalo etário $(\mathrm{x}, \mathrm{x}+\mathrm{n})$

OMS Organização Mundial de Saúde

$\hat{\mathbf{p}}_{\mathbf{i}} \quad$ Estimador da probabilidade de um indivíduo sobreviver de $\mathrm{x}_{\mathrm{i}}$ a $\mathrm{x}_{\mathrm{i}+\mathrm{n}}$

PIB Produto interno bruto

PNAD Pesquisa Nacional de Amostras por Domicílio

PNUD Programa das Nações Unidas para o Desenvolvimento

Pox. Probabilidade de sobreviver hipotética

QALE Quality-Adjusted Life Expectancy

QALY Quality-Adjusted Life Year

$\mathbf{q}_{\mathrm{ij}} \quad$ Probabilidade de um indivíduo vivo, no tempo $\mathrm{x}_{\mathrm{i}}$, vir a morrer no intervalo $\left(x_{i}, x_{i+n}\right)$ se a causa específica, ou grupo de causas, $R_{j}$, for o único fator de risco atuando sobre a população

$\hat{\mathrm{q}}_{\mathrm{ij}} \quad$ Estimador da probabilidade $\mathrm{q}_{\mathrm{ij}}$

$\mathbf{q}_{\mathrm{i}, \mathrm{j}} \quad$ Probabilidade de um indivíduo vivo, no tempo $\mathrm{x}_{\mathrm{i}}$, vir a morrer no intervalo $\left(x_{i}, x_{i+n}\right)$ se a causa específica, ou grupo de causas, $R_{j}$, for eliminada como fator de risco de morte

$\hat{\mathbf{q}}_{\mathrm{i} . \mathbf{j}} \quad$ Estimador da probabilidade $\mathrm{q}_{\mathrm{i}, \mathrm{j}}$

qx Proporção de mortes no intervalo etário $(\mathrm{x}, \mathrm{x}+\mathrm{n})$

qx. Probabilidade de morte hipotética

SEI Superintendência de Estudos Econômicos e Sociais da Bahia

SIM Sistema de Informações sobre Mortalidade

SUS Sistema Único de Saúde

$\mathbf{T}_{\mathrm{X}} \quad$ Total de anos vividos no intervalo etário $(\mathrm{x}, \mathrm{X}+\mathrm{n})$

$\mu_{\mathrm{i} . \mathrm{j}}(\mathrm{t}) \quad$ Força de mortalidade na idade i excluída uma causa de óbito $\mathrm{j}$, ou grupo de causas, num instante $\mathrm{t}$

$\mu_{i}(t) \quad$ Força de mortalidade total na idade $i$, num instante $t$

WHO World Health Organization

Intervalo ou grupo etário 


\section{ÍNDICE}

1 INTRODUÇÃO 1

$1.1 \quad$ O conceito de saúde 1

$\begin{array}{lll}1.2 & \text { Eqüidade social } & 4\end{array}$

$\begin{array}{lll}1.3 & \text { Indicadores sociais }\end{array}$

$\begin{array}{lll}1.3 .1 & \text { Esperança de vida } & 10\end{array}$

1.4 O Sistema de Informações sobre Mortalidade - SIM 14

$\begin{array}{lll}1.5 & \mathrm{O} \text { impacto das causas de morte na esperança de vida } & 17\end{array}$

1.5.1 Tábuas de vida de múltiplo decremento 19

1.6 A definição do objeto de estudo 22

2 OBJETIVO 26

2.1 Objetivo Geral 26

2.2 Objetivos Específicos 26

3 METODOLOGIA $\quad 27$

3.1 Delineamento 27

3.2 Dados necessários 27

$\begin{array}{lll}3.2 .1 & \text { População } & 27\end{array}$

3.2.2 Óbitos 28

3.2.2.1 Grupos de causas básicas de morte 30

3.3 Construção das tábuas de vida 30

3.3.1 Elementos da tábua de vida 31

3.3.2 Tábua de vida de múltiplo decremento 32

3.3.2.1 Probabilidade bruta de morte 32

3.3.2.2 Probabilidade líquida de morte 33

3.4 Avaliação do impacto dos grupos de causas de morte na esperança de vida 36 
4.1 Estrutura da população, segundo sexo e faixa etária 37

4.2 Esperança de vida 38

4.2.1 Esperança de vida segundo sexo $\quad 38$

4.3 Tábuas de vida de múltiplo decremento 41

4.3.1 Eliminando o grupo das doenças infecciosas $\mathrm{e}$ parasitárias

4.3.1.1 Eliminando o grupo das doenças infecciosas intestinais 48

4.3.1.2 Eliminando o grupo das outras doenças bacterianas $\quad 50$

4.3.1.3 Eliminando o grupo das doenças virais 52

4.3.2 Eliminando o grupo das neoplasias 57

4.3.3 Eliminando o grupo das doenças do aparelho circulatório 63

4.3.3.1 Eliminando o grupo das doenças isquêmicas do coração

4.3.3.2 Eliminando o grupo das doenças cerebrovasculares $\quad 71$

4.3.4 Eliminando o grupo das doenças do aparelho respiratório $\quad 74$

4.3.5 Eliminando o grupo das causas externas de morbidade e mortalidade 79

4.3.5.1 Eliminando o grupo dos acidentes de transporte $\quad 84$

4.3.5.2 Eliminando o grupo das agressões 85

$\begin{array}{lll}4.4 & \text { Análise global } & 87\end{array}$ 


\section{INTRODUÇÃO}

\section{$1.1 O$ conceito de saúde}

$\mathrm{O}$ conceito de saúde tem evoluído muito nos últimos anos. $\mathrm{O}$ assunto não é recente e sua discussão não está próxima de se esgotar. São tantas as visões e definições apresentadas quanto são as ideologias por trás destes conceitos. Partindo da idéia de que um objeto assimétrico e com inúmeros detalhes, fotografado de ângulos distintos, apresenta diversas imagens e que se fosse dado a um exímio artesão, que não o viu, criar outro objeto, a partir de uma única imagem, provavelmente a cópia seria diferente do original.

Por analogia, pode-se dizer que o mesmo se dá com relação ao conceito de saúde que tenta descrever em palavras algo tão complexo e cheio de minúcias a partir de uma imagem que é fruto da visão de quem a formulou. É claro que saúde não é apenas a ausência de doença, como já foi definida no passado, nem tampouco deve ser uma utopia ou algo que nunca será atingido como querem alguns. No entanto, é preciso ter uma idéia norteadora para descrevê-la e, assim, estabelecer uma política e um planejamento a fim de alcançá-la.

Assim, pode-se dizer que houve uma verdadeira "evolução conceitual" dos modos de pensar e fazer em saúde, resultando daí modelos diferenciados de assistência, desde os modos monocausais de pensamento em saúde, passando pela história natural das doenças de Leavell e Clark (GOULART 1999), até chegar ao conceito de Campo de Saúde (LALONDE 1974).

Segundo CARVALHO e RIBEIRO (cit. GOULART 1999), os modelos assistenciais são construções históricas e sociais. São condicionadas pelo modo de desenvolvimento das sociedades e pelo período histórico a que se referem, resultando de um processo de disputas e acordos entre atores sociais. "Decorrem destas definições alguns aspectos essenciais, a saber: (a) não existem modelos em estado puro nas sociedades; (b) não estão isentos dos interesses e das vontades dos diversos grupos sociais; (c) não há modelos 'corretos' ou 'errados', assim como (d) não há modelos gerais ou universais" (GOULART 1999). 
Os marcos conceituais históricos da teoria do Campo da Saúde são baseados na promoção da saúde e inicia-se na década de 70. Parte do pressuposto de que Saúde e Doença não são coisas estanques e isoladas, mas dois estados de um só fenômeno, suas causas são interligadas e expressam um "gradiente de saúde" do ponto de vista individual ou coletivo. As variações deste gradiente estão sujeitas à ação conjunta dos fatores biológicos, estilo de vida, fatores ambientais e o acesso aos sistemas de serviço de saúde. Assim, segundo essa teoria, só é possível transformar o processo saúde/doença se se impactar o processo social de uma forma integrada.

"Desse modo, a saúde deve ser entendida em sentido mais amplo, como
componente da qualidade de vida. Assim, não é um 'bem de troca', mas
um 'bem comum', um bem e um direito social, em que cada um e todos
possam ter assegurados o exercício e a prática do direito à saúde, a partir
da aplicação e utilização de toda a riqueza disponível, conhecimentos e
tecnologia desenvolvidos pela sociedade nesse campo, adequados às suas
necessidades, abrangendo promoção e proteção da saúde, prevenção,
diagnóstico, tratamento e reabilitação de doenças. Em outras palavras,
deve-se considerar esse bem e esse direito como componentes e
exercícios da cidadania, que é um referencial e um valor básico a serem
assimilados pelo poder público para o balizamento e orientação de sua
conduta, decisões, estratégias e ações" (ALMEIDA, CASTRO e VIEIRA
1998, p. 11).

Numa abordagem sociológica, a saúde aparece no âmbito da determinação social como um direito (o destaque é nosso). Logo, o homem doente já revela a falha no sistema de saúde (FARHAT 1989). Conseqüentemente, se a enfermidade é uma disfunção física ou psíquica que afeta o indivíduo, o enfermo é uma disfunção social que afeta a relação entre os indivíduos. Assim, para se obter a saúde integral, GORDON (cit. FARHAT 1989), numa interpretação ecológica e epidemiológica, aponta a combinação de três disciplinas: a Medicina, que adapta o homem ao seu ambiente, a Engenharia, que adapta o ambiente ao homem, e as Ciências Sociais, que adaptam o homem a outros homens. 
Do ponto de vista científico, para se conhecer uma sociedade, utiliza-se o conceito de Modo de Produção, o qual se constitui em diversos níveis: econômico (relação de produção), político (leis, estado etc.) e ideológico (idéias, costumes, religião etc.) (BARBOSA e MANGABEIRA 1985). Logo, se não se conhece bem uma dada população, as propostas de intervenção, prevenção e promoção da saúde serão inadequadas, gerando baixa efetividade das ações e benefícios limitados (o destaque é nosso). Desta sorte, uma sociedade, dentro de seus valores e formas de compreensão da realidade, pode ela própria identificar e priorizar seus problemas de saúde, assim como definir suas relações com os principais fatores causais ou protetores (SEGURA 1998).

Nesse contexto, a saúde é resultado de um processo de produção social, conceito derivado do paradigma proposto por LALONDE, que expressa a qualidade de vida de uma população (acesso a bens e serviços econômicos e sociais) e que foi incorporado no Artigo 196 da Constituição Federal de 1988: "Saúde é direito de todos e dever do Estado..." (MENDES et al. 1999; MENDES 1999).

A Teoria da Produção Social, além de dar conta de um estado de saúde em permanente transformação, é resultante de fatos econômicos, políticos, ideológicos e cognitivos. Com isso, em relação ao estilo e qualidade de vida da população, a saúde pode ser concebida como "acumulação social" e a doença, "desacumulação social", fazendo surgir o conceito de saúde como qualidade de vida (MENDES 1999, o destaque é nosso). Rompe-se, desta forma, com a idéia de um setor saúde, erigindo-a como produto social resultante de fatos sociais (CHIORO, ALMEIDA e ZIONI 1997; ALMEIDA, CASTRO e VIEIRA 1998).

Desta forma, a saúde adquire o "status" de produto social resultante, como anteriormente dito, de fatores políticos, econômicos, ideológicos e culturais e, assim, como campo de conhecimento, exige a interdisciplinaridade e como campo de práticas, a intersetorialidade (GOULART 1999). Não se pode falar em saúde sem mencionar qualidade de vida. $E$, por sua vez, não se pode falar em qualidade de vida sem pensar em eqüidade social. Neste contexto, a informação tem papel fundamental para a definição e orientação de ações que visem desenvolver políticas públicas saudáveis, criar ambientes adequados, fortalecer a ação comunitária, desenvolver habilidades pessoais e reorientar os serviços de saúde. 


\subsection{Eqüidade social}

Segundo GOLDBAUM (1997), a saúde das populações tem merecido análises e interpretações, desde a mais remota história da humanidade, e têm sido objeto privilegiado de estudo as desigualdades na distribuição das doenças, expressão das iniqüidades sociais. Algumas análises indicam que essas desigualdades favorecem a constatação de que, em função das diferenças entre as pessoas, a igualdade absoluta talvez seja algo inatingível e por que não dizer indesejável. Trata-se, então, de recuperar a idéia de eqüidade, cuja acepção ultrapassa os limites da igualdade e encontra-se com a idéia de justiça social.

No Brasil, as lutas sociais pelo direito à saúde culminaram com a consagração, na Constituição de 1988, da saúde como um direito universal sendo dever do Estado garanti-lo. Com a criação do Sistema Único de Saúde (SUS), toda a população, independentemente de vínculo previdenciário, formalmente passa a poder ser atendida pelos serviços de saúde do sistema público (GIOVANELLA et al. 1996).

Este é um passo fundamental para a redução das desigualdades sociais e, embora inegável a importância do SUS na atenção médico-hospitalar no país, paralelamente aos avanços legais visando a universalização do direito à saúde, gestou-se na sociedade uma outra dinâmica que reciclou o modelo médicoassistencial privativista, re-segmentou clientelas e cristalizou desigualdades no acesso aos serviços de saúde (GIOVANELLA et al. 1996).

O liberalismo clássico considerava ser possível alcançar a igualdade de oportunidades mediante a igual atribuição de direitos fundamentais à vida e à propriedade. Deste modo, surgiria uma mobilidade social perfeita advinda da igualdade de oportunidades e todos, independentemente de sua origem, teriam as mesmas oportunidades de alcançar as mais altas posições sociais (GIOVANELLA et al. 1996).

"Reconhece-se, atualmente, que a igualdade de direitos não é suficiente para garantir oportunidades iguais entre os indivíduos socialmente desfavorecidos e os socialmente privilegiados. Há necessidade de distribuições desiguais para colocar os primeiros no mesmo nível de partida. Para a igualdade de oportunidades ter conteúdo significativo 
dever-se-ia promover a igualdade de condições. Embora as necessidades pessoais variem, haveria um mínimo de necessidades básicas substancialmente idênticas em todos, em cada sociedade e época histórica, cuja satisfação deveria ser nivelada" (BOBBIO, MATTEUCCI e PASQUINO 1986:604).

Para a doutrina liberal, não é possível compatibilizar igualdade e liberdade. A regulamentação da economia, que o alcance de igualdade de condições requer, limita certas liberdades individuais. Não há, porém, um inevitável conflito entre interesses individuais e coletivos. Existe uma relação fundamental entre cidadania, igualdade social e desenvolvimento individual. $\mathrm{O}$ maior desenvolvimento das potencialidades individuais, nas sociedades modernas, tem sido possível, através da extensão dos direitos de cidadania - civis, políticos e sociais - de forma universal (GIOVANELLA et al. 1996).

As iniqüidades em saúde referem-se às diferenças desnecessárias e evitáveis e que são, ao mesmo tempo, consideradas injustas e indesejáveis. O objetivo das políticas de eqüidade, segundo WHITEHEAD (cit. GIOVANELLA et al. 1996), é reduzir ou eliminar essas diferenças e devem ser dirigidas tanto às raizes dos problemas, diminuindo riscos diferenciais, como provendo serviços de saúde que dêem conta das maiores necessidades de cuidados que aquelas iniqüidades criam.

Alcançar um mesmo nível de saúde, entre grupos sociais e/ou regiões de um país, é um objetivo que transcende o escopo de ação dos serviços de saúde, pois cuidados de saúde são apenas um entre inúmeros fatores que contribuem para desigualdades em saúde. A ação isolada dos serviços de saúde não é suficiente para resolver o conjunto das iniqüidades em saúde mas certamente pode contribuir para reduzi-las. As análises no campo da saúde têm enfocado principalmente iniqüidades na distribuição e consumo de serviços de saúde, embora sejam sugeridas freqüentemente políticas econômicas e sociais integradas com o objetivo de redução das iniqüidades diagnosticadas (GIOVANELLA et al. 1996).

Há um certo consenso que a definição mais agregadora para a eqüidade em cuidados de saúde refere-se à igual utilização por igual necessidade, em que o grupo de iguais é definido pelas suas mesmas condições de saúde. Essa definição, embora 
restrita ao consumo de serviços de saúde, não é facilmente operacionalizável. A percepção das necessidades é diferenciada entre indivíduos conforme a sua inserção social e nível de conhecimento dos processos saúde-doença; e estas são produzidas pelo próprio complexo médico industrial. O grande problema metodológico está na dificuldade de serem produzidos indicadores capazes de englobar aspectos culturais, biológicos e sociais na definição das necessidades de saúde (GIOVANELLA et al. 1996).

\subsection{Indicadores sociais}

A complexidade dos problemas que atingem a população de um município clama pela busca de soluções que sejam sustentáveis ao longo do tempo e que transcendam o saber de um único setor. Para DUHL (cit. AKERMAN 1997), o planejamento urbano seria mais eficaz se conseguisse aglutinar visões distintas e que, por uma série de processos de negociação, pudesse acomodar as diversas expectativas. Isso faz surgir a necessidade da emergência da transdiciplinaridade que, diferentemente da interdisciplinaridade (na qual as disciplinas envolvidas, num determinado projeto, interagem sem perder sua origem epistemiológica), busca a emergência de uma nova epistemiologia que age no sentido de religar $o$ conhecimento dividido nas disciplinas (AKERMAN 1997, CHAVES 1998).

Assim, a idéia de resumir num único indicador as diferentes variações socioeconômicas e ambientais para analisar as características de grupos populacionais, vivendo em determinadas áreas geográficas, pode ser considerada uma tentativa de se entender um sistema complexo, através de uma medida que possibilite comparabilidade de uma determinada situação no tempo e no espaço.

Os indicadores compostos são, portanto, instrumentos que possibilitam descrever fenômenos em áreas geográficas específicas, classificando-as de tal forma que reflitam as circunstâncias materiais ou sociais daquilo que se quer examinar.

Esta operação de sintetização da informação social, na forma de indicadores compostos, costuma incorrer em perda crescente de proximidade entre conceito e medida e de transparência para seus potenciais usuários (JANNUZZI 2001). 
BARATA (1997) afirma que os indicadores de saúde tradicionalmente utilizados não se mostram capazes de documentar claramente as condições de vida da população que são afetadas, de modo considerável, pelas mudanças econômicas, implicando na sua escassa utilidade na tomada de decisão.

Segundo esta autora, "no plano teórico, o desafio constitui-se pela necessidade de esclarecer as mediações que operam entre as condições reais em que ocorre a reprodução dos grupos humanos, em sociedades concretas, e a produção da saúde e da doença. No plano metodológico, torna-se preciso desenvolver estratégias de investigação, com seus correspondentes instrumentos de coleta e análise de informações, que permitam traduzir, no âmbito da pesquisa científica, os avanços obtidos na formulação teórica. No plano prático, o de intervenção na realidade dos serviços de saúde, trata-se de formular sistemas de modo a definir os dados básicos, os indicadores, os recursos de análise para conhecer os impactos que as políticas de desenvolvimento a cada momento provocam na saúde dos grupos populacionais; identificar aqueles mais vulneráveis a certos problemas ou conjunto de problemas, e, por fim, avaliar o resultado das intervenções propostas" (BARATA 1997, p. 5).

Assim, pode-se dizer que a escolha/coleta dos dados e o tratamento adequado destes na/para produção da informação são fundamentais para a definição das políticas de desenvolvimento e sua avaliação, na medida em que a informação subsidia a tomada de decisões e, portanto, deve ter qualidade.

MORAES (1994), ao defender a discussão sobre uma Política de Informações em Saúde, afirma que "esta deve iniciar-se pelo próprio entendimento de seu campo de ação, ou seja, o conceito de Saúde", e que "as concepções adotadas de Saúde irão definir e delimitar o âmbito e o modelamento das informações. Afinal, sem idéias não há informação!".

No processo de seleção de um indicador a ser utilizado para refletir uma dada situação, a tarefa inicial é a de delimitação do problema, condição, tema ou evento que necessite ser observado ou medido para o qual se escolhe o indicador e se elabora a respectiva definição operacional. $O$ grau de validade refere-se à adequação 
do indicador para medir ou representar, sinteticamente, o fenômeno considerado. $\mathrm{O}$ indicador deve, então, ser capaz de discriminar corretamente um dado evento de outros, assim como detectar as mudanças ocorridas com o passar do tempo (PEREIRA 1995).

Além da validade, existem mais quatro aspectos a serem considerados para a seleção e avaliação de indicadores de saúde:

1. reprodutibilidade - a obtenção de resultados semelhantes, quando a mensuração é repetida em condições semelhantes;

2. representatividade - um indicador será tanto mais apropriado quanto maior a cobertura;

3. obediência a preceitos éticos - é imprescindível que a coleta de dados e divulgação de resultados não acarretem malefícios ou prejuízos às pessoas investigadas, respeitando todas as normas e preceitos éticos e

4. viabilidade - do ponto de vista técnico-administrativo, o emprego de indicadores exige consideração detalhada de outras características, como simplicidade, flexibilidade, facilidade de obtenção, custo operacional compatível e oportunidade.

Para que um indicador de saúde passe a ter aplicabilidade prática, deve ser capaz de retratar com fidedignidade e praticidade, seguindo os preceitos éticos, os aspectos da saúde individual ou coletiva para os quais foi proposto (PEREIRA 1995).

Para JORDAN FILHO e colaboradores (cit. MORAES 1994), um indicador deve possuir sete qualidades:

1. simplicidade - deve ser fácil de ser calculado;

2. validade - deve ser função da característica que se deseja medir;

3. disponibilidade - deve usar dados habitualmente disponíveis ou de fácil obtenção;

4. robustez - pouco sensível às deficiências dos dados necessários à sua construção;

5. sinteticidade - deve refletir o efeito do maior número possível de fatores;

6. discriminatoriedade - deve possuir um alto poder discriminatório para vários níveis de saúde e indicar alterações que ocorram com o tempo e 
7. cobertura - deve referir-se, tanto quanto possível, se necessário for, a cada país ou território, como um todo, e não somente a determinada área selecionada ou a um grupo da população.

Além dessas características, vale a pena lembrar que o indicador é a quantificação da realidade, a fim de planejar um modo de interferir nessa própria realidade. No entanto, a quantidade mede somente um aspecto da qualidade (realidade concreta). Isso faz com que o conhecimento retirado dos números, muitas vezes, mascare aspectos importantes da realidade. Além disso, os indicadores refletem o "Sistema de Valores" de quem os constrói, o que implica em que se formule certas hipóteses e perguntas e não outras (MORAES 1994).

$\mathrm{Na}$ prática, nem sempre o indicador de maior validade é o mais confiável; nem sempre o mais confiável é o mais inteligível; nem sempre o mais claro é o mais sensível; enfim, nem sempre o indicador que reúne todas essas qualidades é passível de ser obtido na escala espacial e periodicidade requerida. Além disso, poucas vezes se poderá dispor de séries históricas plenamente compatíveis de indicadores para a escala geográfica ou grupo social de interesse (JANNUZZI 2001).

A construção de um indicador que retrate as reais condições de saúde não é, portanto, uma tarefa simples e, embora, por "estranho que pareça", com todas as afirmativas que foram enunciadas, desde a formulação do conceito de saúde pela Organização Mundial de Saúde (OMS), ainda não há instrumentos adequados para medir saúde e, sim, o seu oposto (o destaque é nosso), a doença (CHAVES 1998).

Para o Programa das Nações Unidas para o Desenvolvimento (PNUD), “os indicadores são fortes aliados na luta pelos direitos humanos na medida em que tornam possível às pessoas e organizações identificar quais os atores importantes e responsabilizá-los pelas suas ações. É por isso que o desenvolvimento e a utilização de indicadores para os direitos humanos se transformou na área mais avançada da defesa de causas. Trabalhando em conjunto, governos, ativistas, advogados, estatísticos e especialistas do desenvolvimento estão a descobrir novas formas de utilizar as estatísticas para incentivar mudanças nas percepções políticas e práticas" (PNUD 2000, p. 89). 
Os indicadores podem ser utilizados como instrumentos para:

1. desenvolver melhores políticas públicas e acompanhar os seus efeitos;

2. identificar impactos não intencionais das leis, políticas e práticas;

3. identificar que atores têm impacto na realização de direitos;

4. revelar se as obrigações destes atores estão ou não sendo cumpridas;

5. alertar sobre riscos potenciais, desencadeando ações preventivas;

6. aumentar o consenso social sobre as dificeis escolhas a fazer, face às restrições de recursos $e$

7. tornar conhecidos assuntos que tenham sido negligenciados ou silenciados.

\subsubsection{Esperança de vida}

O IDH (Índice de Desenvolvimento Humano) é um dos principais indicadores, recomendados pelo PNUD, desde 1990. "Avalia operacionalmente o nível e o progresso do desenvolvimento humano" (JANUZZI 2001), em um único índice composto, que possibilita a comparação e a classificação dos países, segundo esse critério. Apresenta três componentes básicos na sua constituição: a esperança de vida ao nascer (componente de saúde), as taxas brutas de alfabetização de adultos e de escolaridade primária, secundária e superior (componente de educação) e o PIB (Produto Interno Bruto) per capita em dólares americanos (componente de renda).

De todos os possíveis indicadores de saúde, a esperança de vida ao nascer (EVN) foi justamente o escolhido pelo PNUD. Isto não é por acaso, pois "existe uma relação direta entre a vida média e as condições de saúde das coletividades". Populações de países economicamente desenvolvidos gozam, em geral, de melhores condições de saúde e, conseqüentemente, conseguem atingir uma esperança de vida bem maior do que a dos países subdesenvolvidos (KERR-PONTES e ROUQUAYROL 1999).

A EVN é uma medida resumo que representa o número esperado de anos a serem vividos por uma coorte hipotética sujeita a probabilidades de morte que variam com o sexo e com a idade, mas mantém-se constantes ao longo do tempo. É 
calculada através da tábua de vida, sobrevivência ou mortalidade, como preferem alguns autores. Do ponto de vista de Saúde Pública, é bem mais importante do que a duração máxima da vida que, para SHRYOCK (cit. GOTLIEB 1977), seria ultrapassada apenas por menos de $0,1 \%$ da coorte e que constitui um limite biológico inerente à espécie.

Apresentando um valor sujeito às influências do meio, a EVN tem sofrido modificações substanciais ao longo do tempo. Na medida em que as condições gerais da vida melhoram e na proporção em que os avanços científicos e tecnológicos são colocados a serviço do homem, aquela tende a aumentar (KERR-PONTES e ROUQUAYROL 1999).

Segundo DUBLIN, LOTKA e SPIEGELMAN (cit. KERR-PONTES e ROUQUAYROL 1999), o homem pré-histórico teria uma EVN extremamente baixa, em torno de 18 anos. Na Grécia e Roma antigas, a vida média estaria situada entre 20 e 30 anos, pouco se modificando na Idade Média e na Renascença.

De acordo com WILMOTH (2000), a EVN triplicou ao longo da história da humanidade. Este é um fenômeno global que não atinge todas as coletividades de maneira uniforme. De fato, a esperança de vida (EV), via de regra, varia de acordo com os padrões de renda per capita, diminuindo à medida que diminui o grau de desenvolvimento econômico da população. No entanto, observa-se que, em países com diferentes níveis socioeconômicos, a sobrevida média apresenta em comum um aumento ao longo do tempo (KERR-PONTES e ROUQUAYROL 1999).

É interessante notar a discrepância temporal no aumento da EV em países desenvolvidos e em desenvolvimento. Enquanto nos primeiros, a redução da mortalidade ocorreu de forma lenta, acompanhando tanto o desenvolvimento progressivo do conhecimento científico, médico e químico, da adoção gradual de técnicas aprimoradas, visando ao incentivo da produção agrícola e industrial (e respectivas distribuições destes produtos), bem como das inovações no campo da Saúde Pública, agregados a um conseqüente melhor nível socioeconômico das populações, aumentando, assim, paulatinamente a EV em função do combate à fome e à doença; nos países em desenvolvimento, a redução da mortalidade se deu posteriormente, de forma acelerada, aproveitando técnicas e conhecimentos dos 
países desenvolvidos a um custo relativamente mais baixo. Como as taxas de mortalidade eram muito altas, foi possível alcançar grandes reduções, mediante técnicas eficientes e relativamente não dispendiosas (GOTLIEB 1977).

Um fato decorrente disto, e que vale a pena ressaltar, é nem sempre ser possível atribuir a redução de mortalidade ao aprimoramento das condições socioeconômicas das populações. Na América Latina, entre 1900 e 1960, todos os países estudados por ARRIAGA (cit. GOTLIEB 1977), sem exceção, reduziram a mortalidade em velocidade nunca antes registrada, o que não se deu graças ao desenvolvimento socioeconômico, mas sim devido às facilidades que estes países tiveram para importar técnicas, conhecimentos científicos e medicamentos de outras nações mais adiantadas. Essa afirmação é ainda reforçada pelo fato de que o país mais rico do mundo, os Estados Unidos da América, tem uma EVN mais baixa do que outros países menos privilegiados $\mathrm{e}$, portanto, os fatores econômico $\mathrm{e}$ tecnológico, embora importantes, não são suficientes para garantir uma melhor qualidade de vida e conseqüentemente uma maior EV para uma dada população.

No passado, GABALDON (cit. KERR-PONTES e ROUQUAYROL 1999) classificava os países e regiões segundo o progresso alcançado nas ações de saúde pública em: subdesenvolvidos (EVN < 50 anos), intermediários (EVN 50-64 anos) e desenvolvidos ( $E V N \geq 65$ anos). No entanto, trabalhos recentes demonstram que tais valores deveriam ser revistos. Segundo HARMAN (1998), a média da EVN, em países desenvolvidos, encontra-se hoje em dia em torno de 76 a 79 anos, menor seis a nove anos do que o limite de 85 anos, imposto pela "velhice" (acumulação de mudanças que aumentam o risco de morte).

WILMOTH (2000), baseando-se nas evidências demográficas disponíveis, afirma que "a duração da vida humana não apresenta qualquer sinal de aproximação a um limite imposto pela biologia ou por outros fatores". A EVN e a duração da vida cresceram continuamente por mais de um século. A complexidade e estabilidade histórica destas mudanças sugerem, segundo este autor, que o método mais confiável de predizer o futuro é simplesmente a extrapolação das tendências do passado. Tais métodos sugerem que a EVN, em países industrializados, será algo entre 85 e 87 anos em meados do século XXI. 
Os primeiros ganhos na $\mathrm{EV}$ foram decorrentes de melhorias no padrão de vida e esforços organizados para o controle da expansão de doenças infecciosas. Reduções das taxas de mortalidade infantil, nos séculos XIX e XX, propiciaram um rápido incremento na $\mathrm{EV}$. Desde os anos setenta, o principal fator responsável por ganhos na $\mathrm{EV}$ dos países industrializados tem sido a redução das taxas de mortalidade ao longo do processo de envelhecimento. Em particular, o declínio dessas taxas, nas últimas décadas, devido às doenças cardiovasculares e às neoplasias, em função de diversos fatores, incluindo intervenções médicas bem sucedidas (WILMOTH 2000).

Além da variação encontrada em função do grau de desenvolvimento da população estudada, a EV apresenta valores diferenciados em função do sexo, ressaltando-se que as mulheres têm maior sobrevida que os homens, provavelmente em conseqüência da maior exposição do sexo masculino a alguns agravos à saúde (KERR-PONTES e ROUQUAYROL 1999).

Pode-se dizer que a EV é um indicador que varia segundo a estrutura etária e às condições socioeconômicas da população estudada. A distribuição das mortes, segundo causas, tem grande influência sobre esta medida, mas o seu valor não expressa com clareza tal relação.

Para obtê-la, é preciso construir tábuas de vida que são calculadas a partir de dados sobre a população e do número de óbitos em cada faixa etária trabalhada. Tais tábuas devem ser elaboradas separadamente para cada sexo, pois há diferenças de comportamento das respectivas mortalidades. Sua construção depende da qualidade dos dados e a elaboração para populações humanas, dada a necessidade de existirem, em pelo menos cem anos, estatísticas vitais fidedignas e registros adequados dos movimentos migratórios, é muito difícil. No entanto, partindo-se de algumas pressuposições, é possível obtê-las para uma coorte hipotética de nascidos vivos e que, geralmente, se inicia com cem mil indivíduos (LAURENTI et al. 1987).

Os dados de população são, geralmente, provenientes dos recenseamentos demográficos e das estimativas populacionais, geradas a partir destes, para o período intercensitário. Os óbitos são coletados nos sistemas de estatísticas vitais. No Brasil, este levantamento se dá através de dois sistemas paralelos de informação: o Sistema 
de Estatísticas Vitais de responsabilidade do Instituto Brasileiro de Geografia e Estatística (IBGE) e o SIM (Sistema de Informações sobre Mortalidade), desenvolvido pelo Ministério da Saúde.

\subsection{O Sistema de Informações sobre Mortalidade - SIM}

O SIM foi criado pelo Ministério da Saúde, em 1975, e foi o pioneiro a empregar um documento individualizado e padronizado (Declaração de Óbito - DO) para a coleta das informações sobre óbitos (ALMEIDA 1998). Constitui-se em uma fonte alternativa às estatísticas de óbito publicadas anualmente pela Fundação Instituto Brasileiro de Geografia e Estatística (FIBGE), desde 1974, sob o título de Estatísticas do Registro Civil (SZWARCWALD et al. 1997).

A implantação do modelo padronizado da DO, em todo o território nacional, proporcionou um grande avanço, pois, anteriormente, as diversas unidades da federação possuíam modelos distintos de atestado médico de morte, e vários não seguiam a padronização internacional de coleta de dados proposta pela OMS (ALMEIDA 1998).

As informações divulgadas pela FIBGE são provenientes da transcrição das informações das DO, em mapas mensais, emitidos pelos Cartórios de Registro Civil e enviados trimestralmente às superintendências estaduais do IBGE e destas, para o nível central. Já o SIM tem como base do sistema as informações individualizadas das próprias DO (SZWARCWALD et al. 1997).

Não cabe, aqui, entrar no mérito da questão de por que implementar dois sistemas de informação sobre óbitos em nível nacional; isso já gerou muita polêmica e certamente é um desperdício de recursos públicos. Apesar disso, não se conseguiu resolver um problema fundamental que é o sub-registro de óbitos e que tem magnitude expressiva, sobretudo nas regiões menos desenvolvidas, onde se dá principalmente devido à ocorrência de sepultamentos, sem a exigência da certidão de óbito, nos denominados cemitérios clandestinos (SZWARCWALD et al. 1997).

Quando o SIM foi criado, tinha como um dos objetivos suplantar a cobertura óbitos apresentada pelo IBGE, em virtude de poder abranger a coleta em outras 
fontes, além dos óbitos registrados, via cartórios do Registro Civil. No entanto, ao serem comparados os dois sistemas, verifica-se que, apesar do elevado volume de dados coletados pelo SIM, em algumas áreas não chega a ultrapassar os totais do IBGE. Em números gerais, o IBGE teve uma melhor cobertura no periodo analisado de 1979 a 1995. Esse fato se deve, na maioria das vezes, à recusa de alguns cartórios em enviar as DO registradas ao órgão da saúde encarregado do processamento e posterior envio ao Ministério da Saúde, já que a obrigatoriedade legal existe somente com relação à remessa ao IBGE (MELLO JORGE e GOTLIEB 2000).

VASCONCELOS (1998), analisando a qualidade das estatísticas de óbito do Brasil com base na comparação dos dois sistemas (MS e IBGE), verifica que, em nível nacional, os dois sistemas apresentam cada vez mais resultados similares, mas, do ponto de vista regional, diferenças importantes podem ser observadas. Por outro lado, se em níveis mais agregados, nacional e regional, as diferenças entre os dois sistemas são sempre mais favoráveis ao sistema do IBGE, quando a análise é por Unidades da Federação, algumas diferenças aparecem em favor do SIM.

O sub-registro de óbitos no Brasil é diferenciado por região, sendo superior no Norte e Nordeste, e, por idade, com predomínio entre menores de um ano. Para SZWARCWALD e colaboradores (1997), tem grandeza tão relevante, na maioria das unidades da federação, que torna inviável o cálculo dos indicadores de mortalidade através de sua fórmula definidora, necessitando estimativas.

Aceita-se o fato de que a subenumeração de óbitos tenha diminuído da década de $80(20 \%)$ até o final da década de $90(\approx 10 \%)$. Este déficit está desigualmente distribuído, nas diferentes regiões do país, e é mais acentuado nas menos desenvolvidas. Também é maior, nestas áreas, a proporção de óbitos por causas mal definidas que, apesar de ter diminuído no Brasil, como um todo, nas regiões Norte e Nordeste, está muito acima da média brasileira (MELLO JORGE e GOTLIEB 2000).

SZWARCWALD e colaboradores (1997) chamam a atenção para o fato de que, ainda que se corrijam as informações de registro por fatores diferenciados por região, estar-se-ão corrigindo apenas aqueles referentes às áreas que, de alguma forma, notificaram a mortalidade e que são, possivelmente, as que têm as melhores situações de saúde. Para minimizar este efeito, os autores procuram encontrar indicadores da situação de saúde que pudessem ser escolhidos por meio dos dados 
disponíveis e que sob determinadas suposições fossem invariantes ao sub-registro de óbitos'.

Utilizando-se, então, da técnica estatística denominada de análise de componentes principais, SZWARCWALD et al. (1997) procuraram sintetizar as várias situações de mortalidade infantil das unidades da federação, a partir de um conjunto inicial de cinco indicadores (proporção de óbitos por anomalias congênitas entre os óbitos com causa definida, proporção de óbitos por diarréia entre os óbitos com causa definida, proporção de óbitos sem definição da causa básica, cobertura de registro de óbitos e a proporção de óbitos no período pós-neonatal). Os autores chegaram à conclusão de que "a realidade crua das estatísticas de saúde flagra as precárias condições de vida de grande parte da população brasileira que apresenta uma realidade bem diversa e com muitos Brasis", onde os estados do Amazonas, Mato Grosso, Ceará, Rio Grande do Norte, Paraíba, Pernambuco, Alagoas e Bahia são aqueles com a pior situação de mortalidade infantil. Neste quadro, a Bahia ocupa a $22^{\mathrm{a}}$ posição e São Paulo, a $3^{\mathrm{a}}$, logo atrás do Rio Grande do Sul e do Distrito Federal.

Esses resultados são coerentes com os valores encontrados por VASCONCELOS (2000). Para esta autora, "a qualidade das informações sobre óbitos no Brasil é muito variável e estreitamente relacionada com as condições sócioeconômicas predominantes nas Unidades da Federação".

Apesar de todos estes problemas, o SIM (MS 2000a) ainda é o melhor sistema para se estudar a mortalidade existente hoje no Brasil e, de forma indireta, avaliar as condições de saúde da população. É um dos mais abrangentes sistemas de informação do Ministério da Saúde (MS), em termos de cobertura, e os seus problemas de notificação têm diminuído nos últimos anos. A acessibilidade aos seus registros aliada às facilidades de programas de tabulação, como o TabWin, desenvolvidos pelo próprio MS, permitem fazer o cruzamento de dados com muita flexibilidade. Possibilita, assim, considerando a limitação, aprofundar o conhecimento sobre a mortalidade da população brasileira e tecer estudos

\footnotetext{
1 A palavra registro, nesse texto, se refere a captação do dado pelo sistema de informação, ou seja, a sua notificação no sistema. Portanto, segundo este princípio, o sub-registro de um dado significa que o mesmo não foi captado pelo sistema de informação, embora possa ter sido registrado no Cartório de Registro Civil.
} 
comparativos que evidenciem a influência dos principais determinantes de saúde no adoecer e morrer da população estudada.

\subsection{0 impacto das causas de morte na esperança de vida}

A esperança de vida ao nascer, embora seja um bom indicador da saúde de uma população, por si só, não aponta caminhos mais específicos do que fazer para melhorar os níveis de saúde desta mesma população. Assim, as tábuas de vida podem, por exemplo, indicar que, para se melhorar rapidamente a EVN da Região Nordeste, é necessário reduzir a mortalidade em uma determinada faixa etária do sexo masculino, mas não indica que tipo de ação deveria ser priorizada. Assim, outras medidas se fazem necessárias para se obter um indicador mais completo.

A OMS, em recente relatório (WHO 2000), aponta para o fato de que o resumo da situação de saúde de populações heterogêneas em uma medida única pode gerar distorções. Este documento recomenda, também, que tanto o nível global de saúde como a distribuição da saúde, na população, devem ser medidos, para que os objetivos de qualquer sistema de saúde sejam alcançados. Além disso, reconhece que qualquer dado individual da saúde da população tem um caráter multivariado e, então, procede a caracterização da situação de saúde em termos de anos de vida/expectativa de vida ajustados à incapacidade (Disability-Adjusted Life Years/Expectancy - DALY/DALE) (MULLAHY 2000).

O DALE é um indicador que combina eventos fatais e não-fatais para representar, na forma de um simples valor, o estado de saúde de uma população específica. Ele mede o tempo médio de vida, em anos, que uma pessoa de uma dada idade pode esperar viver, gozando de boa saúde. O indicador é calculado com base na estimativa da $\mathrm{EV}$, descontando o número de anos que foram vividos com alguma incapacidade (MS 2000b).

De maneira muito semelhante, são calculados os anos de vida ajustados à qualidade ou QALY (Quality-Adjusted Life Year), anos de vida ajustados à saúde (HALY - Health-Adjusted Life Year), e a esperança de vida ajustada à qualidade e à saúde respectivamente (QALE - Quality-Adjusted Life Expectancy/HALE -Health- 
Adjusted Life Expectancy). Todos partem da construção de tábuas de vida utilizadas no cálculo da esperança de vida e ajustam os valores de cada faixa etária, através de fatores de correção, calculados a partir de fórmulas/medidas definidas, segundo distintas escolhas metodológicas.

O cálculo destes fatores de correção nem sempre é tarefa fácil, passível de ser reproduzida para outras populações, sendo somente para aquelas para as quais foi inicialmente definida. O cálculo da "carga da doença" (burden of disease), por exemplo, necessita obter dados de 483 tipos de enfermidade e suas complicações associadas, cada uma delas agrupadas em sete níveis de gravidade (MURRAY e LOPEZ 1996). Em geral, estes valores são obtidos indiretamente, utilizando tabelas que evidenciam certos grupos de enfermidade. Este processo demanda um grande número de tomadas de decisão, arbitradas livremente, o que pode tornar o julgamento altamente subjetivo e a informação pode não ser confiável (MS 2000b).

Em função das dificuldades e problemas de cobertura que os sistemas de informação de morbidade brasileiros apresentam (geralmente cobrem apenas a parte da população brasileira atendida pelos serviços públicos e conveniados do SUS), torna-se mais viável trabalhar apenas com o componente de mortalidade das técnicas anteriormente descritas. Tal procedimento tem a vantagem de ser mais facilmente implementado e viabiliza o trabalho com dados de regiões mais desprovidas de recursos, como é o caso do Nordeste e, em particular, da Bahia.

A não inclusão do efeito da morbidade simplifica em muito o trabalho, embora traga perdas consideráveis em termos de análise do efeito dos agravos à saúde na população como um todo (MUENNING e GOLD 2001). Mesmo assim, importantes análises podem ser feitas quando se conjugam os Anos Potenciais de Vida Ganhos (APVG), caso um determinado grupo de causa de óbito deixasse de ocorrer, a diferença dos valores da EV calculada com e sem a presença destes agravos, e a distribuição dos óbitos por grupos de causas básicas estudadas, segundo sexo e idade.

Os APVG são facilmente obtidos pela diferença entre o total de anos vividos, por uma coorte, a partir da idade 0 , obtidos das tábuas de vida de múltiplo decremento, calculadas com e sem a presença dos óbitos decorrentes do grupo de agravos estudado. Tal medida não deve ser confundida com os Anos Potenciais de 
Vida Perdidos (APVP) que é o somatório dos anos que ainda seriam necessários, para que cada pessoa falecida de uma dada população atingisse uma idade arbitrária X (LAURENTI et al. 1987).

A grande diferença está no fato de que, para o cálculo dos APVP, é necessário arbitrar um valor de idade limite e nem sempre é possível se chegar a um consenso de que valor deve ser utilizado e se seria factível, para uma dada população, reduzir significativamente este valor. Já o cálculo dos APVG independem de se arbitrar tal valor, mas necessita da construção de duas tábuas de mortalidade (com e sem os óbitos que se espera evitar). Do ponto de vista do planejamento dos serviços, este segundo indicador pode ser bem mais interessante, na medida em que permite prever os resultados que possíveis reduções na mortalidade teriam no incremento da EV e, em última análise, em termos de total de anos ganhos pela população.

\subsubsection{Tábuas de vida de múltiplo decremento}

As tábuas de vida representam o padrão de mortalidade de uma população. Para SHRYOCK (cit. GOTLIEB 1977), elas são uma forma de combinar coeficientes de mortalidade de uma população, em diferentes idades, em modelo estatístico simples. Sendo importante lembrar que esta não é somente um simples arranjo de números, mas sim um documento humano contendo, numa seqüência temporal, a história dos esforços do homem para prolongar sua existência.

Representar o padrão de mortalidade para uma dada região, definido pela mortalidade específica por causas, pode refletir o grau de qualidade de vida existente, nesta região, e fornecer subsídios para uma política de saúde mais eficiente e eficaz, na medida em que permite estabelecer normas e metas prioritárias para ação das unidades de Saúde Pública.

Entretanto, "considerando-se que a morte não é um evento repetitivo e nem atribuível a um único risco (CHIANG 1968), devem ser levados em conta os vários riscos concomitantes e competitivos que atuam na vida de um ser humano. Neste sentido, é recomendável o emprego de outros modelos de análise de mortalidade; estes modelos, sendo diferentes dos 
usuais coeficientes de mortalidade específicos por causa, estão baseados em tábuas de vida. Desta maneira, as tábuas de vida, fundamento sobre o qual se apoiam os cálculos das estimativas de probabilidade de morte, nas diferentes idades e da esperança de vida dos contemporâneos de uma época, passaram a representar instrumento analítico extremamente valioso em estudos epidemiológicos e de saúde pública, desde a introdução da noção de riscos competitivos, que deram base à construção das tábuas de sobrevivência de múltiplo decremento" (GOTLIEB 1977, p. 23-24).

Segundo KARN (cit. GOTLIEB 1977), as tábuas de vida só começaram a levar em consideração as possíveis causas de morte, a partir do trabalho de Daniel Bernoulli, em 1760, "De la mortalité causée par la petite vérole et des avantages de l'inoculation pour la prévenir', no qual ressaltava o papel da vacinação como medida de Saúde Pública. Para esclarecer o mérito de tal medida preventiva, fez uso de duas tábuas de vida: uma padrão (Halley) e outra hipotética, mostrando o número de sobreviventes em cada idade, caso a varíola fosse inteiramente eliminada da população. Os resultados apontavam para um incremento na EVN de 3,17 anos (26,58 para 29,75 anos).

Desde então, tanto Bernoulli como outros pesquisadores do porte de D'Alembert, Duvillard e Tremblay supuseram que a mortalidade de uma doença não é seletiva, isto é, a população, depois de ser acometida por uma doença $\mathbf{A}$, é tão suscetível às doenças $\mathbf{B}, \mathbf{C}$ e $\mathbf{D}$ como antes da eliminação da doença $\mathbf{A}$. Isto implica no fato de que a eliminação de uma determinada causa de óbito na população em estudo não anula o efeito que as outras doenças têm sobre esta população. Portanto, os indivíduos, que deixaram de morrer em função de uma doença $\mathbf{A}$, estão sujeitos a morrer por outras causas, e tal fato tem que ser levado em consideração na construção das tábuas de vida (GOTLIEB 1977).

DORN (cit. GOTLIEB 1977) define Força de Mortalidade como coeficiente de mortalidade instantâneo. Na construção da tábua de vida, CHIANG (1968) pressupõe uma força de mortalidade constante para cada grupo etário e admite ainda que os vários riscos de morte atuam simultaneamente em cada indivíduo da 
população, havendo para cada risco uma correspondente força de mortalidade (Teoria dos Riscos Competitivos). A soma destas é igual à força de mortalidade total, existindo uma razão constante entre a força de mortalidade de uma causa e a força de mortalidade total, em cada idade. Assim:

$$
\mu_{i, j}(t)=\frac{\mu_{i}(t) \cdot\left(D_{i}-D_{i, j}\right)}{D_{i}}
$$

Onde:

$\mu_{\mathrm{i}, \mathrm{j}}(\mathrm{t})=$ força de mortalidade na idade $\mathrm{i}$ excluída uma causa de óbito $\mathrm{j}$, ou grupo de causas $j$, no instante $t$;

$\mu_{i}(t)=$ força de mortalidade total na idade $i$, no instante $t$;

$D_{\mathrm{i}}=$ óbitos totais na idade $\mathrm{i}$;

$D_{i, j}=$ óbitos totais na idade $i$, excluindo os óbitos da causa eliminada $j$, ou grupo de causas eliminadas $\mathrm{j}$.

As tábuas de vida construídas, a partir da metodologia proposta por CHIANG (1968), são mais coerentes com a realidade, pois levam em consideração a interdependência dos vários riscos e seus efeitos ao se eliminar uma causa específica, ou grupo de causas.

O modelo proposto por CHIANG passou a ter boa aceitação, no país, a partir da década de 70, com o advento de vários trabalhos, entre eles: GOTLIEB (1977) que aplicou a técnica da tábua de vida de múltiplo decremento aos dados do Município de São Paulo de 1970, PAES (1982) que trabalhou os dados do Município de Recife para o ano de 1977 e OLIVEIRA (1983) que verificou as implicações dos pressupostos da técnica para o Município de Araraquara de 1979 a 1981.

Mais recentemente, tal técnica foi utilizada para avaliar o impacto de causas de óbito na esperança de vida do Brasil (BARBOSA e ANDRADE 2000; ORTIZ 1998, SILVA 1998; SILVA e BEZERRA FILHO 1998; SANTOS, ORTIZ e YAZAKI 1984), da Itália (CONTI et al. 1999), Estados Unidos (ROCKETT e POLLARD 1995), Singapura (LUN 1995), Kuwait (al-BUSTAN, el-ZEIN e KOHLI 1988) e outros com destaque especial para trabalhos que ressaltam a influência de alguns agravos na EV, tais como: doenças coronarianas (LLOYDE-JONES et al. 1999), 
câncer (WUN, MERRILL e FEUER 1998; FRASER e SHAVLIK 1997; FEUER et al. 1993), Agressão (ROCKETT 1998), Aids (GOTLIEB, CASTILHO e BUCHALLA 2000; STOVER e WAY 1998; LAI, TSAI e HARDY 1997) e Suicídio (MANTON, BLAZER e WOODBURY 1987).

Esta metodologia se presta para avaliar não só o impacto das causas de óbito na EV de populações com sistemas de estatística vital confiáveis, como também com cobertura parcial do número de óbitos, desde que a cobertura não seja diferencial por causas (SANTOS, ORTIZ e YAZAKI 1984).

\subsection{A definição do objeto de estudo}

Diante do exposto, as tábuas de vida de múltiplo decremento representam uma metodologia adequada para quem deseja avaliar impactos, que certos grupos de causa têm na esperança de vida de uma determinada população. De cálculo relativamente fácil, pode ser utilizada para comparar populações com diferentes realidades socioeconômicas e é um importante instrumento teórico de apoio ao planejamento e priorização de ações, visando à melhoria das condições de vida das populações estudadas.

Em função da inserção como Professor da Disciplina Informática em Saúde do Mestrado em Saúde Coletiva da Universidade Estadual de Feira de Santana, na Bahia, surgiu o interesse em conhecer mais minuciosamente a influência que diferentes causas de óbito tem na esperança de vida da população baiana e comparar os resultados obtidos com os de uma região mais desenvolvida em termos socioeconômicos. Assim, foi pensado, inicialmente, comparar os Estados da Bahia e São Paulo mas havia um fator limitante, a má qualidade dos dados de óbito referentes à Bahia (subenumeração de cerca de $30 \%$ ).

O problema tão conhecido do sub-registro de óbitos, presente em toda a Região Nordeste, poderia ser contornado com a adoção de técnicas indiretas de estimativas de mortalidade, entre elas a adotada pela Superintendência de Estudos Econômicos e Sociais da Bahia (SEI 1999) que, dentre as possíveis metodologias de correção de óbitos, utiliza a da equação de balanço (BRASS 1975) e, paralelamente, o método 
sugerido por COURBAGE e FARGUES (1979) através das tábuas-modelo Brasil de mortalidade (IBGE 1981).

Tal metodologia para a correção do sub-registro de óbitos é coerente com o documento publicado em primeiro de dezembro de 1999, pela Coordenação Geral de Comunicação Social do IBGE, no qual delineia os procedimentos para a construção da tábua de mortalidade para a população brasileira. Neste documento, o IBGE reconhece que a captação do número de óbitos pelo Registro Civil de Pessoas Naturais é falha e desigual fazendo-se necessária a adoção de técnicas de correção para o sub-registro de óbitos (IBGE 1999).

Assim, são trabalhadas as médias dos óbitos dos triênios em torno dos anos de estudo. Estas são divididas, segundo a causa de morte por fatores externos, em "violentas" e "naturais", pois se parte do pressuposto de que as mortes por causas externas têm cobertura bastante superior em relação às demais causas. Considerando que o sub-registro pelas causas violentas é desprezível, procede-se, então, somente a correção das causas naturais (SEI 1999).

Corrigidos os óbitos por causas naturais, são adicionados os óbitos por causas violentas sem qualquer correção e com as informações populacionais, calculam-se as taxas de mortalidade específicas por sexo e idade. A não correção dos óbitos por causas externas visa evitar a superestimação da mortalidade por violência, notadamente nas faixas etárias de adultos jovens do sexo masculino (SEI 1999).

A mortalidade infantil, também um forte indicador das desigualdades sociais, é calculada à parte, e seus valores são introduzidos diretamente nas tábuas de mortalidade, pois se presume que o sub-registro de óbitos seja mais acentuado para a faixa etária de menores de um ano.

Dentre as várias alternativas para se calcular a mortalidade infantil, a SEI (1999) se valeu da técnica da mortalidade infanto-juvenil de BRASS (1975), que se baseia nos valores das probabilidades de morrer até três anos e até cinco anos ${ }_{3} \mathrm{q}_{0} \mathrm{e}$ $\left.{ }_{5} q_{0}\right)$. Estes, encontrados por meio das informações censitárias de 1970 a 1991 e da PNAD 95, foram interpolados, em suas respectivas séries históricas, para a mesma data de realização dos censos demográficos. Os valores de $\mathrm{q}_{0}$ foram obtidos utilizando-se equações cuja variável dependente era a probabilidade de morrer no 
primeiro ano de vida, $q_{0}$, e as variáveis independentes, as probabilidades ${ }_{3} q_{0}$ e ${ }_{5} q_{0}$. Este procedimento buscou isentar o cálculo de $\mathrm{q}_{0}$ da tradicional utilização de um padrão de mortalidade diretamente retirado de algum conjunto de tábuas modelo.

No entanto, todo este esforço seria inútil, pois pretende-se avaliar o impacto que diferentes causas de óbito tem na esperança de vida e, para isso, é necessário conhecer a distribuição delas por sexo e faixa etária. Para este problema, duas soluções são propostas:

$1^{\mathrm{a}}$. dispor de um modelo de distribuição de causas de morte por idade e sexo e, a partir dele, corrigir a subestimação dos óbitos por causa básica (este modelo não existe, pelo menos, para o Brasil).

$2^{a}$. para populações com baixa proporção de óbitos por causas mal definidas, pode-se assumir que os óbitos não registrados têm a mesma distribuição dos que foram captados pelo sistema de informação.

A segunda opção seria a melhor solução, não fosse o fato de que, em todo o Brasil, somente 287 municípios possuem dados de óbitos captados pelo SIM, entre os anos de 1996 e 1998, não comprometidos pelas causas mal definidas, isto é, com menos de $10 \%$ de óbitos por causas mal definidas em cada uma das faixas etárias utilizadas na construção das tábuas de vida. Destes 287 municípios, 216 (todos com menos de 30.000 habitantes) não possuem óbitos por causas mal definidas. Dos 71 restantes, dez são capitais (Teresina, Natal, Recife, Salvador, Belo Horizonte, São Paulo, Curitiba, Florianópolis, Porto Alegre e Brasília), e os outros 61 municípios pertencentes a este grupo estão concentrados nas Regiões Sudeste e Sul.

Assim, optou-se por estudar os Municípios de Salvador e São Paulo, que já tinha a vantagem de um estudo anterior (GOTLIEB 1977), lamentando as limitações que um sistema de mortalidade, com mais de vinte anos, ainda, impõe, mas que constitui em um desafio de implantação a ser vencido e que se espera poder contribuir, num futuro breve, para superá-lo.

São vários os questionamentos que conduziram a este estudo, entre eles:

- por que as EVN destas populações não é mais elevada 
- quais ações teriam que ser priorizadas para aumentar as EVN dessas comunidades

- quais causas de óbito têm mais influência e em quais grupos etários

- até que ponto as diferenças socioeconômicas entre estas duas capitais interferem na $\mathrm{EV}$ de suas populações

- como superar ou, pelo menos, minimizar as disparidades sociais existentes entre estas duas realidades

- qual o papel da informação neste processo

- o que pode ser feito a respeito

Estas e tantas outras perguntas que vêm à mente, impulsionam a buscar uma metodologia que ajude a responder, pelo menos em parte, estas questões e, quem sabe, propor algumas soluções para os problemas apresentados, ajudando, assim, a construir uma política de informações mais coerente com as necessidades da Bahia e que faça com que se sinta mais satisfeito com o papel na sociedade em que se vive. 


\section{OBJETIVO}

\subsection{Objetivo Geral:}

Avaliar e analisar o impacto de algumas causas básicas de morte na esperança de vida dos residentes nos Municípios de Salvador, Bahia, e São Paulo, São Paulo, em 1996.

\subsection{Objetivos Específicos:}

- Analisar a distribuição dos grupos de agravos segundo sexo e idade para as populações estudadas;

- Avaliar possíveis incrementos na Esperança de Vida decorrentes de eliminações de óbitos segundo causas/grupos de causas. 


\section{METODOLOGIA}

\subsection{Delineamento}

Trata-se de um estudo ecológico descritivo, utilizando dados secundários existentes. Por meio de um corte transversal (1996), avaliar-se-á o impacto de diferentes grupos de causas de óbito na esperança de vida.

\subsection{Dados necessários}

\subsubsection{População}

As populações consideradas foram as residentes nos Municípios de Salvador e São Paulo, em $1^{\circ}$ de julho de 1996, estimadas através da Contagem Populacional feita pelo IBGE (Tabela 1).

TABELA 1 - Número de habitantes, segundo sexo e grupo etário, de residentes nos Municípios de Salvador (BA) e São Paulo (SP) em 01/07/1996.

\begin{tabular}{|c|c|c|c|c|c|c|}
\hline \multirow{2}{*}{$\begin{array}{c}\text { G. Etário } \\
\text { (Anos) }\end{array}$} & \multicolumn{3}{|c|}{ Salvador } & \multicolumn{3}{|c|}{ São Paulo } \\
\hline & Masc. & Fem. & Total & Masc. & Fem. & Total \\
\hline$\overline{0}$ & 18.456 & 17.502 & 35.958 & 82.125 & 79.328 & 161.453 \\
\hline 1 & 18.774 & 18.084 & 36.858 & 79.626 & 76.919 & 156.545 \\
\hline 2 & 19.663 & 19.279 & 38.942 & 81.182 & 78.662 & 159.844 \\
\hline 3 & 19.245 & 18.785 & 38.030 & 81.867 & 78.944 & 160.811 \\
\hline 4 & 19.681 & 19.030 & 38.711 & 78.655 & 76.549 & 155.204 \\
\hline 5 a 9 & 100.148 & 97.232 & 197.380 & 423.950 & 414.224 & 838.174 \\
\hline 10 a 14 & 124.507 & 125.727 & 250.234 & 461.183 & 460.778 & 921.961 \\
\hline 15 a 19 & 126.573 & 140.481 & 267.054 & 460.289 & 482.947 & 943.236 \\
\hline 20 a 24 & 106.720 & 123.434 & 230.154 & 463.327 & 484.909 & 948.236 \\
\hline 25 a 29 & 95.008 & 110.382 & 205.390 & 440.623 & 460.886 & 901.509 \\
\hline 30 a 34 & 88.669 & 103.964 & 192.633 & 413.911 & 450.828 & 864.739 \\
\hline 35 a 39 & 77.357 & 90.496 & 167.853 & 370.789 & 412.441 & 783.230 \\
\hline 40 a 44 & 63.609 & 73.157 & 136.766 & 320.051 & 358.597 & 678.648 \\
\hline 45 a 49 & 48.006 & 54.824 & 102.830 & 253.753 & 286.635 & 540.388 \\
\hline 50 a 54 & 33.890 & 40.849 & 74.739 & 193.877 & 221.528 & 415.405 \\
\hline 55 a 59 & 24.832 & 32.075 & 56.907 & 150.297 & 177.551 & 327.848 \\
\hline 60 a 64 & 18.651 & 26.380 & 45.031 & 121.465 & 153.834 & 275.299 \\
\hline 65 a 69 & 13.448 & 21.199 & 34.647 & 97.435 & 129.939 & 227.374 \\
\hline 70 a 74 & 9.435 & 14.945 & 24.380 & 65.699 & 93.783 & 159.482 \\
\hline 75 a 79 & 5.084 & 9.463 & 14.547 & 36.539 & 58.313 & 94.852 \\
\hline 80 e mais & 5.219 & 11.840 & 17.059 & 30.612 & 61.480 & 92.092 \\
\hline & 975 & 169.128 & 206.103 & 707.255 & 5.099 .075 & 9.806 .330 \\
\hline
\end{tabular}

FONTE: DATASUS (disponivel em http://www.datasus.gov.br). 


\subsection{2 Óbitos}

A partir de 1996, por recomendação da OMS, o Ministério da Saúde passou a apresentar os dados de óbitos classificados pela $10^{\mathrm{a}}$ Revisão da CID $^{2}$ (OMS 1995). Considerando que, para o cálculo da esperança de vida, se recomenda trabalhar com a média do triênio em torno do ano de estudo, isto levou a fazer uma escolha entre:

$1^{\circ}$. trabalhar com o ano de 1997 (população projetada) e óbitos referentes aos anos de 1996 a 1998 captados pelo SIM, para evitar variações pontuais;

$2^{\circ}$. trabalhar com o ano de 1996 (dados da Contagem da População - IBGE) e óbitos referentes somente ao ano 1996, captados pelo SIM (MS 2000a).

Optou-se pela segunda alternativa, a fim de evitar maiores distorções com relação à população, pois os dados corrigidos das estimativas populacionais, levando em consideração o Censo 2000, ainda não estão disponíveis. Pressupôs-se que a possivel variação pontual na mortalidade para as populações estudadas não seria crítica (Tabela 2).

TABELA 2 - Número de óbitos, segundo sexo e grupo etário, de residentes nos Municípios de Salvador (BA) e São Paulo (SP), 1996.

\begin{tabular}{|c|c|c|c|c|c|c|}
\hline \multirow{2}{*}{$\begin{array}{c}\text { G. Etário } \\
\text { (Anos) }\end{array}$} & \multicolumn{3}{|c|}{ Salvador } & \multicolumn{3}{|c|}{ São Paulo } \\
\hline & Masc. & Fem. & Total & Masc. & Fem. & Total \\
\hline$\overline{\mathbf{0}}$ & 572 & 541 & 1.113 & 2.571 & 2.028 & 4.599 \\
\hline 1 & 51 & 50 & 101 & 156 & 159 & 315 \\
\hline 2 & 30 & 26 & 56 & 75 & 80 & 155 \\
\hline 3 & 17 & 17 & 34 & 59 & 46 & 105 \\
\hline 4 & 13 & 9 & 22 & 36 & 27 & 63 \\
\hline 5 a 9 & 54 & 27 & 81 & 191 & 140 & 331 \\
\hline 10 a 14 & 73 & 64 & 137 & 303 & 187 & 490 \\
\hline 15 a 19 & 284 & 83 & 367 & 1.366 & 314 & 1.681 \\
\hline 20 a 24 & 352 & 62 & 414 & 2.014 & 428 & 2.442 \\
\hline 25 a 29 & 304 & 114 & 418 & 2.385 & 523 & 2.908 \\
\hline 30 a 34 & 317 & 139 & 456 & 2.416 & 678 & 3.094 \\
\hline 35 a 39 & 349 & 199 & 548 & 2.522 & 891 & 3.413 \\
\hline 40 a 44 & 364 & 240 & 604 & 2.506 & 944 & 3.450 \\
\hline 45 a 49 & 363 & 273 & 636 & 2.473 & 1.211 & 3.684 \\
\hline 50 a 54 & 398 & 295 & 693 & 2.602 & 1.389 & 3.991 \\
\hline 55 a 59 & 444 & 362 & 806 & 2.768 & 1.648 & 4.416 \\
\hline 60 a 64 & 507 & 417 & 924 & 3.282 & 2.067 & 5.349 \\
\hline 65 a 69 & 547 & 534 & 1.081 & 3.709 & 2.571 & 6.280 \\
\hline 70 a 74 & 564 & 531 & 1.095 & 3.618 & 3.011 & 6.629 \\
\hline 75 a 79 & 447 & 539 & 986 & 3.035 & 3.094 & 6.129 \\
\hline 80 e mais & 730 & 1.392 & 2.122 & 4.813 & 7.591 & 12.404 \\
\hline Total & 6.780 & 5.914 & 12.694 & 42.900 & 29.027 & 71.928 \\
\hline
\end{tabular}

FONTE: DATASUS (disponível em http://www.datasus.gov.br).

${ }^{2}$ CID - Classificação Internacional de Doenças. 
Entretanto, como já comentado anteriormente, há de ser salientado que a cobertura do SIM para cada uma das capitais é bastante discrepante. Enquanto em São Paulo, considera-se haver uma alta abrangência, não havendo praticamente subnotificação, em Salvador, a situação é diferente. Embora não existam dados oficiais para esta capital, estimativas mostram que o sub-registro de óbitos em menores de um ano em 1998 na Bahia era de 61,1\% e estava concentrado no interior do estado (SIMÕES 2002). Adotou-se o pressuposto que tal sub-registro não é seletivo em função das causas básicas e procedeu-se a correção dos óbitos apenas para Salvador.

Foi corrigida a sub-informação dos óbitos "naturais" (total de óbitos descontando as mortes por causas externas), da população de Salvador, a partir de um ano de idade, de acordo com a metodologia proposta por COURBAGE e FARGUES (1979), utilizando-se, como tábua padrão de mortalidade, as do Modelo Brasil (IBGE 1981) por serem as mais indicadas dentre as existentes (ALBUQUERQUE et al. 1986).

Os valores referentes ao índice de concentração de óbitos para idades avançadas - $\mathrm{i}(1,50)$ - foram escolhidos como os mais adequados à população de Salvador, o que implica em fatores de correção de 1,05 e 1,13 para os óbitos "naturais" masculinos e femininos respectivamente.

Para menores de um ano, foi utilizada como base a interpolação dos dados de 1994 e 1998 das estimativas de mortalidade infantil, desenvolvidas por Celso Simões para o Ministério da Saúde (SIMÕES 1999). A partir desta interpolação, e considerando-se o número de nascidos vivos para o ano de 1996 fornecidos pelo sistema de registro de nascimentos do Ministério da Saúde (SINASC), foi possível estimar um sub-registro de $33 \%$ para os óbitos em menores de um ano de Salvador.

Cada grupo de causas básicas de morte do Município de Salvador, com exceção das causas externas, que permaneceram inalteradas, tiveram seus valores alterados pelos fatores de correção adotados. Uma vez corrigidos os óbitos naturais, foram acrescentados os óbitos por causas externas e procedeu-se ao cálculo das tábuas de vida normalmente. Os dados de São Paulo não sofreram qualquer correção e foram calculados e trabalhados exatamente com a mesma metodologia utilizada por GOTLIEB (1977). 


\subsubsection{Grupos de causas básicas de morte}

As causas básicas de morte utilizadas, neste trabalho, representam as principais causas de óbito no País e seguem a lista de apresentação da CID-10 BR (MS 2000a), sendo agrupadas da seguinte forma:

G1. Algumas doenças infecciosas e parasitárias (A00-B99)

G2. Neoplasias (C00-D48)

G3. Doenças do aparelho circulatório (I00-I99)

G4. Doenças do aparelho respiratório (J00-J99)

G5. Causas externas de morbidade e mortalidade (V01-Y98)

Dentre alguns dos grupos selecionados, será analisada a influência de alguns subgrupos específicos, a saber:

No Grupo 1 (A00-B99)

- Doenças infeciosas intestinais (A00-A09)

- Outras doenças bacterianas (A20-A64)

- Doenças virais (A80-B24)

No Grupo 3 (100-199)

- Doenças isquêmicas do coração (I20-I25)

- Doenças cerebrovasculares (I60-I69)

No Grupo 5 (V01-Y98)

- Acidentes de transporte (V01-V99)

- Agressões (X85-Y09)

\subsection{Construção das tábuas de vida}

A esperança de vida foi calculada por meio de tábua de vida. Para isso, foi necessário estimar a probabilidade de uma pessoa com idade exata $X$, no início de um determinado ano, vir a falecer neste mesmo ano. Conhecendo-se o número de casos que compõe o evento "vir a falecer durante o período" e o número de indivíduos com idade exata $\mathrm{X}$, no início do período, é possível estimar estas probabilidades.

Foram consideradas as seguintes suposições: a mortalidade, em cada idade, mantém-se constante e igual a do ano calendário, no qual a tábua é baseaḍ; a 
população exposta é estacionária, isto é, o número anual de nascidos vivos é igual ao número de mortes; o saldo migratório é nulo, ano após ano.

\subsubsection{Elementos da tábua de vida}

Basicamente as tábuas de vida são formadas por sete colunas, cuja estrutura é apresentada nas Tabelas 3 e 4:

Coluna 1: Intervalo ou grupo etário - $(\mathbf{X}, \mathbf{X}+\mathbf{n})$ - Cada intervalo é definido por duas idades exatas, exceto o último grupo etário $(80$ anos $\mathrm{e}+$ ).

Coluna 2: Número de sobreviventes que iniciaram a idade $\mathbf{X}-\left(\mathbf{l}_{\mathbf{X}}\right)-\mathrm{O}$ primeiro valor desta variável $\left(\mathrm{l}_{0}\right)$ é arbitrário, no caso 100.000 indivíduos. Os demais valores desta coluna correspondem aos sobreviventes em cada idade $\mathrm{X}$, de acordo com a mortalidade existente na população estudada.

Coluna 3: Proporção de mortes no intervalo etário $(X, X+n)-\left({ }_{n} q \mathbf{X}\right)-E$ a estimativa da probabilidade de um indivíduo vivo na idade $\mathrm{X}$ vir a morrer no intervalo $(X, X+n)$. É a partir desta coluna que são calculados os valores de todas as outras colunas, e $\mathrm{q}_{\mathrm{X}}$ é calculado relacionando o número de mortes no intervalo $(X, X+n)$ com a população exposta:

$$
\mathrm{q}_{\mathrm{X}}=\frac{{ }_{\mathrm{n}} \mathrm{O}_{\mathrm{X}}}{{ }_{\mathrm{n}} \mathrm{P}_{\mathrm{X}}+\left(1-\mathrm{a}^{\prime}\right)_{\mathrm{n}} \mathrm{O}_{\mathrm{X}}}
$$

Onde:

$$
\begin{aligned}
& { }_{n} \mathrm{O}_{X}=\text { óbitos ocorridos no intervalo etário }(X, X+n) \\
& { }_{n} P_{X}=\text { população estimada no intervalo etário }(X, X+n) \\
& a^{\prime}=\text { fator de separação }{ }^{3}
\end{aligned}
$$

Coluna 4: Número de mortes no intervalo $(\mathbf{X}, \mathbf{X}+\mathbf{n})-\left({ }_{n} \mathbf{d}_{X}\right)$ - Representa o número de mortes da tábua de vida no intervalo etário. Os valores desta coluna são dependentes da raiz $l_{0}$ que iniciou a tábua e são obtidos aplicando os vários $\mathrm{q}_{\mathrm{X}}$ no total de sobreviventes de cada grupo etário.

\footnotetext{
${ }^{3} \mathrm{a}^{\prime}=$ conhecido como fator de separação é a proporção do total de óbitos com idade $\mathrm{X}$, durante o ano calendário $t$, que teve o seu último aniversário no ano $t-1$. Neste trabalho, foram utilizados os valores calculados por OYA (cit. GOTLIEB 1977), no qual: para a idade de menores de um ano o valor foi de 0,174 para o sexo feminino e 0,137 para o sexo masculino; para a idade de um ano, em ambos os sexos, o valor foi de 0,30. Acima desta idade, utilizou-se o valor 0,50.
} 
Coluna 5: Número de anos vividos no intervalo $(X, X+n)-\left({ }_{n} \mathbf{L}_{X}\right)$ - Cada indivíduo da coorte que sobrevive o ano contribui para ${ }_{n} \mathrm{~L}_{X}$ com um ano completo, e cada um dos que morreram contribui com a respectiva fração (a'). Para o último grupo etário, neste caso, 80 anos e mais, seguiu-se a recomendação de Barclay, citada por BERQUÓ (1972) e adotada por LAURENTI et al. (1987):

$\mathbf{L}_{\mathrm{X}}=\frac{\mathrm{dx}}{\mathbf{D}_{\mathrm{X}}} \cdot \mathbf{P}_{\mathrm{X}}$

onde,

$\mathrm{dx}=$ número de mortes no intervalo etário final;

$\mathbf{D}_{\mathrm{X}}=$ número de óbitos na população, no intervalo etário final;

$\mathbf{P}_{\mathrm{X}}=$ população recenseada e estimada para o último intervalo etário.

Coluna 6: Total de anos vividos além da idade $X-\left({ }_{n} \mathbf{T}_{X}\right)-$ Corresponde à soma do número de anos vividos em cada intervalo de idade começando com a idade X. Os valores são obtidos pelo somatório (inverso) dos números da coluna (5) - número de anos vividos no intervalo $(X, X+n)$, começando pelo último grupo etário apresentado.

Coluna 7: Esperança de vida observada na idade $\mathbf{X}-\left({ }_{n} \mathbf{e}_{\mathrm{X}}\right)-$ É o número médio de anos a serem vividos pelas pessoas na idade $(X, X+n)$. É obtida pela divisão dos valores da coluna (6) pelos valores da coluna (2).

\subsubsection{Tábua de vida de múltiplo decremento}

A construção da tábua de vida de múltiplo decremento requer o conhecimento de diferentes tipos de probabilidade de morte por causa especifica (GOTLIEB 1977). Assim:

\subsubsection{Probabilidade bruta de morte}

É a probabilidade de morte por uma causa específica, ou grupo de causas, na presença de todos os outros fatores de risco atuando na população. Pode ser representada por: 
$\mathrm{q}_{\mathrm{ij}}=$ probabilidade de um indivíduo vivo, no tempo $X_{\mathrm{i}}$, morrer no intervalo $\left(\mathrm{X}_{\mathrm{i}}, \mathrm{X}_{\mathrm{i}+1}\right)$, pela causa $\mathrm{j}$, na presença de todos os outros riscos de morte atuando na população.

O estimador desta probabilidade é:

$$
\hat{\mathrm{q}}_{\mathrm{ij}}=\frac{\mathrm{N}_{\mathrm{i}} \mathrm{M}_{\mathrm{ij}}}{1+\left(1-\mathrm{a}_{\mathrm{i}}\right) \mathrm{N}_{\mathrm{i}} \mathrm{M}_{\mathrm{i}}}
$$

Onde:

$\mathrm{i}=0,1,2,3,4,5,10 \ldots(\operatorname{anos})$

$\mathrm{j}=1,2 \ldots \mathrm{r}$ (causa);

$\mathrm{N}_{\mathrm{i}}$ = intervalo de classe para o grupo etário considerado;

$\mathrm{M}_{\mathrm{ij}}=$ coeficiente de mortalidade específico pela causa $\mathrm{j}$, ou grupo de causas, na idade $\mathrm{i}$;

$a^{\prime}{ }_{i}=$ fator de separação para idade $i$

$M_{i}=$ coeficiente de mortalidade na idade $i$.

\subsubsection{Probabilidade líquida de morte}

É a probabilidade de morte se um fator de risco específico for o único agindo sobre a população ou, também, é a probabilidade de morte se o fator de risco específico for eliminado da população (GOTLIEB 1977). Pode ser representada por:

$\mathrm{q}_{\mathrm{ij}}=$ probabilidade de um indivíduo vivo, no tempo $\mathrm{X}_{\mathrm{i}}$, vir a morrer no intervalo $\left(\mathrm{X}_{\mathrm{i}}, \mathrm{X}_{\mathrm{i}+\mathrm{n}}\right)$ se a causa específica, ou grupo de causas, $\mathrm{j}$ for $\mathrm{o}$ único fator de risco atuando sobre a população.

$\mathrm{q}_{\mathrm{i}, \mathrm{j}}=$ probabilidade de um indivíduo vivo, no tempo $X_{i}$, vir a morrer no intervalo $\left(X_{i}, X_{i+n}\right)$ se a causa específica, ou grupo de causas, $j$ for eliminada como fator de risco de morte.

Os estimadores dessas probabilidades são:

$$
\hat{\mathrm{q}}_{i j}=1-\hat{\mathrm{p}}_{\mathrm{i}}^{\left(\mathrm{D}_{\mathrm{ij}} / \mathrm{D}_{\mathrm{i}}\right)}
$$




$$
\hat{q}_{i, j}=1-\hat{p}_{i}^{\left[\left(D_{i}-D_{i j}\right) / D_{i}\right]}
$$

Onde:

$\mathrm{i}=0,1,2,3,4,5,10 \ldots($ anos $)$;

$\mathrm{j}=1,2 \ldots \mathrm{r}$ (causa);

$\hat{p}_{i}=$ estimador da probabilidade de um indivíduo sobreviver de $x_{i}$ a $x_{i+n}$ :

$$
\hat{p}_{i}=\frac{1-a^{\prime}{ }_{i} N_{i} M_{i}}{1+\left(1-a_{i}\right)} \frac{N_{i}}{M_{i}}
$$

$D_{\mathrm{ij}}=$ número de óbitos ocorridos na idade i pela causa $\mathrm{j}$, ou grupo de causas;

$\mathrm{D}_{\mathrm{i}}=$ número de óbitos ocorridos na idade $\mathrm{i}$.

A metodologia utilizada, na construção da tábua de vida de múltiplo decremento, diferencia-se daquela da tábua de vida (LAURENTI et al. 1987), unicamente na coluna (3) das Tabelas 3 e 4 - proporção de mortes no intervalo etário $(\mathrm{X}, \mathrm{X}+\mathrm{n})-\mathrm{q}_{\mathrm{X}}$. Neste caso, a probabilidade de morte é líquida, isto é, admite-se que alguma causa específica de morte tenha sido eliminada da população. Isso faz com que $\left(q_{x}\right)$ passe, então, a ser estimada por:

$$
q_{X} \equiv \hat{q}_{i . j}=1-\hat{p}_{i}^{\left[\left(D_{i}-D_{i j}\right) / D_{i}\right]}
$$

Adotar-se-á, neste trabalho, a nomenclatura de probabilidade de morte hipotética $\left(q_{x}\right)$, probabilidade de sobreviver hipotética ( $p_{O X}$ ) e esperança de vida hipotética $\left(\mathrm{e}_{\mathrm{X}}\right)$ para as variáveis calculadas nas tábuas de vida de múltiplo decremento, isto é, seriam hipotéticas, pois pressupõe-se a inexistência de determinada doença ou grupo de agravos, como causa de óbito. 
TABELA 3 - Tábua de vida. População residente no Município de Salvador (BA), 1996 (ambos os sexos).

\begin{tabular}{|c|c|c|c|c|c|c|}
\hline $\begin{array}{c}\mathbf{X} \\
\text { (1) }\end{array}$ & $\begin{array}{l}\mathbf{l}_{\mathbf{X}} \\
(2)\end{array}$ & $\begin{array}{c}\mathbf{n q} \mathbf{x} \\
(3)\end{array}$ & $\begin{array}{l}{ }_{n} \mathbf{d}_{\mathbf{X}} \\
(4)\end{array}$ & $\begin{array}{c}{ }_{(5)} \mathbf{L}_{\mathbf{X}} \\
\end{array}$ & $\begin{array}{l}T_{\mathbf{X}} \\
(6)\end{array}$ & $\begin{array}{l}\mathbf{e}_{\mathbf{X}} \\
\text { (7) }\end{array}$ \\
\hline 0 & 100.000 & 0,03975 & 3.975 & 96.641 & 6.742 .534 & 67,43 \\
\hline 1 & 96.025 & 0,00298 & 286 & 95.825 & 6.645 .893 & 69,21 \\
\hline 2 & 95.739 & 0,00154 & 147 & 95.665 & 6.550 .068 & 68,42 \\
\hline 3 & 95.592 & 0,00097 & 93 & 95.545 & 6.454 .403 & 67,52 \\
\hline 4 & 95.499 & 0,00059 & 57 & 95.470 & 6.358 .857 & 66,59 \\
\hline 5 a 9 & 95.442 & 0,00215 & 205 & 476.697 & 6.263 .387 & 65,63 \\
\hline 10 a 14 & 95.237 & 0,00289 & 276 & 475.495 & 5.786 .690 & 60,76 \\
\hline 15 a 19 & 94.961 & 0,00705 & 670 & 473.132 & 5.311 .196 & 55,93 \\
\hline 20 a 24 & 94.291 & 0,00919 & 867 & 469.291 & 4.838 .064 & 51,31 \\
\hline 25 a 29 & 93.425 & 0,01056 & 986 & 464.658 & 4.368 .774 & 46,76 \\
\hline 30 a 34 & 92.438 & 0,01243 & 1.149 & 459.319 & 3.904 .115 & 42,23 \\
\hline 35 a 39 & 91.289 & 0,01728 & 1.577 & 452.503 & 3.444 .796 & 37,73 \\
\hline 40 a 44 & 89.712 & 0,02352 & 2.110 & 443.286 & 2.992.292 & 33,35 \\
\hline 45 a 49 & 87.602 & 0,03286 & 2.878 & 430.815 & 2.549 .007 & 29,10 \\
\hline 50 a 54 & 84.724 & 0,04901 & 4.152 & 413.239 & 2.118 .192 & 25,00 \\
\hline 55 a 59 & 80.572 & 0,07412 & 5.972 & 387.929 & 1.704 .953 & 21,16 \\
\hline 60 a 64 & 74.600 & 0,10569 & 7.885 & 353.288 & 1.317 .025 & 17,65 \\
\hline 65 a 69 & 66.715 & 0,15680 & 10.461 & 307.423 & 963.737 & 14,45 \\
\hline 70 a 74 & 56.254 & 0,21816 & 12.272 & 250.589 & 656.313 & 11,67 \\
\hline 75 a 79 & 43.982 & 0,31310 & 13.771 & 185.481 & 405.725 & 9,22 \\
\hline 80 e + & 30.211 & 1,00000 & 30.211 & 220.243 & 220.243 & 7,29 \\
\hline
\end{tabular}

TABELA 4 - Tábua de vida. População residente no Município de São Paulo (SP), 1996 (ambos os sexos).

\begin{tabular}{|c|c|c|c|c|c|c|}
\hline $\begin{array}{r}\mathbf{X} \\
\text { (1) } \\
\end{array}$ & $\begin{array}{l}\mathbf{l} \mathbf{X} \\
(2) \\
\end{array}$ & $\underset{\text { (3) }}{{ }^{n} \mathbf{q}_{\mathbf{X}}}$ & $\begin{array}{c}{ }_{n} \mathbf{d}_{\mathbf{X}} \\
(4)\end{array}$ & 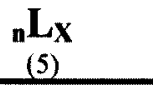 & $\begin{array}{l}\mathbf{T}_{\mathbf{X}} \\
(6) \\
\end{array}$ & $\begin{array}{l}\mathbf{e}_{\mathbf{X}} \\
(7) \\
\end{array}$ \\
\hline$\overline{0}$ & 100.000 & 0,02781 & 2.781 & 97.645 & 6.856 .605 & 68,57 \\
\hline 1 & 97.219 & 0,00201 & 195 & 97.082 & 6.758 .960 & 69,52 \\
\hline 2 & 97.023 & 0,00097 & 94 & 96.976 & 6.661 .878 & 68,66 \\
\hline 3 & 96.929 & 0,00065 & 63 & 96.898 & 6.564 .902 & 67,73 \\
\hline 4 & 96.866 & 0,00041 & 39 & 96.846 & 6.468 .005 & 66,77 \\
\hline 5 a 9 & 96.827 & 0,00197 & 191 & 483.656 & 6.371 .158 & 65,80 \\
\hline 10 a 14 & 96.636 & 0,00265 & 256 & 482.537 & 5.887 .503 & 60,92 \\
\hline 15 a 19 & 96.379 & 0,00887 & 855 & 479.758 & 5.404 .966 & 56,08 \\
\hline 20 a 24 & 95.524 & 0,01279 & 1.222 & 474.565 & 4.925 .208 & 51,56 \\
\hline 25 a 29 & 94.302 & 0,01600 & 1.509 & 467.738 & 4.450 .642 & 47,20 \\
\hline 30 a 34 & 92.793 & 0,01773 & 1.645 & 459.853 & 3.982 .904 & 42,92 \\
\hline 35 a 39 & 91.148 & 0,02155 & 1.965 & 450.828 & 3.523 .052 & 38,65 \\
\hline 40 a 44 & 89.183 & 0,02510 & 2.238 & 440.321 & 3.072 .223 & 34,45 \\
\hline 45 a 49 & 86.945 & 0,03352 & 2.914 & 427.440 & 2.631 .903 & 30,27 \\
\hline 50 a 54 & 84.031 & 0,04691 & 3.942 & 410.300 & 2.204 .463 & 26,23 \\
\hline 55 a 59 & 80.089 & 0,06515 & 5.218 & 387.400 & 1.794 .163 & 22,40 \\
\hline 60 a 64 & 74.871 & 0,09265 & 6.937 & 357.012 & 1.406 .764 & 18,79 \\
\hline 65 a 69 & 67.934 & 0,12918 & 8.776 & 317.732 & 1.049 .751 & 15,45 \\
\hline 70 a 74 & 59.159 & 0,18827 & 11.138 & 267.949 & 732.020 & 12,37 \\
\hline 75 a 79 & 48.021 & 0,27815 & 13.357 & 206.712 & 464.071 & 9,66 \\
\hline 80 e + & 34.664 & 1,00000 & 34.664 & 257.358 & 257.358 & 7,42 \\
\hline
\end{tabular}




\subsection{Avaliação do impacto dos grupos de causas de morte na esperança de vida}

O impacto de um determinado grupo de causas de óbito na esperança de vida pode ser medido pelos APVG (vide seção 1.5) e pela diferença entre os valores da esperança de vida calculada com e sem a inclusão dos óbitos devido a esse mesmo grupo de causa.

O cálculo fica bastante simplificado, na medida em que a metodologia de construção das tábuas de vida de múltiplo decremento está bem definida. Assim, tais valores podem ser obtidos por uma simples subtração dos resultados da construção de duas tábuas de vida (com e sem o grupo de agravo em questão).

A diferença entre probabilidade de morte em cada grupo etário $\left(\hat{\mathrm{q}}_{\mathrm{x}}\right)$ e probabilidade líquida de morte $\left(\hat{\mathrm{q}}_{\mathrm{X}}\right)$, isto é, excluindo-se um determinado grupo de causas básicas de óbito, entende-se aqui por diferença absoluta: $\left|q_{\mathrm{X}}-\mathrm{q}_{\mathrm{x}}\right| \mathrm{e}$ por diferença relativa (\%):

$$
\frac{|\mathrm{qx}-\mathrm{qx} .|}{\mathrm{q}_{\mathrm{x}}} \times 100
$$

Além da probabilidade de morte em cada grupo etário $\left(\hat{\mathrm{q}}_{\mathrm{x}}\right)$, estimou-se também a probabilidade de sobreviver do nascimento até a idade $\mathrm{X}\left(\hat{\mathrm{p}}_{\text {OXX }}\right)$ que é obtida pela relação:

$$
p_{o x}=\frac{1 x}{l_{0}}
$$




\section{RESULTADOS E DISCUSSÃO}

\subsection{Estrutura da população, segundo sexo e faixa etária}

Conhecer a composição etária dos residentes nos Municípios de Salvador e São Paulo contribui para se avaliar o perfil de saúde das populações estudadas. Uma das formas de fazê-lo mais facilmente é a visualização por meio de pirâmides populacionais (Figura 1).

FIGURA 1 - Pirâmides populacionais, segundo sexo e faixa etária (\%). Municípios de Salvador e São Paulo, 1996.

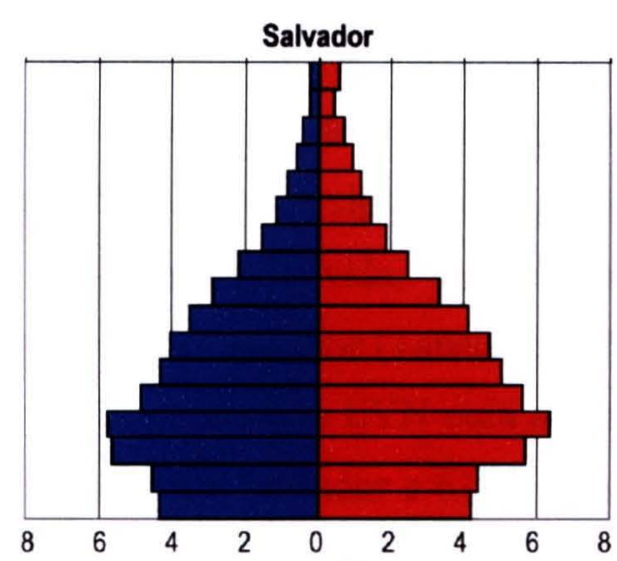

$(\%)$

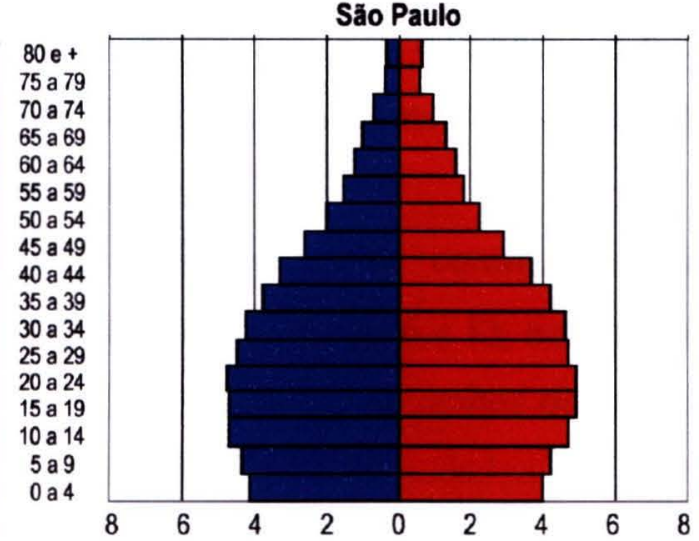

$(\%)$

Pode-se verificar que a população da capital paulista encontra-se em um nível de envelhecimento maior que a residente em Salvador, caminhando para uma concentração proporcionalmente maior de indivíduos em idades mais avançadas. Por conseguinte a capital baiana apresenta uma proporção maior de adolescentes, provavelmente em função das quedas da fecundidade e da mortalidade infantil, mais recentemente. Ambas as pirâmides populacionais possuem uma certa assimetria, privilegiando a população feminina, o que já era de se esperar, principalmente entre os adultos e os idosos. Há em todas as capitais brasileiras esse mesmo fenômeno e possivelmente em face da emigração feminina à procura de trabalho. 


\subsection{Esperança de vida}

Para se avaliar o impacto de diferentes grupos de causas de óbito na esperança de vida das populações dos Municípios de Salvador e São Paulo, em 1996, faz-se necessária a construção das tábuas de vida correspondentes (Tabelas 3 e 4). A partir de então, é possível medir o efeito que determinadas causas/grupos de causa de óbito têm na EV, por meio da técnica de múltiplo decremento, com a eliminação dos óbitos pelos grupos de causas em estudo.

\subsubsection{Esperança de vida segundo sexo}

Mais interessante do que estudar a variação da esperança de vida, nas populações, é estudar o seu comportamento com relação à mortalidade diferencial por sexo. Já é bem conhecido o fenômeno da sobremortalidade masculina, isto é, a mortalidade feminina se manifesta de forma mais branda. Este é um achado mundial e que tende a mudar as estruturas etárias (diferenciadamente por sexo) das populações, de forma significativa, ao longo dos anos.

As tábuas de vida, segundo os sexos, foram, então, construídas para os Municípios de Salvador (Tabelas 5 e 7) e São Paulo (Tabelas 6 e 8), acompanhando o esperado. Assim, as EVN para as populações masculinas de ambos os municípios (64,10 anos, em Salvador e 63,39 anos, em São Paulo) ficaram abaixo das EVN das respectivas populações femininas (70,33 anos, em Salvador e 73,92, em São Paulo).

GOTLIEB (1977), para o Município de São Paulo, chama a atenção que a EVN das mulheres vai se distanciando da masculina quando se analisam os dados de 1950, 1960 e 1970 (uma diferença de 5,25, 7,59 e 7,09 anos respectivamente). Esta tendência é aqui confirmada, a medida que, em 1996, a diferença das EVN entre os sexos masculino e feminino chegou a 10,53 anos (Tabela 9). Para o município de Salvador, não se dispõe da informação, mas como esta é uma tendência global, presume-se que o mesmo tenha se dado com este município.

O ganho da EVN, em São Paulo, entre 1950 e 1970, foi de 5,61 anos para os homens e 7,45 anos para as mulheres. Entre 1970 e 1996, estes ganhos passaram para 3,27 e 6,71 anos respectivamente, mostrando uma desaceleração nesses ganhos, para ambos os sexos, mas de forma mais abrupta para os homens, em parte, explicando $o$ aumento da disparidade entre sexos. 
TABELA 5 - Tábua de vida. População masculina residente no Município de Salvador (BA), 1996.

\begin{tabular}{|c|c|c|c|c|c|c|}
\hline $\begin{array}{c}\mathbf{X} \\
(1)\end{array}$ & $\begin{array}{l}\mathbf{l X}_{\mathbf{X}} \\
\text { (2) }\end{array}$ & $\underset{(3)}{\mathbf{n} \mathbf{q}}$ & $\begin{array}{c}\mathbf{n}^{\mathbf{d}} \mathbf{d} \\
(4)\end{array}$ & $\begin{array}{c}{ }_{n} \mathbf{L}_{\mathbf{X}} \\
(5)\end{array}$ & $\begin{array}{l}\mathbf{T}_{\mathbf{X}} \\
(6)\end{array}$ & $\begin{array}{l}\mathbf{e x} \\
\text { (7) }\end{array}$ \\
\hline 0 & 100.000 & 0,03977 & 3.977 & 96.568 & 6.409 .630 & 64,10 \\
\hline 1 & 96.023 & 0,00287 & 276 & 95.830 & 6.313 .062 & 65,75 \\
\hline 2 & 95.748 & 0,00158 & 151 & 95.672 & 6.217 .231 & 64,93 \\
\hline 3 & 95.597 & 0,00093 & 89 & 95.552 & 6.121 .559 & 64,04 \\
\hline 4 & 95.508 & 0,00066 & 63 & 95.476 & 6.026 .006 & 63,09 \\
\hline 5 a 9 & 95.445 & 0,00279 & 266 & 476.556 & 5.930 .530 & 62,14 \\
\hline 10 a 14 & 95.178 & 0,00301 & 286 & 475.175 & 5.453 .974 & 57,30 \\
\hline 15 a 19 & 94.892 & 0,01131 & 1.073 & 471.775 & 4.978 .799 & 52,47 \\
\hline 20 a 24 & 93.818 & 0,01663 & 1.561 & 465.190 & 4.507 .024 & 48,04 \\
\hline 25 a 29 & 92.258 & 0,01623 & 1.498 & 457.545 & 4.041 .834 & 43,81 \\
\hline 30 a 34 & 90.760 & 0,01833 & 1.663 & 449.642 & 3.584 .289 & 39,49 \\
\hline 35 a 39 & 89.097 & 0,02325 & 2.072 & 440.304 & 3.134 .647 & 35,18 \\
\hline 40 a 44 & 87.025 & 0,02958 & 2.574 & 428.689 & 2.694 .342 & 30,96 \\
\hline 45 a 49 & 84.450 & 0,03901 & 3.294 & 414.016 & 2.265 .654 & 26,83 \\
\hline 50 a 54 & 81.156 & 0,06010 & 4.878 & 393.586 & 1.851 .637 & 22,82 \\
\hline 55 a 59 & 76.278 & 0,09018 & 6.879 & 364.195 & 1.458 .052 & 19,11 \\
\hline 60 a 64 & 69.400 & 0,13429 & 9.320 & 323.699 & 1.093 .856 & 15,76 \\
\hline 65 a 69 & 60.080 & 0,19435 & 11.677 & 271.207 & 770.157 & 12,82 \\
\hline 70 a 74 & 48.403 & 0,27356 & 13.241 & 208.913 & 498.950 & 10,31 \\
\hline 75 a 79 & 35.162 & 0,37805 & 13.293 & 142.577 & 290.037 & 8,25 \\
\hline 80 e + & 21.869 & 1,00000 & 21.869 & 147.460 & 147.460 & 6,74 \\
\hline
\end{tabular}

TABELA 6 - Tábua de vida. População masculina residente no Município de São Paulo (SP), 1996.

\begin{tabular}{|c|c|c|c|c|c|c|}
\hline $\begin{array}{c}\mathbf{X} \\
(1)\end{array}$ & $\begin{array}{l}\mathbf{I X}_{\mathbf{X}} \\
(2)\end{array}$ & $\underset{(3)}{\mathbf{n q}}$ & $\begin{array}{l}{ }^{n} \mathbf{d}_{\mathbf{X}} \\
(\mathbf{4})\end{array}$ & $\begin{array}{c}{ }_{n} \mathbf{L X}_{\mathbf{X}} \\
(5)\end{array}$ & $\begin{array}{l}\mathbf{T}_{\mathbf{X}} \\
(6)\end{array}$ & $\begin{array}{l}\mathbf{e x}_{\mathbf{X}} \\
(7)\end{array}$ \\
\hline 0 & 100.000 & 0,03048 & 3.048 & 97.369 & 6.338 .504 & 63,39 \\
\hline 1 & 96.952 & 0,00196 & 190 & 96.819 & 6.241 .134 & 64,37 \\
\hline 2 & 96.762 & 0,00092 & 89 & 96.717 & 6.144 .315 & 63,50 \\
\hline 3 & 96.673 & 0,00072 & 70 & 96.638 & 6.047 .598 & 62,56 \\
\hline 4 & 96.603 & 0,00046 & 44 & 96.581 & 5.950 .960 & 61,60 \\
\hline 5 a 9 & 96.559 & 0,00225 & 217 & 482.251 & 5.854 .379 & 60,63 \\
\hline 10 a 14 & 96.342 & 0,00328 & 316 & 480.918 & 5.372 .128 & 55,76 \\
\hline 15 a 19 & 96.026 & 0,01473 & 1.414 & 476.592 & 4.891 .210 & 50,94 \\
\hline 20 a 24 & 94.611 & 0,02150 & 2.034 & 467.971 & 4.414 .617 & 46,66 \\
\hline 25 a 29 & 92.577 & 0,02670 & 2.472 & 456.705 & 3.946 .647 & 42,63 \\
\hline 30 a 34 & 90.105 & 0,02877 & 2.592 & 444.045 & 3.489 .941 & 38,73 \\
\hline 35 a 39 & 87.513 & 0,03344 & 2.926 & 430.250 & 3.045 .896 & 34,81 \\
\hline 40 a 44 & 84.587 & 0,03840 & 3.248 & 414.814 & 2.615 .646 & 30,92 \\
\hline 45 a 49 & 81.339 & 0,04757 & 3.869 & 397.020 & 2.200 .833 & 27,06 \\
\hline 50 a 54 & 77.469 & 0,06493 & 5.030 & 374.773 & 1.803 .813 & 23,28 \\
\hline 55 a 59 & 72.440 & 0,08803 & 6.377 & 346.256 & 1.429 .040 & 19,73 \\
\hline 60 a 64 & 66.063 & 0,12655 & 8.360 & 309.413 & 1.082 .784 & 16,39 \\
\hline 65 a 69 & 57.702 & 0,17379 & 10.028 & 263.441 & 773.371 & 13,40 \\
\hline 70 a 74 & 47.674 & 0,24203 & 11.538 & 209.525 & 509.930 & 10,70 \\
\hline 75 a 79 & 36.136 & 0,34390 & 12.427 & 149.611 & 300.405 & 8,31 \\
\hline 80 e + & 23.709 & 1,00000 & 23.709 & 150.794 & 150.794 & $.6,36$ \\
\hline
\end{tabular}


TABELA 7 - Tábua de vida. População feminina residente no Município de Salvador (BA), 1996.

\begin{tabular}{|c|c|c|c|c|c|c|}
\hline $\begin{array}{c}\mathbf{X} \\
\text { (1) }\end{array}$ & $\begin{array}{l}\mathbf{l}_{\mathbf{X}} \\
(2) \\
\end{array}$ & $\begin{array}{l}\mathbf{n q x} \\
(3)\end{array}$ & $\begin{array}{l}{ }_{n} \mathbf{d}_{\mathbf{X}} \\
(4)\end{array}$ & ${ }_{(5)} \mathbf{L}_{\mathbf{X}}$ & $\begin{array}{l}T_{\mathbf{X}} \\
(6)\end{array}$ & $\begin{array}{l}\mathbf{e x} \\
(7)\end{array}$ \\
\hline 0 & 100.000 & 0,03973 & 3.973 & 96.718 & 7.032 .971 & 70,33 \\
\hline 1 & 96.027 & 0,00309 & 297 & 95.819 & 6.936 .253 & 72,23 \\
\hline 2 & 95.730 & 0,00150 & 144 & 95.658 & 6.840 .434 & 71,46 \\
\hline 3 & 95.586 & 0,00101 & 97 & 95.538 & 6.744 .776 & 70,56 \\
\hline 4 & 95.489 & 0,00053 & 50 & 95.464 & 6.649 .238 & 69,63 \\
\hline 5 a 9 & 95.439 & 0,00149 & 142 & 476.841 & 6.553 .773 & 68,67 \\
\hline 10 a 14 & 95.297 & 0,00278 & 265 & 475.823 & 6.076 .932 & 63,77 \\
\hline 15 a 19 & 95.032 & 0,00320 & 304 & 474.401 & 5.601 .109 & 58,94 \\
\hline 20 a 24 & 94.728 & 0,00271 & 257 & 472.999 & 5.126 .708 & 54,12 \\
\hline 25 a 29 & 94.472 & 0,00565 & 533 & 471.024 & 4.653 .709 & 49,26 \\
\hline 30 a 34 & 93.938 & 0,00738 & 693 & 467.958 & 4.182 .685 & 44,53 \\
\hline 35 a 39 & 93.245 & 0,01214 & 1.132 & 463.395 & 3.714 .727 & 39,84 \\
\hline 40 a 44 & 92.113 & 0,01822 & 1.678 & 456.371 & 3.251 .332 & 35,30 \\
\hline 45 a 49 & 90.435 & 0,02743 & 2.481 & 445.973 & 2.794 .961 & 30,91 \\
\hline 50 a 54 & 87.954 & 0,03971 & 3.493 & 431.039 & 2.348 .987 & 26,71 \\
\hline 55 a 59 & 84.461 & 0,06149 & 5.194 & 409.322 & 1.917 .949 & 22,71 \\
\hline 60 a 64 & 79.268 & 0,08494 & 6.733 & 379.506 & 1.508 .626 & 19,03 \\
\hline 65 a 69 & 72.535 & 0,13216 & 9.587 & 338.708 & 1.129 .121 & 15,57 \\
\hline 70 a 74 & 62.948 & 0,18132 & 11.414 & 286.207 & 790.413 & 12,56 \\
\hline 75 a 79 & 51.534 & 0,27601 & 14.224 & 222.113 & 504.206 & 9,78 \\
\hline 80 e + & 37.311 & 1,00000 & 37.311 & 282.093 & 282.093 & 7,56 \\
\hline
\end{tabular}

TABELA 8 - Tábua de vida. População feminina residente no Município de São Paulo (SP), 1996.

\begin{tabular}{|c|c|c|c|c|c|c|}
\hline $\begin{array}{c}\mathbf{X} \\
(1) \\
\end{array}$ & $\begin{array}{l}\mathbf{I X}_{\mathbf{X}} \\
(2)\end{array}$ & $\begin{array}{c}\mathbf{n}_{\mathbf{x}} \\
(3) \\
\end{array}$ & $\begin{array}{c}{ }_{n} \mathbf{d}_{\mathbf{X}} \\
(4)\end{array}$ & $\begin{array}{c}\mathbf{L}_{\mathbf{X}} \\
(5)\end{array}$ & $\begin{array}{l}\mathbf{T}_{\mathbf{X}} \\
(6)\end{array}$ & $\begin{array}{l}\mathbf{e x}_{(7)} \\
\end{array}$ \\
\hline 0 & 100.000 & 0,02504 & 2.504 & 97.932 & 7.392 .130 & 73,92 \\
\hline 1 & 97.496 & 0,00206 & 201 & 97.356 & 7.294 .198 & 74,82 \\
\hline 2 & 97.295 & 0,00102 & 99 & 97.246 & 7.196 .843 & 73,97 \\
\hline 3 & 97.196 & 0,00058 & 57 & 97.168 & 7.099.597 & 73,04 \\
\hline 4 & 97.140 & 0,00035 & 34 & 97.123 & 7.002 .429 & 72,09 \\
\hline 5 a 9 & 97.105 & 0,00169 & 164 & 485.117 & 6.905 .307 & 71,11 \\
\hline 10 a 14 & 96.941 & 0,00203 & 197 & 484.216 & 6.420 .190 & 66,23 \\
\hline 15 a 19 & 96.745 & 0,00325 & 314 & 482.940 & 5.935 .974 & 61,36 \\
\hline 20 a 24 & 96.431 & 0,00440 & 425 & 481.093 & 5.453 .034 & 56,55 \\
\hline 25 a 29 & 96.006 & 0,00566 & 543 & 478.673 & 4.971 .942 & 51,79 \\
\hline 30 a 34 & 95.463 & 0,00749 & 715 & 475.528 & 4.493 .268 & 47,07 \\
\hline 35 a 39 & 94.748 & 0,01074 & 1.018 & 471.195 & 4.017 .741 & 42,40 \\
\hline 40 a 44 & 93.730 & 0,01308 & 1.226 & 465.586 & 3.546 .546 & 37,84 \\
\hline 45 a 49 & 92.504 & 0,02090 & 1.934 & 457.688 & 3.080 .960 & 33,31 \\
\hline 50 a 54 & 90.571 & 0,03087 & 2.796 & 445.864 & 2.623 .272 & 28,96 \\
\hline 55 a 59 & 87.775 & 0,04536 & 3.981 & 428.922 & 2.177 .408 & 24,81 \\
\hline 60 a 64 & 83.794 & 0,06500 & 5.447 & 405.353 & 1.748 .485 & 20,87 \\
\hline 65 a 69 & 78.347 & 0,09427 & 7.386 & 373.273 & 1.343 .132 & 17,14 \\
\hline 70 a 74 & 70.962 & 0,14860 & 10.545 & 328.446 & 969.859 & 13,67 \\
\hline 75 a 79 & 60.417 & 0,23422 & 14.151 & 266.706 & 641.414 & 10,62 \\
\hline 80 e + & 46.266 & 1,00000 & 46.266 & 374.708 & 374.708 & $\cdot 8,10$ \\
\hline
\end{tabular}


TABELA 9 - Esperança de vida ao nascer (em anos), segundo sexo e respectivas diferenças, no Município de São Paulo, em $1950^{\circ}, 1960^{\circ}, 1970^{\circ}, 1980^{* *}$, $1991^{* "} \mathrm{e} 1996$.

\begin{tabular}{lcc|cc}
\hline & \multicolumn{2}{c|}{ Sexo } & \multicolumn{2}{c}{ Diferença } \\
\cline { 2 - 5 } Ano & Masculino & Feminino & absoluta & relativa (\%) \\
\hline 1950 & 54,51 & 59,76 & 5,25 & 9,6 \\
1960 & 60,64 & 68,23 & 7,59 & 12,5 \\
1970 & 60,12 & 67,21 & 7,09 & 11,8 \\
1980 & 63,58 & 70,83 & 7,25 & 11,4 \\
1991 & 63,90 & 73,64 & 9,74 & 15,2 \\
1996 & 63,39 & 73,92 & 10,53 & 16,6 \\
\hline
\end{tabular}

* Fonte: GOTLIEB (1977).

* Fonte: SEADE - Disponivel em URL: http://www.seade.com.br.

\subsection{Tábuas de vida de múltiplo decremento}

Como já comentado, as tábuas de vida de múltiplo decremento servem para avaliar o papel que exercem alguns agravos à saúde, possibilitam análises mais profundas na medida em que quantificam o efeito que a supressão, total ou parcial, de um determinado agravo teria na esperança de vida. Assim, podem ser estabelecidas metas e priorizadas ações, visando a sanar os problemas mais importantes.

Observando a mortalidade proporcional, baseada em dados oficiais do Ministério da Saúde (MS 2000a), para grupos de agravos, de acordo com os capítulos da CID-10, cinco deles foram responsáveis pela grande maioria dos óbitos (Tabela 10). Em uma primeira análise simplificada, percebe-se que as doenças do aparelho circulatório são o principal responsável pela mortalidade nos Municípios de Salvador e São Paulo, afetando ambos os sexos, mas sendo mais significativo, proporcionalmente, no sexo feminino. As neoplasias têm papel importante em ambos os sexos; a população masculina é fortemente afetada pelas causas externas (segunda causa mais importante de óbito), e as doenças do aparelho respiratório, embora apresentem o mesmo patamar para ambos os sexos, em Salvador, têm importância relativa maior para as mulheres residentes em São Paulo.

Nos anexos, são apresentadas as tábuas de vida de múltiplo decremento, onde são calculadas as esperanças de vida hipotéticas ( $e_{\mathrm{X}}$.) para as populações masculina $\mathrm{e}$ feminina dos Municípios de Salvador e São Paulo. 
TABELA 10 - Proporção de óbitos segundo sexo e tipo de agravo (capítulos da CID-10), Salvador (BA) e São Paulo (SP), 1996.

\begin{tabular}{lrrr|rrr}
\hline & \multicolumn{3}{c|}{ Salvador } & \multicolumn{3}{c}{ São Paulo } \\
\cline { 2 - 7 } Tipo de agravo & Masc. & Fem. & Total & Masc. & Fem. & Total \\
\hline D. Infecciosas e Parasitárias & 10,07 & 7,86 & 9,05 & $\mathbf{8 , 4 1}$ & 5,52 & 7,25 \\
Neoplasias & 10,84 & 14,54 & 12,55 & 12,91 & 17,11 & 14,60 \\
D. do Aparelho Circulatório & 24,33 & 34,16 & 28,88 & 27,73 & 38,13 & 31,91 \\
D. do Aparelho Respiratório & 10,19 & 10,75 & 10,45 & 10,81 & 12,84 & 11,62 \\
Causas Externas & 20,29 & 4,93 & 13,18 & 22,19 & 5,61 & 15,52 \\
\hline Subtotal & $\mathbf{7 5 , 7 2}$ & $\mathbf{7 2 , 2 4}$ & $\mathbf{7 4 , 1 1}$ & $\mathbf{8 2 , 0 5}$ & $\mathbf{7 9 , 2 1}$ & $\mathbf{8 0 , 9 0}$ \\
\hline Causas Mal-definidas & 1,62 & 1,98 & 1,79 & 1,28 & 1,14 & 1,23 \\
Outras Causas & 22,66 & 25,78 & 24,10 & 16,67 & 19,65 & 17,87 \\
\hline Total & $\mathbf{1 0 0}$ & $\mathbf{1 0 0}$ & $\mathbf{1 0 0}$ & $\mathbf{1 0 0}$ & $\mathbf{1 0 0}$ & $\mathbf{1 0 0}$ \\
\hline
\end{tabular}

FONTE: DATASUS - MS (dados brutos) - (disponivel em http://www.datasus.gov.br).

\subsubsection{Eliminando o grupo das doenças infecciosas e parasitárias}

Diferentemente do que acontecia em São Paulo, na década de setenta, o perfil de mortalidade por doenças infecciosas e parasitárias, sob o ponto de vista da comparação entre probabilidades de morte em cada grupo etário e a probabilidade líquida de morte, isto é, excluindo-se esse grupo de causas, mudou (Tabela 11 e Figura 2). Um agravo à saúde, que predominantemente afetava menores de um ano, nos anos 70, hoje afeta, de maneira considerável, adultos, notadamente homens de 25 a 45 anos.

FIGURA 2 - Distribuição proporcional (\%) dos óbitos por doenças infecciosas e parasitárias, segundo sexo e faixa etária. Municípios de Salvador e São Paulo, 1996.

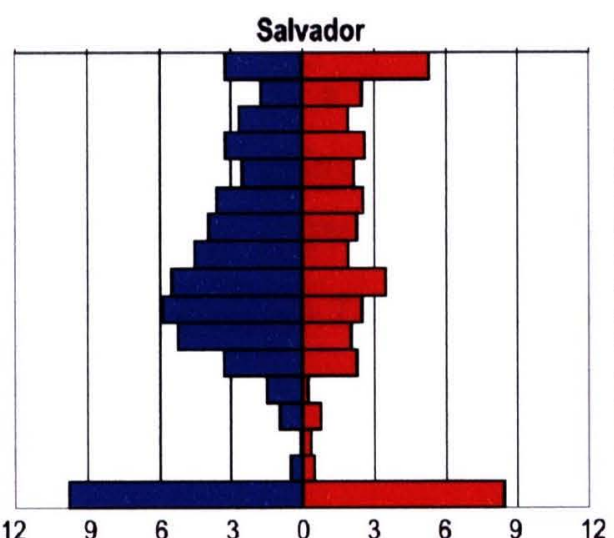

(\%)

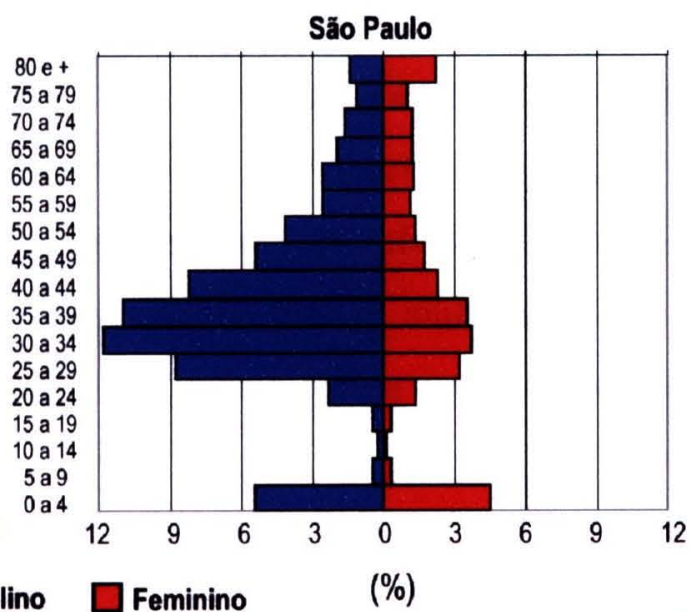

(\%) 
TABELA 11 - Comparação entre as probabilidades de morte real $\left(q_{\mathrm{x}}\right)$ e líquida $\left(\mathrm{q}_{\mathrm{x} .}\right)$, eliminando as doenças infecciosas e parasitárias como fator de risco de morte, segundo sexo e idade, Municípios de Salvador (BA) e São Paulo (SP), 1996.

\begin{tabular}{|c|c|c|c|c|c|c|c|c|}
\hline \multirow{3}{*}{$\begin{array}{l}\text { Idade } \\
\text { (anos) }\end{array}$} & \multicolumn{4}{|c|}{ Salvador } & \multicolumn{4}{|c|}{ São Paulo } \\
\hline & \multicolumn{2}{|c|}{ Masculino } & \multicolumn{2}{|c|}{ Feminino } & \multicolumn{2}{|c|}{ Masculino } & \multicolumn{2}{|c|}{ Feminino } \\
\hline & $\left|\mathbf{q}_{\mathrm{x}}-\mathbf{q}_{\mathrm{x}}\right| \overrightarrow{\mid}$ & $\begin{array}{c}\left|g_{x}-g_{x}\right|(\%) \\
g_{x}\end{array}$ & $|9 x-9 x \cdot|$ & $\begin{array}{c}\left|q_{x}-q_{x}\right|(\%) \\
q_{x}\end{array}$ & $\left|q_{x}-q_{x}\right| \mid$ & $\begin{array}{c}\left|q_{x}-q_{x}\right|(\%) \\
q_{x}\end{array}$ & $\left|\mathbf{q}_{\mathrm{x}}-\mathbf{q}_{\mathrm{x}}\right|$ & $\frac{\left|q_{x}-q_{x}\right|(\%)}{q_{x}}$ \\
\hline 0 & 0,00571 & 14,35 & 0,00505 & 12,71 & 0,00247 & 8,09 & 0,00205 & 8,19 \\
\hline 1 & 0,00042 & 14,80 & 0,00039 & 12,48 & 0,00040 & 20,50 & 0,00036 & 17,60 \\
\hline 2 & 0,00015 & 9,67 & 0,00016 & 10,34 & 0,00023 & 25,32 & 0,00029 & 28,74 \\
\hline 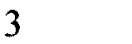 & 0,00021 & 22,21 & 0,00027 & 26,31 & 0,00017 & 23,72 & 0,00016 & 28,25 \\
\hline 4 & 0,00000 & 0,00 & 0,00005 & 10,00 & 0,00009 & 19,44 & 0,00007 & 18,52 \\
\hline 5 a 9 & 0,00035 & 12,48 & 0,00036 & 24,12 & 0,00027 & 12,03 & 0,00019 & 11,42 \\
\hline 10 a 14 & 0,00004 & 1,33 & 0,00020 & 7,13 & 0,00016 & 4,94 & 0,00006 & 3,21 \\
\hline 15 a 19 & 0,00047 & 4,14 & 0,00035 & 11,10 & 0,00026 & 1,74 & 0,00017 & 5,09 \\
\hline 20 a 24 & 0,00088 & 5,27 & 0,00012 & 4,47 & 0,00130 & 6,05 & 0,00073 & 16,56 \\
\hline 25 a 29 & 0,00218 & 13,41 & 0,00135 & 23,95 & 0,00507 & 18,99 & 0,00181 & 32,06 \\
\hline 30 a 34 & 0,00372 & 20,28 & 0,00124 & 16,83 & 0,00725 & 25,22 & 0,00217 & 28,98 \\
\hline 35 a 39 & $\mathbf{0 , 0 0 4 7 5}$ & 20,41 & 0,00175 & 14,40 & 0,00748 & 22,38 & 0,00221 & 20,56 \\
\hline 40 a 44 & 0,00535 & 18,10 & 0,00302 & 16,60 & 0,00644 & 16,76 & 0,00165 & 12,64 \\
\hline 45 a 49 & 0,00582 & 14,93 & 0,00222 & 8,09 & 0,00527 & 11,08 & 0,00157 & 7,52 \\
\hline 50 a 54 & 0,00696 & 11,58 & 0,00353 & 8,90 & 0,00520 & 8,01 & 0,00153 & 4,96 \\
\hline 55 a 59 & 0,00847 & 9,40 & 0,00484 & 7,87 & 0,00414 & 4,70 & 0,00161 & 3,56 \\
\hline 60 a 64 & 0,00747 & 5,56 & 0,00487 & 5,74 & 0,00487 & 3,85 & 0,00201 & 3,09 \\
\hline 65 a 69 & 0,01242 & 6,39 & 0,00700 & 5,30 & 0,00435 & 2,50 & 0,00227 & 2,41 \\
\hline 70 a 74 & 0,01332 & 4,87 & 0,00690 & 3,80 & 0,00501 & 2,07 & 0,00292 & 1,96 \\
\hline 75 a 79 & 0,01386 & 3,67 & 0,01245 & 4,51 & 0,00512 & 1,49 & 0,00351 & 1,50 \\
\hline 80 et & - & - & - & - & - & - & 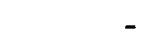 & - \\
\hline
\end{tabular}

Os resultados da comparação entre as probabilidades de sobrevivência real e hipotética (pox.), caso o grupo de agravos em estudo não produzisse morte, para os Municípios de Salvador e São Paulo (Tabela 12), mostram que os indivíduos do sexo masculino teriam um aumento relativamente maior do que o das mulheres, em ambos os locais. Mudanças sensíveis aconteceram de 1970 para 1996, no município paulista, com relação a este fator de risco. Para a década de setenta, GOTLIEB (1977) estimou as diferenças entre as probabilidades de sobreviver até os 80 anos iguais a $8,12 \%$ e $4,93 \%$ respectivamente, para o sexo masculino e feminino. Em 1996, diminuíram para 7,60\% para os homens e 3,00\% para as mulheres. Sendo que a queda é mais abrupta para as idades iniciais, coerente com a estrutura dos óbitos (Figura 3). 
TABELA 12 - Comparação entre as probabilidades de sobreviver real (pox) e hipotética (pox.), eliminando as doenças infecciosas e parasitárias como fator de risco de morte, segundo sexo e idade, dos residentes dos Municípios de Salvador (BA) e São Paulo (SP), 1996.

\begin{tabular}{|c|c|c|c|c|c|c|c|c|}
\hline \multirow{3}{*}{$\begin{array}{l}\text { Idade } \\
\text { (anos) }\end{array}$} & \multicolumn{4}{|c|}{ Salvador } & \multicolumn{4}{|c|}{ São Paulo } \\
\hline & \multicolumn{2}{|c|}{ Masculino } & \multicolumn{2}{|c|}{ Feminino } & \multicolumn{2}{|c|}{ Masculino } & \multicolumn{2}{|c|}{ Feminino } \\
\hline & $\left|\mathrm{po}_{\mathrm{x}}-\mathrm{po}_{\mathrm{X}}\right| \overrightarrow{\mid}$ & $\begin{array}{c}\text { pox }- \text { pox } \\
\text { pox } \\
\text { pox }\end{array}$ & $\left|p_{\mathrm{x}}-\mathrm{pog}_{\mathrm{x}} \cdot\right|$ & 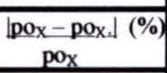 & $\left|\mathrm{po}_{\mathrm{x}}-\mathrm{po}_{\mathrm{x}}\right| \mid$ & $\begin{array}{c}\text { pox }- \text { pox } \\
\text { pox } \\
\text { pox }\end{array}$ & $\mid \mathbf{p o} \mathrm{o}_{\mathrm{x}}-\mathbf{p o \mathrm { x } _ { \mathrm { x } } |}$ & 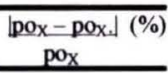 \\
\hline 0 & - & - & - & 7 & - & - & - & - \\
\hline 1 & 0,00571 & 0,59 & 0,00505 & 0,53 & 0,00247 & 0,25 & 0,00205 & 0,21 \\
\hline 2 & 0,00610 & 0,64 & 0,00541 & 0,56 & 0,00285 & 0,29 & 0,00240 & 0,25 \\
\hline 3 & 0,00624 & 0,65 & 0,00555 & 0,58 & 0,00308 & 0,32 & 0,00268 & 0,28 \\
\hline 4 & 0,00643 & 0,67 & 0,00580 & 0,61 & 0,00324 & 0,34 & 0,00284 & 0,29 \\
\hline 5 a 9 & 0,00643 & 0,67 & 0,00584 & 0,61 & 0,00332 & 0,34 & 0,00290 & 0,30 \\
\hline 10 a 14 & 0,00675 & 0,71 & 0,00618 & 0,65 & 0,00358 & 0,37 & 0,00309 & 0,32 \\
\hline 15 a 19 & 0,00676 & 0,71 & 0,00635 & 0,67 & 0,00372 & 0,39 & 0,00314 & 0,33 \\
\hline 20 a 24 & 0,00714 & 0,76 & 0,00667 & 0,70 & 0,00392 & 0,41 & 0,00329 & 0,34 \\
\hline 25 a 29 & 0,00784 & 0,85 & 0,00677 & 0,72 & 0,00507 & 0,55 & 0,00399 & 0,42 \\
\hline 30 a 34 & 0,00974 & 1,07 & 0,00802 & 0,85 & 0,00965 & 1,07 & 0,00571 & 0,60 \\
\hline 35 a 39 & 0,01297 & 1,46 & 0,00914 & 0,98 & 0,01598 & 1,83 & 0,00775 & 0,82 \\
\hline 40 a 44 & 0,01696 & 1,95 & 0,01067 & 1,16 & 0,02212 & 2,61 & 0,00978 & 1,04 \\
\hline 45 a 49 & 0,02121 & 2,51 & 0,01330 & 1,47 & 0,02686 & 3,30 & 0,01122 & 1,21 \\
\hline 50 a 54 & 0,02542 & 3,13 & 0,01497 & 1,70 & 0,03001 & 3,87 & 0,01246 & 1,38 \\
\hline 55 a 59 & 0,02972 & 3,90 & 0,01753 & 2,08 & 0,03224 & 4,45 & 0,01348 & 1,54 \\
\hline 60 a 64 & 0,03376 & 4,86 & 0,02063 & 2,60 & 0,03254 & 4,93 & 0,01431 & 1,71 \\
\hline 65 a 69 & 0,03466 & 5,77 & 0,02284 & 3,15 & 0,03180 & 5,51 & 0,01509 & 1,93 \\
\hline 70 a 74 & 0,03582 & 7,40 & 0,02506 & 3,98 & 0,02892 & 6,07 & 0,01548 & 2,18 \\
\hline 75 a 79 & 0,03295 & 9,37 & 0,02503 & 4,86 & 0,02445 & 6,77 & 0,01529 & 2,53 \\
\hline $80 \mathrm{e}+$ & 0,02582 & 11,81 & 0,02485 & 6,66 & 0,01802 & 7,60 & 0,01388 & 3,00 \\
\hline
\end{tabular}

FIGURA 3 - Distribuição proporcional (\%) dos óbitos por doenças infecciosas e parasitárias, segundo sexo e faixa etária. Município de São Paulo, 1970 e 1996.

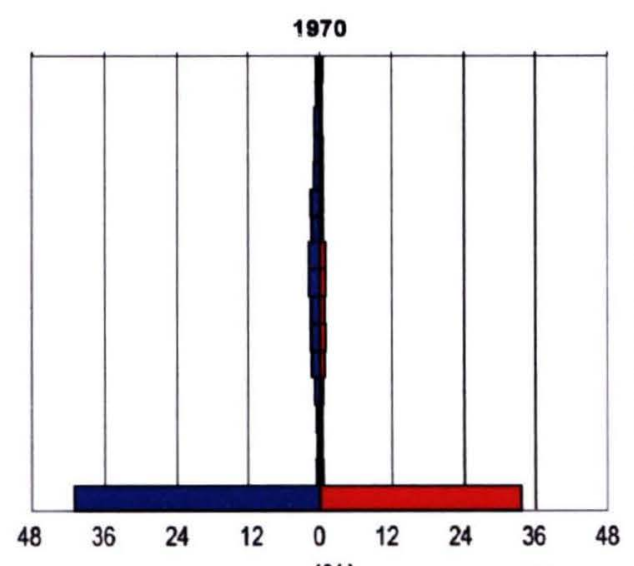

(\%)

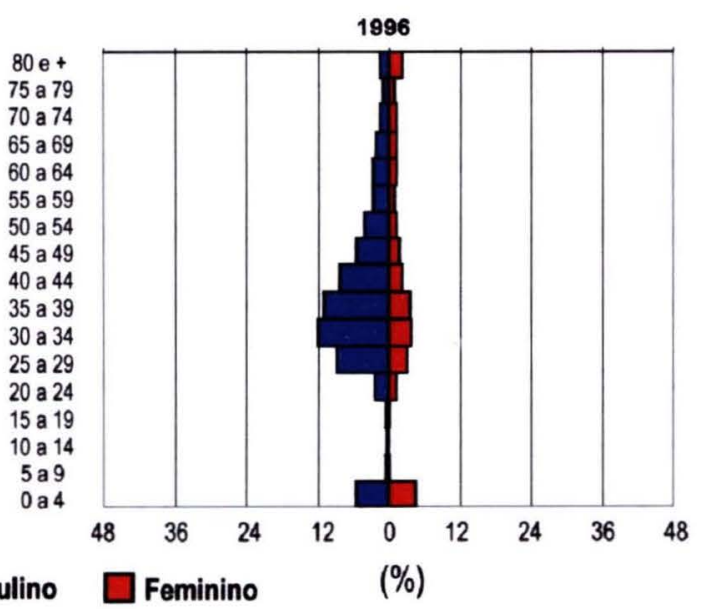


Comparando a esperança de vida real ( $\left.\mathrm{e}_{\mathrm{X}}\right)$ e a hipotética (e $\mathrm{e}_{\mathrm{X}}$ ), haveria um ganho de 1,79 anos (2,79\%) e 1,56 anos (2,46\%) para os homens dos Municípios de Salvador e São Paulo, respectivamente, e 1,39 anos (1,98\%) e 0,90 anos $(1,22 \%)$ para as respectivas populações femininas (Tabela 13).

TABELA 13 - Comparação entre as esperanças de vida real (ex) e hipotética (ex.), eliminando as doenças infecciosas e parasitárias como fator de risco de morte, segundo sexo e idade, dos residentes dos Municípios de Salvador (BA) e São Paulo (SP), 1996.

\begin{tabular}{|c|c|c|c|c|c|c|c|c|}
\hline \multirow{3}{*}{$\begin{array}{l}\text { Idade } \\
\text { (anos) }\end{array}$} & \multicolumn{4}{|c|}{ Salvador } & \multicolumn{4}{|c|}{ São Paulo } \\
\hline & \multicolumn{2}{|c|}{ Masculino } & \multicolumn{2}{|c|}{ Feminino } & \multicolumn{2}{|c|}{ Masculino } & \multicolumn{2}{|c|}{ Feminino } \\
\hline & $\left|e_{x}-e_{x}\right| \mid$ & $\mid \begin{array}{c}\left|e_{x}-e_{x}\right|(\%) \\
e_{X}\end{array}$ & $\left|e_{x}-e_{x}\right|$ & $\begin{array}{c}\left|e_{x}-e_{x}\right|(\%) \\
e_{x}\end{array}$ & $\left|e_{x}-e_{x}\right|$ & $\begin{array}{l}e_{x}-e_{x} \mid \\
e_{x}\end{array}$ & $\left|e_{x}-e_{x}\right|$ & $\frac{\mid e_{x}-e_{x}}{e_{x}}(\%)$ \\
\hline 0 & 1,79 & 2,79 & 1,39 & 1,98 & 1,56 & 2,46 & 0,90 & 1,22 \\
\hline 1 & 1,45 & 2,21 & 1,06 & 1,47 & 1,44 & 2,24 & 0,76 & 1,02 \\
\hline 2 & 1,43 & 2,20 & 1,04 & 1,45 & 1,42 & 2,23 & 0,73 & 0,99 \\
\hline 3 & 1,42 & 2,22 & 1,03 & 1,46 & 1,40 & 2,24 & 0,71 & 0,98 \\
\hline 4 & 1,41 & 2,24 & 1,01 & 1,45 & 1,39 & 2,26 & 0,70 & 0,97 \\
\hline 5 a 9 & 1,41 & 2,27 & 1,01 & 1,46 & 1,39 & 2,29 & 0,70 & 0,98 \\
\hline 10 a 14 & 1,39 & 2,43 & 0,98 & 1,54 & 1,38 & 2,47 & 0,69 & 1,04 \\
\hline 15 a 19 & 1,40 & 2,66 & 0,97 & 1,65 & 1,37 & 2,69 & 0,68 & 1,11 \\
\hline 20 a 24 & 1,39 & 2,89 & 0,96 & 1,77 & 1,38 & 2,96 & 0,68 & 1,19 \\
\hline 25 a 29 & 1,37 & 3,12 & 0,95 & 1,93 & 1,35 & 3,16 & 0,64 & 1,23 \\
\hline 30 a 34 & 1,29 & 3,28 & 0,89 & 2,00 & 1,16 & 3,01 & 0,55 & 1,17 \\
\hline 35 a 39 & 1,17 & 3,33 & 0,84 & 2,12 & 0,91 & 2,62 & 0,46 & 1,07 \\
\hline 40 a 44 & 1,03 & 3,33 & 0,79 & 2,23 & 0,68 & 2,20 & 0,37 & 0,98 \\
\hline 45 a 49 & 0,90 & 3,34 & 0,70 & 2,25 & 0,51 & 1,87 & 0,31 & 0,94 \\
\hline 50 a 54 & 0,78 & 3,40 & 0,65 & 2,43 & 0,39 & 1,66 & 0,27 & 0,93 \\
\hline 55 a 59 & 0,66 & 3,45 & 0,58 & 2,55 & 0,29 & 1,46 & 0,23 & 0,94 \\
\hline 60 a 64 & 0,55 & 3,49 & 0,50 & 2,65 & 0,23 & 1,40 & 0,21 & 0,99 \\
\hline 65 a 69 & 0,50 & 3,89 & 0,45 & 2,91 & 0,17 & 1,29 & 0,18 & 1,03 \\
\hline 70 a 74 & 0,42 & 4,03 & 0,40 & 3,16 & 0,14 & 1,30 & 0,15 & 1,13 \\
\hline 75 a 79 & 0,37 & 4,46 & 0,38 & 3,86 & 0,11 & 1,35 & 0,14 & 1,28 \\
\hline 80 et & 0,38 & 5,59 & 0.34 & 4.54 & 0,10 & 1,58 & 0.13 & 1.59 \\
\hline
\end{tabular}

Em 1970, a diferença entre as esperanças de vida real e hipotética, a partir de um ano, para a capital paulista, era de 0,88 ano $(1,35 \%)$ para os homens e 0,70 ano $(0,98 \%)$ para as mulheres. Estes valores diminuíam até que, para a população com 80 anos e mais, atingiam as cifras de 0,12 ano $(1,60 \%)$ e 0,09 ano $(1,15 \%)$. Em 1996, as diferenças absolutas decrescem com o aumento da idade, mas assumem valores relativos maiores em algumas idades adultas. Isso é explicado pelo fato do perfil de mortalidade pelas doenças infecciosas e parasitárias ter mudado e, entre as principais causas desta mudança, está o aparecimento da Aids nos anos oitenta, com o decorrente aumento da mortalidade por esta doença e pela tuberculose. 
Vale a pena salientar que, nas duas capitais, os homens são os que sofrem maior impacto deste tipo de causa. Esta desigualdade é acentuada, na fase adulta, quando os homens acabam se expondo mais aos riscos. Embora, no caso da Aids, este comportamento tenha sofrido alterações nos últimos anos, com o aumento significativo de mulheres contaminadas pelos companheiros, ainda assim, os homens são os mais expostos ao risco de morrer por estas causas de óbito.

FIGURA 4 - Proporção de população atendida por "condições mínimas de água, esgoto e lixo"," respectivamente, nos Estados da Bahia e São Paulo de acordo com dados do Censo Populacional do IBGE de 1991.
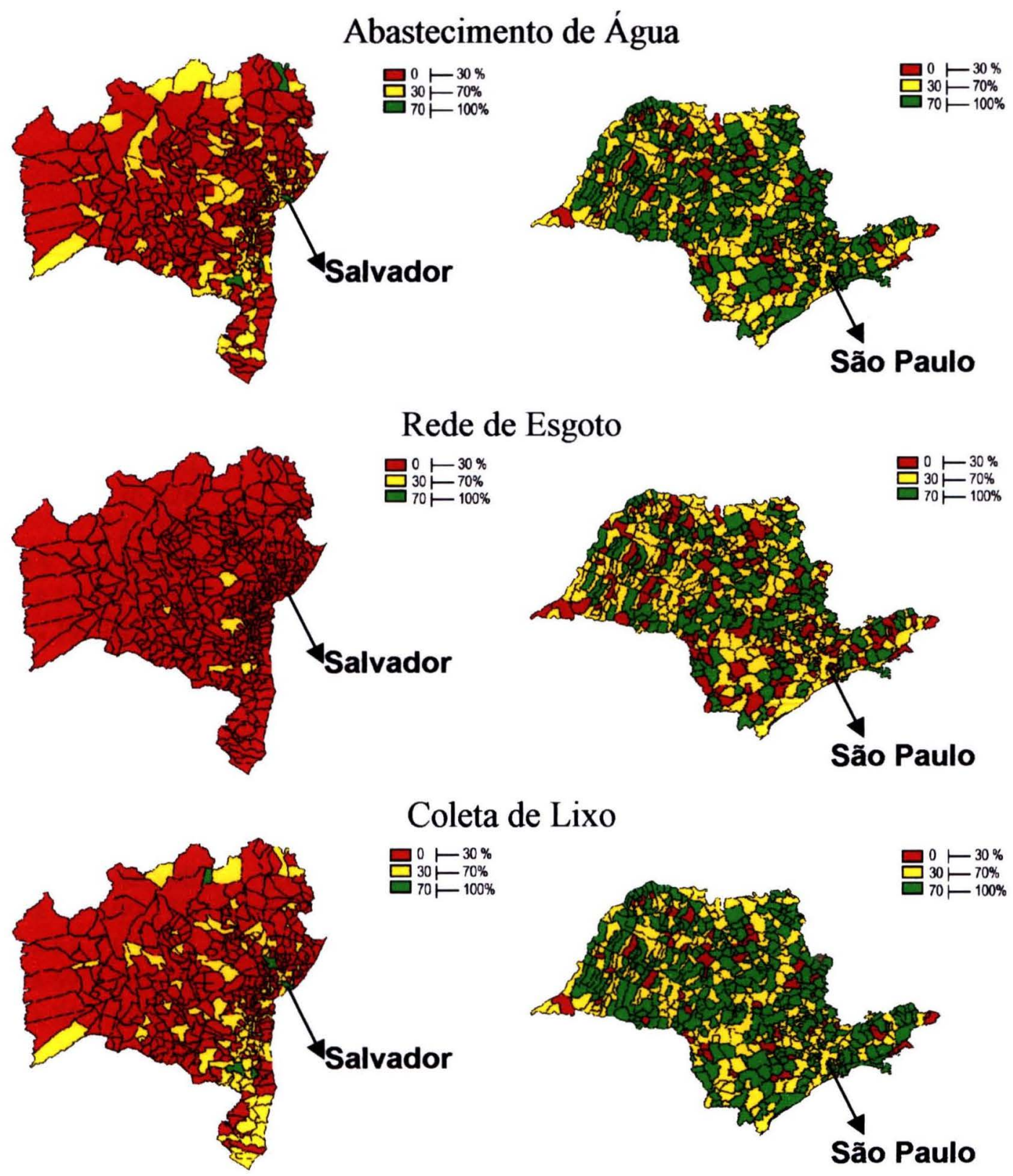

* Residência com canalização interna ligada à rede pública de água, esgoto e lixo coletado. FONTE: DATASUS (disponivel em http://www.datasus.gov.br). 
Já o efeito das desigualdades sociais, representada pela carência de saneamento e infra-estrutura urbana/assistencial, pode ser sentido na comparação entre os dois municípios, onde Salvador, mesmo sendo a cidade com a melhor infra-estrutura do Estado da Bahia, ainda não chegou ao nível de organização econômico-social de São Paulo. Embora difícil e apesar de hipotética, a suposição de eliminação do grupo de doenças infecciosas e parasitárias como causa de morte, na sua quase totalidade, é possível, conforme as palavras de GOTLIEB (1977, p. 74), "são plenamente evitáveis, bastando para tanto não haver deficiência em saneamento básico, nem lacunas na cobertura de vacinação e nem demais problemas de Saúde Pública".

TABELA 14 - Comparação entre os totais de anos vividos além de $X$ real $\left(T_{X}\right)$ e hipotético ( $\mathrm{T}_{\mathrm{X}}$.) (Anos Potenciais de Vida Ganhos - APVG), eliminando as doenças infecciosas e parasitárias como fator de risco de morte, segundo sexo e idade, dos residentes dos Municípios de Salvador (BA) e São Paulo (SP), 1996.

\begin{tabular}{|c|c|c|c|c|c|c|c|c|}
\hline \multirow{3}{*}{$\begin{array}{l}\text { Idade } \\
\text { (anos) }\end{array}$} & \multicolumn{4}{|c|}{ Salvador } & \multicolumn{4}{|c|}{ São Paulo } \\
\hline & \multicolumn{2}{|c|}{ Masculino } & \multicolumn{2}{|c|}{ Feminino } & \multicolumn{2}{|c|}{ Masculino } & \multicolumn{2}{|c|}{ Feminino } \\
\hline & $\left|T_{x}-T_{x}\right|$ & $\underset{T}{\left[T_{x}-T_{x}\right\rfloor(\%)}$ & $\left|T_{x}-T_{x}\right|$ & $\frac{\left.T_{x}-T_{x}\right](\%)}{T_{x}}$ & $\left|T_{x}-T_{x}\right|$ & $\frac{\left|T_{x}-T_{x}\right|(\%)}{T_{x}}$ & $\left|T_{X}-T_{X}\right|$ & $\begin{array}{c}{\left[I_{x}-T_{x}\right](\%)} \\
T_{x}\end{array}$ \\
\hline 0 & 178.534 & 2,79 & 139.349 & 1,98 & 156.216 & 2,46 & 89.843 & 1,22 \\
\hline 1 & 178.042 & 2,82 & 138.932 & 2,00 & 156.003 & 2,50 & 89.674 & 1,23 \\
\hline 2 & 177.443 & 2,85 & 138.402 & 2,02 & 155.730 & 2,53 & 89.445 & 1,24 \\
\hline 3 & 176.826 & 2,89 & 137.854 & 2,04 & 155.434 & 2,57 & 89.190 & 1,26 \\
\hline 4 & 176.193 & 2,92 & 137.287 & 2,06 & 155.118 & 2,61 & 88.914 & 1,27 \\
\hline 5 a 9 & 175.550 & 2,96 & 136.705 & 2,09 & 154.790 & 2,64 & 88.627 & 1,28 \\
\hline 10 a 14 & 172.256 & 3,16 & 133.698 & 2,20 & 153.064 & 2,85 & 87.129 & 1,36 \\
\hline 15 a 19 & 168.879 & 3,39 & 130.565 & 2,33 & 151.239 & 3,09 & 85.571 & 1,44 \\
\hline 20 a 24 & 165.404 & 3,67 & 127.308 & 2,48 & 149.329 & 3,38 & 83.961 & 1,54 \\
\hline 25 a 29 & 161.659 & 4,00 & 123.947 & 2,66 & 147.083 & 3,73 & 82.141 & 1,65 \\
\hline 30 a 34 & 157.263 & 4,39 & 120.249 & 2,87 & 143.403 & 4,11 & 79.717 & 1,77 \\
\hline 35 a 39 & 151.584 & 4,84 & 115.960 & 3,12 & 136.994 & 4,50 & 76.351 & 1,90 \\
\hline 40 a 44 & 144.100 & 5,35 & 111.008 & 3,41 & 127.469 & 4,87 & 71.967 & 2,03 \\
\hline 45 a 49 & 134.557 & 5,94 & 105.016 & 3,76 & 115.226 & 5,24 & 66.717 & 2,17 \\
\hline 50 a 54 & 122.898 & 6,64 & 97.950 & 4,17 & 101.011 & 5,60 & 60.799 & 2,32 \\
\hline 55 a 59 & 109.111 & 7,48 & 89.825 & 4,68 & 85.448 & 5,98 & 54.315 & 2,49 \\
\hline 60 a 64 & 93.241 & 8,52 & 80.283 & 5,32 & 69.253 & 6,40 & 47.369 & 2,71 \\
\hline 65 a 69 & 76.136 & 9,89 & 69.416 & 6,15 & 53.170 & 6,88 & 40.021 & 2,98 \\
\hline 70 a 74 & 58.516 & 11,73 & 57.441 & 7,27 & 37.991 & 7,45 & 32.379 & 3,34 \\
\hline 75 a 79 & 41.325 & 14,25 & 44.918 & 8,91 & 24.648 & 8,20 & 24.686 & 3,85 \\
\hline $80 \mathrm{e}^{+}$ & 26.633 & 18,06 & 32.448 & 11,50 & 14.029 & 9,30 & 17.392 & 4,64 \\
\hline
\end{tabular}

Assim, mesmo que não se consiga eliminar totalmente os óbitos por estas causas, é de se esperar reduções cada vez maiores nestas doenças. Problema que a 
Bahia ainda vai continuar convivendo por mais tempo, pois as condições de saneamento e infra-estrutura no interior ainda deixam muito a desejar em relação à capital, que não é o caso de São Paulo, pois, muitas cidades do interior apresentam condições de saneamento e acesso aos serviços básicos de saúde melhores e mais bem estruturados do que a capital, uma megalópole um tanto quanto difícil de se administrar (Figura 4).

Os Anos Potenciais de Vida Ganhos com a eliminação de um determinado grupo de causas de morte dá dimensão do que uma população perde em termos de vida e força de trabalho. Facilmente pode-se constatar que os APVG de Salvador são maiores do que os de São Paulo (Tabela 14). Nesta última, a população feminina é bem menos afetada que a população masculina, ao passo que em Salvador as diferenças são menores.

\subsubsection{Eliminando o grupo das doenças infecciosas intestinais}

GOTLIEB (1977) avaliou o impacto da eliminação da gastroenterite na esperança de vida da população paulistana, em 1970. Doença intimamente ligada a problemas de saneamento, era uma das principais responsáveis pelos óbitos infantis naquele município, daí a sua inclusão no estudo. No presente trabalho, esta doença está agrupada com outras semelhantes nas assim chamadas doenças infeciosas intestinais, de acordo com a classificação da CID10-BR (A00-A09).

Assim, verifica-se, facilmente, que este grupo de causas tem uma influência maior, de um modo geral, sobre a mortalidade de Salvador do que em São Paulo (Tabela 15). Surpreendentemente, em menores de um ano do sexo feminino em Salvador, haveria um ganho na $\operatorname{EVN}(0,38$ ano) maior que no masculino $(0,33$ ano) contra 0,11 ano (São Paulo - sexo feminino) e 0,12 ano (masculino).

GOTLIEB (1977) chamou a atenção que um investimento na tão necessária redução da gastroenterite seria uma boa maneira de resolver um problema de saúde pública e aumentar rapidamente a EVN do Município de São Paulo e que esforços deveriam ser dirigidos neste sentido. Sua argumentação baseava-se no fato de que os países desenvolvidos levaram em torno de dez anos para aumentar a sua EVN em 2,5 anos e, segundo os dados oficiais, para 1970, o ganho com a eliminação desse agravo 
seria de pelo menos 1,7 anos, já que trabalhos anteriores (LAURENTI cit. GOTLIEB 1977) estimavam um sub-registro na ordem de $39 \%$ nos dados oficiais de mortalidade do distrito de São Paulo em 1968/70. Em 1996, seria necessária a eliminação de todos os óbitos pertencentes ao capítulo das doenças infecciosas e parasitárias para conseguir um efeito parecido sobre a EVN.

TABELA 15 - Comparação entre as esperanças de vida real ( $\left(e_{X}\right)$ e hipotética ( $\left.e_{X}\right)$, eliminando as doenças infecciosas intestinais como fator de risco de morte, segundo sexo e idade, dos residentes dos Municípios de Salvador (BA) e São Paulo (SP), 1996.

\begin{tabular}{|c|c|c|c|c|c|c|c|c|}
\hline \multirow{3}{*}{$\begin{array}{l}\text { Idade } \\
\text { (anos) }\end{array}$} & \multicolumn{4}{|c|}{ Salvador } & \multicolumn{4}{|c|}{ São Paulo } \\
\hline & \multicolumn{2}{|c|}{ Masculino } & \multicolumn{2}{|c|}{ Feminino } & \multicolumn{2}{|c|}{ Masculino } & \multicolumn{2}{|c|}{ Feminino } \\
\hline & $\left|e_{x}-e_{x}\right|$ & $\begin{array}{c}\left|e_{x}-e_{x}\right|(\%) \\
e_{x}\end{array}$ & $\left|e_{x}-e_{x}\right|$ & $\begin{array}{c}e_{x}-e_{x} J(\%) \\
e_{x}\end{array}$ & $\left|e_{x}-e_{x}\right|$ & $\begin{array}{c}\left|e_{x}-e_{x}\right|(\%) \\
e_{x}\end{array}$ & $\left|e_{x}-e_{x}\right|$ & $\begin{array}{c}e_{x}-e_{x} \mid(\%) \\
e_{x}\end{array}$ \\
\hline 0 & 0,33 & 0,52 & 0,38 & 0,53 & 0,12 & 0,19 & 0,11 & 0,14 \\
\hline 1 & 0,09 & 0,14 & 0,11 & 0,16 & 0,03 & 0,04 & 0,04 & 0,05 \\
\hline 2 & 0,08 & 0,13 & 0,10 & 0,14 & 0,02 & 0,03 & 0,03 & 0,04 \\
\hline 3 & 0,08 & 0,12 & 0,10 & 0,14 & 0,02 & 0,03 & 0,03 & 0,04 \\
\hline 4 & 0,08 & 0,12 & 0,10 & 0,14 & 0,02 & 0,03 & 0,03 & 0,04 \\
\hline 5 a 9 & 0,08 & 0,12 & 0,10 & 0,14 & 0,02 & 0,03 & 0,03 & 0,04 \\
\hline 10 a 14 & 0,07 & 0,12 & 0,09 & 0,14 & 0,02 & 0,03 & 0,03 & 0,04 \\
\hline 15 a 19 & 0,07 & 0,13 & 0,09 & 0,16 & 0,02 & 0,03 & 0,03 & 0,05 \\
\hline 20 a 24 & 0,07 & 0,14 & 0,09 & 0,16 & 0,01 & 0,03 & 0,03 & 0,05 \\
\hline 25 a 29 & 0,07 & 0,16 & 0,09 & 0,18 & 0,01 & 0,03 & 0,03 & 0,06 \\
\hline 30 a 34 & 0,07 & 0,17 & 0,09 & 0,20 & 0,01 & 0,04 & 0,03 & 0,06 \\
\hline 35 a 39 & 0,06 & 0,18 & 0,09 & 0,23 & 0,01 & 0,04 & 0,03 & 0,07 \\
\hline 40 a 44 & 0,06 & 0,21 & 0,09 & 0,25 & 0,01 & 0,05 & 0,03 & 0,08 \\
\hline 45 a 49 & 0,06 & 0,23 & 0,09 & 0,29 & 0,01 & 0,05 & 0,03 & 0,08 \\
\hline 50 a 54 & 0,06 & 0,25 & 0,09 & 0,33 & 0,01 & 0,06 & 0,03 & 0,09 \\
\hline 55 a 59 & 0,05 & 0,27 & 0,09 & 0,38 & 0,01 & 0,07 & 0,03 & 0,11 \\
\hline 60 a 64 & 0,04 & 0,27 & 0,08 & 0,43 & 0,01 & 0,09 & 0,03 & 0,13 \\
\hline 65 a 69 & 0,04 & 0,32 & 0,08 & 0,53 & 0,01 & 0,10 & 0,03 & 0,16 \\
\hline 70 a 74 & 0,04 & 0,36 & 0,09 & 0,76 & 0,01 & 0,12 & 0,03 & 0,21 \\
\hline 75 a 79 & 0,04 & 0,54 & 0,10 & 0,97 & 0,01 & 0,11 & 0,03 & 0,26 \\
\hline 80 et & 0,04 & 0,65 & 0,09 & 1,16 & 0,01 & 0,17 & 0,03 & 0,32 \\
\hline
\end{tabular}

As distribuições etárias de óbito para este grupo de causas (Figura 5) se assemelham ao que era encontrado para o Município de São Paulo na década de 70, demonstrando que, neste caso, praticamente toda a mortalidade recai sobre os menores de 1 ano. Embora a eliminação das doenças infecciosas intestinais ainda constitui um desafio a ser vencido, os dados já revelam uma sensível redução nos óbitos por estas causas de morte, a sua total eliminação representaria um aumento de no máximo 0,38 anos (sexo feminino - Salvador). Esta situação poderia ser ainda melhor caso houvesse maior cobertura dos serviços de saneamento de Salvador que em 1991 atendia a $85,91 \%$ (água), 22,12\% (esgoto) e 77,30\% (lixo) da população. 
Na capital paulista, a situação de saneamento é melhor, com uma cobertura populacional de $97,16 \%$ (água), 84,43\% (esgoto) e 98,06\% (lixo), e esta diferença tem influência direta na mortalidade por doenças infecciosas intestinais, notadamente a oferta de serviços adequados de água e esgoto a uma parcela maior da população.

FIGURA 5 - Distribuição proporcional (\%) dos óbitos por doenças infecciosas e intestinais, segundo sexo e faixa etária. Municípios de Salvador e São Paulo, 1996.

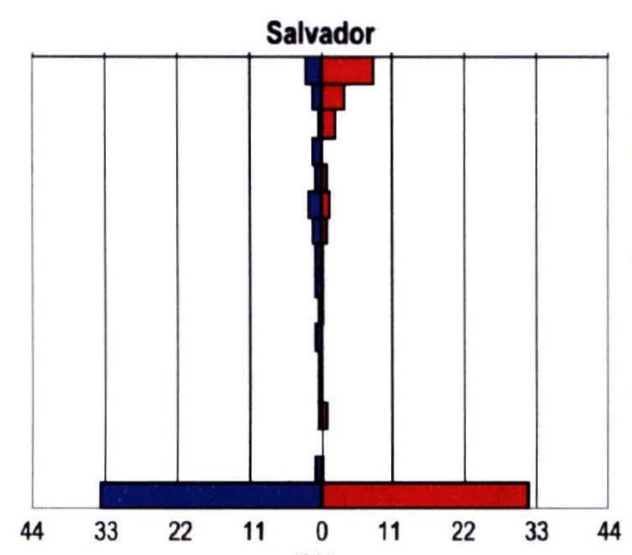

$(\%)$

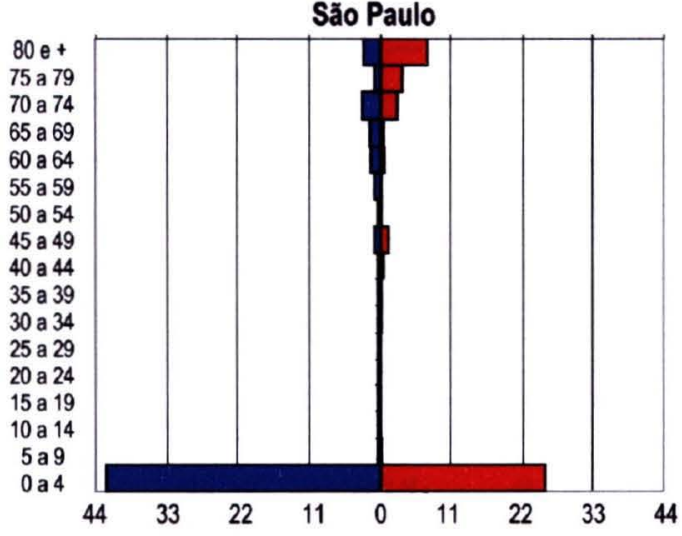

(\%)

\subsubsection{Eliminando o grupo das outras doenças bacterianas}

O grupo das outras doenças bacterianas corresponde aos códigos A20-A64 da CID-10 e engloba peste, leptospirose, hanseníase, tétano, difteria, coqueluche, infecção meningocócica, septicemia e infecções de transmissão predominantemente sexual. Algumas destas doenças são perfeitamente preveníveis por vacinação e o seu impacto na EV foi estudado por GOTLIEB em 1977. As demais, são velhas conhecidas como a leptospirose, peste e hanseníase, mas que não se justifica existirem ainda óbitos por estas doenças.

A mortalidade por estas doenças tende a zero, à medida que há melhoria nas condições de higiene, infra-estrutura, orientação à população e atendimento dos serviços de saúde. Faz-se necessário um controle constante no combate a estas doenças; o desenvolvimento de novas drogas tem ajudado na cura de doenças antes incuráveis, como é o caso da Hanseníase que, ainda, conta com muita desinformação por parte da sociedade como um todo. 
O ganho em termos de esperança de vida é discreto, principalmente, em São Paulo, e, em ambos os municípios, os ganhos relativos são maiores nas idades mais avançadas (Tabela 16).

TABELA 16 - Comparação entre as esperanças de vida real ( $\left.e_{\mathrm{x}}\right)$ e hipotética (ex.), eliminando as outras doenças bacterianas como fator de risco de morte, segundo sexo e idade, dos residentes dos Municípios de Salvador (BA) e São Paulo (SP), 1996.

\begin{tabular}{|c|c|c|c|c|c|c|c|c|}
\hline \multirow{3}{*}{$\begin{array}{l}\text { Idade } \\
\text { (anos) }\end{array}$} & \multicolumn{4}{|c|}{ Salvador } & \multicolumn{4}{|c|}{ São Paulo } \\
\hline & \multicolumn{2}{|c|}{ Masculino } & \multicolumn{2}{|c|}{ Feminino } & \multicolumn{2}{|c|}{ Masculino } & \multicolumn{2}{|c|}{ Feminino } \\
\hline & $\left|\mathbf{e}_{\mathrm{x}}-\mathbf{e}_{\mathrm{x} .}\right|$ & $\begin{array}{c}\left|e_{x}-e_{x}\right|(\%) \\
e_{x}\end{array}$ & $\left|e_{x}-e_{x}\right|$ & $\begin{array}{c}\left|e_{x}-e_{x}\right|(\%) \\
e_{x}\end{array}$ & $\left|\mathbf{e}_{\mathbf{x}}-\mathbf{e}_{\mathbf{x}}\right|$ & $\begin{array}{c}\left|e_{x}-e_{x}\right|(\%) \\
e_{x}\end{array}$ & $\left|\mathbf{e}_{\mathrm{x}}-\mathbf{e}_{\mathrm{x}}\right|$ & 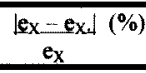 \\
\hline 0 & 0,44 & 0,68 & 0,36 & 0,51 & 0,18 & 0,28 & 0,20 & 0,27 \\
\hline 1 & 0,32 & 0,48 & 0,29 & 0,41 & 0,13 & 0,21 & 0,14 & 0,19 \\
\hline 2 & 0,31 & 0,47 & 0,29 & 0,40 & 0,12 & 0,19 & 0,13 & 0,18 \\
\hline 3 & 0,30 & 0,47 & 0,29 & 0,41 & 0,12 & 0,18 & 0,12 & 0,16 \\
\hline 4 & 0,30 & 0,47 & 0,28 & 0,41 & 0,11 & 0,18 & 0,11 & 0,15 \\
\hline 5 a 9 & 0,30 & 0,48 & 0,28 & 0,41 & 0,11 & 0,17 & 0,11 & 0,16 \\
\hline 10 a 14 & 0,29 & 0,50 & 0,27 & 0,43 & 0,10 & 0,17 & 0,11 & 0,16 \\
\hline 15 a 19 & 0,29 & 0,55 & 0,27 & 0,46 & 0,09 & 0,18 & 0,10 & 0,17 \\
\hline 20 a 24 & 0,28 & 0,59 & 0,26 & 0,48 & 0,09 & 0,20 & 0,10 & 0,18 \\
\hline 25 a 29 & 0,28 & 0,63 & 0,26 & 0,52 & 0,09 & 0,21 & 0,10 & 0,19 \\
\hline 30 a 34 & 0,27 & 0,69 & 0,25 & 0,55 & 0,09 & 0,23 & 0,10 & 0,21 \\
\hline 35 a 39 & 0,27 & 0,75 & 0,25 & 0,62 & 0,09 & 0,24 & 0,10 & 0,23 \\
\hline 40 a 44 & 0,27 & 0,86 & 0,24 & 0,67 & 0,08 & 0,25 & 0,09 & 0,25 \\
\hline 45 a 49 & 0,23 & 0,86 & 0,22 & 0,70 & 0,07 & 0,28 & 0,09 & 0,27 \\
\hline 50 a 54 & 0,23 & 1,02 & 0,20 & 0,74 & 0,07 & 0,31 & 0,09 & 0,31 \\
\hline 55 a 59 & 0,21 & 1,08 & 0,18 & 0,81 & 0,06 & 0,32 & 0,09 & 0,35 \\
\hline 60 a 64 & 0,20 & 1,29 & 0,17 & 0,89 & 0,06 & 0,36 & 0,09 & 0,41 \\
\hline 65 a 69 & 0,21 & 1,61 & 0,16 & 1,03 & 0,05 & 0,38 & 0,08 & 0,47 \\
\hline 70 a 74 & 0,19 & 1,82 & 0,15 & 1,22 & 0,04 & 0,42 & 0,08 & 0,56 \\
\hline 75 a 79 & 0,18 & 2,14 & 0,16 & 1,65 & 0,04 & 0,50 & 0,07 & 0,69 \\
\hline $80 \mathrm{e}^{+}$ & 0,16 & 2,38 & 0,16 & 2,09 & 0,04 & 0,63 & 0,07 & 0,92 \\
\hline
\end{tabular}

Este grupo de doenças afeta todas as idades com uma tendência um pouco maior para sexo masculino. Nota-se, porém, que em algumas faixas etárias predominam os óbitos de mulheres e, em menores de cinco anos, ainda é notada a ocorrência de mortes por este grupo de causas (Figura 6). 
FIGURA 6 - Distribuição proporcional (\%) dos óbitos por outras doenças bacterianas, segundo sexo e faixa etária. Municípios de Salvador e São Paulo, 1996.

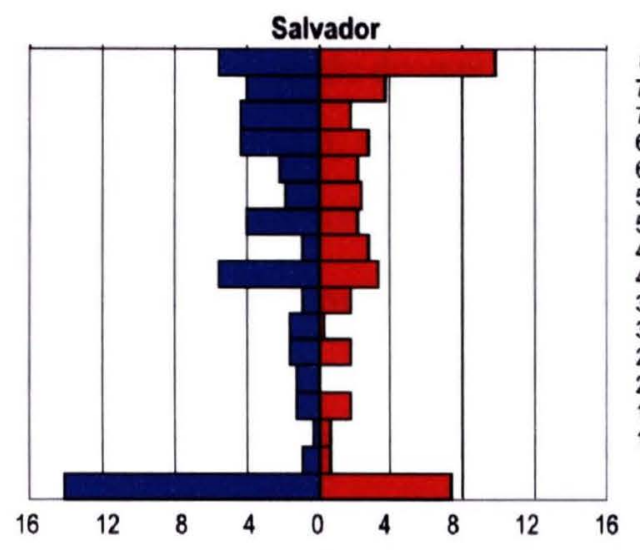

(\%)

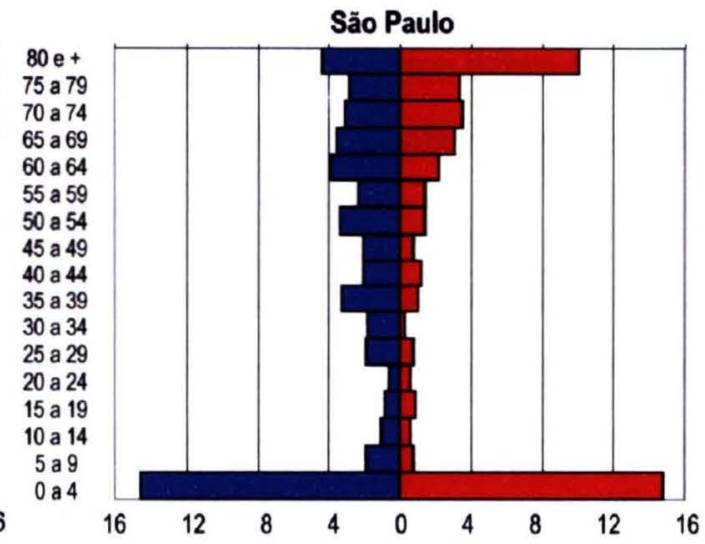

(\%)

\subsubsection{Eliminando o grupo das doenças virais}

Fazem parte deste grupo a poliomielite aguda, a raiva, a dengue, a febre amarela, outras febres por arbovírus e febres hemorrágicas virais, sarampo, hepatite viral e doenças pelo vírus da imunodeficiência humana - HIV. Algumas destas doenças são imunopreveníveis por vacinação e o Ministério da Saúde do Brasil vem lutando pela sua erradicação há muitos anos. Internacionalmente é reconhecido o seu esforço, pois, com as suas campanhas o Brasil conseguiu não apresentar casos de poliomielite, desde 1984, e há redução importante em relação aos de sarampo. Outras doenças, como a Aids, cujo primeiro caso registrado no Brasil se deu em São Paulo, em 1980 (WALDVOGEL e MORAES 1998), seguido de um rápido avanço, têm sofrido significativas reduções com a política de combate do MS baseada na distribuição de medicamentos de última geração.

O melhor combate a este grupo de doenças ainda é a prevenção. A Aids foi a grande responsável pela valorização deste grupo como causa de morte, em função da conseqüente mudança do perfil de óbitos pelas doenças infecciosas e parasitárias (discutido na seção 4.3.1) e ser, predominantemente, uma doença que atua na faixa etária produtiva (Figura 7), com forte impacto na economia, se não for devidamente controlada. 
A política brasileira com relação à Aids tem sido elogiada em toda a imprensa internacional pelo impacto na redução da hospitalização e da mortalidade pela doença devido à combinação de medidas preventivas e a distribuição universal e gratuita do "coquetel" de drogas. Atualmente o programa brasileiro lidera um esforço maior de saúde pública, no sentido de deter o avanço da epidemia em outros países, em especial nas nações da África Sub-Saara (LOTUFO 2001).

O tratamento com drogas anti-retrovírus inibe a replicação do HIV-1 e, significativamente, altera a história natural da infecção. WOOD et al. (2000) fazem uma projeção demográfica para os dados da África do Sul, no qual comparam os efeitos da utilização ou não de tal tratamento e concluem que o tratamento entre 2000 e 2005 poderia prevenir cerca de 110.000 nascimentos de crianças HIV positivas, com um custo efetivo bem menor do que o da hospitalização que seria necessária para tratá-las.

FIGURA 7 - Distribuição proporcional (\%) dos óbitos por doenças virais, segundo sexo e faixa etária. Municípios de Salvador e São Paulo, 1996.

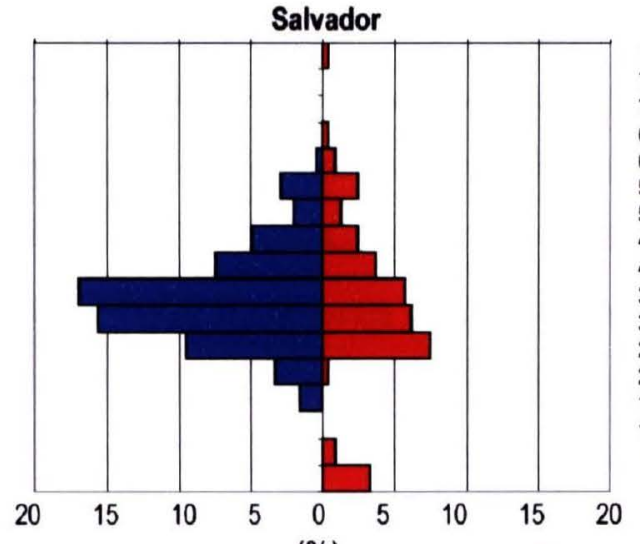

$(\%)$

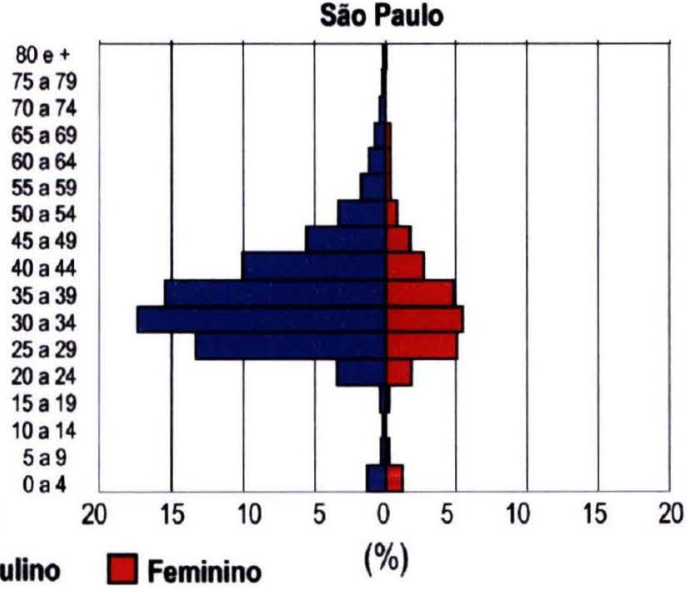

Para LOTUFO (2001), a ação do governo brasileiro se deu por forte pressão da camada mais rica da sociedade que, segundo os dados de São Paulo, é a que apresenta os maiores riscos relativos, daí, a sua priorização. $\mathrm{O}$ grande fator limitante diz respeito aos custos do tratamento; como no Brasil a elite é a mais atingida, esta mesma soube canalizar os esforços no sentido de se beneficiar. No entanto, pode-se dizer que foi acertada a decisão do governo brasileiro de combate à Aids devendo ser estendida de forma a se tornar o mais universal possível, reduzindo-se ao máximo os custos com o tratamento. 
É bastante conhecido o flagelo e as nefastas consequêencias que o abandono das autoridades, a falta de recursos financeiros e estruturais e a ganância dos grandes laboratórios têm contribuído para a terrível situação da África onde, de acordo com as projeções da United States Agency for International Development (USAID) para 2003, Botswana, África do Sul e Zimbábue, irão experimentar um crescimento negativo e outros cinco países terão uma taxa de crescimento populacional próxima de zero (STEPHENSON 2000). A situação é tão grave que, em alguns países, mais de $10 \%$ da população é HIV positivo; a Aids é responsável por quatro em cada cinco óbitos de pessoas entre 25 e 34 anos e dois terços da população com 15 anos em Botswana irá morrer por este agravo antes de completar 50 anos. A utilização do tratamento com drogas específicas, em $25 \%$ da população HIV positivo, reduziria o declínio da esperança de vida em pouco mais de 3 anos.

No presente estudo, apesar da subnotificação de casos de Aids ser reconhecida, esta doença tem um efeito mais importante para a população da capital de São Paulo, e são necessárias mais do que ações contínuas de vigilância e prevenção para ser eliminada, pois os mecanismos de "escape" do vírus, através de mutações, e as facilidades de transmissão dos mesmos são fatores difíceis de controlar e que põem em risco as medidas de saúde pública, que muitas vezes implicam em mudanças de hábitos. GOTLIEB, CASTILHO e BUCHALLA (2000) calcularam ganho de 1,03 anos, na EVN de homens residentes em São Paulo caso fossem eliminadas as mortes por Aids e casos presumíveis da mesma. Mais significativo do que se poderia ganhar em termos de EV com a erradicação destas doenças (Tabela 17), é o quanto se perderia se elas saírem totalmente fora do controle.

Uma vigilância epidemiológica bem estruturada, agindo em conjunto com ações preventivas, incluindo a vacinação em larga escala da população como é o caso do sarampo ou mesmo a doação/desenvolvimento de medicamentos mais avançados, como é o caso da Aids, é fundamental para o combate bem sucedido deste grupo de doenças virais.

A Figura 8 apresenta a distribuição das doenças infecciosas e parasitárias (infecciosas intestinais, tuberculoses, outras doenças bacterianas, doenças virais, doenças transmitidas por protozoários, helmintíases e o restante das doenças 
infecciosas e parasitárias), segundo o sexo, para os Municípios de Salvador e São Paulo.

TABELA 17 - Comparação entre as esperanças de vida real $\left(e_{\mathrm{X}}\right)$ e hipotética $\left(\mathrm{e}_{\mathrm{X}}\right.$.), eliminando as doenças virais como fator de risco de morte, segundo sexo e idade, dos residentes dos Municípios de Salvador (BA) e São Paulo (SP), 1996.

\begin{tabular}{|c|c|c|c|c|c|c|c|c|}
\hline \multirow{3}{*}{$\begin{array}{l}\text { Idade } \\
\text { (anos) }\end{array}$} & \multicolumn{4}{|c|}{ Salvador } & \multicolumn{4}{|c|}{ São Paulo } \\
\hline & \multicolumn{2}{|c|}{ Masculino } & \multicolumn{2}{|c|}{ Feminino } & \multicolumn{2}{|c|}{ Masculino } & \multicolumn{2}{|c|}{ Feminino } \\
\hline & $\left|\mathbf{e}_{\mathrm{x}}-\mathbf{e}_{\mathrm{x}}\right|$ & $\begin{array}{c}\frac{\mid \mathbf{e}_{x}-\mathbf{e}_{x}}{e_{x}}(\%) \\
e_{x}\end{array}$ & $\left|\mathbf{e}_{\mathrm{x}}-\mathbf{e}_{\mathrm{x} .}\right|$ & $\frac{\left.\mid e_{x}-e_{x}\right\rfloor(\%)}{e_{x}}$ & $\left|e_{x}-e_{x}\right|$ & $\begin{array}{c}\left.\underline{e}_{x}-e_{x}\right\rfloor \\
e_{x}\end{array}$ & $\left|e_{x}-e_{x}\right| \mid$ & $\frac{\left.\mid e_{x}-e_{x}\right\rfloor(\%)}{e_{x}}$ \\
\hline$\overline{0}$ & 0,31 & 0,49 & 0,20 & 0,28 & 0,93 & 1,47 & 0,41 & 0,55 \\
\hline 1 & 0,33 & 0,50 & 0,18 & 0,25 & 0,94 & 1,46 & 0,40 & 0,53 \\
\hline 2 & 0,33 & 0,50 & 0,18 & 0,26 & 0,94 & 1,48 & 0,39 & 0,53 \\
\hline 3 & 0,33 & 0,51 & 0,18 & 0,26 & 0,93 & 1,49 & 0,39 & 0,53 \\
\hline 4 & 0,33 & 0,52 & 0,17 & 0,25 & 0,93 & 1,52 & 0,39 & 0,54 \\
\hline 5 a 9 & 0,33 & 0,53 & 0,17 & 0,25 & 0,93 & 1,54 & 0,38 & 0,54 \\
\hline 10 a 14 & 0,33 & 0,57 & 0,17 & 0,26 & 0,93 & 1,67 & 0,38 & 0,57 \\
\hline 15 a 19 & 0,33 & 0,63 & 0,17 & 0,28 & 0,93 & 1,83 & 0,38 & 0,62 \\
\hline 20 a 24 & 0,33 & 0,68 & 0,17 & 0,31 & 0,94 & 2,01 & 0,37 & 0,66 \\
\hline 25 a 29 & 0,31 & 0,72 & 0,17 & 0,34 & 0,91 & 2,13 & 0,34 & 0,66 \\
\hline 30 a 34 & 0,27 & 0,68 & 0,13 & 0,29 & 0,74 & 1,91 & 0,26 & 0,56 \\
\hline 35 a 39 & 0,19 & 0,55 & 0,10 & 0,25 & 0,52 & 1,49 & 0,18 & 0,42 \\
\hline 40 a 44 & 0,11 & 0,35 & 0,07 & 0,20 & 0,32 & 1,03 & 0,11 & 0,29 \\
\hline 45 a 49 & 0,07 & 0,26 & 0,05 & 0,17 & 0,19 & 0,70 & 0,07 & 0,21 \\
\hline 50 a 54 & 0,04 & 0,18 & 0,04 & 0,14 & 0,11 & 0,49 & 0,04 & 0,15 \\
\hline 55 a 59 & 0,03 & 0,14 & 0,03 & 0,13 & 0,06 & 0,33 & 0,03 & 0,10 \\
\hline 60 a 64 & 0,00 & 0,02 & 0,01 & 0,06 & 0,04 & 0,23 & 0,02 & 0,09 \\
\hline 65 a 69 & 0,00 & 0,00 & 0,01 & $\mathbf{0 , 0 4}$ & 0,02 & 0,16 & 0,01 & 0,08 \\
\hline 70 a 74 & 0,00 & 0,00 & 0,00 & 0,02 & 0,01 & 0,11 & 0,01 & 0,05 \\
\hline 75 a 79 & 0,00 & 0,00 & 0,00 & 0,04 & 0,00 & 0,06 & 0,01 & 0,06 \\
\hline $80 \mathrm{e}+$ & 0,00 & 0,00 & 0,00 & 0,06 & 0,00 & 0,04 & 0,01 & 0,07 \\
\hline
\end{tabular}

FIGURA 8 - Coeficiente de mortalidade (100.000 habitantes) por doenças infecciosas e parasitárias, segundo subgrupos de causa (CID10-BR) e sexo. Municípios de Salvador e São Paulo, 1996.

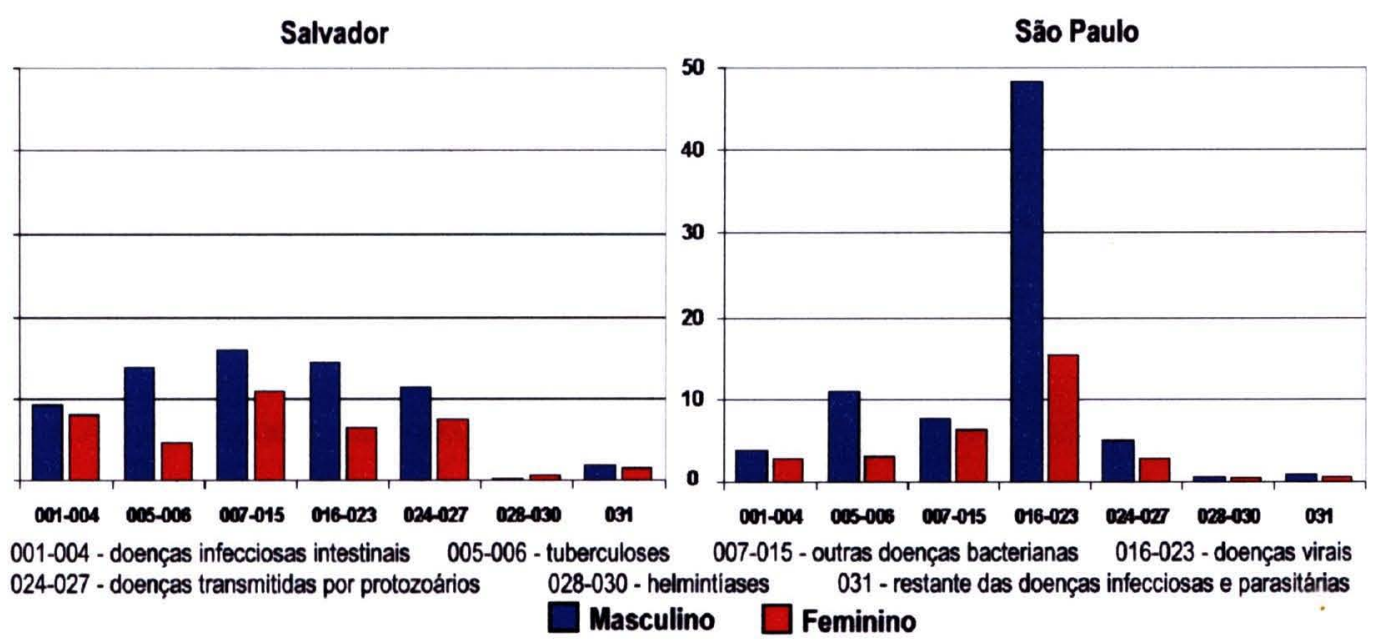


Na capital paulista, o grupo das doenças virais assume claramente um papel predominante, notadamente no sexo masculino, enquanto que em Salvador este papel é mais discreto. Isto se deve basicamente às doenças causadas pelo HIV que representam 20,92\% e $60,73 \%$ dos casos de doenças infecciosas e parasitárias para a população masculina dos Municípios de Salvador e São Paulo, respectivamente, e $14,29 \%$ e $46,07 \%$ para as correspondentes mortes femininas.

Considerando que a Aids se manifestou inicialmente em São Paulo, espalhando-se depois, progressivamente, para o restante do País (SZWARCWALD et al. 2000), pode-se dizer que, neste município, sua disseminação se encontra em um estágio mais avançado do que na capital baiana. Assim, o gráfico apresentado na figura 8 para o município paulista, de certa forma, representa uma possível projeção futura que se espera em Salvador. É claro que a situação mudou, pois estão disponíveis medicamentos que não existiam há dez anos atrás e que podem evitar que a doença cresça tanto na Bahia como cresceu em São Paulo. Mas para isso é preciso garantir que o programa de combate à doença não deixe de cumprir o seu papel, nesta capital, onde o turismo é uma das principais fontes de renda da população.

FIGURA 9 - Coeficiente de mortalidade (100.000 habitantes) por doenças infecciosas e parasitárias, segundo subgrupos de causa (CID10-BR) e sexo, eliminando-se doenças pelo vírus da imunodeficiência humana - HIV. Municípios de Salvador e São Paulo, 1996.

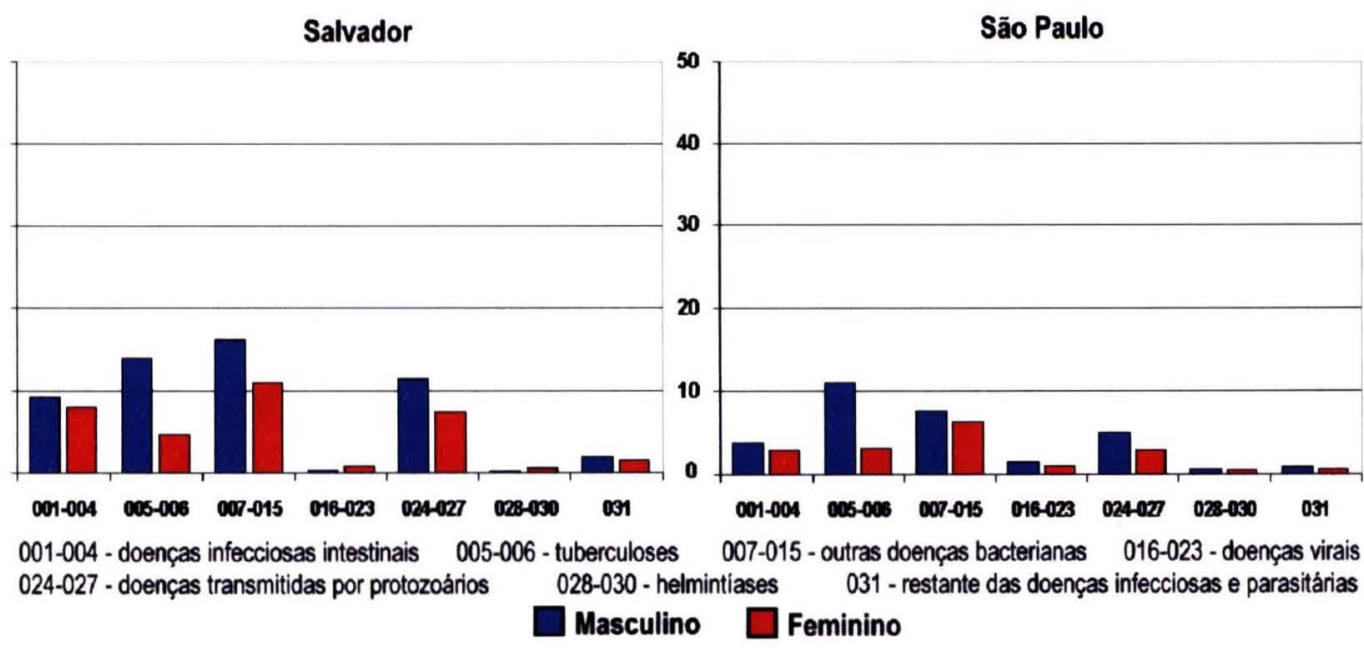

A importância da Aids, como causa de morte, pode ser facilmente reconhecida quando se observa a Figura 9 que apresenta a distribuição das doenças infecciosas e parasitárias por sexo eliminando-se as doenças pelo vírus da imunodeficiência 
humana - HIV. Comparando esta figura com os gráficos da Figura 8, logo é constatado como a Aids é a grande responsável pela mudança do perfil de mortalidade pelas doenças infecciosas e parasitárias, notadamente em São Paulo.

\subsubsection{Eliminando o grupo das neoplasias}

As neoplasias estão entre as principais causas de morte no Brasil, apresentando uma curva de crescimento ascendente, para todas as regiões brasileiras. Compreendem um grupo de doenças de etiologia multifatorial com características biológicas, clínicas e epidemiológicas distintas. São consideradas doenças crônicas e podem apresentar um longo período de latência entre a exposição a um fator de risco e o início das manifestações clínicas. Constituem um sério problema de saúde pública em nível mundial, em função de aumentos acentuados na sua incidência, em face de diferentes características socioeconômicas e culturais (MELLO JORGE e GOTLIEB 2000).

Com relação à mortalidade por este tipo de causa, MELLO JORGE e GOTLIEB (2000) observaram diferenças marcantes entre as regiões brasileiras. Enquanto nas Regiões Norte e Nordeste, as taxas médias de mortalidade variam em torno de 27 e 30 por cem mil habitantes, valores relativamente baixos, nas Regiões Sudeste e Sul, possivelmente, marcando estágio diferente da transição epidemiológica, os coeficientes médios para o sexo masculino variam entre 78,2 e 107,1 por cem mil homens (1979-1995) e para o sexo feminino os valores ficam entre 58,3 e 79,9. Na Região Centro-Oeste, as taxas médias de mortalidade apresentam valores intermediários entre os das Regiões Norte/Nordeste e Sudeste/Sul. Assim, é de se esperar que ocorram taxas mais elevadas de mortalidade por neoplasias nos estados da Região Sudeste em relação aos da Região Nordeste e uma sobremortalidade masculina, também em todo o Brasil. No entanto, a mortalidade proporcional por este tipo de causa no sexo feminino costuma ser maior do que no masculino, pois, para eles, há outros agravos mais freqüentes. 
Quanto às probabilidades de morte real $\left(\hat{\mathrm{q}}_{\mathrm{X}}\right)$ em comparação à probabilidade líquida de morte $\left(\hat{\mathrm{q}}_{\mathrm{x}}\right)$, excluindo as neoplasias como fator de risco de morte, verificase um comportamento bastante semelhante ao encontrado por GOTLIEB (1977). Ou seja, as neoplasias têm uma atuação mínima em menores de um ano e, à medida que a idade aumenta, as diferenças absolutas apresentam progressivamente incrementos (Tabela 18). De um modo geral, cresceu a importância das neoplasias como causa de óbito no Município de São Paulo, de 1970 para 1996.

TABELA 18 - Comparação entre as probabilidades de morte real $\left(q_{x}\right)$ e líquida $\left(q_{x}.\right)$, eliminando as neoplasias como fator de risco de morte, segundo sexo e idade, dos residentes dos Municípios de Salvador (BA) e São Paulo (SP), 1996.

\begin{tabular}{|c|c|c|c|c|c|c|c|c|}
\hline \multirow{3}{*}{$\begin{array}{l}\text { Idade } \\
\text { (anos) }\end{array}$} & \multicolumn{4}{|c|}{ Salvador } & \multicolumn{4}{|c|}{ São Paulo } \\
\hline & \multicolumn{2}{|c|}{ Masculino } & \multicolumn{2}{|c|}{ Feminino } & \multicolumn{2}{|c|}{ Masculino } & \multicolumn{2}{|c|}{ Feminino } \\
\hline & $\left|q_{x}-9 x\right|$ & $\frac{a_{x}-q_{x} \perp(\%)}{q_{x}}$ & $\left|q_{x}-q_{x}\right|$ & $\begin{array}{c}\left|g_{x}-q_{x}\right|(\%) \\
q_{x}\end{array}$ & $\left|q_{x}-q_{x}\right|$ & $\begin{array}{c}\left|q_{x}-q_{x}\right|(\%) \\
q_{x} \mid(\%)\end{array}$ & $\left|q_{x}-q_{x}\right|$ & $\begin{array}{c}\left|g_{x}-9 x\right|(\%) \\
g_{x}\end{array}$ \\
\hline 0 & 0,00015 & 0,39 & 0,00016 & 0,41 & 0,00007 & 0,23 & 0,00011 & 0,44 \\
\hline 1 & 0,00021 & 7,40 & 0,00000 & 0,00 & 0,00005 & 2,56 & 0,00004 & 1,88 \\
\hline 2 & 0,00010 & 6,45 & 0,00005 & 3,45 & 0,00004 & 4,00 & 0,00006 & 6,25 \\
\hline 3 & 0,00021 & 22,21 & 0,00016 & 15,78 & 0,00010 & 13,56 & 0,00003 & 4,35 \\
\hline 4 & 0,00000 & 0,00 & 0,00000 & 0,00 & 0,00008 & 16,66 & 0,00003 & 7,41 \\
\hline 5 a 9 & 0,00025 & 8,92 & 0,00036 & 24,12 & 0,00033 & 14,65 & 0,00024 & 14,28 \\
\hline 10 a 14 & 0,00024 & 7,99 & 0,00036 & 12,84 & 0,00037 & 11,20 & 0,00027 & 13,36 \\
\hline 15 a 19 & 0,00039 & 3,45 & 0,00032 & 9,99 & 0,00042 & 2,83 & 0,00031 & 9,54 \\
\hline 20 a 24 & 0,00046 & 2,77 & 0,00028 & 10,44 & 0,00035 & 1,62 & 0,00037 & 8,39 \\
\hline 25 a 29 & 0,00031 & 1,91 & 0,00050 & 8,78 & 0,00052 & 1,94 & 0,00043 & 7,63 \\
\hline 30 a 34 & 0,00033 & 1,81 & 0,00124 & 16,83 & 0,00103 & 3,59 & 0,00109 & 14,55 \\
\hline 35 a 39 & 0,00145 & 6,25 & 0,00240 & 19,81 & 0,00140 & 4,17 & 0,00209 & 19,44 \\
\hline 40 a 44 & 0,00267 & 9,04 & 0,00417 & 22,89 & 0,00307 & 7,99 & 0,00340 & 26,04 \\
\hline 45 a 49 & 0,00361 & 9,26 & 0,00659 & 24,01 & 0,00642 & 13,50 & 0,00560 & 26,79 \\
\hline 50 a 54 & 0,00906 & 15,07 & 0,00815 & 20,51 & 0,01016 & 15,65 & 0,00841 & 27,26 \\
\hline 55 a 59 & 0,01367 & 15,16 & 0,01297 & 21,09 & 0,01756 & 19,95 & 0,01278 & 28,17 \\
\hline 60 a 64 & 0,01904 & 14,18 & 0,01593 & 18,76 & 0,02754 & 21,76 & 0,01653 & 25,43 \\
\hline 65 a 69 & 0,03283 & 16,89 & 0,02432 & 18,40 & 0,03393 & 19,53 & 0,02264 & 24,01 \\
\hline 70 a 74 & 0,04234 & 15,48 & 0,02795 & 15,41 & 0,04506 & 18,62 & 0,03028 & 20,37 \\
\hline 75 a 79 & 0,06279 & 16,61 & 0,03923 & 14,21 & 0,05939 & 17,27 & 0,03395 & 14,50 \\
\hline $80 \mathrm{e}+$ & - & - & - & - & - & - & - & - \\
\hline
\end{tabular}

A afirmação de GOTLIEB (1977) de que "a atuação desse grupo de causas é mais acentuada no sexo feminino e principalmente no grupo etário de 30 a 65 anos, chegando a uma diferença máxima de, aproximadamente, $25 \%$ entre 40 e 54 anos" permanece válida para o Município de São Paulo em 1996, com a diferença de que se estende até os 64 anos. Os resultados de Salvador seguem a mesma tendência. 
A estrutura por sexo e faixa etária dos óbitos (Figura 10) evidencia que este grupo de doenças atinge predominantemente indivíduos adultos, caracterizando-as como típicas do envelhecimento.

FIGURA 10 - Distribuição proporcional (\%) dos óbitos por neoplasias, segundo sexo e faixa etária. Municípios de Salvador e São Paulo, 1996.

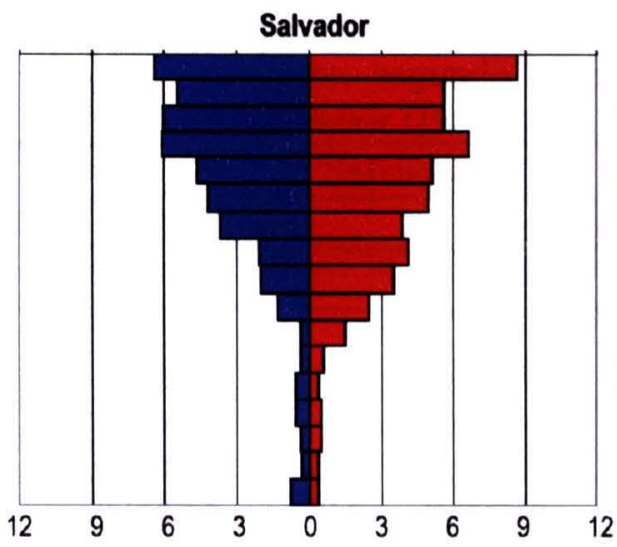

$(\%)$

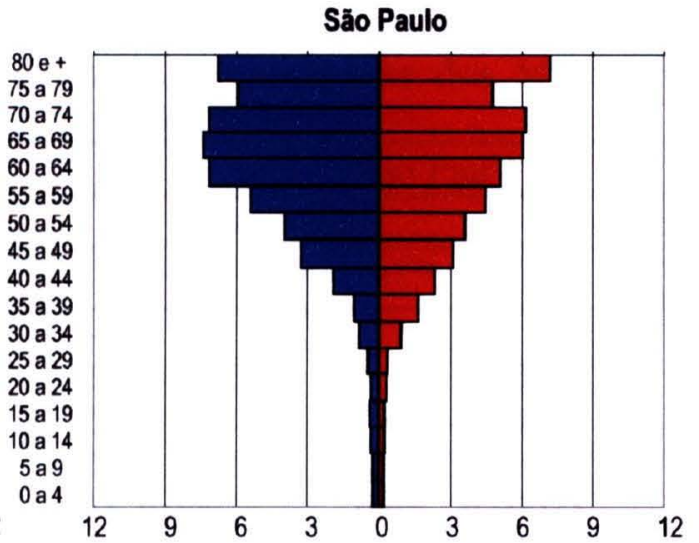

(\%)

Confirma-se aqui o comportamento diferencial da mortalidade por sexo, descrito por GOTLIEB (1977), com relação às neoplasias, que é, predominantemente, uma doença das idades adultas e idosas, raramente aparecendo em jovens adultos e crianças e com um surgimento mais precoce nas mulheres do que nos homens. Em São Paulo, na faixa de idade entre 20 e 40 anos, a diferença relativa entre as probabilidades de morte real e líquida no sexo feminino é mais de três vezes maior do que no masculino; já, no grupo etário de 50 a 75 anos, é mais comum entre os homens.

Os valores das probabilidades de sobrevivência real e hipotética, eliminando-se as neoplasias como causa de morte, mostram que dos cem mil nascidos vivos, que iniciaram a coorte, chegariam aos 80 anos, em São Paulo, 29,74\% a mais dos homens e $16,97 \%$ das mulheres contra, $28,36 \%$ de homens e $18,56 \%$ das mulheres de Salvador (Tabela 19).

No seu trabalho, GOTLIEB (1977) chama a atenção para o aumento da proporção de indivíduos de 15 anos que chegariam aos 65 anos, limite superior da faixa etária considerada economicamente ativa, caso o câncer fosse eliminado como causa de morte da população paulistana em 1970. Naquela época, tal situação representava uma mudança de $61,87 \%$ para $66,58 \%$ nas chances de sobrevivência do 
sexo masculino e de $77,29 \%$ para $81,86 \%$ para as mulheres. Em 1996, esta situação, com relação às neoplasias, passa de $60,09 \%$ para $64,75 \%$ (sexo masculino) e $80,98 \%$ para $85,39 \%$ (sexo feminino) no caso de São Paulo, e 63,31\% para 66,94\% (sexo masculino) e $76,33 \%$ para $80,66 \%$ (sexo feminino) para o Município de Salvador.

TABELA 19 - Comparação entre as probabilidades de sobreviver real (pox) e hipotética (pox.), eliminando as neoplasias como fator de risco de morte, segundo sexo e idade, dos residentes dos Municípios de Salvador (BA) e São Paulo (SP), 1996.

\begin{tabular}{|c|c|c|c|c|c|c|c|c|}
\hline \multirow{3}{*}{$\begin{array}{l}\text { Idade } \\
\text { (anos) }\end{array}$} & \multicolumn{4}{|c|}{ Salvador } & \multicolumn{4}{|c|}{ São Paulo } \\
\hline & \multicolumn{2}{|c|}{ Masculino } & \multicolumn{2}{|c|}{ Feminino } & \multicolumn{2}{|c|}{ Masculino } & \multicolumn{2}{|c|}{ Feminino } \\
\hline & $\left|\mathrm{po}_{\mathrm{x}}-\mathbf{p o} \mathrm{x}.\right|$ & $\begin{array}{c}\left|00_{x}-100_{x}\right|(\%) \\
p 0_{x}\end{array}$ & poox - pox $_{x} \mid$ & $\begin{array}{c}120 x-p 0 x d(\%) \\
100 x\end{array}$ & $|\mathrm{po} x-\mathrm{pox}|$. & $\begin{array}{c}\left|p 0_{x}-p_{0 x}\right|(\%) \\
p_{0 x}\end{array}$ & $\left|\mathbf{p o} \mathrm{o}_{\mathrm{x}}-\mathrm{pop}_{\mathrm{x}}\right| \mathrm{|}$ & $\begin{array}{c}\left.p 0_{x}-p 0 x\right\rfloor(\%) \\
p 0_{x}\end{array}$ \\
\hline 0 & - & - & - & - & - & - & 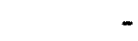 & - \\
\hline 1 & 0,00015 & 0,02 & 0,00016 & 0,02 & 0,00007 & 0,01 & 0,00011 & 0,01 \\
\hline 2 & 0,00036 & 0,04 & 0,00016 & 0,02 & 0,00012 & 0,01 & 0,00015 & 0,02 \\
\hline 3 & 0,00045 & 0,05 & 0,00021 & 0,02 & 0,00015 & 0,02 & 0,00021 & 0,02 \\
\hline 4 & 0,00065 & 0,07 & 0,00036 & 0,04 & 0,00025 & 0,03 & 0,00023 & 0,02 \\
\hline 5 a 9 & 0,00065 & 0,07 & 0,00036 & 0,04 & 0,00032 & 0,03 & 0,00026 & 0,03 \\
\hline 10 a 14 & 0,00089 & 0,09 & 0,00071 & 0,07 & 0,00064 & 0,07 & 0,00049 & 0,05 \\
\hline 15 a 19 & 0,00111 & 0,12 & 0,00104 & 0,11 & 0,00099 & 0,10 & 0,00075 & 0,08 \\
\hline 20 a 24 & 0,00147 & 0,16 & 0,00135 & 0,14 & 0,00138 & 0,15 & 0,00105 & 0,11 \\
\hline 25 a 29 & 0,00188 & 0,20 & 0,00161 & 0,17 & 0,00168 & 0,18 & 0,00140 & 0,15 \\
\hline 30 a 34 & 0,00214 & 0,24 & 0,00207 & 0,22 & 0,00212 & 0,23 & 0,00181 & 0,19 \\
\hline 35 a 39 & 0,00240 & 0,27 & 0,00322 & 0,35 & 0,00299 & 0,34 & 0,00284 & 0,30 \\
\hline 40 a 44 & 0,00364 & 0,42 & 0,00543 & 0,59 & 0,00411 & 0,49 & 0,00479 & 0,51 \\
\hline 45 a 49 & 0,00587 & 0,70 & 0,00920 & 1,02 & 0,00657 & 0,81 & 0,00794 & 0,86 \\
\hline 50 a 54 & 0,00871 & 1,07 & 0,01496 & 1,70 & 0,01152 & 1,49 & 0,01300 & 1,44 \\
\hline 55 a 59 & 0,01562 & 2,05 & 0,02166 & 2,56 & 0,01876 & 2,59 & 0,02033 & 2,32 \\
\hline 60 a 64 & 0,02485 & 3,58 & 0,03156 & 3,98 & 0,03016 & 4,57 & 0,03088 & 3,69 \\
\hline 65 a 69 & 0,03520 & 5,86 & 0,04201 & 5,79 & 0,04537 & 7,86 & 0,04324 & 5,52 \\
\hline 70 a 74 & 0,04924 & 10,17 & 0,05512 & 8,76 & 0,05861 & 12,29 & 0,05787 & 8,16 \\
\hline 75 a 79 & 0,05835 & 16,59 & 0,06426 & 12,47 & 0,06854 & 18,97 & 0,07251 & 12,00 \\
\hline $80 \mathrm{e}+$ & 0,06203 & 28,36 & 0,06926 & 18,56 & 0,07050 & 29,74 & 0,07850 & 16,97 \\
\hline
\end{tabular}

A EVN para os homens aumentaria em 1,96 / 2,23 anos e em 2,33 / 2,62 anos, para as mulheres, de Salvador/São Paulo, respectivamente. Estas diferenças aumentam com o decorrer das idades e, até os 34 anos, estes ganhos são maiores para as mulheres de Salvador, havendo depois uma inversão, isto é, maior ganho para os homens, refletindo a maior incidência precoce do câncer feminino. No caso da capital paulista, esta inversão, que em 1970 acontecia após os 45 anos, passou a ocorrer após os três anos de idade, indicando uma tendência para a eqüidade nos padrões da mortalidade por neoplasias, entre sexos, no Município de São Paulo. Os ganhos relativos, maiores para a população masculina, são devidos à sua menor esperança de vida (Tabela 20). 
TABELA 20 - Comparação entre as esperanças de vida real ( $\left.e_{X}\right)$ e hipotética $\left(e_{X}\right.$.), eliminando as neoplasias como fator de risco de morte, segundo sexo e idade, dos residentes dos Municípios de Salvador (BA) e São Paulo (SP), 1996.

\begin{tabular}{|c|c|c|c|c|c|c|c|c|}
\hline \multirow{3}{*}{$\begin{array}{l}\text { Idade } \\
\text { (anos) }\end{array}$} & \multicolumn{4}{|c|}{ Salvador } & \multicolumn{4}{|c|}{ São Paulo } \\
\hline & \multicolumn{2}{|c|}{ Masculino } & \multicolumn{2}{|c|}{ Feminino } & \multicolumn{2}{|c|}{ Masculino } & \multicolumn{2}{|c|}{ Feminino } \\
\hline & $\left|e_{x}-e_{x}\right|$ & $\begin{array}{c}\left|e_{x}-e_{x}\right|(\%) \\
e_{x}\end{array}$ & $\left|e_{x}-e_{x}\right|$ & $\begin{array}{c}e_{x}-e_{x} . \\
e_{x}\end{array}$ & $\left|e_{x}-e_{x}\right|$ & $\begin{array}{c}\left|e_{x}-e_{x}\right|(\%) \\
e_{x}\end{array}$ & $\left|e_{x}-e_{x}\right|$ & $\begin{array}{c}e_{x x}-e_{x}(\%) \\
e_{x}\end{array}$ \\
\hline 0 & 1,96 & 3,05 & 2,33 & 3,32 & 2,23 & 3,52 & 2,62 & 3,54 \\
\hline 1 & 2,03 & 3,08 & 2,42 & 3,35 & 2,30 & 3,57 & 2,67 & 3,58 \\
\hline 2 & 2,02 & 3,11 & 2,43 & 3,39 & 2,30 & 3,62 & 2,68 & 3,62 \\
\hline 3 & 2,02 & 3,15 & 2,43 & 3,44 & 2,30 & 3,68 & 2,68 & 3,66 \\
\hline 4 & 2,00 & 3,18 & 2,42 & 3,47 & 2,30 & 3,73 & 2,67 & 3,71 \\
\hline 5 a 9 & 2,00 & 3,23 & 2,42 & 3,52 & 2,29 & 3,78 & 2,67 & 3,76 \\
\hline 10 a 14 & 2,00 & 3,48 & 2,40 & 3,76 & 2,28 & 4,08 & 2,66 & 4,02 \\
\hline 15 a 19 & 1,99 & 3,79 & 2,38 & 4,04 & 2,26 & 4,44 & 2,65 & 4,32 \\
\hline 20 a 24 & 1,99 & 4,14 & 2,37 & 4,38 & 2,28 & 4,88 & 2,64 & 4,67 \\
\hline 25 a 29 & 2,00 & 4,57 & 2,36 & 4,79 & 2,31 & 5,42 & 2,63 & 5,08 \\
\hline 30 a 34 & 2,02 & 5,11 & 2,35 & 5,28 & 2,35 & 6,06 & 2,62 & 5,57 \\
\hline 35 a 39 & 2,04 & 5,81 & 2,31 & 5,80 & 2,38 & 6,83 & 2,59 & 6,10 \\
\hline 40 a 44 & 2,04 & 6,59 & 2,24 & 6,35 & 2,41 & 7,78 & 2,53 & 6,68 \\
\hline 45 a 49 & 2,02 & 7,51 & 2,13 & 6,90 & 2,40 & 8,87 & 2,43 & 7,29 \\
\hline 50 a 54 & 1,99 & 8,74 & 1,98 & 7,42 & 2,33 & 10,01 & 2,29 & 7,89 \\
\hline 55 a 59 & 1,90 & 9,92 & 1,83 & 8,08 & 2,23 & 11,29 & 2,10 & 8,48 \\
\hline 60 a 64 & 1,78 & 11,31 & 1,63 & 8,59 & 2,04 & 12,44 & 1,87 & 8,94 \\
\hline 65 a 69 & 1,68 & 13,14 & 1,45 & 9,29 & 1,78 & 13,26 & 1,62 & 9,45 \\
\hline 70 a 74 & 1,51 & 14,63 & 1,21 & 9,64 & 1,55 & 14,45 & 1,35 & 9,88 \\
\hline 75 a 79 & 1,37 & 16,61 & 1,02 & 10,47 & 1,32 & 15,85 & 1,08 & 10,19 \\
\hline 80 e+ & 1,15 & 17,10 & 0,82 & 10,91 & 1,11 & 17,39 & 0,90 & 11,14 \\
\hline
\end{tabular}

A principal localização anatômica dos óbitos femininos por neoplasias é o câncer de mama, seguido pelos tumores de cólon, reto e ânus, em ambos os municípios. Em Salvador, o câncer do colo do útero ocupa o terceiro lugar; já na capital paulista, esta posição pertence ao câncer de estômago. Com referência ao sexo masculino, a principal causa de óbito, neste contexto, é representada pelas neoplasias malignas de traquéia, brônquios e pulmões em ambos os municípios. Em Salvador, as neoplasias malignas da próstata e o câncer de estômago ocupam respectivamente o segundo e terceiro lugar, e, em São Paulo, estas posições se invertem (Figura 11).

Diferentemente do que aconteceu em relação às doenças infecciosas e parasitárias, as neoplasias apresentaram valores de APVG maiores para o Município de São Paulo do que para Salvador (Tabela 21). É claro que estes valores estão padronizados para população inicial de cem mil habitantes, o que torna possível a comparação, mas com cautela, em função da subnotificação dos óbitos. Isso leva a 
crer que a eliminação das neoplasias é mais importante para a capital paulista do que para a capital nordestina, reforçando, assim, as afirmações anteriores.

FIGURA 11 - Coeficiente de mortalidade (100.000 habitantes) por neoplasias, segundo localizações anatômicas mais freqüentes e sexo. Municípios de Salvador e São Paulo, 1996.

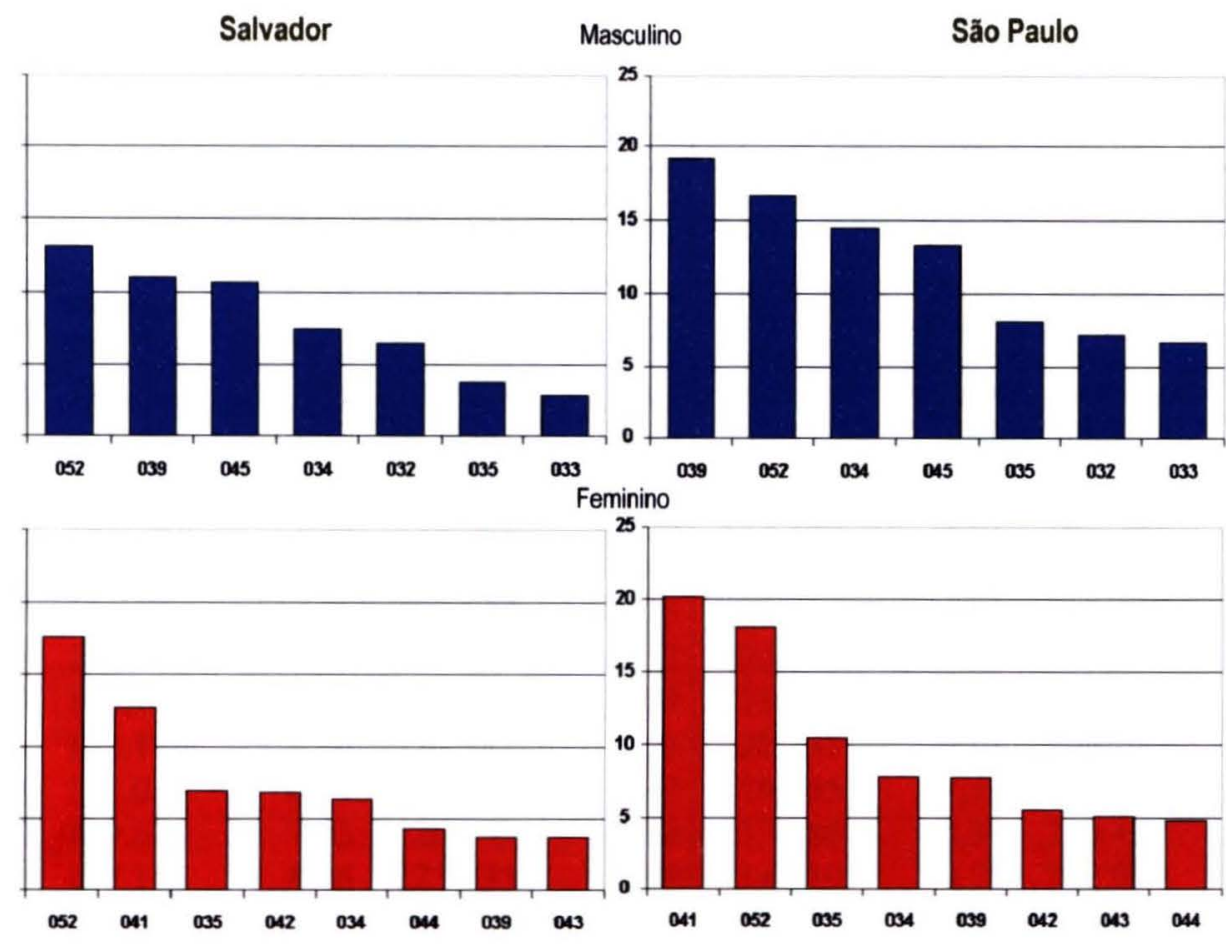

032 - lábio, cavidade oral e faringe 033 - esôfago 034 - Estômago 035 - cólon, reto e ânus 039 - traquéia, brônquios e pulmőes 041 - mama $\quad 042$ - colo do útero 043 - corpo e partes não especificadas do útero 044 - ovário 045 - próstata 052 - restante das neoplasias malignas

Em função do caráter diversificado e da multicausalidade/multifatoriedade das neoplasias, a suposição da sua eliminação completa como causa de óbito talvez seja irreal e impraticável, pois implica na modificação de hábitos de vida, desenvolvimento de novas técnicas de diagnóstico e tratamento cada vez mais precisos e eficazes, além do controle de agentes cancerígenos, o que nem sempre é possível controlar. No entanto, conforme já dizia GOTLIEB (1977), “deve existir, para os sanitaristas, o objetivo de prevenir ou mesmo retardar a mortalidade por câncer".

Para esta autora, existem pelo menos dois níveis de prevenção importantes a serem trabalhados: o primário, no qual mudanças de hábito e a adoção de algumas medidas simples de saúde pública reduziriam em muito a incidência/mortalidade por neoplasias. O segundo nível, ou nível secundário, implica em investimentos no 
sentido de deteç̧ão da doença em um estágio inicial, simplificando em muito o tratamento e aumentando significativamente as chances de sucesso, resultando em mais sobrevida e melhor qualidade de vida.

TABELA 21 - Comparação entre os totais de anos vividos além de $X$ real $\left(T_{X}\right)$ e hipotético $\left(T_{X}\right.$.) (Anos Potenciais de Vida Ganhos - APVG), eliminando as neoplasias como fator de risco de morte, segundo sexo e idade, dos residentes dos Municípios de Salvador (BA) e São Paulo (SP), 1996.

\begin{tabular}{|c|c|c|c|c|c|c|c|c|}
\hline \multirow{3}{*}{$\begin{array}{l}\text { Idade } \\
\text { (anos) }\end{array}$} & \multicolumn{4}{|c|}{ Salvador } & \multicolumn{4}{|c|}{ São Paulo } \\
\hline & \multicolumn{2}{|c|}{ Masculino } & \multicolumn{2}{|c|}{ Feminino } & \multicolumn{2}{|c|}{ Masculino } & \multicolumn{2}{|c|}{ Feminino } \\
\hline & $\left|T_{x}-T_{x}\right|$ & $\begin{array}{c}\left|T_{x}-T_{x}\right|(\%) \\
T_{x}\end{array}$ & $\left|T_{x}-T_{x}\right|$ & $\frac{\left.I_{x}-T_{x}\right]}{T_{x}}(\%)$ & $\left|T_{X}-T_{X} \cdot\right|$ & $\frac{I_{x}-I_{x} \mid}{T_{x}}(\%)$ & $\left|T_{X}-T_{X}\right|$ & $\begin{array}{c}\left.I_{x}-T_{x}\right](\%) \\
T_{x}\end{array}$ \\
\hline 0 & 195.749 & 3,05 & 233.455 & 3,32 & 223.364 & 3,52 & 261.650 & 3,54 \\
\hline 1 & 195.735 & 3,10 & 233.442 & 3,37 & 223.358 & 3,58 & 261.641 & 3,59 \\
\hline 2 & 195.706 & 3,15 & 233.426 & 3,41 & 223.348 & 3,64 & 261.627 & 3,64 \\
\hline 3 & 195.665 & 3,20 & 233.407 & 3,46 & 223.334 & 3,69 & 261.609 & 3,68 \\
\hline 4 & 195.610 & 3,25 & 233.378 & 3,51 & 223.314 & 3,75 & 261.587 & 3,74 \\
\hline 5 a 9 & 195.545 & 3,30 & 233.342 & 3,56 & 223.285 & 3,81 & 261.563 & 3,79 \\
\hline 10 a 14 & 195.160 & 3,58 & 233.075 & 3,84 & 223.045 & 4,15 & 261.375 & 4,07 \\
\hline 15 a 19 & 194.659 & 3,91 & 232.637 & 4,15 & 222.637 & 4,55 & 261.063 & 4,40 \\
\hline 20 a 24 & 194.013 & 4,30 & 232.039 & 4,53 & 222.044 & 5,03 & 260.612 & 4,78 \\
\hline 25 a 29 & 193.174 & 4,78 & 231.301 & 4,97 & 221.280 & 5,61 & 259.998 & 5,23 \\
\hline 30 a 34 & 192.170 & 5,36 & 230.381 & 5,51 & 220.331 & 6,31 & 259.194 & 5,77 \\
\hline 35 a 39 & 191.035 & 6,09 & 229.058 & 6,17 & 219.055 & 7,19 & 258.032 & 6,42 \\
\hline 40 a 44 & 189.524 & 7,03 & 226.893 & 6,98 & 217.280 & 8,31 & 256.123 & 7,22 \\
\hline 45 a 49 & 187.145 & 8,26 & 223.235 & 7,99 & 214.610 & 9,75 & 252.939 & 8,21 \\
\hline 50 a 54 & 183.499 & 9,91 & 217.195 & 9,25 & 210.089 & 11,65 & 247.705 & 9,44 \\
\hline 55 a 59 & 177.415 & 12,17 & 208.040 & 10,85 & 202.519 & 14,17 & 239.373 & 10,99 \\
\hline 60 a 64 & 167.297 & 15,29 & 194.737 & 12,91 & 190.289 & 17,57 & 226.570 & 12,96 \\
\hline 65 a 69 & 152.285 & 19,77 & 176.346 & 15,62 & 171.406 & 22,16 & 208.041 & 15,49 \\
\hline 70 a 74 & 131.176 & 26,29 & 152.065 & 19,24 & 145.412 & 28,52 & 182.764 & 18,84 \\
\hline 75 a 79 & 104.280 & 35,95 & 122.220 & 24,24 & 113.625 & 37,82 & 150.168 & 23,41 \\
\hline $80 \mathrm{e}^{+}$ & 74.186 & 50,31 & 88.841 & 31,49 & 78.863 & 52,30 & 112.414 & 30,00 \\
\hline
\end{tabular}

\subsubsection{Eliminando o grupo das doenças do aparelho circulatório}

As doenças do aparelho circulatório (Capítulo 09 - CID-10) compreendem as febres reumáticas aguda e doenças reumáticas crônicas do coração, as doenças hipertensivas, as doenças isquêmicas do coração, as outras doenças cardíacas, as doenças cerebrovasculares, a arteriosclerose e o restante das doenças do aparelho circulatório. Este grupo de doenças foi o principal responsável pelos óbitos nos Municípios de São Paulo (27,73\% homens/38,13\% mulheres) e de Salvador (24,33\% homens/34,16\% mulheres), no ano de 1996, mas esta situação também se repete para 
todo o Brasil, conforme os dados apresentados por MELLO JORGE e GOTLIEB (2000).

Enquanto que em Salvador a principal causa de morte foi o agrupamento das doenças cerebrovasculares, em São Paulo, as doenças isquêmicas do coração ocuparam o primeiro lugar. Merecem destaque especial o conjunto das outras doenças do coração e as doenças hipertensivas (Figura 12).

FIGURA 12 - Coeficiente de mortalidade (100.000 habitantes) por doenças do aparelho circulatório, segundo subgrupos de causa (CID10-BR) e sexo. Municípios de Salvador e São Paulo, 1996.

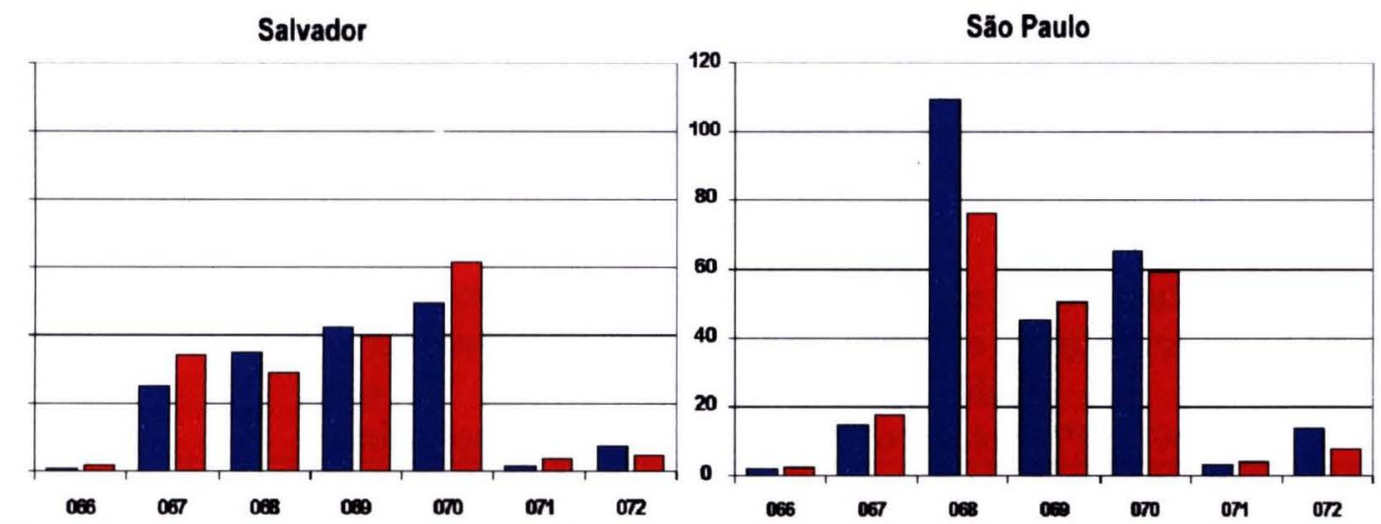

066 - febres reumáticas aguda e doenças reumáticas crônicas do coraçāo 067 - doenças hipertensivas 068 - doenças isquêmicas do coraçăo 069 - outras doenças cardiacas 070 - doenças cerebrovasculares 071 -arteriosclerose 072 -restante das doenças do aparelho circulatório

Masculino $\square$ Feminino

Caso estas doenças deixassem de ser causas fatais, as probabilidades de morrer, masculina e feminina, sofreriam sensíveis reduções (Tabela 22). As diferenças absolutas entre as probabilidades de morte real e hipotética - eliminando-se as doenças do aparelho circulatório - aumentam com a idade, em ambos os sexos e nos dois municípios, com discrepâncias maiores para o sexo masculino. No entanto, quando se comparam as diferenças relativas, estas são freqüentemente maiores entre as mulheres, em função do menor risco de morte apresentado por elas. Estes resultados são perfeitamente concordantes com os valores obtidos por GOTLIEB (1977) no seu estudo da população paulistana de 1970.

Por sua vez, quando são comparados os dados da capital paulista obtidos, neste trabalho, com os de 1970, constata-se que houve uma redução nas diferenças relativas das probabilidades de morte, com o decorrer destes anos. Em 70, a redução na probabilidade de morte entre os homens a partir dos 35 anos era de $20,76 \%$ e em 1996 , este valor passa para $11,13 \%$, pouco mais da metade; já para as mulheres, os 
$24,25 \%$ se transformam em $22,13 \%$. Na faixa etária de 75 a 79 anos, destacada por GOTLIEB (1977), os valores de 50,64\% (homens) e 58,20\% (mulheres) passam a ser de $38,38 \%$ e $45,35 \%$ respectivamente. Demonstram que uma redução maior se deu com relação ao sexo masculino.

Há também de se observar (Tabela 22), que as diferenças absolutas permanecem maiores para o Município de Salvador do que para São Paulo até os 34 anos (homens)/74 anos (mulheres), enquanto que as diferenças relativas são maiores para o município baiano até os 49 anos (sexo masculino)/54 anos (sexo feminino). Isto indica que na capital paulista, a mortalidade pelas doenças do aparelho circulatório se dá em idades mais avançadas do que na capital baiana, possivelmente em função de melhores condições de assistência médica e do envelhecimento populacional.

TABELA 22 - Comparação entre as probabilidades de morte real $\left(q_{\mathrm{x}}\right)$ e liquida $\left(q_{x}\right.$.), eliminando as doenças do aparelho circulatório como fator de risco de morte, segundo sexo e idade, dos residentes dos Municípios de Salvador (BA) e São Paulo (SP), 1996.

\begin{tabular}{|c|c|c|c|c|c|c|c|c|}
\hline \multirow{3}{*}{$\begin{array}{l}\text { Idade } \\
\text { (anos) } \\
\end{array}$} & \multicolumn{4}{|c|}{ Salvador } & \multicolumn{4}{|c|}{ São Paulo } \\
\hline & \multicolumn{2}{|c|}{ Masculino } & \multicolumn{2}{|c|}{ Feminino } & \multicolumn{2}{|c|}{ Masculino } & \multicolumn{2}{|c|}{ Feminino } \\
\hline & $\mid \mathbf{q x}_{\mathrm{x}-\mathrm{9} x \mid}$ & $\underset{9 x}{\left|g_{x}-9 x .\right|(\%)}$ & $|9 x-9 x|$ & $\frac{|a x-9 x|(\%)}{9 x}$ & $|9 x-9 x|$ & $\frac{\mid 9 x-9 x .}{9 x}(\%)$ & $\left|q_{x}-q_{x}\right|$ & $\frac{\left.\mid q_{x}-q_{x}\right\rfloor(\%)}{q_{x}}$ \\
\hline$\overline{0}$ & 0,00005 & 0,13 & 0,00005 & 0,14 & 0,00029 & 0,96 & 0,00023 & 0,93 \\
\hline 1 & 0,00016 & 5,55 & 0,00000 & 0,00 & 0,00005 & 2,56 & 0,00010 & 5,03 \\
\hline 2 & 0,00010 & 6,45 & 0,00000 & 0,00 & 0,00002 & 2,67 & 0,00004 & 3,75 \\
\hline 3 & 0,00005 & 5,55 & 0,00000 & 0,00 & 0,00000 & $\mathbf{0 , 0 0}$ & 0,00001 & 2,17 \\
\hline 4 & 0,00000 & 0,00 & 0,00005 & 10,00 & 0,00000 & 0,00 & 0,00003 & 7,41 \\
\hline 5 a 9 & 0,00015 & 5,35 & 0,00005 & 3,45 & 0,00005 & 2,09 & 0,00011 & 6,42 \\
\hline 10 a 14 & 0,00016 & 5,33 & 0,00036 & 12,84 & 0,00008 & 2,31 & 0,00014 & 6,95 \\
\hline 15 a 19 & 0,00055 & 4,83 & 0,00025 & 7,77 & 0,00037 & 2,54 & 0,00019 & 5,72 \\
\hline 20 a 24 & 0,00051 & 3,05 & 0,00044 & 16,40 & 0,00041 & 1,92 & 0,00031 & 6,99 \\
\hline 25 a 29 & 0,00119 & 7,34 & 0,00095 & 16,76 & 0,00085 & 3,19 & 0,00051 & 8,96 \\
\hline 30 a 34 & 0,00172 & 9,37 & 0,00153 & 20,72 & 0,00148 & 5,14 & 0,00093 & 12,35 \\
\hline 35 a 39 & 0,00367 & 15,78 & 0,00284 & 23,42 & 0,00372 & 11,13 & 0,00238 & 22,13 \\
\hline 40 a 44 & 0,00651 & 21,99 & 0,00518 & 28,44 & 0,00724 & 18,85 & 0,00369 & 28,26 \\
\hline 45 a 49 & 0,01128 & 28,91 & 0,00927 & 33,79 & 0,01308 & 27,49 & 0,00698 & 33,37 \\
\hline 50 a 54 & 0,01778 & 29,59 & 0,01588 & 40,00 & 0,02182 & 33,60 & 0.01142 & 37,00 \\
\hline 55 a 59 & 0,03190 & 35,37 & 0,02176 & 35,39 & 0,03398 & 38,60 & 0,01764 & 38,89 \\
\hline 60 a 64 & 0,05195 & 38,68 & 0,03412 & 40,17 & 0,05213 & 41,19 & 0,02701 & 41,56 \\
\hline 65 a 69 & 0,06277 & 32,30 & 0,04803 & 36,34 & 0,07286 & 41,93 & 0,03967 & 42,08 \\
\hline 70 a 74 & 0,09677 & 35,38 & 0,07197 & 39,69 & 0,10118 & 41,81 & 0,06485 & 43,64 \\
\hline 75 a 79 & 0,12441 & 32,91 & 0,11294 & 40,92 & 0,13199 & 38,38 & 0,10622 & 45,35 \\
\hline $80 \mathrm{e}+$ & - & - & & s & - & - & . & \\
\hline
\end{tabular}


A composição etária e por sexo dos óbitos (Figura 13), por este grupo de causas de morte, assemelha-se em muito a de óbitos por neoplasias (Figura 10), indicando ser este agravo típico do envelhecimento.

FIGURA 13 - Distribuição proporcional (\%) dos óbitos por doenças do aparelho circulatório, segundo sexo e faixa etária. Municípios de Salvador e São Paulo, 1996.

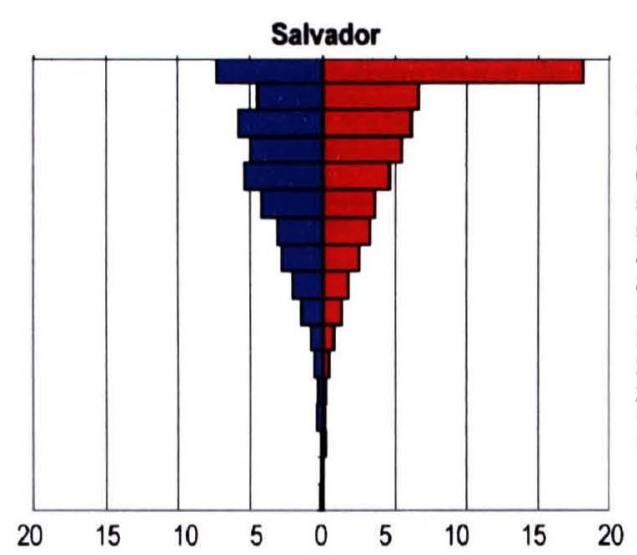

$(\%)$

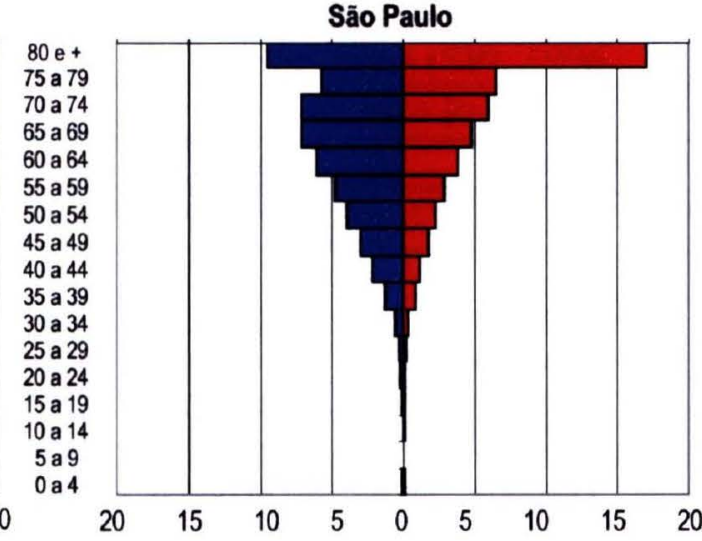

(\%)

A probabilidade de sobreviver (Tabela 23) mostra que, na ausência das doenças do aparelho circulatório como causa de morte, de cem mil nascidos vivos chegariam 36.810 homens aos 80 anos, em vez de 21.869 (68,32\% a mais) e 54.577 mulheres, em vez de 37.311 (46,28\% a mais), no Município de Salvador. Em São Paulo, esses valores seriam 40.660 homens aos 80 anos, em vez de 23.709 (71,50\% a mais) e 63.747 mulheres, em vez de 46.266 (37,78\% a mais).

Tal como as neoplasias, este grupo de doenças tem forte impacto na faixa etária economicamente ativa da população. Caso elas não fossem causa de morte, daqueles que completaram 15 anos, 72,65\% dos homens chegariam aos 65 anos (e não somente $63,31 \%$ ) e $84,08 \%$ das mulheres (em vez de 76,33\%), no Município de Salvador, em 1996. Já em São Paulo, a mudança seria de 60,09\% para 69,52\% (homens) e $80,98 \%$ para $87,18 \%$ (mulheres). Assim, pode-se dizer que houve uma pequena redução na probabilidade dos homens que completaram 15 anos chegar ao 65 anos no Município de São Paulo, de 1970 para 1996 (de 61,87\% para 60,09\%). Com relação às mulheres, houve um aumento de $77,29 \%$ para $80,98 \%$.

Ao se considerarem as doenças do aparelho circulatório, nota-se uma diminuição de importância destas na faixa etária economicamente ativa do sexo 
masculino que, em 1970, representava um ganho de sobrevivência de $12,28 \%$ e que em 1996 passou a ser de $9,43 \%$ (uma redução de $23,21 \%$ ). Quanto ao sexo feminino, o ganho de sobrevivência que em 1970 era de 8,54\%, em 1996 passou a ser de $6,20 \%$, representando uma redução, relativamente maior, de $27,40 \%$.

TABELA 23 - Comparação entre as probabilidades de sobreviver real (pox) e hipotética (pox.), eliminando as doenças do aparelho circulatório como fator de risco de morte, segundo sexo e idade, dos residentes dos Municípios de Salvador (BA) e São Paulo (SP), 1996.

\begin{tabular}{lrrrr|rrrr}
\hline & \multicolumn{4}{c|}{ Salvador } & \multicolumn{4}{c}{ São Paulo } \\
\cline { 2 - 9 } Idade \\
\cline { 2 - 9 } (anos)
\end{tabular}

Nos Anexos 25 a 28, estão apresentadas as tábuas de vida de múltiplo decremento com a exclusão das Doenças do Aparelho Circulatório como causa de morte. Os valores das EVN passam a ser 69,48/77,96 (homens/mulheres) e 69,62/83,18 (homens/mulheres) para os Municípios de Salvador e São Paulo respectivamente.

A comparação entre as esperanças de vida real e hipotética (Tabela 24) mostra ganhos acentuados de 5,38/7,63 anos (Salvador) e 6,23/9,26 anos (São Paulo), respectivamente, na esperança de vida masculina e feminina. Os dados são coerentes com o trabalho de GOTLIEB (1977), demonstrando sempre número maior de anos 
ganhos entre as mulheres, com valores máximos de $\mathbf{8 , 0 0}$ anos para as mulheres na faixa etária de 20 a 29 anos em Salvador e 9,60 anos para as mulheres da faixa etária de 35 a 39 anos em São Paulo. As diferenças relativas também se mantêm maiores para o sexo feminino, nas duas capitais, crescendo concomitantemente às idades.

TABELA 24 - Comparação entre as esperanças de vida real $\left(e_{X}\right)$ e hipotética $\left(e_{X}\right.$.), eliminando as doenças do aparelho circulatório como fator de risco de morte, segundo sexo e idade, dos residentes dos Municípios de Salvador (BA) e São Paulo (SP), 1996.

\begin{tabular}{|c|c|c|c|c|c|c|c|c|}
\hline \multirow{3}{*}{$\begin{array}{l}\text { Idade } \\
\text { (anos) }\end{array}$} & \multicolumn{4}{|c|}{ Salvador } & \multicolumn{4}{|c|}{ São Paulo } \\
\hline & \multicolumn{2}{|c|}{ Masculino } & \multicolumn{2}{|c|}{ Feminino } & \multicolumn{2}{|c|}{ Masculino } & \multicolumn{2}{|c|}{ Feminino } \\
\hline & $\left|e_{x}-e_{x}\right|$ & $\begin{array}{c}k_{x}-e_{x} \mid \\
e_{x}\end{array}$ & $\left|e_{x}-e_{x}\right|$ & $\begin{array}{c}e_{x}-e_{x} \mid(\%) \\
e_{x}\end{array}$ & $\left|e_{x}-e_{x}\right|$ & $\begin{array}{c}\left|x-e_{x}\right|(\%) \\
e_{x}\end{array}$ & $\left|e_{x}-e_{x}\right|$ & 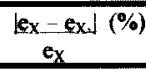 \\
\hline 0 & 5,38 & 8,40 & 7,63 & 10,85 & 6,23 & 9,83 & 9,26 & 12,53 \\
\hline 1 & 5,60 & 8,52 & 7,94 & 11,00 & 6,41 & 9,95 & 9,48 & 12,67 \\
\hline 2 & 5,60 & 8,63 & 7,97 & 11,15 & 6,41 & 10,10 & 9,49 & 12,83 \\
\hline 3 & 5,61 & 8,76 & 7,98 & 11,31 & 6,42 & 10,26 & 9,50 & 13,00 \\
\hline 4 & 5,61 & 8,89 & 7,99 & 11,47 & 6,42 & 10,43 & 9,50 & 13,18 \\
\hline 5 a 9 & 5,61 & 9,03 & 7,99 & 11,63 & 6,43 & 10,60 & 9,50 & 13,36 \\
\hline 10 a 14 & 5,62 & 9,80 & 8,00 & 12,54 & 6,44 & 11,54 & 9,51 & 14,36 \\
\hline 15 a 19 & 5,62 & 10,72 & 7,99 & 13,56 & 6,45 & 12,67 & 9,52 & 15,51 \\
\hline 20 a 24 & 5,66 & 11,78 & 8,00 & 14,79 & 6,53 & 13,99 & 9,54 & 16,86 \\
\hline 25 a 29 & 5,73 & 13,07 & 8,00 & 16,24 & 6,65 & 15,60 & 9,56 & 18,46 \\
\hline 30 a 34 & 5,76 & 14,59 & 7,99 & 17,95 & 6,79 & 17,53 & 9,58 & 20,36 \\
\hline 35 a 39 & 5,80 & 16,47 & 7,97 & 20,01 & 6,93 & 19,90 & 9,60 & 22,65 \\
\hline 40 a 44 & 5,79 & 18,69 & 7,94 & 22,49 & 7,01 & 22,67 & 9,59 & 25,34 \\
\hline 45 a 49 & 5,73 & 21,35 & 7,87 & 25,46 & 7,01 & 25,92 & 9,55 & 28,66 \\
\hline 50 a 54 & 5,60 & 24,53 & 7,74 & 28,98 & 6,92 & 29,70 & 9,46 & 32,66 \\
\hline 55 a 59 & 5,44 & 28,47 & 7,52 & 33,10 & 6,72 & 34,06 & 9,33 & 37,60 \\
\hline 60 a 64 & 5,16 & 32,75 & 7,34 & 38,57 & 6,43 & 39,20 & 9,17 & 43,95 \\
\hline 65 a 69 & 4,76 & 37,11 & 7,08 & 45,51 & 6,05 & 45,11 & 8,98 & 52,39 \\
\hline 70 a 74 & 4,55 & 44,16 & 6,95 & 55,31 & 5,66 & 52,87 & 8,82 & 64,54 \\
\hline 75 a 79 & 4,27 & 51,72 & 6,81 & 69,56 & 5,31 & 63,86 & 8,70 & 81,94 \\
\hline 80 et & 4,18 & 61,92 & 6,77 & 89,59 & 5,25 & 82,59 & 8,68 & 107,23 \\
\hline
\end{tabular}

É interessante observar os altos valores das diferenças absolutas dos anos vividos além da idade $X$ real e hipotético (Tabela 25). Os valores são tão altos que superam o somatório dos óbitos por doenças infecciosas e parasitárias e das neoplasias (Tabelas 14 e 21). Mas isto já era de se esperar, uma vez que, conforme mostrado na Tabela 11, a proporção de doenças do aparelho circulatório supera a soma das proporções dos outros dois grupos de causas de óbito.

Visto que as doenças isquêmicas do coração e as cerebrovasculares constituem as duas mais importantes causas de óbito dentre as doenças do aparelho circulatório, analisou-se separadamente a atuação de cada uma delas. 
TABELA 25 - Comparação entre os totais de anos vividos além de $X$ real $\left(T_{X}\right)$ e hipotético ( $\mathrm{T}_{\mathrm{X}}$ ) (Anos Potenciais de Vida Ganhos - APVG), eliminando as doenças do aparelho circulatório como fator de risco de morte, segundo sexo e idade, dos residentes dos Municípios de Salvador (BA) e São Paulo (SP), 1996.

\begin{tabular}{|c|c|c|c|c|c|c|c|c|}
\hline \multirow{3}{*}{$\begin{array}{l}\text { Idade } \\
\text { (anos) }\end{array}$} & \multicolumn{4}{|c|}{ Salvador } & \multicolumn{4}{|c|}{ São Paulo } \\
\hline & \multicolumn{2}{|c|}{ Masculino } & \multicolumn{2}{|c|}{ Feminino } & \multicolumn{2}{|c|}{ Masculino } & \multicolumn{2}{|c|}{ Feminino } \\
\hline & $\left|T_{x}-T_{x}\right|$ & $\begin{array}{c}{\left[\mathbf{T}_{\mathrm{x}}-\mathbf{T}_{\mathrm{x}} \mathbf{T}_{(\%)}\right.} \\
\mathbf{T}_{\mathrm{X}}\end{array}$ & $\left|T_{x}-T_{x}\right|$ & $\begin{array}{c}{\left[T_{x}-T_{x}\right](\%)} \\
T_{x}\end{array}$ & $\left|T_{x}-T_{x}\right|$ & $\begin{array}{l}{\left[T_{x}-T_{X}\right](\%)} \\
T_{x}\end{array}$ & $\left|T_{x}-T_{x}\right|$ & $\begin{array}{c}\left|T_{x}-T_{x}\right|(\%) \\
T_{X}\end{array}$ \\
\hline 0 & 538.102 & 8,40 & 763.152 & 10,85 & 623.089 & 9,83 & 926.139 & 12,53 \\
\hline 1 & 538.097 & 8,52 & 763.147 & 11,00 & 623.064 & 9,98 & 926.120 & 12,70 \\
\hline 2 & 538.082 & 8,65 & 763.142 & 11,16 & 623.031 & 10,14 & 926.090 & 12,87 \\
\hline 3 & 538.056 & 8,79 & 763.136 & 11,31 & 622.996 & 10,30 & 926.055 & 13,04 \\
\hline 4 & 538.024 & 8,93 & 763.131 & 11,48 & 622.960 & 10,47 & 926.017 & 13,22 \\
\hline 5 a 9 & 537.989 & 9,07 & 763.123 & 11,64 & 622.923 & 10,64 & 925.978 & 13,41 \\
\hline 10 a 14 & 537.778 & 9,86 & 763.059 & 12,56 & 622.731 & 11,59 & 925.749 & 14,42 \\
\hline 15 a 19 & 537.495 & 10,80 & 762.898 & 13,62 & 622.509 & 12,73 & 925.459 & 15,59 \\
\hline 20 a 24 & 537.045 & 11,92 & 762.593 & 14,87 & 622.181 & 14,09 & 925.092 & 16,96 \\
\hline 25 a 29 & 536.354 & 13,27 & 762.124 & 16,38 & 621.672 & 15,75 & 924.606 & 18,60 \\
\hline 30 a 34 & 535.279 & 14,93 & 761.329 & 18,20 & 620.881 & 17,79 & 923.927 & 20,56 \\
\hline 35 a 39 & 533.557 & 17,02 & 759.955 & 20,46 & 619.580 & 20,34 & 922.909 & 22,97 \\
\hline 40 a 44 & 530.660 & 19,70 & 757.571 & 23,30 & 617.170 & 23,60 & 921.115 & 25,97 \\
\hline 45 a 49 & 525.593 & 23,20 & 753.359 & 26,95 & 612.488 & 27,83 & 917.909 & 29,79 \\
\hline 50 a 54 & 516.862 & 27,91 & 745.927 & 31,76 & 603.773 & 33,47 & 912.262 & 34,78 \\
\hline 55 a 59 & 502.464 & 34,46 & 733.069 & 38,22 & 588.521 & 41,18 & 902.515 & 41,45 \\
\hline 60 a 64 & 479.128 & 43,80 & 712.559 & 47,23 & 563.652 & 52,06 & 886.552 & 50,70 \\
\hline 65 a 69 & 442.404 & 57,44 & 681.645 & 60,37 & 525.675 & 67,97 & 861.603 & 64,15 \\
\hline 70 a 74 & 391.360 & 78,44 & 637.450 & 80,65 & 472.006 & 92,56 & 824.424 & 85,00 \\
\hline 75 a 79 & 327.195 & 112,81 & 577.585 & 114,55 & 402.419 & 133,96 & 770.643 & 120,15 \\
\hline 80 et & 254.448 & 172,55 & 500.227 & 177,33 & 321.396 & 213,14 & 695.221 & 185,54 \\
\hline
\end{tabular}

\subsubsection{Eliminando o grupo das doenças isquêmicas do coração}

Com uma estrutura etária de óbitos e por sexo bem semelhante a do grupo das doenças do aparelho circulatório, as doenças isquêmicas do coração (Figura 14) têm uma elevada incidência/mortalidade, nas populações estudadas, notadamente em São Paulo, tanto que, de acordo com a Tabela 26, a sua eliminação, na população de Salvador, implicaria num ganho na EVN de quase um ano para ambos os sexos $(0,90$ anos para os homens e 0,85 anos para as mulheres). Na população paulistana, corresponderia a pouco mais do que o dobro (2,04 anos para os homens e 2,12 anos para as mulheres), indicando, ainda, que a eliminação destas doenças tem impacto semelhante em relação ao gênero, mas existe uma diferenciação bastante acentuada com relação às duas capitais. Provavelmente, além da melhor cobertura dos óbitos, 
os fatores de risco para as doenças isquêmicas do coração estariam mais presentes na capital paulistana.

FIGURA 14 - Distribuição proporcional (\%) dos óbitos por doenças isquêmicas do coração, segundo sexo e faixa etária. Municípios de Salvador e São Paulo, 1996.

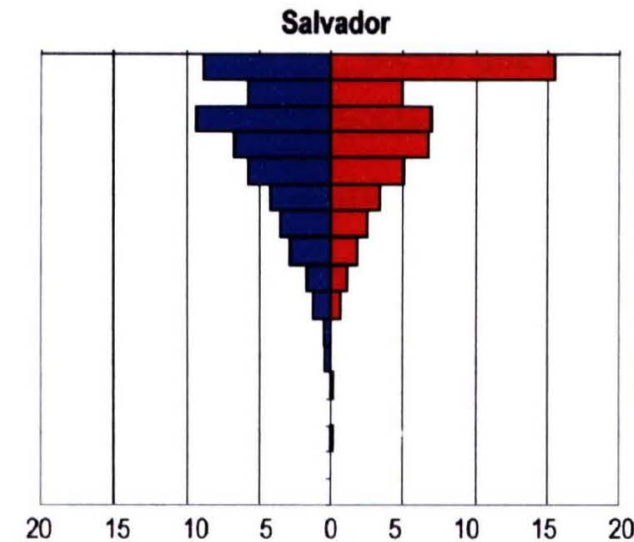

$(\%)$

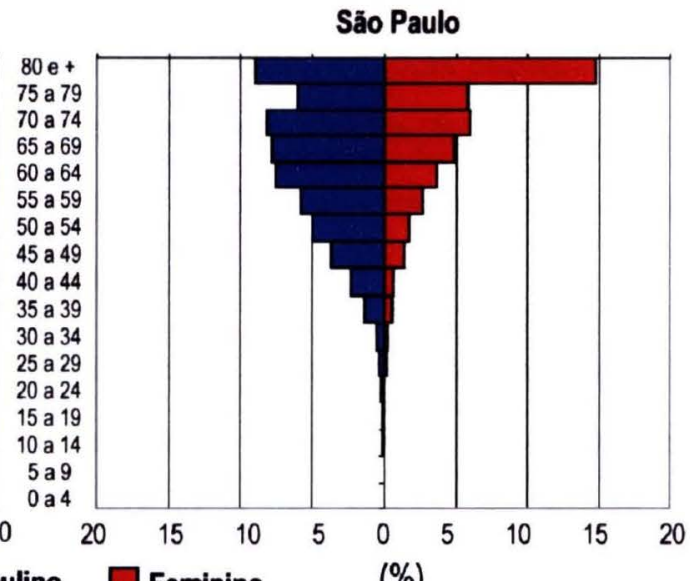

(\%)

TABELA 26 - Comparação entre as esperanças de vida real $\left(e_{\mathrm{X}}\right)$ e hipotética $\left(\mathrm{e}_{\mathrm{X}}\right.$.), eliminando as doenças isquêmicas do coração como fator de risco de morte, segundo sexo e idade, dos residentes dos Municípios de Salvador (BA) e São Paulo (SP), 1996.

\begin{tabular}{|c|c|c|c|c|c|c|c|c|}
\hline \multirow{3}{*}{$\begin{array}{l}\text { Idade } \\
\text { (anos) }\end{array}$} & \multicolumn{4}{|c|}{ Salvador } & \multicolumn{4}{|c|}{ São Paulo } \\
\hline & \multicolumn{2}{|c|}{ Masculino } & \multicolumn{2}{|c|}{ Feminino } & \multicolumn{2}{|c|}{ Masculino } & \multicolumn{2}{|c|}{ Feminino } \\
\hline & $\left|e_{x}-e_{x}\right|$ & $\begin{array}{c}e_{x}-e_{x} \\
e_{x}\end{array}$ & $\left|e_{x}-e_{x}\right|$ & $\begin{array}{c}\begin{array}{l}e_{x}-e_{x} \mid \\
e_{x}\end{array}(\%) \\
\end{array}$ & $\left|e_{x}-e_{x}\right| \mid$ & $\begin{array}{c}\mid \begin{array}{l}e_{x}-e_{x} \mid \\
e_{x}\end{array}(\%) \\
\end{array}$ & $\left|e_{x}-e_{x}\right|$ & $\begin{array}{c}\left|e_{x}-e_{x}\right|(\%) \\
e_{x}\end{array}$ \\
\hline$\overline{0}$ & 0,90 & 1,40 & 0,85 & 1,20 & 2,04 & 3,22 & 2,12 & 2,87 \\
\hline 1 & 0,94 & 1,42 & 0,88 & 1,22 & 2,11 & 3,27 & 2,18 & 2,91 \\
\hline 2 & 0,94 & 1,44 & 0,88 & 1,24 & 2,11 & 3,33 & 2,18 & 2,95 \\
\hline 3 & 0,94 & 1,47 & 0,89 & 1,26 & 2,11 & 3,38 & 2,18 & 2,99 \\
\hline 4 & 0,94 & 1,49 & 0,89 & 1,27 & 2,12 & 3,43 & 2,18 & 3,03 \\
\hline 5 a 9 & 0,94 & 1,51 & 0,89 & 1,29 & 2,12 & 3,49 & 2,19 & 3,07 \\
\hline 10 a 14 & 0,94 & 1,65 & 0,89 & 1,39 & 2,12 & 3,80 & 2,19 & 3,31 \\
\hline 15 a 19 & 0,95 & 1,80 & 0,89 & 1,51 & 2,13 & 4,18 & 2,19 & 3,58 \\
\hline 20 a 24 & 0,96 & 1,99 & 0,89 & 1,65 & 2,16 & 4,62 & 2,20 & 3,89 \\
\hline 25 a 29 & 0,97 & 2,22 & 0,89 & 1,81 & 2,20 & 5,16 & 2,21 & 4,26 \\
\hline 30 a 34 & 0,98 & 2,49 & 0,90 & 2,01 & 2,25 & 5,81 & 2,21 & 4,70 \\
\hline 35 a 39 & 0,99 & 2,82 & 0,90 & 2,27 & 2,29 & 6,59 & 2,22 & 5,23 \\
\hline 40 a 44 & 0,99 & 3,21 & 0,90 & 2,56 & 2,31 & 7,48 & 2,21 & 5,85 \\
\hline 45 a 49 & 0,99 & 3,70 & 0,90 & 2,91 & 2,31 & 8,52 & 2,21 & 6,64 \\
\hline 50 a 54 & 0,97 & 4,26 & 0,89 & 3,32 & 2,24 & 9,62 & 2,18 & 7,54 \\
\hline 55 a 59 & 0,94 & 4,94 & 0,86 & 3,80 & 2,12 & 10,73 & 2,15 & 8,65 \\
\hline 60 a 64 & 0,91 & 5,80 & 0,83 & 4,35 & 1,96 & 11,94 & 2,07 & 9,93 \\
\hline 65 a 69 & 0,86 & 6,74 & 0,77 & 4,92 & 1,74 & 13,01 & 1,98 & 11,55 \\
\hline 70 a 74 & 0,81 & 7,87 & 0,69 & 5,48 & 1,56 & 14,61 & 1,88 & 13,72 \\
\hline 75 a 79 & 0,67 & 8,18 & 0,61 & 6,22 & 1,36 & 16,32 & 1,77 & 16,67 \\
\hline 80 e+ & 0,64 & 9,48 & 0,62 & 8,22 & 1,28 & 20,11 & 1,74 & 21,44 \\
\hline
\end{tabular}


Ao se observarem mais detalhadamente os resultados apresentados (Tabela 26), nota-se que para a capital baiana as diferenças absolutas entre as esperanças de vida real e hipotética são sempre maiores para os homens. Já no Município de São Paulo, o ganho somente é maior para o sexo masculino nas faixas etárias dos 30 aos 54 anos. Em 1970, não era assim, GOTLIEB (1977) mostra que os homens teriam um ganho absoluto na EV, maior que as mulheres, em todas as faixas etárias, caso essas doenças fossem eliminadas como causa de óbito na população paulistana. Com relação ao ganho relativo, é sempre maior para os homens, nas duas capitais, com exceção para a população paulistana de 75 anos e mais.

Isto leva a crer que está se dando uma mudança no comportamento deste grupo de doenças com relação ao sexo, onde as mulheres começam a ser mais afetadas, mais precocemente, possivelmente em decorrência do hábito de fumar e sua participação mais presente no mercado de trabalho, com conseqüente aumento no nivel de estresse, e diminuição de atividade fisica.

\subsubsection{Eliminando o grupo das doenças cerebrovasculares}

De comportamento epidemiológico diferente, segundo sexo e grupos etários, quando comparadas ao das doenças isquêmicas do coração, as cerebrovasculares têm um peso maior para o Município de Salvador do que para São Paulo (Figura 12). Tal comportamento era esperado, pois a mortalidade por este tipo de agravo é maior do que o referente às doenças isquêmicas do coração quanto menos desenvolvida é a área, em termos de saúde pública (Figura 15).

$\mathrm{Na}$ comparação entre os sexos, a proporção de óbitos masculinos por estas doenças, na capital paulista, representa 50,36\% (41,66\% em Salvador), no entanto, o seu impacto maior é no sexo feminino, para ambos os municípios, onde representa, respectivamente, $7,14 \%$ e $10,44 \%$ do total de óbitos masculinos e femininos (São Paulo Capital) e 7,39\% (homens) e 12,01\% (mulheres) - Salvador.

Observa-se que, em todas as faixas etárias, existiria um ganho absoluto maior na EV feminina em relação a masculina em ambos os municípios estudados. De um modo geral, em termos relativos, isto também é assim e, em Salvador, os potenciais 
incrementos na EV são sempre maiores que os seus correspondentes aumentos na capital paulista (Tabela 27).

FIGURA 15 - Distribuição proporcional (\%) dos óbitos por doenças cerebrovasculares, segundo sexo e faixa etária. Municípios de Salvador e São Paulo, 1996.

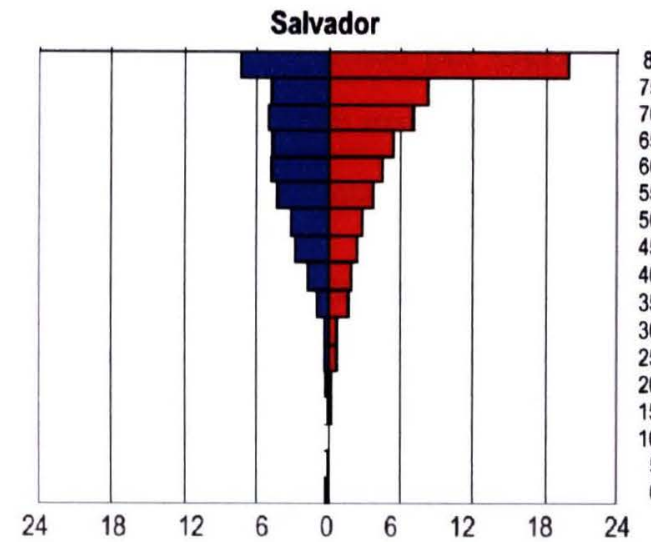

(\%)

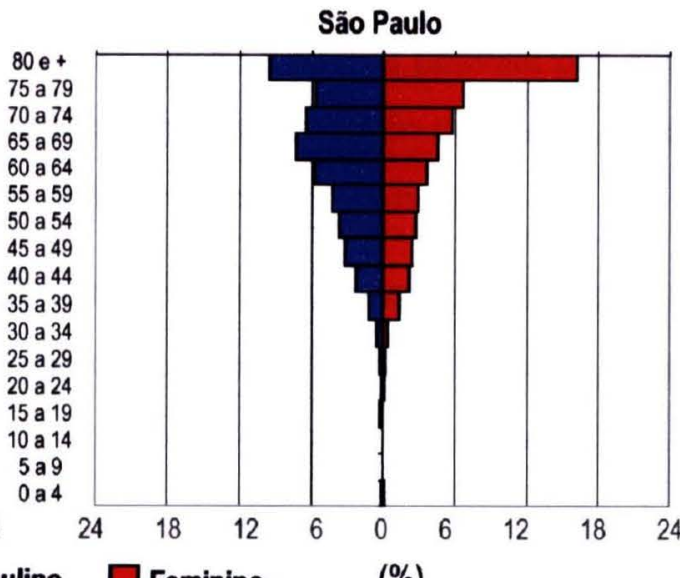

(\%)

TABELA 27 - Comparação entre as esperanças de vida real $\left(e_{\mathrm{X}}\right)$ e hipotética ( $\mathrm{e}_{\mathrm{X}}$.), eliminando as doenças cerebrovasculares como fator de risco de morte, segundo sexo e idade, dos residentes dos Municípios de Salvador (BA) e São Paulo (SP), 1996.

\begin{tabular}{|c|c|c|c|c|c|c|c|c|}
\hline \multirow{3}{*}{$\begin{array}{l}\text { Idade } \\
\text { (anos) }\end{array}$} & \multicolumn{4}{|c|}{ Salvador } & \multicolumn{4}{|c|}{ São Paulo } \\
\hline & \multicolumn{2}{|c|}{ Masculino } & \multicolumn{2}{|c|}{ Feminino } & \multicolumn{2}{|c|}{ Masculino } & \multicolumn{2}{|c|}{ Feminino } \\
\hline & $\left|e_{x}-e_{x}\right| \mid$ & $\begin{array}{c}\mid e_{x}-e_{x} d(\%) \\
e_{x}\end{array}$ & $\left|e_{x}-e_{x}\right|$ & $\begin{array}{c}\left\lfloor e_{x}-e_{x}\right\rfloor(\%) \\
e_{x}\end{array}$ & $\left|e_{x}-e_{x}\right|$ & 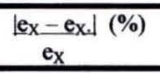 & $\left|e_{x}-e_{x}\right|$ & $\begin{array}{c}\frac{\mid e_{x}-e_{x}}{e_{x}}(\%) \\
e_{x}\end{array}$ \\
\hline$\overline{0}$ & 1,29 & 2,01 & 1,92 & 2,73 & 1,16 & 1,83 & 1,60 & 2,16 \\
\hline 1 & 1,34 & 2,04 & 2,00 & 2,77 & 1,19 & 1,85 & 1,63 & 2,18 \\
\hline 2 & 1,34 & 2,07 & 2,00 & 2,81 & 1,19 & 1,87 & 1,64 & 2,21 \\
\hline 3 & 1,34 & 2,10 & 2,01 & 2,85 & 1,19 & 1,90 & 1,64 & 2,24 \\
\hline 4 & 1,34 & 2,13 & 2,01 & 2,89 & 1,19 & 1,94 & 1,64 & 2,27 \\
\hline 5 a 9 & 1,34 & 2,16 & 2,01 & 2,93 & 1,19 & 1,97 & 1,64 & 2,31 \\
\hline 10 a 14 & 1,35 & 2,35 & 2,01 & 3,16 & 1,19 & 2,14 & 1,64 & 2,48 \\
\hline 15 a 19 & 1,35 & 2,57 & 2,02 & 3,43 & 1,20 & 2,35 & 1,64 & 2,68 \\
\hline 20 a 24 & 1,36 & 2,84 & 2,02 & 3,74 & 1,21 & 2,59 & 1,65 & 2,91 \\
\hline 25 a 29 & 1,38 & 3,15 & 2,02 & 4,10 & 1,23 & 2,89 & 1,65 & 3,18 \\
\hline 30 a 34 & 1,40 & 3,53 & 2,01 & 4,52 & 1,26 & 3,25 & 1,65 & 3,50 \\
\hline 35 a 39 & 1,41 & 4,01 & 2,01 & 5,04 & 1,28 & 3,68 & 1,65 & 3,89 \\
\hline 40 a 44 & 1,41 & 4,57 & 1,98 & 5,61 & 1,29 & 4,18 & 1,63 & 4,30 \\
\hline 45 a 49 & 1,40 & 5,23 & 1,95 & 6,32 & 1,28 & 4,72 & 1,58 & 4,75 \\
\hline 50 a 54 & 1,36 & 5,96 & 1,92 & 7,17 & 1,24 & 5,31 & 1,53 & 5,28 \\
\hline 55 a 59 & 1,30 & 6,82 & 1,87 & 8,23 & 1,19 & 6,02 & 1,47 & 5,91 \\
\hline 60 a 64 & 1,21 & 7,66 & 1,80 & 9,48 & 1,13 & 6,91 & 1,41 & 6,76 \\
\hline 65 a 69 & 1,11 & 8,66 & 1,74 & 11,19 & 1,05 & 7,83 & 1,35 & 7,90 \\
\hline 70 a 74 & 1,05 & 10,22 & 1,72 & 13,69 & 0,94 & 8,83 & 1,31 & 9,57 \\
\hline 75 a 79 & 1,01 & 12,30 & 1,65 & 16,84 & 0,88 & 10,64 & 1,26 & 11,87 \\
\hline 80 e+ & 0,97 & 14,33 & 1,56 & 20,65 & 0,87 & 13,73 & 1,22 & 15,08 \\
\hline
\end{tabular}


A probabilidade de um indivíduo de 15 anos chegar aos 65 anos, caso as doenças cerebrovasculares não fossem causa de óbito, seria de 66,02\% (em vez de $63,31 \%$ ) para os homens e $78,75 \%$ (em vez de 76,33\%) para as mulheres de Salvador e $62,32 \%$ (em vez de $60,09 \%$ ) para os homens e $82,79 \%$ (em vez de $80,98 \%$ ) para as mulheres de São Paulo, em 1996. Estes resultados mantêm perfeita concordância com o que foi apresentado por GOTLIEB (1977) para a capital paulista nos anos 70, onde os homens teriam um ganho percentual um pouco maior do que as mulheres (de $61,87 \%$ para $65 \%$ homens e de $77,29 \%$ para $80,03 \%$ para as mulheres).

$\mathrm{O}$ aumento progressivo nos ganhos relativos da EV concomitantemente ao da idade demonstra o caráter deste grupo de doenças, como importante causa de morte nas idades avançadas (mais de $10 \%$ de diferença na EV a partir dos 75 anos).

Na medida em que ainda é impossível a eliminação total das doenças do aparelho circulatório como causa de óbito, dadas as condições tecnológicas atuais, vale a pena dizer que, de 1970 para 1996, foi possível reduzir significativamente o impacto deste grupo de doenças na EVN, pois, naquela época, em São Paulo, a total eliminação deste grupo de doenças como causa de morte implicaria num ganho de 9,14 anos na EVN masculina e de 11,44 anos na feminina. Em 1996, estes valores mudaram para 6,23 anos e 9,26 anos respectivamente. Tal redução deve refletir possível diminuição da incidência de casos, a melhor eficiência dos tratamentos (clínicos e ou cirúrgicos), fazendo com que a morte seja posposta no tempo.

A exemplo do que acontece com as neoplasias, não pode ser omitido que a prevenção da doença ainda é a melhor solução para a sua redução. $O$ hábito de fumar, o sedentarismo, a obesidade, o consumo de certos tipos de gordura e alimentos e o estresse são alguns dos principais fatores de risco que, ao serem controlados, têm forte impacto na diminuição das doenças do aparelho circulatório. Entretanto, esta não é uma tarefa simples, dada a relutância do ser humano em aceitar a disciplina exigida para evitar fatores de risco (GOTLIEB 1977).

No nível secundário de prevenção, estão o diagnóstico e tratamento precoces, isto é, prolongar a sobrevivência do indivíduo, dado que a doença exista. Neste sentido, muito já se avançou com o desenvolvimento de novos aparelhos, modernas técnicas de cirurgia e com a descoberta de novos medicamentos. A tendência é de 
que a assistência médica altamente especializada (que tais procedimentos exigem), seja disponível em maior amplitude, dada a importância que as doenças do aparelho circulatório têm na morbi-mortalidade da população mundial.

Neste sentido, a criação do SUS e a sua completa implantação são fundamentais para garantir uma assistência médica de qualidade sem discriminações. Assim, uma parcela importante da população, que estava fadada a morrer sem assistência médica, passa a ter assegurado o seu direito à vida através do acesso a uma assistência médica mais sofisticada.

\subsubsection{Eliminando o grupo das doenças do aparelho respiratório}

As doenças do aparelho respiratório compreendem as seguintes enfermidades: influenza ou gripe, pneumonia, outras infecções agudas das vias aéreas inferiores, doenças crônicas das vias aéreas inferiores e o restante das doenças do aparelho respiratório. Entre as principais causas de morte das doenças do aparelho respiratório, estão as pneumonias e as doenças crônicas das vias aéreas inferiores, sendo a asma o seu principal representante. De caráter transmissível ou com sintomas provocados por agentes externos e ambientais, este grupo de doenças costuma ser associado às doenças infecciosas e parasitárias nas análises epidemiológicas, notadamente as que envolvem estudos sobre a transição epidemiológica de populações (Figura 16).

FIGURA 16 - Coeficiente de mortalidade (100.000 habitantes) por doenças do aparelho respiratório, segundo subgrupos de causa (CID10-BR) e sexo. Municípios de Salvador e São Paulo, 1996.

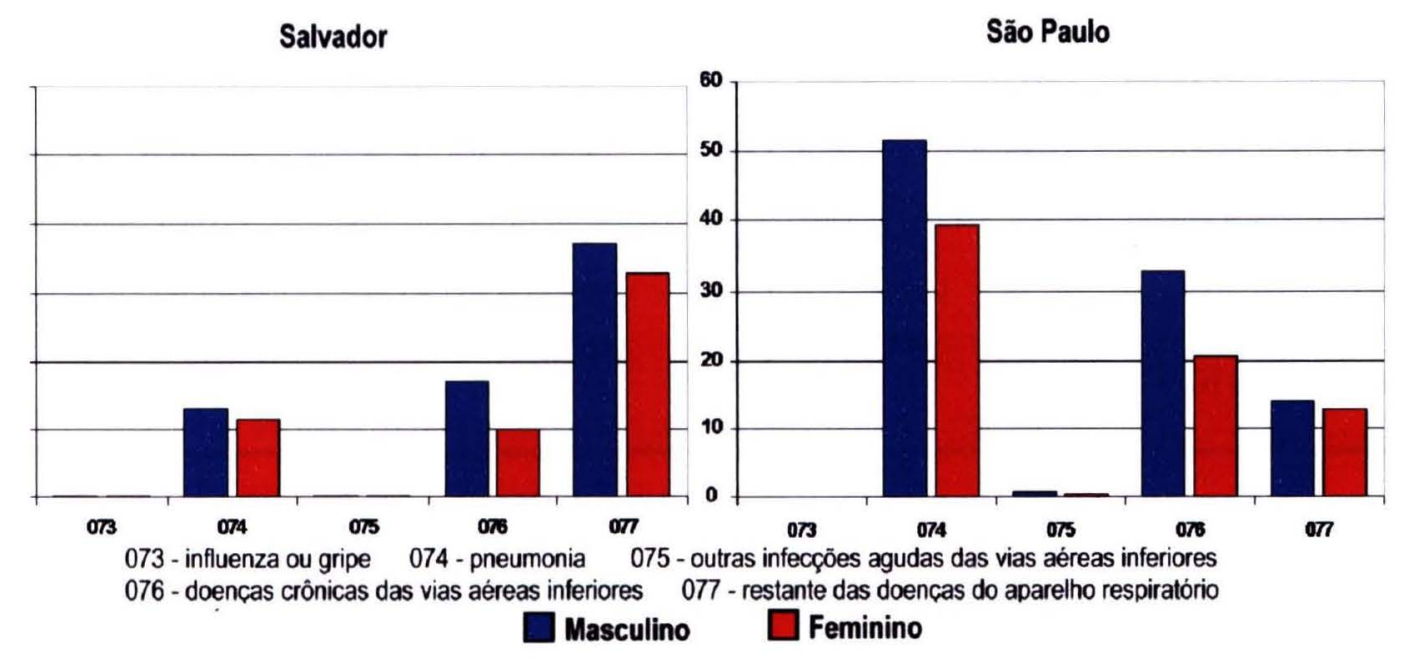


FIGURA 17 - Distribuição proporcional (\%) dos óbitos por doenças do aparelho respiratório, segundo sexo e faixa etária. Municípios de Salvador e São Paulo, 1996.

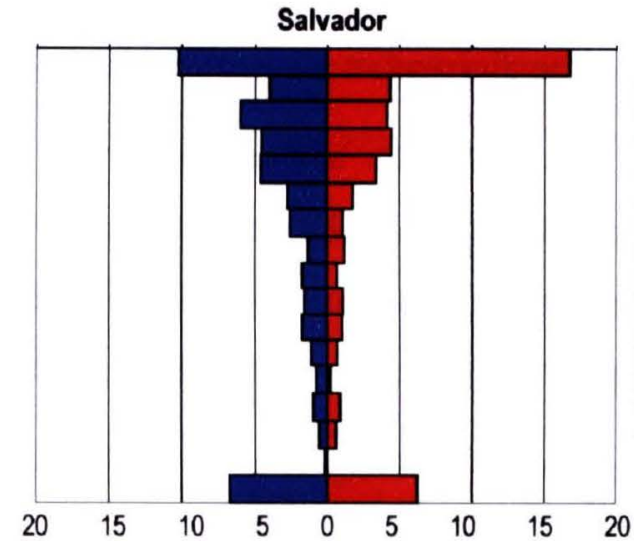

$(\%)$

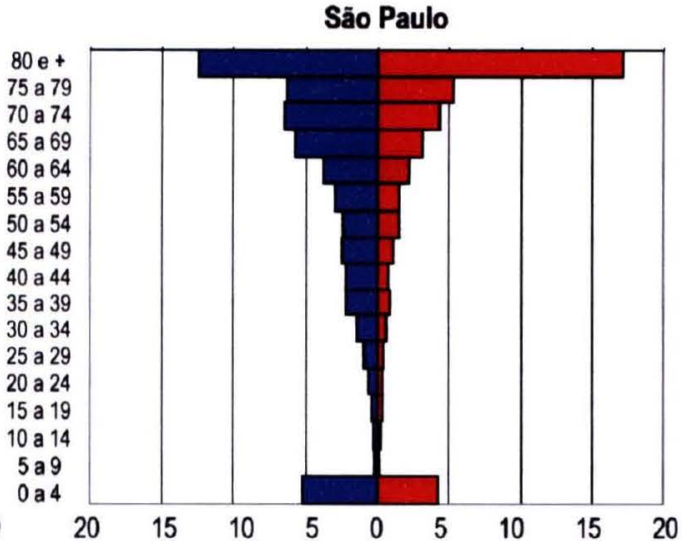

(\%)

TABELA 28 - Comparação entre as probabilidades de morte real $\left(q_{\mathrm{X}}\right)$ e líquida ( $\left.\mathrm{q}_{\mathrm{x} .}\right)$, eliminando as doenças do aparelho respiratório como fator de risco de morte, segundo sexo e idade, dos residentes dos Municípios de Salvador (BA) e São Paulo (SP), 1996.

\begin{tabular}{|c|c|c|c|c|c|c|c|c|}
\hline \multirow{3}{*}{$\begin{array}{l}\text { Idade } \\
\text { (anos) }\end{array}$} & \multicolumn{4}{|c|}{ Salvador } & \multicolumn{4}{|c|}{ São Paulo } \\
\hline & \multicolumn{2}{|c|}{ Masculino } & \multicolumn{2}{|c|}{ Feminino } & \multicolumn{2}{|c|}{ Masculino } & \multicolumn{2}{|c|}{ Feminino } \\
\hline & $\left|q_{x}-q_{x}\right| \mid$ & 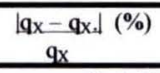 & $\left|\mathbf{q}_{\mathrm{x}}-\mathbf{q}_{\mathrm{x}-\mid}\right|$ & $\frac{\left.\mid \mathbf{g}_{\mathrm{x}}-\mathbf{q}_{\mathrm{x}}\right\rfloor(\%)}{\mathbf{q}_{\mathrm{x}}}$ & $\left|\mathbf{q}_{\mathrm{x}}-\mathbf{q}_{\mathrm{x}}\right| \mid$ & $\begin{array}{c}\left.\mid q_{x}-q_{x}\right\rfloor(\%) \\
q_{x}\end{array}$ & $\left|\mathbf{q}_{\mathrm{x}}-\mathbf{q}_{\mathrm{x}}-\right|$ & $\frac{\mid q_{x}-q_{x} \downarrow}{q_{x}}$ \\
\hline 0 & 0,00396 & 9,95 & 0,00331 & 8,33 & 0,00415 & 13,62 & 0,00342 & 13,66 \\
\hline 1 & 0,00042 & 14,80 & 0,00116 & 37,46 & 0,00065 & 33,31 & 0,00062 & 30,17 \\
\hline 2 & 0,00041 & 25,79 & 0,00031 & 20,68 & 0,00021 & 22,66 & 0,00017 & 16,24 \\
\hline 3 & 0,00005 & 5,55 & 0,00005 & 5,26 & 0,00009 & 11,86 & 0,00010 & 17,39 \\
\hline 4 & 0,00015 & 23,07 & 0,00016 & 29,99 & 0,00004 & 8,33 & 0,00005 & 14,81 \\
\hline 5 a 9 & 0,00005 & 1,78 & 0,00000 & 0,00 & 0,00019 & 8,37 & 0,00019 & 11,42 \\
\hline 10 a 14 & 0,00032 & 10,65 & 0,00036 & 12,84 & 0,00022 & 6,59 & 0,00022 & 10,69 \\
\hline 15 a 19 & 0,00055 & 4,83 & 0,00050 & 15,53 & 0,00036 & 2,47 & 0,00032 & 9,86 \\
\hline 20 a 24 & 0,00051 & 3,05 & 0,00012 & 4,47 & 0,00052 & 2,41 & 0,00032 & 7,23 \\
\hline 25 a 29 & 0,00083 & 5,10 & 0,00050 & 8,78 & 0,00083 & 3,10 & 0,00043 & 7,63 \\
\hline 30 a 34 & 0,00138 & 7,56 & 0,00072 & 9,71 & 0,00144 & 5,02 & 0,00061 & 8,08 \\
\hline 35 a 39 & 0,00145 & 6,25 & 0,00093 & 7,65 & 0,00236 & 7,06 & 0,00089 & 8,26 \\
\hline 40 a 44 & 0,00191 & 6,45 & 0,00074 & 4,05 & 0,00269 & 7,01 & 0,00095 & 7,26 \\
\hline 45 a 49 & 0,00190 & 4,88 & 0,00169 & 6,15 & 0,00393 & 8,26 & 0,00156 & 7,44 \\
\hline 50 a 54 & 0,00515 & 8,56 & 0,00200 & 5,04 & 0,00486 & 7,49 & 0,00272 & 8,80 \\
\hline 55 a 59 & 0,00736 & 8,16 & 0,00381 & 6,20 & 0,00735 & 8,35 & 0,00345 & 7,60 \\
\hline 60 a 64 & 0,01572 & 11,70 & 0,00872 & 10,27 & 0,01123 & 8,88 & 0,00570 & 8,77 \\
\hline 65 a 69 & 0,02009 & 10,34 & 0,01364 & 10,32 & 0,02049 & 11,79 & 0,00936 & 9,93 \\
\hline 70 a 74 & 0,03457 & 12,64 & 0,01694 & 9,34 & 0,03195 & 13,20 & 0,01663 & 11,19 \\
\hline 75 a 79 & 0,03721 & 9,84 & 0,02512 & 9,10 & 0,04991 & 14,51 & 0,03010 & 12,85 \\
\hline 80 et & - & - & - & - & - & - & - & 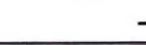 \\
\hline
\end{tabular}

A idéia básica que está por detrás disso é que as doenças infecciosas e parasitárias e as doenças do aparelho respiratório tendem a desaparecer, à medida 
que problemas de saneamento e atenção básica à saúde são resolvidos. Na prática, estas doenças são mais prevalentes/incidentes em populações com piores condições sociais. Já as neoplasias, as doenças do aparelho circulatório e as causas externas são típicas do processo de industrialização e urbanização.

De fato, há de se concordar que as primeiras mencionadas apresentam semelhante estrutura de mortalidade e com uma importante influência, na faixa etária de menores de cinco anos (Figuras 2 e 17), que fica ainda mais acentuada se a Aids for excluída das doenças infecciosas e parasitárias.

TABELA 29 - Comparação entre as probabilidades de sobreviver real (pox) e hipotética ( $p_{o x}$ ), eliminando as doenças do aparelho respiratório como fator de risco de morte, segundo sexo e idade, dos residentes dos Municípios de Salvador (BA) e São Paulo (SP), 1996.

\begin{tabular}{lrrrr|rrrr}
\hline & \multicolumn{4}{c|}{ Salvador } & \multicolumn{4}{c}{ São Paulo } \\
\cline { 2 - 9 } Idade \\
\cline { 2 - 9 } (anos)
\end{tabular}

Comparando as probabilidades de morte real e líquida, eliminando-se as doenças do aparelho respiratório, para os Municípios de Salvador e São Paulo, no ano de 1996, observa-se que os ganhos absolutos são maiores na população masculina, em ambos os municípios (Tabela 28). 
$\mathrm{Na}$ ausência deste grupo de doenças, haveria uma redução de $37,46 \%$ na probabilidade de morte de meninas de um ano de idade em Salvador e 30,17\% em São Paulo. Menores de cinco anos teriam suas chances de sobrevivência significativamente aumentadas, com a eliminação destas causas de óbito. A população da terceira idade também seria beneficiada grandemente com tal situação. A probabilidade de sobreviver, do nascimento até os 80 anos (Tabela 29), estaria aumentada de 19,13\%/20,12\% (homens) e 10,14/9,49\% (mulheres) de Salvador/São Paulo.

TABELA 30 - Comparação entre as esperanças de vida real (e $\left.e_{\mathbf{X}}\right)$ e hipotética (ex.), eliminando as doenças do aparelho respiratório como fator de risco de morte, segundo sexo e idade, dos residentes dos Municípios de Salvador (BA) e São Paulo (SP), 1996.

\begin{tabular}{|c|c|c|c|c|c|c|c|c|}
\hline \multirow{3}{*}{$\begin{array}{l}\text { Idade } \\
\text { (anos) }\end{array}$} & \multicolumn{4}{|c|}{ Salvador } & \multicolumn{4}{|c|}{ São Paulo } \\
\hline & \multicolumn{2}{|c|}{ Masculino } & \multicolumn{2}{|c|}{ Feminino } & \multicolumn{2}{|c|}{ Masculino } & \multicolumn{2}{|c|}{ Feminino } \\
\hline & $\left|e_{x}-e_{x}\right|$ & 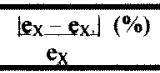 & $\left|e_{x}-e_{x}\right|$ & $\begin{array}{c}\left.\mid e_{x}-e_{x}\right\rfloor(\%) \\
e_{x}\end{array}$ & $\left|e_{x}-e_{x}\right|$ & $\begin{array}{c}\left|e_{x}-e_{x}\right|(\%) \\
e_{x}\end{array}$ & $\left|e_{x}-e_{x}\right|$ & $\underset{\left|e_{x}-e_{x}\right|(\%)}{e_{x}}$ \\
\hline$\overline{0}$ & 1,89 & 2,95 & 1,81 & 2,57 & 2,02 & 3,19 & 2,22 & 3,01 \\
\hline 1 & 1,69 & 2,57 & 1,63 & 2,25 & 1,80 & 2,79 & 2,01 & 2,68 \\
\hline 2 & 1,66 & 2,56 & 1,55 & 2,16 & 1,76 & 2,77 & 1,96 & 2,65 \\
\hline 3 & 1,64 & 2,56 & 1,53 & 2,16 & 1,75 & 2,79 & 1,95 & 2,67 \\
\hline 4 & 1,64 & 2,60 & 1,52 & 2,19 & 1,74 & 2,83 & 1,95 & 2,70 \\
\hline 5 a 9 & 1,63 & 2,62 & 1,51 & 2,20 & 1,74 & 2,87 & 1,94 & 2,73 \\
\hline 10 a 14 & 1,63 & 2,85 & 1,52 & 2,38 & 1,73 & 3,11 & 1,93 & 2,92 \\
\hline 15 a 19 & 1,62 & 3,08 & 1,50 & 2,54 & 1,73 & 3,39 & 1,92 & 3,13 \\
\hline 20 a 24 & 1,61 & 3,35 & 1,47 & 2,72 & 1,74 & 3,72 & 1,91 & 3,38 \\
\hline 25 a 29 & 1,61 & 3,68 & 1,47 & 2,99 & 1,75 & 4,10 & 1,90 & 3,67 \\
\hline 30 a 34 & 1,60 & 4,05 & 1,46 & 3,27 & 1,76 & 4,54 & 1,89 & 4,01 \\
\hline 35 a 39 & 1,57 & 4,47 & 1,43 & 3,60 & 1,75 & 5,04 & 1,87 & 4,42 \\
\hline 40 a 44 & 1,56 & 5,04 & 1,42 & 4,01 & 1,73 & 5,59 & 1,86 & 4,91 \\
\hline 45 a 49 & 1,55 & 5,76 & 1,42 & 4,58 & 1,71 & 6,32 & 1,85 & 5,54 \\
\hline 50 a 54 & 1,56 & 6,82 & 1,40 & 5,25 & 1,68 & 7,22 & 1,83 & 6,32 \\
\hline 55 a 59 & 1,53 & 8,00 & 1,40 & 6,19 & 1,67 & 8,49 & 1,81 & 7,29 \\
\hline 60 a 64 & 1,52 & 9,65 & 1,40 & 7,37 & 1,67 & 10,19 & 1,80 & 8,64 \\
\hline 65 a 69 & 1,45 & 11,33 & 1,35 & 8,66 & 1,69 & 12,58 & 1,80 & 10,49 \\
\hline 70 a 74 & 1,45 & 14,03 & 1,30 & 10,33 & 1,67 & 15,64 & 1,80 & 13,16 \\
\hline 75 a 79 & 1,41 & 17,12 & 1,30 & 13,32 & 1,68 & 20,21 & 1,82 & 17,16 \\
\hline $80 \mathrm{e}^{+}$ & 1,62 & 24,04 & 1,40 & 18,55 & 1,75 & 27,56 & 1,89 & 23,31 \\
\hline
\end{tabular}

A EVN com a eliminação desse grupo de causas seria de 65,99 anos/65,41 anos (homens) e 72,14 anos/76,14 anos (mulheres), respectivamente para Salvador e São Paulo (Anexos 37, 38, 39 e 40). O ganho absoluto, na EV, é maior para os homens de Salvador e para as mulheres de São Paulo; quanto ao ganho relativo, este é sempre maior para os homens, independentemente do município estudado (Tabela $30)$. 
A probabilidade de um individuo de 15 anos chegar aos 65 anos, caso as doenças do aparelho respiratório não fossem causa de óbito, seria de $65,92 \%$ (em vez de $63,31 \%$ ) para os homens de Salvador, de $77,94 \%$ (em vez de $76,33 \%$ ) para as mulheres da capital baiana, de 62,45\% (em vez de 60,09\%) para os homens de São Paulo e de $82,42 \%$ (em vez de $\mathbf{8 0 , 9 8 \%}$ ) para as mulheres da capital paulista. $O$ que demonstra um impacto maior na faixa etária produtiva masculina dos dois municípios. Quanto aos APVG (Tabela 31), estes se encontram em um valor intermediário entre os APVG com a eliminação das doenças infecciosas e parasitárias (Tabela 14) e os obtidos com a eliminação das neoplasias (Tabela 21).

TABELA 31 - Comparação entre os totais de anos vividos além de $X$ real $\left(T_{X}\right)$ e hipotético $\left(\mathrm{T}_{\mathrm{X}}\right.$ ) (Anos Potenciais de Vida Ganhos - APVG), eliminando as doenças do aparelho respiratório como fator de risco de morte, segundo sexo e idade, dos residentes dos Municípios de Salvador (BA) e São Paulo (SP), 1996.

\begin{tabular}{|c|c|c|c|c|c|c|c|c|}
\hline \multirow{3}{*}{$\begin{array}{l}\text { Idade } \\
\text { (anos) }\end{array}$} & \multicolumn{4}{|c|}{ Salvador } & \multicolumn{4}{|c|}{ São Paulo } \\
\hline & \multicolumn{2}{|c|}{ Masculino } & \multicolumn{2}{|c|}{ Feminino } & \multicolumn{2}{|c|}{ Masculino } & \multicolumn{2}{|c|}{ Feminino } \\
\hline & $\left|T_{x}-T_{x} \cdot\right|$ & $\begin{array}{c}\left|T_{x} \in T_{x}\right|(\%) \\
T_{X}\end{array}$ & $\left|\mathrm{~T}_{\mathbf{x}}-\mathrm{T}_{\mathbf{x}}\right|$ & $\begin{array}{c}\left.T_{x}-T_{x}\right\rfloor(\%) \\
T_{x} \\
\end{array}$ & $\left|T_{x}-T_{x}\right|$ & $\frac{\left[T_{x}-T_{x}\right](\%)}{T_{x}}$ & $\mid T_{x}-T_{x} \|$ & $\frac{\left.T_{x}-T_{x}\right\rfloor}{T_{X}}(\%)$ \\
\hline 0 & 189.140 & 2,95 & 180.942 & 2,57 & 202.261 & 3,19 & 222.249 & 3,01 \\
\hline 1 & 188.799 & 2,99 & 180.669 & 2,60 & 201.903 & 3,24 & 221.967 & 3,04 \\
\hline 2 & 188.375 & 3,03 & 180.261 & 2,64 & 201.443 & 3,28 & 221.583 & 3,08 \\
\hline 3 & 187.921 & 3,07 & 179.805 & 2,67 & 200.956 & 3,32 & 221.173 & 3,12 \\
\hline 4 & 187.445 & 3,11 & 179.332 & 2,70 & 200.454 & 3,37 & 220.750 & 3,15 \\
\hline 5 a 9 & 186.959 & 3,15 & 178.849 & 2,73 & 199.946 & 3,42 & 220.320 & 3,19 \\
\hline 10 a 14 & 184.488 & 3,38 & 176.400 & 2,90 & 197.357 & 3,67 & 218.113 & 3,40 \\
\hline 15 a 19 & 181.934 & 3,65 & 173.871 & 3,10 & 194.677 & 3,98 & 215.810 & 3,64 \\
\hline 20 a 24 & 179.193 & 3,98 & 171.146 & 3,34 & 191.881 & 4,35 & 213.383 & 3,91 \\
\hline 25 a 29 & 176.240 & 4,36 & 168.280 & 3,62 & 188.925 & 4,79 & 210.810 & 4,24 \\
\hline 30 a 34 & 173.023 & 4,83 & 165.281 & 3,95 & 185.724 & 5,32 & 208.068 & 4,63 \\
\hline 35 a 39 & 169.353 & 5,40 & 162.013 & 4,36 & 182.092 & 5,98 & 205.096 & 5,10 \\
\hline 40 a 44 & 165.117 & 6,13 & 158.391 & 4,87 & 177.724 & 6,79 & 201.793 & 5,69 \\
\hline 45 a 49 & 160.248 & 7,07 & 154.435 & 5,53 & 172.416 & 7,83 & 198.094 & 6,43 \\
\hline 50 a 54 & 154.720 & 8,36 & 150.013 & 6,39 & 165.952 & 9,20 & 193.872 & 7,39 \\
\hline 55 a 59 & 148.004 & 10,15 & 144.912 & 7,56 & 158.088 & 11,06 & 188.777 & 8,67 \\
\hline 60 a 64 & 139.315 & 12,74 & 138.814 & 9,20 & 148.512 & 13,72 & 182.492 & 10,44 \\
\hline 65 a 69 & 127.389 & 16,54 & 130.596 & 11,57 & 136.707 & 17,68 & 174.580 & 13,00 \\
\hline 70 a 74 & 111.524 & 22,35 & 119.009 & 15,06 & 121.699 & 23,87 & 164.223 & 16,93 \\
\hline 75 a 79 & 91.793 & 31,65 & 103.966 & 20,62 & 102.709 & 34,19 & 150.239 & 23,42 \\
\hline 80 et & 70.433 & 47,76 & 86.213 & 30,56 & 80.274 & 53,23 & 131.188 & 35,01 \\
\hline
\end{tabular}




\subsubsection{Eliminando o grupo das causas externas de morbidade e mortalidade}

A mortalidade por causas externas merece especial atenção em função do preocupante aumento gradativo da sua ocorrência em todo o mundo. É uma das principais causas de mortalidade no Brasil que, no início da década de 80 , contribuía com cerca de $9 \%$ do total de mortes. Esse percentual elevou-se para 12,3\% em 1990 ( $37 \%$ de aumento), e a taxa de mortalidade, por estas causas, elevou-se de 59 para 70 óbitos por cem mil habitantes neste mesmo período (César e Rodrigues 1998).

Em importância, representa o segundo grupo de causas de morte para a população masculina em todo o Brasil e em todas as grandes regiões, com exceção da Região Norte, onde é o primeiro, desde meados dos anos 80 (MELLO JORGE e GOTLIEB 2000).

Tanto a sobremortalidade masculina como a forte concentração, nas idades jovens, ficam evidenciadas nos dados de Salvador e São Paulo (Figura 18), acompanhando o comportamento típico deste grupo de causas de óbito, não só no Brasil, mas em todo o mundo.

FIGURA 18 - Distribuição proporcional (\%) dos óbitos por causas externas, segundo sexo e faixa etária. Municípios de Salvador e São Paulo, 1996.

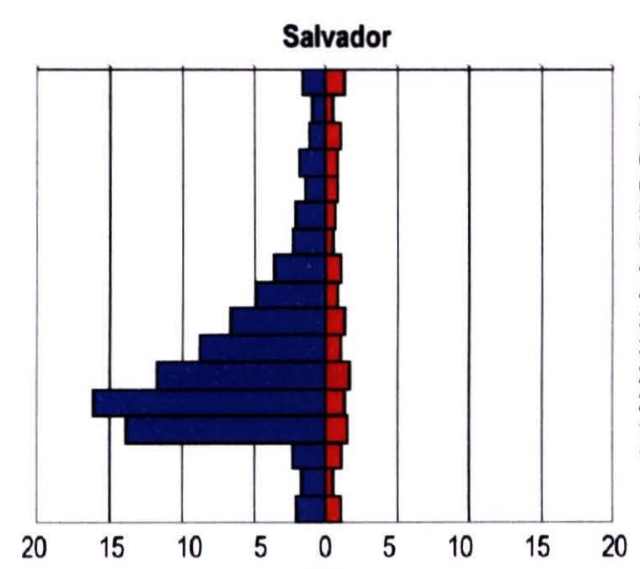

$(\%)$

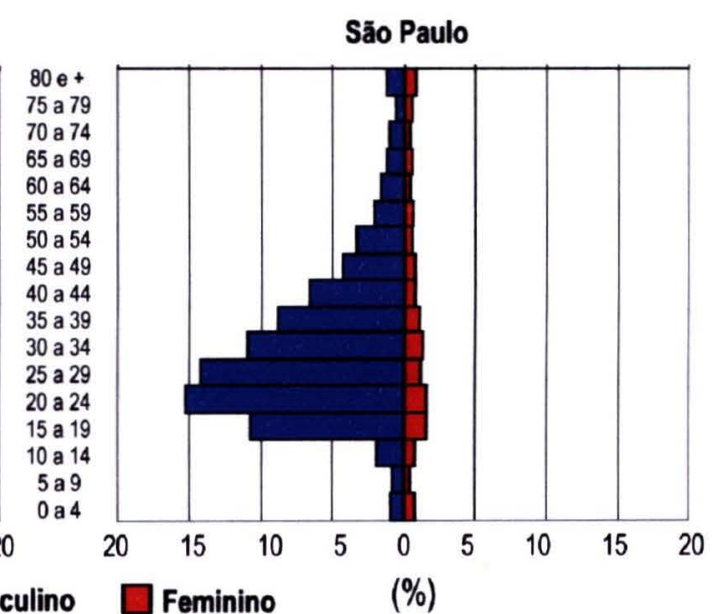

(\%)

Fica evidenciado o impacto diferencial, por sexo, ao serem analisadas as probabilidades de morte real e hipotética (na ausência das causas externas como risco) para ambos os municípios estudados (Tabela 32). No sexo masculino, a probabilidade de morrer na idade de um ano estaria reduzida em 12,95\% e 10,89\% 
para os municípios de Salvador e São Paulo respectivamente. Para se ter uma idéia de como cresceu o impacto deste tipo de causa na mortalidade da população de São Paulo, em 1970, este valor era de 5,01\% (GOTLIEB 1977). Este aumento, provavelmente, é decorrente da diminuição das outras causas de morte e do crescimento da violência nas capitais.

TABELA 32 - Comparação entre as probabilidades de morte real $\left(q_{x}\right)$ e líquida $\left(q_{x}.\right)$, eliminando as causas externas como fator de risco de morte, segundo sexo e idade, dos residentes dos Municípios de Salvador (BA) e São Paulo (SP), 1996.

\begin{tabular}{|c|c|c|c|c|c|c|c|c|}
\hline \multirow{3}{*}{$\begin{array}{l}\text { Idade } \\
\text { (anos) }\end{array}$} & \multicolumn{4}{|c|}{ Salvador } & \multicolumn{4}{|c|}{ São Paulo } \\
\hline & \multicolumn{2}{|c|}{ Masculino } & \multicolumn{2}{|c|}{ Feminino } & \multicolumn{2}{|c|}{ Masculino } & \multicolumn{2}{|c|}{ Feminino } \\
\hline & $\left|q_{x}-q_{x}\right|$ & $\begin{array}{c}9 x-9 x \mid(\%) \\
9 x\end{array}$ & $\left|q_{x}-q_{x}\right|$ & $\begin{array}{c}\left|9 x-9 x_{1}\right|(\%) \\
9 x\end{array}$ & $\left|q_{x}-q_{x}\right|$ & $\frac{|9 x-9 x|(\%)}{9 x}$ & $|9 x-9 x|$ & $\begin{array}{c}|q x-q x|(\%) \\
q x\end{array}$ \\
\hline 0 & 0,00031 & 0,77 & 0,00022 & 0,55 & 0,00043 & 1,42 & 0,00046 & 1,85 \\
\hline 1 & 0,00037 & 12,95 & 0,00017 & 5,35 & 0,00021 & 10,89 & 0,00023 & 11,31 \\
\hline 2 & 0,00030 & 19,34 & 0,00016 & 10,34 & 0,00017 & 18,66 & 0,00015 & 14,99 \\
\hline 3 & 0,00010 & 11,11 & 0,00021 & 21,04 & 0,00021 & 28,81 & 0,00015 & 26,08 \\
\hline 4 & 0,00046 & 69,22 & 0,00011 & 20,00 & 0,00018 & 38,88 & 0,00012 & 33,33 \\
\hline 5 a 9 & 0,00140 & 49,97 & 0,00041 & 27,57 & 0,00105 & 46,57 & 0,00060 & 35,69 \\
\hline 10 a 14 & 0,00152 & 50,63 & 0,00071 & 25,69 & 0,00214 & 65,31 & 0,00091 & 44,89 \\
\hline 15 a 19 & 0,00883 & 78,03 & 0,00092 & 28,86 & 0,01268 & 86,08 & 0,00185 & 56,97 \\
\hline 20 a 24 & 0,01219 & 73,30 & 0,00089 & 32,81 & 0,01788 & 83,17 & 0,00182 & 41,30 \\
\hline 25 a 29 & 0,00989 & 60,90 & 0,00122 & 21,55 & 0,01747 & 65,44 & 0,00145 & 25,57 \\
\hline 30 a 34 & 0,00789 & 43,07 & 0,00081 & 11,00 & 0,01427 & 49,59 & 0,00155 & 20,73 \\
\hline 35 a 39 & 0,00684 & 29,43 & 0,00120 & 9,90 & 0,01279 & 38,26 & 0,00140 & 13,07 \\
\hline 40 a 44 & 0,00605 & 20,44 & 0,00087 & 4,79 & 0,01100 & 28,65 & 0,00116 & 8,85 \\
\hline 45 a 49 & 0,00582 & 14,93 & 0,00151 & 5,50 & 0,00881 & 18,51 & 0,00154 & 7,36 \\
\hline 50 a 54 & 0,00515 & 8,56 & 0,00094 & 2,37 & 0,00875 & 13,48 & 0,00138 & 4,47 \\
\hline 55 a 59 & 0,00625 & 6,94 & 0,00161 & 2,62 & 0,00701 & 7,96 & 0,00191 & 4,21 \\
\hline 60 a 64 & 0,00536 & 3,99 & 0,00226 & 2,66 & 0,00632 & 5,00 & 0,00170 & 2,62 \\
\hline 65 a 69 & 0,00877 & 4,51 & 0,00288 & 2,18 & 0,00593 & 3,41 & 0,00206 & 2,19 \\
\hline 70 a 74 & 0,00741 & 2,71 & 0,00469 & 2,58 & 0,00659 & 2,72 & 0,00241 & 1,62 \\
\hline 75 a 79 & 0,01005 & 2,66 & 0,00348 & 1,26 & 0,00604 & 1,76 & 0,00411 & 1,75 \\
\hline $80 \mathrm{e}+$ & - & - & - & & - & - & - & \\
\hline
\end{tabular}

As diferenças relativas são crescentes e atinge o seu ápice na faixa etária de 15 a 19 anos, para ambos os municípios (78,03\% - Salvador e $86,08 \%$ - São Paulo). As reduções se mantêm elevadas para todas as idades da faixa etária economicamente ativa. No sexo feminino, apesar da grande discrepância com os dados relativos aos homens, dado o menor risco de morte das mulheres, as diferenças relativas também apresentam valores consideráveis até os 49 anos.

Quando se considera a probabilidade de sobreviver até os 80 anos completos (Tabela 33), o Municipio de Salvador contaria com 12,57\% a mais de homens 
(contra $2,89 \%$ a mais de mulheres), e São Paulo teria $16,25 \%$ a mais de população masculina (contra 2,96\% a mais da feminina), caso as causas externas não existissem, como causa de óbito, em 1996.

TABELA 33 - Comparação entre as probabilidades de sobreviver real ( $p_{\text {ox }}$ ) e hipotética (pox.), eliminando as causas externas como fator de risco de morte, segundo sexo e idade, dos residentes dos Municípios de Salvador (BA) e São Paulo (SP), 1996.

\begin{tabular}{lrrrr|rrrr}
\hline & \multicolumn{4}{c}{ Salvador } & \multicolumn{4}{c}{ São Paulo } \\
\cline { 2 - 9 } Idade \\
\cline { 2 - 10 } (anos)
\end{tabular}

As tábuas de vida de múltiplo decremento, considerando a exclusão deste grupo específico de causas de óbito (Anexos 41, 42, 43 e 44), apresentam as estimativas da EV. O ganho, na EVN (Tabela 34), seria de 2,86 anos e 4,23 anos para as populações masculinas dos municípios de Salvador e São Paulo respectivamente. As diferenças relativas, em termos de anos ganhos, têm o seu ápice, entre os homens de 15 a 19 anos (respectivamente $5,20 \%$ e $8,12 \%$ ).

A probabilidade de um indivíduo de 15 anos chegar aos 65 anos, caso as causas externas fossem eliminadas como fator de risco de morte, em 1996, seria de $68,38 \%$ (em vez de $63,31 \%$ ) para a população masculina de Salvador, de $77,30 \%$ (em vez de $76,33 \%$ ) para as mulheres deste mesmo município, de $67,83 \%$ (em vez de $60,09 \%$ ) para os homens da capital paulistana e de $82,30 \%$ (em vez de $80,98 \%$ ) para a 
população feminina de São Paulo; representando um ganho percentual de 6,3 vezes maior para a população masculina, em relação ao da população feminina em Salvador, e de 7,9 vezes maior, em São Paulo.

TABELA 34 - Comparação entre as esperanças de vida real $\left(e_{\mathrm{X}}\right)$ e hipotética $\left(e_{\mathrm{X}}\right)$, eliminando as causas externas como fator de risco de morte, segundo sexo e idade, dos residentes dos Municípios de Salvador (BA) e São Paulo (SP), 1996.

\begin{tabular}{|c|c|c|c|c|c|c|c|c|}
\hline \multirow{3}{*}{$\begin{array}{l}\text { Idade } \\
\text { (anos) }\end{array}$} & \multicolumn{4}{|c|}{ Salvador } & \multicolumn{4}{|c|}{ São Paulo } \\
\hline & \multicolumn{2}{|c|}{ Masculino } & \multicolumn{2}{|c|}{ Feminino } & \multicolumn{2}{|c|}{ Masculino } & \multicolumn{2}{|c|}{ Feminino } \\
\hline & $\left|e_{x}-e_{x}\right|$ & $\underset{\left.e_{x}-e_{x}\right]}{e_{x}}(\%)$ & $\left|\mathbf{e}_{\mathbf{x}}-\mathbf{e}_{\mathbf{x}}\right| \mid$ & $\begin{array}{c}\mid \begin{array}{l}\mid e x-e x \\
e_{x}\end{array} \\
\end{array}$ & $\left|e_{x}-e_{x}\right|$ & $\begin{array}{c}\left|e_{x}-e_{x}\right|(\%) \\
e_{x}\end{array}$ & $\left|e_{x}-e_{x}\right|$ & $\begin{array}{c}\left|e_{x}-e_{x}\right|(\%) \\
e_{x}\end{array}$ \\
\hline$\overline{0}$ & 2,86 & 4,46 & $\overline{0,63}$ & 0,90 & 4,23 & 6,68 & 0,89 & 1,20 \\
\hline 1 & 2,95 & 4,49 & 0,64 & 0,89 & 4,34 & 6,73 & 0,87 & 1,17 \\
\hline 2 & 2,94 & 4,52 & 0,63 & 0,88 & 4,33 & 6,82 & 0,86 & 1,16 \\
\hline 3 & 2,92 & 4,56 & 0,62 & 0,88 & 4,32 & 6,91 & 0,85 & 1,16 \\
\hline 4 & 2,91 & 4,62 & 0,61 & 0,87 & 4,31 & 7,00 & 0,84 & 1,16 \\
\hline 5 a 9 & 2,89 & 4,65 & 0,60 & 0,87 & 4,30 & 7,09 & 0,83 & 1,17 \\
\hline 10 a 14 & 2,81 & 4,90 & 0,57 & 0,90 & 4,25 & 7,61 & 0,79 & 1,19 \\
\hline 15 a 19 & 2,73 & 5,20 & 0,53 & 0,90 & 4,14 & 8,12 & 0,73 & 1,19 \\
\hline 20 a 24 & 2,29 & 4,76 & 0,48 & 0,88 & 3,52 & 7,54 & 0,62 & 1,10 \\
\hline 25 a 29 & 1,73 & 3,95 & 0,43 & 0,88 & 2,72 & 6,39 & 0,53 & 1,01 \\
\hline 30 a 34 & 1,32 & 3,35 & 0,38 & 0,85 & 2,02 & 5,22 & 0,46 & 0,97 \\
\hline 35 a 39 & 1,04 & 2,95 & 0,35 & 0,87 & 1,51 & 4,34 & 0,39 & 0,92 \\
\hline 40 a 44 & 0,82 & 2,65 & 0,30 & 0,86 & 1,11 & 3,57 & 0,33 & 0,88 \\
\hline 45 a 49 & 0,66 & 2,46 & 0,28 & 0,90 & 0,80 & 2,97 & 0,30 & 0,89 \\
\hline 50 a 54 & 0,53 & 2,32 & 0,24 & 0,90 & 0,60 & 2,57 & 0,25 & 0,87 \\
\hline 55 a 59 & 0,44 & 2,32 & 0,23 & 1,00 & 0,43 & 2,17 & 0,22 & 0,90 \\
\hline 60 a 64 & 0,36 & 2,28 & 0,20 & 1,07 & 0,32 & 1,96 & 0,19 & 0,89 \\
\hline 65 a 69 & 0,32 & 2,48 & 0,18 & 1,14 & 0,25 & 1,88 & 0,16 & 0,95 \\
\hline 70 a 74 & 0,25 & 2,45 & 0,15 & 1,23 & 0,21 & 1,94 & 0,14 & 1,04 \\
\hline 75 a 79 & 0,24 & 2,85 & 0,12 & 1,20 & 0,18 & 2,15 & 0,13 & 1,22 \\
\hline 80 et & 0,23 & 3,34 & 0,11 & 1,49 & 0,19 & 2,97 & 0,11 & 1,38 \\
\hline
\end{tabular}

Os APVG (Tabela 35) com a exclusão das causas externas são mais representativos para a população da capital paulista de ambos os sexos. Compreenderam pouco mais da metade dos ganhos a serem obtidos com a eliminação das doenças do aparelho circulatório (Tabela 25) e apresentam valores maiores do que quaisquer outras causas estudadas neste trabalho.

Quanto aos subgrupos, as causas externas são habitualmente apresentadas em acidentes de transporte e demais acidentes e as violências propriamente ditas, englobando os suicídios e os homicídios. Na apresentação da CID10-BR, estão assim representados: acidentes de transporte, quedas, afogamentos e submersões acidentais, exposições à fumaça, ao fogo e às chamas, envenenamentos, intoxicação por exposições à substâncias nocivas, lesões autoprovocadas voluntariamente, agressúes, 
eventos (fatos) cuja intenção é indeterminada, intervenções legais e operações de guerra e todas as outras causas externas (Figura 19).

TABELA 35 - Comparação entre os totais de anos vividos além de $\mathrm{X}$ real $\left(\mathrm{T}_{\mathrm{X}}\right)$ e hipotético $\left(\mathrm{T}_{\mathrm{X}}\right.$.) (Anos Potenciais de Vida Ganhos - APVG), eliminando as causas externas como fator de risco de morte, segundo sexo e idade, dos residentes dos Municípios de Salvador (BA) e São Paulo (SP), 1996.

\begin{tabular}{|c|c|c|c|c|c|c|c|c|}
\hline \multirow{3}{*}{$\begin{array}{l}\text { Idade } \\
\text { (anos) }\end{array}$} & \multicolumn{4}{|c|}{ Salvador } & \multicolumn{4}{|c|}{ São Paulo } \\
\hline & \multicolumn{2}{|c|}{ Masculino } & \multicolumn{2}{|c|}{ Feminino } & \multicolumn{2}{|c|}{ Masculino } & \multicolumn{2}{|c|}{ Feminino } \\
\hline & $\left|T_{x}-T_{x} \cdot\right|$ & $\begin{array}{c}\left|\mathbf{T}_{\mathrm{x}}-\mathbf{T}_{\mathrm{X}}\right|(\%) \\
\mathrm{T}_{\mathrm{X}} \mid \\
\end{array}$ & $\left|T_{x}-T_{x}\right|$ & 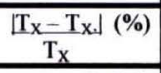 & $\left|\mathrm{T}_{\mathrm{x}}-\mathrm{T}_{\mathrm{X} \cdot \mathrm{J}}\right|$ & $\begin{array}{c}\left|\mathbf{T}_{\mathrm{x}}-\mathbf{T}_{\mathrm{x}}\right|(\%) \\
\mathrm{T}_{\mathrm{x}} \mid \\
\end{array}$ & $\left|T_{x}-T_{x}\right|$ & $\begin{array}{c}\left|\mathbf{T}_{\mathrm{x}}-\mathbf{T}_{\mathrm{x}}\right|(\%) \\
\mathrm{T}_{\mathrm{x}}\end{array}$ \\
\hline$\overline{0}$ & 285.609 & 4,46 & 63.087 & 0,90 & 423.324 & 6,68 & 88.764 & 1,20 \\
\hline 1 & 285.583 & 4,52 & 63.069 & 0,91 & 423.287 & 6,78 & 88.726 & 1,22 \\
\hline 2 & 285.527 & 4,59 & 63.037 & 0,92 & 423.229 & 6,89 & 88.664 & 1,23 \\
\hline 3 & 285.446 & 4,66 & 62.992 & 0,93 & 423.157 & 7,00 & 88.587 & 1,25 \\
\hline 4 & 285.346 & 4,74 & 62.929 & 0,95 & 423.067 & 7,11 & 88.496 & 1,26 \\
\hline 5 a 9 & 285.219 & 4,81 & 62.852 & 0,96 & 422.958 & 7,22 & 88.392 & 1,28 \\
\hline 10 a 14 & 284.142 & 5,21 & 62.341 & 1,03 & 422.117 & 7,86 & 87.696 & 1,37 \\
\hline 15 a 19 & 282.371 & 5,67 & 61.563 & 1,10 & 420.509 & 8,60 & 86.635 & 1,46 \\
\hline 20 a 24 & 278.148 & 6,17 & 60.397 & 1,18 & 415.344 & 9,41 & 84.907 & 1,56 \\
\hline 25 a 29 & 268.988 & 6,66 & 58.804 & 1,26 & 402.923 & 10,21 & 82.297 & 1,66 \\
\hline 30 a 34 & 254.740 & 7,11 & 56.718 & 1,36 & 382.320 & 10,95 & 78.910 & 1,76 \\
\hline 35 a 39 & 236.545 & 7,55 & 54.166 & 1,46 & 354.714 & 11,65 & 74.824 & 1,86 \\
\hline 40 a 44 & 215.284 & 7,99 & 51.166 & 1,57 & 321.590 & 12,29 & 70.065 & 1,98 \\
\hline 45 a 49 & 191.614 & 8,46 & 47.727 & 1,71 & 284.145 & 12,91 & 64.754 & 2,10 \\
\hline 50 a 54 & 166.075 & 8,97 & 43.822 & 1,87 & 243.833 & 13,52 & 58.901 & 2,25 \\
\hline 55 a 59 & 139.398 & 9,56 & 39.497 & 2,06 & 201.958 & 14,13 & 52.524 & 2,41 \\
\hline 60 a 64 & 112.340 & 10,27 & 34.840 & 2,31 & 159.997 & 14,78 & 45.649 & 2,61 \\
\hline 65 a 69 & 86.040 & 11,17 & 29.729 & 2,63 & 119.937 & 15,51 & 38.367 & 2,86 \\
\hline 70 a 74 & 61.605 & 12,35 & 24.196 & 3,06 & 83.712 & 16,42 & 30.893 & 3,19 \\
\hline 75 a 79 & 40.433 & 13,94 & 18.256 & 3,62 & 53.070 & 17,67 & 23.480 & 3,66 \\
\hline $80 \mathrm{e}+$ & 24.081 & 16,33 & 12.474 & 4,42 & 29.717 & 19,71 & 16.408 & 4,38 \\
\hline
\end{tabular}

FIGURA 19 - Coeficiente de mortalidade (100.000 habitantes) por causas externas, segundo subgrupos de causa (CID10-BR) e sexo. Municípios de Salvador e São Paulo, 1996.

Salvador

Săo Paulo

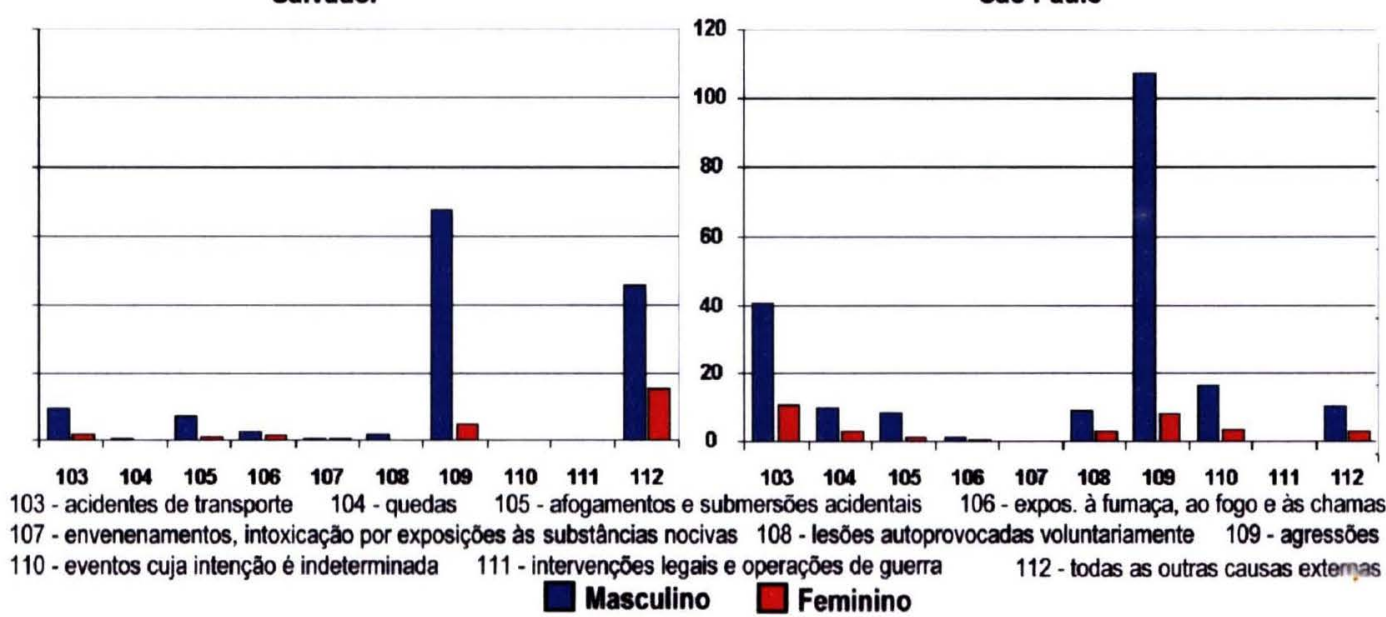




\subsubsection{Eliminando o grupo dos acidentes de transporte}

No Brasil, a ocupação desorganizada do espaço urbano, como conseqüência do rápido processo de urbanização da população, a partir dos anos 60 , e a predominância do transporte rodoviário de passageiros e de mercadorias, com um aumento da frota de veículos de 3,1 para 25 milhões de 1970 a 1995, contribuíram inegavelmente para os elevados níveis de morbi-mortalidade por acidentes de trânsito, onde as estatísticas nacionais contabilizam uma média de 30.000 óbitos por ano e mais de 340.000 feridos na década de 90 (VASCONCELOS e LIMA 2001). Com relação às idades, as mortes estão concentradas no grupo adulto jovem, no qual a motocicleta desempenha um fator importante, por ser, além de veículo de lazer, instrumento de trabalho. Nas idades mais avançadas, as mortes são principalmente decorrentes de atropelamentos.

Predominantemente, o homem está mais exposto a estes fatores de risco (Figura 20), notadamente a faixa etária economicamente ativa, agravando as questões sociais e se constituindo em um importante problema de Saúde Pública no qual o Brasil apresenta uma das maiores taxas de mortalidade por acidentes de trânsito no mundo. Em 1995, as taxas masculinas eram duas vezes maiores que a dos EUA e quatro vezes àquela observada no Reino Unido (VASCONCELOS e LIMA 2001).

FIGURA 20 - Distribuição proporcional (\%) dos óbitos por acidentes de transporte. Municípios de Salvador e São Paulo, 1996.

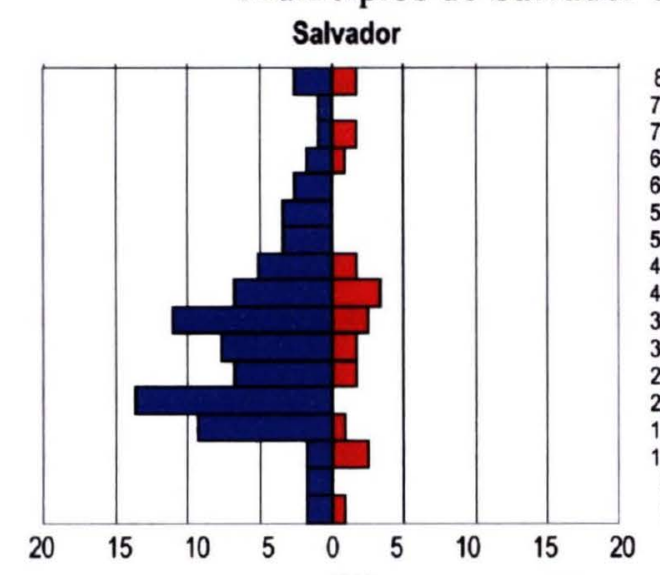

(\%)

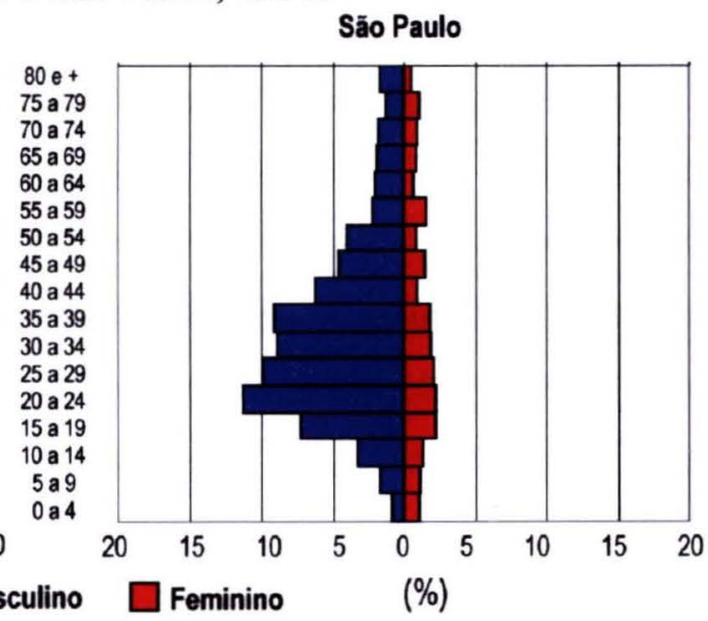

(\%)

As EVN, calculadas pelas tábuas de vida de múltiplo decremento (Anexos 45, 46, 47 e 48), mostram ganhos respectivos de 0,20 anos para os homens $(0,05$ anos para as mulheres) e 0,81 anos para os homens (0,30 anos - mulheres) de Salvador e São Paulo, respectivamente (Tabela 36). 
TABELA 36 - Comparação entre as esperanças de vida real (ex) e hipotética (ex.), eliminando os acidentes de transporte como fator de risco de morte, segundo sexo e idade, dos residentes dos Municípios de Salvador (BA) e São Paulo (SP), 1996.

\begin{tabular}{|c|c|c|c|c|c|c|c|c|}
\hline \multirow{3}{*}{$\begin{array}{l}\text { Idade } \\
\text { (anos) }\end{array}$} & \multicolumn{4}{|c|}{ Salvador } & \multicolumn{4}{|c|}{ São Paulo } \\
\hline & \multicolumn{2}{|c|}{ Masculino } & \multicolumn{2}{|c|}{ Feminino } & \multicolumn{2}{|c|}{ Masculino } & \multicolumn{2}{|c|}{ Feminino } \\
\hline & $\left|e_{x}-e_{x}\right|$ & 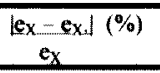 & $\left|e_{x}-e_{x}\right|$ & 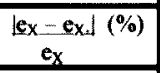 & $\left|\mathbf{e}_{x}-e_{x}\right|$ & $\begin{array}{c}e_{x}-e_{x} \mid \\
e_{x}\end{array}$ & $\left|e_{x}-e_{x}\right|$ & $\begin{array}{c}\left|e_{x}-e_{x}\right|(\%) \\
e_{x}\end{array}$ \\
\hline 0 & 0,20 & 0,31 & 0,05 & 0,07 & 0,81 & 1,28 & 0,30 & 0,41 \\
\hline 1 & 0,21 & 0,31 & 0,05 & 0,07 & 0,83 & 1,30 & 0,31 & 0,41 \\
\hline 2 & 0,21 & 0,32 & 0,05 & 0,07 & 0,84 & 1,32 & 0,30 & 0,41 \\
\hline 3 & 0,21 & 0,32 & 0,05 & 0,07 & 0,84 & 1,34 & 0,30 & 0,41 \\
\hline 4 & 0,21 & 0,33 & 0,05 & 0,07 & 0,83 & 1,35 & 0,29 & 0,41 \\
\hline 5 a 9 & 0,20 & 0,32 & 0,05 & 0,07 & 0,82 & 1,36 & 0,29 & 0,41 \\
\hline 10 a 14 & 0,19 & 0,34 & 0,05 & 0,07 & 0,80 & 1,43 & 0,26 & 0,40 \\
\hline 15 a 19 & 0,19 & 0,36 & 0,04 & 0,07 & 0,75 & 1,48 & 0,24 & 0,39 \\
\hline 20 a 24 & 0,17 & 0,36 & 0,04 & 0,07 & 0,67 & 1,43 & 0,21 & 0,37 \\
\hline 25 a 29 & 0,14 & 0,32 & 0,04 & 0,08 & 0,55 & 1,28 & 0,18 & 0,35 \\
\hline 30 a 34 & 0,12 & 0,31 & 0,03 & 0,08 & 0,45 & 1,16 & 0,16 & 0,33 \\
\hline 35 a 39 & 0,11 & 0,30 & 0,03 & 0,08 & 0,36 & 1,04 & 0,13 & 0,31 \\
\hline 40 a 44 & 0,08 & 0,26 & 0,03 & 0,07 & 0,28 & 0,89 & 0,11 & 0,30 \\
\hline 45 a 49 & 0,06 & 0,24 & 0,02 & 0,05 & 0,22 & 0,80 & 0,10 & 0,31 \\
\hline 50 a 54 & 0,05 & 0,23 & 0,01 & 0,04 & 0,17 & 0,73 & 0,08 & 0,29 \\
\hline 55 a 59 & 0,04 & 0,22 & 0,01 & 0,05 & 0,12 & 0,63 & 0,07 & 0,30 \\
\hline 60 a 64 & 0,03 & 0,20 & 0,01 & 0,07 & 0,10 & 0,63 & 0,05 & 0,25 \\
\hline 65 a 69 & 0,02 & 0,19 & 0,01 & 0,09 & 0,09 & 0,64 & 0,05 & 0,27 \\
\hline 70 a 74 & 0,02 & 0,20 & 0,01 & 0,10 & 0,07 & 0,67 & 0,04 & 0,28 \\
\hline 75 a 79 & 0,02 & 0,27 & 0,01 & 0,07 & 0,06 & 0,71 & 0,03 & 0,26 \\
\hline 80 et & 0,03 & 0,39 & 0,01 & 0,13 & 0,05 & 0,84 & 0,01 & 0,16 \\
\hline
\end{tabular}

\subsubsection{Eliminando o grupo das agressões}

Bem mais significativos e preocupantes, são os dados por agressões nos dois municípios estudados (Figura 20). A proporção de violência por homicídio é tão grande em nosso país (30\% das mortes por causas externas), que o Brasil mereceu destaque especial em recente artigo publicado pela OMS (WHO 2001), em que os crimes por armas de fogo foram o assunto de discussão. Novamente, aqui, a população masculina é a mais atingida, notadamente os jovens e os adultos jovens (Figura 21).

Somente no Município de São Paulo, as Agressões seriam responsáveis por 2,20 anos de redução na EVN masculina (contra 0,22 anos entre as mulheres). Em Salvador, estes números se reduzem a 1,36 anos para os homens e 0,11 anos para as mulheres (Tabela 37). A probabilidade de um indivíduo de 15 anos chegar ao 65 
anos, caso os homicídios fossem eliminados como causa de morte, em 1996, seria de $64,00 \%$ para os paulistanos (em vez de $60,09 \%$ ) e $81,35 \%$ para as paulistanas (em vez de $80,98 \%$ ). Um aumento de $6,5 \%$, na sobrevivência masculina, e de $0,5 \%$ para as mulheres.

FIGURA 21 - Distribuição proporcional (\%) dos óbitos por agressões, segundo sexo e faixa etária. Municípios de Salvador e São Paulo, 1996.

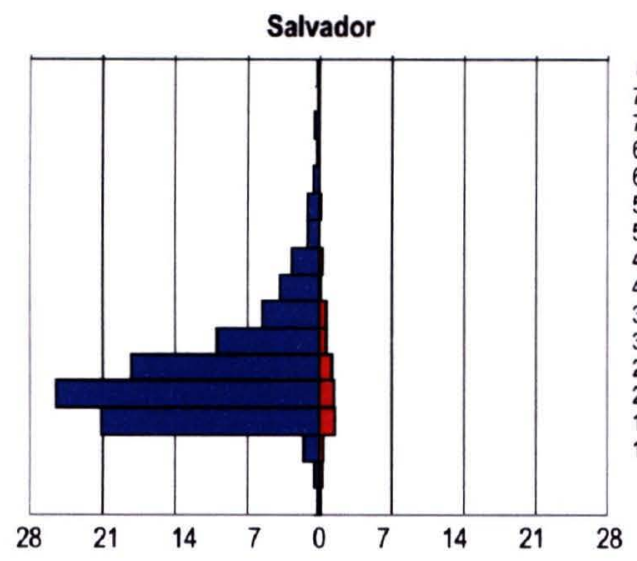

(\%)

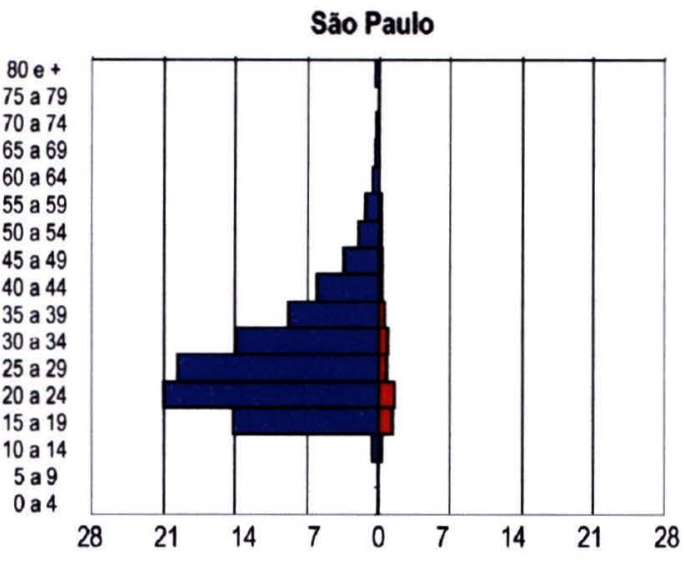

(\%)

Em Salvador, os homens teriam um aumento na probabilidade de sobreviver da faixa economicamente ativa de 3,74\% (65,68\% em vez de 63,31\%) contra uma melhoria de apenas $0,22 \%$ para as mulheres (76,50\% em vez de $76,33 \%)$. Considerando esta diferença, se as Agressões fossem eliminadas, como causa de óbito, na população masculina, conseguir-se-ia um significativo avanço na redução das diferenças entre os sexos e entre os níveis econômicos, pois é reconhecida a concentração de casos de homicídios nas áreas mais periféricas das cidades, onde se encontra justamente a população de mais baixa renda e piores condições sociais.

Indiscutivelmente, estes agravos têm um grande peso entre os óbitos dos residentes dos municípios de Salvador e São Paulo. Medidas, como a introdução do Novo Código de Trânsito Brasileiro, cujo impacto na diminuição na mortalidade por acidentes de trânsito foi avaliado por VASCONCELOS e LIMA (2001), representam uma das mais valiosas armas nesta luta.

Muito ainda está por fazer e, embora a eliminação total deste grupo de causas, como fator de risco de morte, talvez seja algo irrealizável, reduções bastante significativas podem ser alcançadas a curto e médio prazo, através de medidas 
educativas, disciplinadoras e de diminuição das iniqüidades sociais. É preciso priorizar o ser humano e resgatar a sua cidadania inserindo-o na sociedade como elemento participativo e não somente como sujeito passivo das ações e agressões de um meio cada vez mais hostil. É preciso que o cidadão comum tenha consciência do seu papel, neste processo, e só assim a sociedade será capaz de, ela mesma, encontrar os caminhos para as soluções dos seus problemas.

TABELA 37 - Comparação entre as esperanças de vida real ( $\left.e_{X}\right)$ e hipotética (e $e_{X}$.), eliminando as agressões como fator de risco de morte, segundo sexo e idade, dos residentes dos Municípios de Salvador (BA) e São Paulo (SP), 1996.

\begin{tabular}{|c|c|c|c|c|c|c|c|c|}
\hline \multirow{3}{*}{$\begin{array}{l}\text { Idade } \\
\text { (anos) }\end{array}$} & \multicolumn{4}{|c|}{ Salvador } & \multicolumn{4}{|c|}{ São Paulo } \\
\hline & \multicolumn{2}{|c|}{ Masculino } & \multicolumn{2}{|c|}{ Feminino } & \multicolumn{2}{|c|}{ Masculino } & \multicolumn{2}{|c|}{ Feminino } \\
\hline & $\left|e_{x}-e_{x}\right|$ & $\begin{array}{c}\left|e_{x} e_{x}\right|(\%) \\
e_{x}\end{array}$ & $\left|e_{x}-e_{x}\right|$ & $\begin{array}{c}\left|e_{x}-e_{x}\right|(\%) \\
e_{x}\end{array}$ & $\left|e_{x}-e_{x}\right|$ & $\begin{array}{c}\left|e_{x}-e_{x}\right|(\%) \\
e_{x}\end{array}$ & $\left|e_{x}-e_{x}\right|$ & $\begin{array}{c}\left|e_{x}-e_{x}\right|(\%) \\
e_{x}\end{array}$ \\
\hline 0 & 1,36 & 2,12 & 0,11 & 0,16 & 2,20 & 3,46 & 0,22 & 0,29 \\
\hline 1 & 1,42 & 2,15 & 0,11 & 0,16 & 2,26 & 3,52 & 0,22 & 0,29 \\
\hline 2 & 1,42 & 2,19 & 0,12 & 0,16 & 2,27 & 3,57 & 0,22 & 0,30 \\
\hline 3 & 1,42 & 2,22 & 0,12 & 0,16 & 2,27 & 3,62 & 0,22 & 0,30 \\
\hline 4 & 1,42 & 2,25 & 0,12 & 0,17 & 2,27 & 3,68 & 0,22 & 0,30 \\
\hline 5 a 9 & 1,42 & 2,29 & 0,11 & 0,16 & 2,27 & 3,74 & 0,22 & 0,31 \\
\hline 10 a 14 & 1,42 & 2,47 & 0,11 & 0,17 & 2,27 & 4,07 & 0,21 & 0,32 \\
\hline 15 a 19 & 1,39 & 2,66 & 0,10 & 0,17 & 2,26 & 4,43 & 0,20 & 0,32 \\
\hline 20 a 24 & 1,10 & 2,28 & 0,07 & 0,14 & 1,87 & 4,00 & 0,15 & 0,27 \\
\hline 25 a 29 & 0,70 & 1,60 & 0,05 & 0,10 & 1,34 & 3,14 & 0,11 & 0,20 \\
\hline 30 a 34 & 0,42 & 1,05 & 0,03 & 0,07 & 0,87 & 2,24 & 0,08 & 0,18 \\
\hline 35 a 39 & 0,27 & 0,77 & 0,02 & 0,05 & 0,55 & 1,58 & 0,06 & 0,14 \\
\hline 40 a 44 & 0,19 & 0,61 & 0,01 & 0,03 & 0,35 & 1,14 & 0,04 & 0,11 \\
\hline 45 a 49 & 0,13 & 0,48 & 0,01 & 0,03 & 0,22 & 0,80 & 0,03 & 0,10 \\
\hline 50 a 54 & 0,08 & 0,37 & 0,00 & 0,01 & 0,13 & 0,56 & 0,02 & 0,08 \\
\hline 55 a 59 & 0,06 & 0,32 & 0,00 & 0,01 & 0,08 & 0,40 & 0,02 & 0,07 \\
\hline 60 a 64 & 0,04 & 0,24 & 0,00 & 0,00 & 0,04 & 0,26 & 0,01 & 0,04 \\
\hline 65 a 69 & 0,03 & 0,22 & - & - & 0,03 & 0,19 & 0,01 & 0,03 \\
\hline 70 a 74 & 0,02 & 0,24 & - & - & 0,02 & 0,19 & 0,00 & 0,02 \\
\hline 75 a 79 & 0,02 & 0,20 & 0,00 & 0,00 & 0,01 & 0,18 & 0,00 & 0,03 \\
\hline $80 \mathrm{e}+$ & 0,02 & 0,26 & - & - & 0,02 & 0,33 & 0,00 & 0,04 \\
\hline
\end{tabular}

\subsection{Análise global}

Observando a proporção de óbitos, segundo algumas causas (Tabela 10), é possível verificar a relevância destas causas de óbito na mortalidade das populações das duas capitais (Figura 22). Mas, para completar o estudo, é necessário ampliar a visão conjunta dessas causas através da ordenação dos grupos de doenças, em função de seus níveis de atuação, como causa de morte dentro de cada faixa etária e por sexo. 
FIGURA 22 - Proporção de óbitos por capítulo da CID-10 e sexo. Municípios de Salvador e São Paulo, 1996.

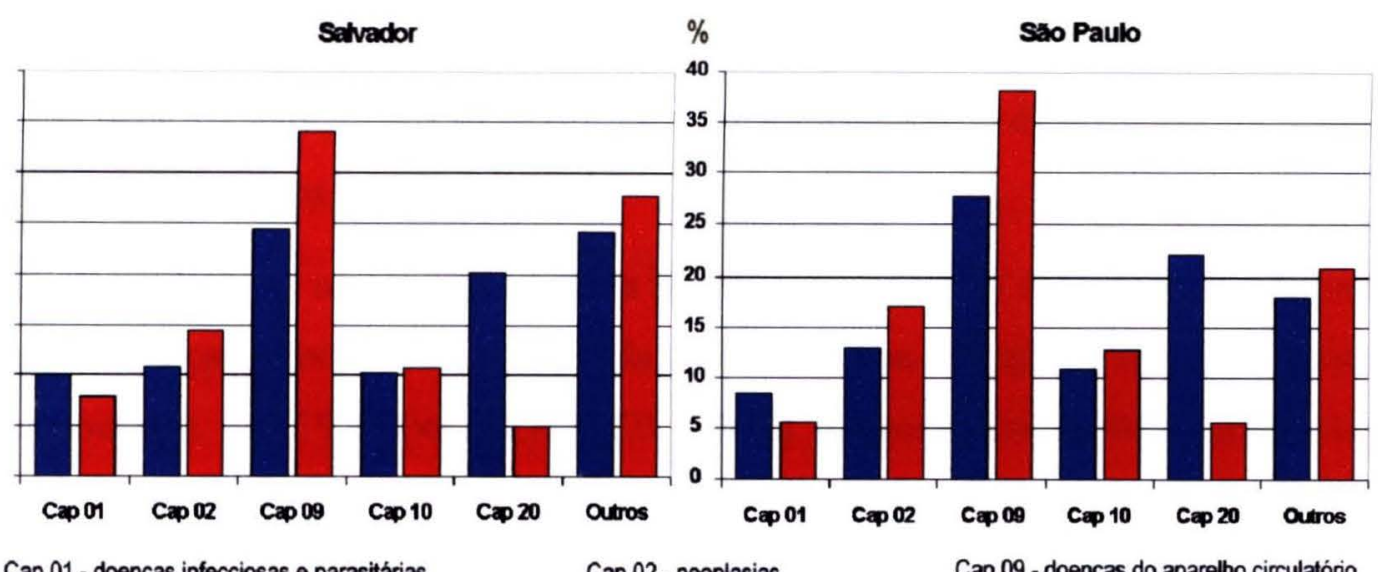

Cap 01 - doenças infecciosas e parasitárias Cap 10 - doenças do aparelho respiratório

Cap 20 - causas 02 - neoplasias externas de morbidade e mortalidade

Masculino $\square$ Feminino

TABELA 38 - Diferenças relativas (\%) entre as probabilidade real e líquida de morte, segundo faixas etárias e grupos de morte eliminados (capítulos da CID-10), para residentes nos Municípios de Salvador (BA) e São Paulo (SP), em 1996 (Sexo masculino).

\begin{tabular}{|c|c|c|c|c|c|c|c|c|c|c|}
\hline \multirow{2}{*}{$\begin{array}{c}\text { Idade } \\
\text { (anos) } \\
\text { Capitulo }\end{array}$} & \multicolumn{5}{|c|}{ Salvador } & \multicolumn{5}{|c|}{ São Paulo } \\
\hline & 01 & 02 & 09 & 10 & 20 & 01 & $\mathbf{0 2}$ & 09 & 10 & 20 \\
\hline 0 & 14,35 & 0,39 & 0,13 & 9,95 & 0,77 & 8,09 & 0,23 & 0,96 & 13,62 & 1,42 \\
\hline 1 & 14,80 & 7,40 & 5,55 & 14,80 & 12,95 & 20,50 & 2,56 & 2,56 & 33,31 & 10,89 \\
\hline 2 & 9,67 & 6,45 & 6,45 & 25,79 & 19,34 & 25,32 & 4,00 & 2,67 & 22,66 & 18,66 \\
\hline 3 & $22,21]$ & 22,21 & 5,55 & 5,55 & 11,11 & 23,72 & 13,56 & 0,00 & 11,86 & 28,81 \\
\hline 4 & 0,00 & 0,00 & 0,00 & 23,07 & 69,22 & 19,44 & 16,66 & 0,00 & 8,33 & 38,88 \\
\hline 5 a 9 & 12,48 & 8,92 & 5,35 & 1,78 & 49,97 & 12,03 & 14,65 & 2,09 & 8,37 & 46,57 \\
\hline 10 a 14 & 1,33 & 7,99 & 5,33 & 10,65 & 50,63 & 4,94 & 11,20 & 2,31 & 6,59 & 65,31 \\
\hline 15 a 19 & 4,14 & 3,45 & 4,83 & 4,83 & 78,03 & 1,74 & 2,83 & 2,54 & 2,47 & 86,08 \\
\hline 20 a 24 & 5,27 & 2,77 & 3,05 & 3,05 & 73,30 & 6,05 & 1,62 & 1,92 & 2,41 & 83,17 \\
\hline 25 a 29 & 13,41 & 1,91 & 7,34 & 5,10 & 60,90 & 18,99 & 1,94 & 3,19 & 3,10 & 65,44 \\
\hline 30 a 34 & 20,28 & 1,81 & 9,37 & 7,56 & $43,07 \mid$ & 25,22 & 3,59 & 5,14 & 5,02 & 49,59 \\
\hline 35 a 39 & 20,41 & 6,25 & 15,78 & 6,25 & 29,43 & 22,38 & 4,17 & 11,13 & 7,06 & 38,26 \\
\hline 40 a 44 & 18,10 & 9,04 & 21,99 & 6,45 & 20,44 & 16,76 & 7,99 & 18,85 & 7,01 & 28,65 \\
\hline 45 a 49 & 14,93 & 9,26 & 28,91 & 4,88 & 14,93 & 11,08 & 13,50 & 27,49 & 8,26 & 18,51 \\
\hline 50 a 54 & 11,58 & 15,07 & 29,59 & 8,56 & 8,56 & 8,01 & 15,65 & 33,60 & 7,49 & 13,48 \\
\hline 55 a 59 & 9,40 & 15,16 & 35,37 & 8,16 & 6,94 & 4,70 & 19,95 & 38,60 & 8,35 & 7,96 \\
\hline 60 a 64 & 5,56 & 14,18 & 38,68 & 11,70 & 3,99 & 3,85 & 21,76 & 41,19 & 8,88 & 5,00 \\
\hline 65 a 69 & 6,39 & 16,89 & 32,30 & 10,34 & 4,51 & 2,50 & 19,53 & 41,93 & 11,79 & 3,41 \\
\hline 70 а 74 & 4,87 & 15,48 & 35,38 & 12,64 & 2,71 & 2,07 & 18,62 & 41,81 & 13,20 & 2,72 \\
\hline 75 a 79 & 3,67 & 16,61 & 32,91 & 9,84 & 2,66 & 1,49 & 17,27 & 38,38 & 14,51 & 1,76 \\
\hline $80 \mathrm{e}+$ & - & - & - & - & - & - & - & - & - & . \\
\hline
\end{tabular}

Cap. 01 - doenças infecciosas e parasitárias

Cap. 02 - neoplasias

Cap. 09 - doenças do aparelho circulatório

Cap. 10 - doenças do aparelho respiratório

Cap. 20 - causas externas de morbidade e mortalidade 
Em 1970, analisando as diferenças relativas entre as probabilidades real e hipotética de morte, para a população paulistana, apresentavam predominância bem definida as doenças infecciosas e parasitárias nas primeiras idades, seguidas das causas externas para jovens adultos e, por último, as doenças do aparelho circulatório dominavam, entre os adultos e idosos.

Em 1996, ao se considerarem as doenças do aparelho respiratório, agrupadas com as doenças infecciosas e parasitárias, ter-se-ia uma situação muito parecida com a encontrada em 1970 por GOTLIEB (1977). Doenças de caráter transmissível teriam uma contribuição maior na redução da probabilidade de morte, nas primeiras idades. Nas idades intermediárias, as causas externas seriam as grandes responsáveis e, nas idades mais avançadas, as doenças do aparelho circulatório exerceriam um papel preponderante (Tabelas 38 e 39).

TABELA 39 - Diferenças relativas (\%) entre as probabilidade real e líquida de morte, segundo faixas etárias e grupos de morte eliminados (capítulos da CID-10), para residentes nos Municípios de Salvador (BA) e São Paulo (SP), em 1996 (Sexo feminino).

\begin{tabular}{|c|c|c|c|c|c|c|c|c|c|c|}
\hline \multirow{2}{*}{$\begin{array}{c}\text { Idade } \\
\text { (anos) } \\
\text { Capitulo }\end{array}$} & \multicolumn{5}{|c|}{ Salvador } & \multicolumn{5}{|c|}{ São Paulo } \\
\hline & 01 & 02 & 09 & 10 & 20 & 01 & 02 & 09 & 10 & 20 \\
\hline$\overline{0}$ & 12,71 & 0,41 & 0,14 & 8,33 & 0,55 & 8,19 & 0,44 & 0,93 & 13,66 & $\overline{1,85}$ \\
\hline 1 & 12,48 & 0,00 & 0,00 & 37,46 & 5,35 & 17,60 & 1,88 & 5,03 & 30,17 & 11,31 \\
\hline 2 & 10,34 & 3,45 & 0,00 & 20,68 & 10,34 & 28,74 & 6,25 & 3,75 & 16,24 & 14,99 \\
\hline 3 & 26,31 & 15,78 & 0,00 & 5,26 & 21,04 & 28,25 & 4,35 & 2,17 & 17,39 & 26,08 \\
\hline 4 & 10,00 & 0,00 & 10,00 & 29,99 & 20,00 & 18,52 & 7,41 & $7,41[$ & 14,81 & 33,33 \\
\hline 5 a 9 & 24,12 & 24,12 & 3,45 & 0,00 & 27,57 & 11,42 & 14,28 & 6,42 & 11,42 & 35,69 \\
\hline 10 a 14 & 7,13 & 12,84 & 12,84 & 12,84 & 25,69 & 3,21 & 13,36 & 6,95 & 10,69 & 44,89 \\
\hline 15 a 19 & 11,10 & 9,99 & 7,77 & 15,53 & 28,86 & 5,09 & 9,54 & 5,72 & 9,86 & 56,97 \\
\hline 20 a 24 & 4,47 & 10,44 & 16,40 & 4,47 & 32,81 & 16,56 & 8,39 & 6,99 & 7,23 & 41,30 \\
\hline 25 a 29 & 23,95 & 8,78 & 16,76 & 8,78 & 21,55 & 32,06 & 7,63 & $8,96[$ & 7,63 & 25,57 \\
\hline 30 a 34 & 16,83 & 16,83 & 20,72 & 9,71 & 11,00 & 28,98 & 14,55 & 12,35 & 8,08 & 20,73 \\
\hline 35 a 39 & 14,40 & $19,81[$ & 23,42 & 7,65 & 9,90 & 20,56 & 19,44 & 22,13 & 8,26 & 13,07 \\
\hline 40 a 44 & 16,60 & 22,89 & 28,44 & 4,05 & 4,79 & 12,64 & 26,04 & 28,26 & 7,26 & 8,85 \\
\hline 45 a 49 & 8,09 & 24,01 & 33,79 & 6,15 & 5,50 & 7,52 & 26,79 & 33,37 & 7,44 & 7,36 \\
\hline 50 a 54 & 8,90 & 20,51 & 40,00 & 5,04 & 2,37 & 4,96 & 27,26 & 37,00 & 8,80 & 4,47 \\
\hline 55 a 59 & 7,87 & 21,09 & 35,39 & 6,20 & 2,62 & 3,56 & 28,17 & 38,89 & 7,60 & 4,21 \\
\hline 60 a 64 & 5,74 & 18,76 & 40,17 & 10,27 & 2,66 & 3,09 & 25,43 & 41,56 & 8,77 & 2,62 \\
\hline 65 а 69 & 5,30 & 18,40 & 36,34 & 10,32 & 2,18 & 2,41 & 24,01 & 42,08 & 9,93 & 2,19 \\
\hline 70 a 74 & 3,80 & 15,41 & 39,69 & 9,34 & 2,58 & 1,96 & 20,37 & 43,64 & 11,19 & 1,62 \\
\hline 75 a 79 & 4,51 & 14,21 & 40,92 & 9,10 & 1,26 & 1,50 & 14,50 & 45,35 & 12,85 & 1,75 \\
\hline 80 e+ & - & - & - & - & - & - & - & - & - & \\
\hline
\end{tabular}


No entanto, uma observação deve ser feita com relação às populações femininas dos dois municípios. Dos 25 aos 34 anos, em Salvador, e dos 25 aos 39 anos, em São Paulo, as doenças infecciosas e parasitárias, em conjunto com as doenças do aparelho respiratório, assumem um papel significativo na mortalidade destas capitais. As neoplasias constituem a segunda causa de óbito para as mulheres de 40 e mais anos, constituindo, assim, um diferencial entre os sexos.

TABELA 40 - Probabilidade de sobreviver (\%), segundo sexo, faixas etárias e grupos de causas de morte eliminados (capítulos da CID-10), para residentes nos Municípios de Salvador (BA) e São Paulo (SP), em 1996.

\begin{tabular}{|c|c|c|c|c|c|c|c|c|c|c|c|c|}
\hline \multirow{3}{*}{ Causas* } & \multicolumn{6}{|c|}{ Salvador } & \multicolumn{6}{|c|}{ São Paulo } \\
\hline & \multicolumn{2}{|c|}{$<15$ anos } & \multicolumn{2}{|c|}{15 a 65 anos } & \multicolumn{2}{|c|}{0 a 80 anos } & \multicolumn{2}{|c|}{$<15$ anos } & \multicolumn{2}{|c|}{15 a 65 anos } & \multicolumn{2}{|c|}{0 a 80 anos } \\
\hline & Masc. & Fem. & Masc. & Fem. & Masc. & Fem. & Masc. & Fem. & Masc. & Fem. & Masc. & Fem. \\
\hline Cap. 1 & 96,57 & 95,67 & 66,49 & 78,21 & 24,45 & 39,80 & 96,40 & 97,06 & 63,16 & 82,28 & 25,51 & 47,65 \\
\hline Cap. 2 & 95,00 & 95,14 & 66,94 & 80,66 & 28,07 & 44,24 & 96,12 & 96,82 & 64,75 & 85,39 & 30,76 & 54,12 \\
\hline Cap. 9 & 94,96 & 95,08 & 72,65 & 84,08 & 36,81 & 54,58 & 96,07 & 96,81 & 69,52 & 87,18 & 40,66 & 63,75 \\
\hline Cap. 10 & 95,42 & 95,55 & 65,92 & 77,94 & 26,05 & 41,09 & 96,57 & 97,22 & 62,45 & 82,42 & 28,48 & 50,66 \\
\hline Cap. 20 & 95,32 & 95,22 & 68,38 & 77,30 & 24,62 & 38,39 & 96,45 & 97,00 & 67,83 & 82,30 & 27,56 & 47,64 \\
\hline $\begin{array}{l}\text { Sem } \\
\text { Exclusão }\end{array}$ & 94,89 & 95,03 & 63,31 & 76,33 & 21,87 & 37,31 & 96,03 & 96,74 & 60,09 & 80,98 & 23,71 & 46,27 \\
\hline
\end{tabular}

* Cap. 1 - doenças infecciosas e parasitárias

Cap. 9 - doenças do aparelho circulatório

Cap. 20 - causas externas de morbidade e mortalidade

Cap. 10 - doenças do aparelho respiratório

A probabilidade de sobreviver do nascimento até aos quinze anos, eliminando algumas causas, tem comportamento semelhante em ambos os sexos e para ambos os municípios. A maior atuação foi exercida pelas doenças infecciosas e parasitárias no Município de Salvador e pelas doenças do aparelho respiratório em São Paulo. Na faixa etária, economicamente ativa da população, predominam as doenças do aparelho circulatório seguidas das causas externas para os homens e das neoplasias para as mulheres. As probabilidades de sobreviver do nascimento até os oitenta anos, quando eliminados os grupos de causa de morte, mostram a importância assumida pelas doenças do aparelho circulatório na mortalidade tardia da população, notadamente a população feminina das duas capitais, destacando-se como segunda causa de óbito as neoplasias.

A análise dos ganhos (em anos) da EVN, pela eliminação dos grupos de causa de morte, por sexo e município estudado, permite definir os principais agravos que atuam sobre a população residente, nestes municípios, sendo a vida média sintetizada 
e expressa em um único valor (Tabela 41). Assim, por ordem de importância atuaram no sexo masculino as doenças do aparelho circulatório, as causas externas, as neoplasias, as doenças do aparelho respiratório e, por fim, as doenças infecciosas e parasitárias, em ambos os municípios estudados. No sexo feminino, a ordem foi: doenças do aparelho circulatório, as neoplasias, as doenças do aparelho respiratório, as doenças infecciosas e parasitárias e por fim as causas externas.

TABELA 41 - Número de anos ganhos na esperança de vida ao nascer, segundo sexo e grupos de causas de morte eliminados (capitulos da CID10), para residentes nos Municípios de Salvador (BA) e São Paulo (SP), em 1996.

\begin{tabular}{|c|c|c|c|c|c|c|c|c|}
\hline \multirow{3}{*}{ Causas } & \multicolumn{4}{|c|}{ Salvador } & \multicolumn{4}{|c|}{ São Paulo } \\
\hline & \multicolumn{2}{|c|}{ Masculino } & \multicolumn{2}{|c|}{ Feminino } & \multicolumn{2}{|c|}{ Masculino } & \multicolumn{2}{|c|}{ Feminino } \\
\hline & n. & $\%$ & n. & $\%$ & m. ${ }^{\circ}$ & $\%$ & n. ${ }^{\circ}$ & $\%$ \\
\hline Doenças Infec & 1,79 & 2,8 & 1,39 & 2,0 & 1,56 & 2,5 & 0,90 & $\overline{1,2}$ \\
\hline Neoplasias & 1,96 & 3,1 & 2,33 & 3,3 & 2,23 & 3,5 & 2,62 & 3,5 \\
\hline Doenças do Aparelho Circulatório & 5,38 & 8,4 & 7,63 & 10,9 & 6,23 & 9,8 & 9,26 & 12,5 \\
\hline Doenças do Aparelho Respiratório & 1,89 & 3,0 & 1,81 & 2,6 & 2,02 & 3,2 & 2,22 & 3,0 \\
\hline Causas Externas & 2,86 & 4,5 & 0,63 & 0,9 & 4,23 & 6,7 & 0,89 & 1,2 \\
\hline
\end{tabular}




\section{CONSIDERAÇÕES FINAIS}

Os coeficientes de mortalidade (6,68 óbitos/mil homens e 5,11 óbitos/mil mulheres - Salvador e 9,16 óbitos/mil homens e 5,70 óbitos/mil mulheres - São Paulo) apontam para um possível sub-registro de óbitos no Município de Salvador, e tudo leva a crer que afete preferencialmente a população masculina, notadamente menores de um ano, mas que não é seletivo, em função das causas básicas de morte. Mesmo assim, partindo-se do princípio de que este município apresenta uma baixa proporção de causas mal definidas, pode-se assumir que os óbitos não registrados têm a mesma distribuição dos que foram captados pelo sistema de informação. Infelizmente, não se dispõem de estimativas oficiais para este sub-registro.

Sendo Salvador um município que, nos anos cinqüenta, apresentava uma população em torno de quatrocentos mil habitantes e que, em pouco menos de meio século, quintuplicou, através de um crescimento desordenado e bem mais caótico que o Município de São Paulo, era de se esperar que a EVN dos residentes, na capital baiana, fosse menor do que a da capital paulista. Isso só se deu para o sexo feminino e, embora as causas externas, as doenças do aparelho circulatório e a Aids atuem de forma bem mais grave entre os paulistanos, não se pode afirmar com toda a certeza de que isso é suficiente para explicar estes resultados. Apesar disso, os problemas de cobertura do SIM, na capital nordestina, não chegam a comprometer o estudo desde que a suposição de que tal sub-registro não é diferencial por causas seja verdadeira, $o$ que possibilita a correção proporcional dos óbitos por grupo de causa e o emprego da técnica de tábua de vida de múltiplo decremento, utilizada por GOTLIEB (1977).

A EVN para os homens residentes no Município de São Paulo, em 1996, foi igual a 63,39 anos e para as mulheres foi de 73,92 anos. Para Salvador, após a correção do sub-registro de óbitos, estes valores foram respectivamente iguais a 64,10 anos e 70,33 anos. Se fosse possível eliminar todos os óbitos pelas doenças infecciosas e parasitárias, neoplasias, doenças dos aparelhos circulatório e respiratório e as causas externas de morbidade e mortalidade, as esperanças de vida para estes municípios seriam bem maiores, mas claro que esta é uma possibilidade no mínimo muito difícil de acontecer, mas que revela uma nítida tendência da EVN da capital paulista ser maior que a baiana e a grande relevância que os cinco capítulos escolhidos da CID-10 têm na mortalidade das populações estudadas. 
A concentração de esforços no sentido de reduzir a mortalidade por estas causas certamente irá contribuir em muito para o aumento da esperança de vida das populações estudadas. A solução deste problema passa pelo entendimento do conceito de saúde no seu sentido mais amplo, como componente da qualidade de vida e um direito social. É uma questão de cidadania que para ser resolvida deve basear-se em uma lógica de inclusão e valorização de cada um e de todos ao mesmo tempo. Para isso, é fundamental a participação social, no qual a informação é elemento essencial para a integração dos vários setores e para a tomada de decisões.

Medindo-se o impacto das mortes prematuras/evitáveis, nas populações é possível estabelecer planos e programas prioritários para a aplicação de recursos em pesquisas e em programas de intervenção de grande importância em Saúde Pública e uma forma de avaliar as mortes prematuras, considerando os diferentes riscos competitivos de morrer, é por meio do ganho potencial na esperança de vida, caso fosse(m) eliminada(s) alguma(s) causa(s) específica(s) de óbito (GOTLIEB, CASTILHO e BUCHALLA 2000).

Analisando os resultados, verifica-se que as doenças de caráter transmissível têm uma influência maior nas primeiras idades. Nas idades intermediárias, as causas externas são as grandes responsáveis pelas mortes, principalmente entre os homens, e, nas idades mais avançadas, as doenças do aparelho circulatório têm uma atuação mais visível. $\mathrm{Na}$ faixa etária economicamente ativa, predominam as doenças do aparelho circulatório seguidas das causas externas para os homens; com relação ao sexo feminino, as doenças infecciosas e parasitárias em conjunto com as doenças do aparelho respiratório (provavelmente um fenômeno associado à Aids) assumem um papel significativo na mortalidade das duas capitais para a faixa adulto jovem e as neoplasias constituem a segunda causa de óbito entre mulheres de 40 anos e mais, constituindo-se, assim, um diferencial entre os sexos.

A distribuição proporcional dos óbitos por doenças infecciosas e parasitárias, segundo o sexo e faixa etária, sofreu uma mudança significativa em São Paulo de 1970 para 1996 (Figura 3), a grande responsável por este fenômeno foi a AIDS com uma mortalidade predominante para o sexo masculino. Na década de setenta, GOTLIEB (1977) estimou as diferenças entre as probabilidades de sobreviver até os 
80 anos iguais a $8,12 \%$ e $4,93 \%$ respectivamente, para o sexo masculino e feminino. Em 1996, estes valores diminuíram para 7,60\% para os homens e 3,00\% para as mulheres, caso fossem eliminados os óbitos por AIDS, esta redução seria ainda maior mostrando que de fato houve uma diminuição na importância das doenças infecciosas e parasitárias como fator de risco de morte para a população paulistana, um possível efeito das ações de saúde pública nesta capital. Como era de se esperar, as doenças infecciosas e parasitárias têm um impacto maior na mortalidade da população de Salvador. Em especial, na população masculina.

As neoplasias, por sua vez, apresentam uma mortalidade maior entre as mulheres e com coeficientes maiores para o Município de São Paulo. Entre os homens, as principais neoplasias ocorrem, por ordem de freqüência: na traquéia, brônquios e pulmões - próstata - estômago - lábio, cavidade oral e faringe - cólon, reto e ânus. Entre as mulheres: mama - cólon, reto e ânus - colo do útero - estômago - traquéia, brônquios e pulmões - ovário - corpo e partes não especificadas do útero.

As doenças hipertensivas afetam mais as mulheres e são mais importantes em Salvador (números absolutos e relativos). As doenças isquêmicas do coração são mais importantes entre os homens, notadamente em São Paulo; já, as doenças cerebrovasculares apresentam, relativamente, um maior impacto na esperança de vida das mulheres de Salvador e para os homens de São Paulo que, de um modo geral, foi o município mais afetado pelas doenças do aparelho circulatório.

As pneumonias, seguidas das doenças crônicas das vias aéreas inferiores, apresentam coeficientes de mortalidade bem maiores para os residentes no Município de São Paulo do que para os de Salvador, acontecendo o inverso para o restante das doenças do aparelho respiratório. O sexo masculino é o mais afetado por este grupo de doenças.

As causas externas afetam tipicamente a população masculina adulta jovem, com graves conseqüências socioeconômicas. Os homicídios seguidos dos acidentes de transporte são os grandes vilões deste grupo de agravos à saúde, notadamente em São Paulo. Cabe um destaque para os afogamentos em São Paulo, com coeficientes maiores que Salvador, uma cidade praiana. Outro destaque importante diz respeito às 
quedas, suicídios e eventos cuja intenção é indeterminada cujos coeficientes são expressivamente maiores para a capital paulista inclusive para o sexo feminino.

Quanto às disparidades sociais entre as duas capitais, pode-se dizer que elas interferem primeiro em um nivel estrutural que vai desde a oferta e qualidade dos serviços oferecidos à população até o nível de informação que estes serviços conseguem gerar. O sub-registro dos óbitos, na Bahia e no Nordeste, é um bom exemplo de como isso pode prejudicar análises mais detalhadas e tornando obrigatório a utilização de técnicas indiretas de estimativa que podem distorcer a realidade por não conseguirem medir mudanças repentinas no padrão de óbitos promovidas por programas de intervenção em saúde.

Um primeiro passo para se resolver os problemas de saúde destes municípios consiste no incremento da cobertura e da qualidade dos sistemas de informação associada a uma melhoria nas condições de análise e divulgação dos resultados entre todos os parceiros no processo de construção da cidadania, ou seja, toda a população.

Municípios com condições socioeconômicas inferiores, como é o caso de Salvador, geralmente encontram maiores dificuldades para promover a participação social de toda a sua população; o analfabetismo e a baixa escolaridade são fatores que comprometem as ações de saúde e cidadania e requerem um esforço extra por parte das autoridades, a fim de garantir uma efetiva participação desta camada da sociedade no planejamento e na execução das ações de saúde pública.

Existe porém, uma convergência de idéias e ações por parte dos ministérios da Educação e Cultura (MEC), Saúde (MS) e Ciência e Tecnologia (MCT) no sentido de democratizar o acesso à informação e aumento da participação social nas decisões envolvendo os recursos públicos. Daí a criação dos conselhos municipais, estaduais e federais de educação e saúde com maior envolvimento popular e a criação da Rede Nacional de Informação em Saúde (MS) e da Sociedade da Informação (MCT) que visam ampliar a participação popular e a integração de serviços através de redes distribuidas de informação via Internet.

É muito difícil avaliar quão grande é o prejuízo causado pelas desigualdades sociais, é mais fácil medir alguns dos seus reflexos como o crescimento da violência urbana e o crescimento das favelas. Os sistemas de informação hoje disponíveic não 
dão conta destas variáveis e tão cedo não se terá tal instrumento de medida, mas uma coisa é certa: é preciso, antes de mais nada, respeitar o ser humano, incluir os excluídos com a idéia de que saúde e qualidade de vida são para todos e não só para quem pode pagar. Só assim, a informação será considerada um instrumento de mudança e progresso de todos e não apenas um instrumento de poder para poucos. $\grave{A}$ medida que melhoram a qualidade dos dados e a cobertura dos sistemas de informação, mais clara é a visão da realidade e à medida que todos compartilham desta visão, as soluções se apresentam. Espera-se poder contribuir para este processo e que, em um futuro breve, não só a capital, mas também o interior da Bahia possa ser melhor analisado pelas técnicas apresentadas neste trabalho. 


\section{REFERÊNCIAS ${ }^{4}$ :}

1. Akerman M. Metodologia de construção de indicadores compostos: um exercício de negociação intersetorial. In: Barata RB (org.). Condições de vida e situação em saúde. Rio de Janeiro: ABRASCO; 1997.

2. Al-Bustan MA, el-Zein FM, Kohli BR. Potential gains in life expectancy of Kuwaiti nationals through partial and complete elimination of infectious and parasitic disease mortality. APMIS Suppl. 1988; 3:88-90.

3. Albuquerque FRP de C e, Silva J da, Areias LC de O, Murayama T. Estimação do sub-registro de óbitos dos municípios das capitais utilizando a metodologia de Courbage e Fargues. Anais do V Encontro Nacional de Estudos Populacionais da ABEP. 1986; p. 1327-1351. Disponível em URL: http://www.abep.org.br.

4. Almeida MF de. Descentralização de sistemas de informação e o uso das informações a nível municipal. IESUS. 1998; 7(3):27-33, Jul./Set.

5. Almeida ES de, Castro CGJ de, Vieira CAL. Distritos Sanitários: concepção e organização. São Paulo: IDS, NAMH/FSP/Banco Itaú; 1998. O conceito de saúde e do processo saúde-doença; p. 11-19.

6. Barata RB (org.). Condições de vida e situação em saúde. Organizado por Rita Barradas Barata. Rio de Janeiro: Fiocruz/Abrasco; 1997.

7. Barbosa LMA, Mangabeira WC. A incrível história dos homens e suas relações sociais. $4^{a}$ ed. Petrópolis: Vozes; 1985.

8. Barbosa LM, Andrade FCD. Aplicação da técnica dos riscos competitivos à mortalidade do Brasil e Macrorregiões - 1991. Anais do XII Encontro Nacional de Estudos Populacionais da ABEP. 2000 Outubro 23-27. Disponível em URL: http://www.abep.org.br.

9. Berquó E et al. Estatística vital. São Paulo, Faculdade de Saúde Pública USP, 1972 [mimeo].

10. Bobbio N, Matteucci N, Pasquino G. Dicionário de Política. Brasília: Ed. Universidade de Brasília; 1986.

\footnotetext{
${ }^{4}$ As referências bibliográficas seguem as recomendações do Guia de Apresentação de Teses (USP 1998).
} 
11. Brass W. Methods for estimating fertility and mortality from limited and defective data. Chapel Hill: University of North Carolina at Chapel Hill, Carolina Population Center, 1975.

12. César IA, Rodrigues RN. A mortalidade por causas externas entre adolescentes do Recife e Salvador, nos anos 80. Anais do XI Encontro Nacional de Estudos Populacionais da ABEP. 1998; p. 1947-1958. Disponível em URL: http://www.abep.org.br.

13. Chaves MM. Complexidade e transdiciplinaridade: uma abordagem multidimensional do setor Saúde. [monografia online]. CEDROS; 1998. p. 118. Disponível em: URL: http://cedros.ufrj.br/complexi.htm.

14. Chiang CL. Introduction to stochastic processes in biostatistics. New York, John Wiley, 1968.

15. Chioro A, Almeida ES de, Zioni F. Políticas Públicas e Organização do sistema de saúde - antecedentes, reforma sanitária e o SUS. São Paulo; 1997. [Apostila do Curso Saúde e Sociedade - Faculdade de Saúde Pública da USP].

16. Conti S, Farchi G, Masocco M, Toccaceli V, Vichi M. The impact of the major causes of death on life expectancy in Italy. Int. J. Epidemiol. 1999 Oct; 28(5):905-10.

17. Courbage Y, Fargues P. A method for deriving mortality estimates from incomplete vital statistics. Population Studies. 1979; 33(1):165-180, Mar.

18. Farhat CK. Fundamentos e Prática das Imunizações em Clínica Médica e Pediatria. $3^{\mathrm{a}}$ ed. Rio de Janeiro, Livraria Atheneu, 1989.

19. Feuer EJ, Wun LM, Boring CC, Flanders WD, Timmel MJ, Tong T. The lifetime risk of developing breast cancer. J. Natl. Cancer Inst. 1993 Jun 2; 85(11):848-9.

20. Fraser GE, Shavlik D. Risk factors, lifetime risk, and age at onset of breast cancer. Ann. Epidemiol. 1997 Aug; 7(6):375-82.

21. Giovanella L, Drummond J, Skaba MMF, Oliveira RG de, Sá VM de. Eqüidade em Saúde no Brasil. Saúde em Debate. 1996 Dez/95-Mar/96; 49/50: 13-22. 
22. Goldbaum M. A Epidemiologia em busca da eqüidade em saúde. In: Barata RB (org.). Equidade e saúde: contribuições da Epidemiologia. Rio de Janeiro: Fiocruz/Abrasco; 1997. p. 63-80.

23. Gotlieb SLD. Mortalidade diferencial por causas - São Paulo, 1970 - Tábuas de Vida de Múltiplo Decremento. São Paulo; 1977. [Tese de Doutorado Faculdade de Saúde Pública da USP].

24. Gotlieb SLD, Castilho EA de, Buchalla CM. O Impacto da Aids na Esperança de Vida, Brasil, 1996. Boletim Epidemiológico AIDS. 2000; 13(2): 33-38.

25. Goulart FAA. Cenários Epidemiológicos, Demográficos e Institucionais para os Modelos de Atenção à Saúde. IESUS. 1999; 8(2): 17-26.

26. Harman D. Extending functional life span. Experimental Gerontology. 1998; 33(1):95-112.

27. Instituto Brasileiro de Geografia e Estatística. Brasil: tábuas-modelo de mortalidade e populações estáveis. Rio de Janeiro, IBGE, 1981.

28. __ Tábua de Vida reflete o envelhecimento da população. 1999 dez 1 . Disponivel em: URL: http://www.ibge.net/ibge/presidencia/noticias/01 1299.shtm.

29. Jannuzzi PM. Indicadores sociais no Brasil. Campinas, SP: Editora Alínea, 2001.

30. Kerr-Pontes LRS, Rouquayrol MZ. A Medida da Saúde Coletiva. In: Rouquayrol MZ, Almeida-Filho N. Epidemiologia \& Saúde. $5^{\text {a }}$ ed. Rio de Janeiro: MEDSI, 1999. p. 31-75.

31. Lalonde M. A new perspective on the health of the health of Canadians: a work document. Ottawa, April 1974, Canada, 1978, 76p.

32. Lai D, Tsai SP, Hardy RJ. Impact of HIV/AIDS on life expectancy in United States. AIDS. 1997 Feb; 11(2):203-7.

33. Laurenti R, Mello Jorge MHP de, Lebrão ML, Gotlieb SLD. Estatísticas de Saúde. $2^{a}$ ed. São Paulo: EPU; 1987.

34. Lloyd-Jones DM, Larson MG, Beiser A, Levy D. Lifetime risk of developing coronary heart disease. Lancet. 1999 Jan 9; 353(9147):89-92. 
35. Lotufo PA. Coffee, Samba, Football and ... Social Inequalities: Reflections on Mortality in São Paulo, Brazil. São Paulo Med J/Rev Paul Med. 2001; 119(3):94-6.

36. Lun KC. Mortality analyses of the 1990 Singapore population: I. General life tables. Ann. Acad. Med. Singapore. 1995 May; 24(3):382-92.

37. Manton KG, Blazer DG, Woodbury MA. Suicide in middle age and later life: sex and race specific life table and cohort analyses. J. Gerontol. 1987 Mar; 42(2):219-27.

38. Mello Jorge MHP de, Gotlieb SLD. As condições de saúde no Brasil. Rio de Janeiro: Editora FIOCRUZ; 2000.

39. Mendes EV. Uma agenda para a saúde. $2^{a}$ ed. São Paulo: Hucitec-Abrasco; 1999.

40. Mendes EV, Teixeira CF, Araújo EC, Cardoso MRL. Distritos Sanitários: conceitos-chave. In: Mendes EV, organizador. Distrito Sanitário: o processo social de mudança das práticas sanitárias do Sistema Único de Saúde. $4^{\text {a }}$ ed. São Paulo - Rio de Janeiro: Hucitec-Abrasco; 1999. p. 159-185.

41. Ministério da Saúde. Sistema de informações sobre mortalidade: 1979-1998. [CD-ROM]. Brasília: CENEPI, 2000a.

42. Report of the Workshop "Health Systems Performance - The World Health Report 2000”. Rio de Janeiro: Brasil; 2000 b.

43. Moraes IHS de. Informações em Saúde: da prática fragmentada ao exercício da cidadania. São Paulo - Rio de Janeiro: Hucitec-Abrasco; 1994.

44. Muenning PA, Gold MR. Using the Years-of-Healthy-Life Measure to Calculate QALYs. Am J Prev Med. 2001; 20(1):35-39.

45. Mullahy J. Live long, live well: quantifying the health of heterogeneous populations. NBER Working Paper. 2000; n. 7895 JEL n. 11, September. Disponível em: URL: http://www.nber.org/papers/w7895.pdf. 
46. Murray CJL, Lopez AD (ed.). The global burden of disease: a comprehensive assessment of mortality and disability from diseases, injuries and risk factors in 1990 and projected to 2020. [WHO/WORLD BANK] - Cambridge MA: Harvard Univ. Press; 1996. (Global Burden of Disease and Injury Series, Vol. 1).

47. Oliveira SMT. A tábua de sobrevivência de riscos competitivos: avaliação de um pressuposto. São Paulo; 1983. [Tese de Mestrado - Instituto de Matemática e Estatística da USP].

48. Organização Mundial de Saúde. Manual da Classificação Estatística Internacional de Doenças e Problemas Relacionados à Saúde - 10 Revisão. São Paulo: Centro Colaborador da OMS para a Classificação de Doenças em Português; 1995.

49. Ortiz LP. O modelo de riscos competitivos no estudo da mortalidade infantil. Anais do XI Encontro Nacional de Estudos Populacionais da ABEP. 1998; p. 1783-1802. Disponível em URL: http://www.abep.org.br.

50. Paes NA. Tábuas de vida de múltiplo decremento - o modelo de Chiang. São Paulo 1982. [Tese de Mestrado - Instituto de Matemática e Estatística da USP].

51. Pereira MG. Epidemiologia: teoria e prática. Rio de Janeiro: Guanabara Koogan S.A.; 1995.

52. Programa das Nações Unidas para o Desenvolvimento. Relatório do Desenvolvimento Humano 2000. Lisboa: Trinova Editora; 2000. Disponível em: URL: http://www.unpd.org/unpd/hdro.

53. Rockett IR. Injury elimination and survival: a cross-national study. Public Health. 1998 Jan; 112(1):27-30.

54. Rockett IR, Pollard JH. Life table analysis of the United States' Year 2000 mortality objectives. Int. J. Epidemiol. 1995 Jun; 24(3):547-51.

55. Santos JLF, Ortiz LP, Yazaki LM. Aplicações da técnica de Riscos Competitivos a dados brasileiros. Anais do IV Encontro Nacional de Estudos Populacionais da ABEP. 1984 Outubro 7-11. Águas de São Pedro: p. 1157-1195. Disponível em URL: http://www.abep.org.br. 
56. Segura A. Avaliação epidemiológica do efeito das intervenções sanitárias. In Barreto et al. (org.). Epidemiologia, Serviços e Tecnologias em Saúde. Rio de Janeiro: ABRASCO/FIOCRUZ; 1998.

57. Silva MGC. Mortalidade por causas evitáveis em Fortaleza de 1978 a 1995. Fortaleza; 1998. [Tese para Concurso de Professor Titular da UECE]. 300p.

58. Silva MGC, BEZERRA FILHO JG. Probabilidade de vir a morrer segundo causas em Fortaleza nos triênios de 1978-80 e 1993-95. Rev. Med. UFC. 1998; $38(1-2)$.

59. Simões CC da S. Brasil: estimativa da mortalidade infantil por micro-regiões e municípios. Brasília: Ministério da Saúde; 1999. Disponível em URL: http://www.datasus.gov.br.

60. ___ Perfis de saúde e de mortalidade no Brasil: uma análise de seus condicionantes em grupos populacionais específicos. Brasília: Organização Pan-Americana de Saúde; 2002.

61. Stephenson J. Apocalypse Now: HIV/AIDS in Africa Exceeds the Experts' Worst Predictions. JAMA. 2000 Aug 2; 284(5):556-557.

62. Stover J, Way P. Projecting the impact of AIDS on mortality. AIDS. 1998; 12(Suppl 1):S29-S39.

63. Superintendência de Estudos Econômicos e Sociais da Bahia. Projeções de População por Sexo e Idade. Bahia - 1991-2020. Salvador: SEI; 1999.

64. Szwarcwald CL, Bastos FI, Esteves MAP, Andrade CLT de. A disseminação da epidemia de AIDS no Brasil, no período de 1987-1996: uma análise espacial. Cad. Saúde Públ. 2000; 16(Sup. 1):7-19.

65. Szwarcwald CL, Leal M do C, Castilho EA de, Andrade CLT de. Mortalidade infantil no Brasil: Belíndia ou Bulgária? Cad. Saúde Públ. 1997 Jul./Set; $13(6): 503-516$.

66. Universidade de São Paulo. Faculdade de Saúde Pública. Biblioteca/CIR. Guia de Apresentação de Teses/Grupo de trabalho, Angela Maria Belloni Cuenca, Daisy Pires Noronha, Maria Lúcia Evangelista de Faria Ferraz, Maria Teresinha Dias de Andrade. São Paulo: A Biblioteca; 1998. 
67. Vasconcelos AMN. Qualidade das estatísticas de óbitos no Brasil: uma classificação das Unidades da Federação. Anais do XII Encontro Nacional de Estudos Populacionais da ABEP. 2000 Outubro 23-27. Disponível em URL: http://www.abep.org.br.

68. Vasconcelos AMN. A qualidade das estatísticas de óbitos no Brasil. Revista Brasileira de Estudos de População, ABEP. 1998; 15(1), jan-jul. Disponível em URL: http://www.abep.org.br.

69. Vasconcelos AMN, Lima DD. A mortalidade por acidentes de trânsito no Brasil: evolução recente. Anais do XXIV General Population Conference. 2001 Agosto 18-24. Salvador - Brasil. Disponível em URL: http://www.abep.org.br.

70. Waldvogel B, Morais LCC. Mortalidade por AIDS em São Paulo: Dezoito anos de História. Anais do XI Encontro Nacional de Estudos Populacionais da ABEP. 1998; p. 2131-2145. Disponível em URL: http://www.abep.org.br.

71. Wilmoth JR. Demography and longevity: past, present and future trends. Experimental Gerontology. 2000; 35: 1111-1129.

72. Wood E, Braitstein P, Montaner JSG, Schechter MT, Tyndall MW, O'Shaughnessy MV, Hogg RS. Extent to which low-level use of antiretroviral treatment could curb the AIDS epidemic in sub-Saharan Africa. The Lancet. 2000 Jun 17; 355:2095-2100.

73. World Health Organization. Small Arms and Global Health. WHO Contribution to the UN Conference on Illicit Trade in Small Arms and Light Weapons. Geneva: WHO; 2001 Jul. 9-20. Disponível em: URL: http://www.who.int/violence_injury_prevention/report.htm.

74. World Health Organization. The World Health Report 2000: Health Systems: Improving Performance. Geneva: WHO; 2000. Disponível em: URL: http://www.who.int/whr/2000/en/report.htm.

75. Wun LM, Merrill RM, Feuer EJ. Estimating lifetime and age-conditional probabilities of developing cancer. Lifetime Data Anal. 1998; 4(2):169-86. 
ANEXOS 
ANEXO 1 - Número de óbitos corrigidos e probabilidades bruta $\left(q_{X}\right)$ e líquida ( $q_{x}$.) de morte dos residentes no Município de Salvador - BA em 1996 (sexo masculino), segundo faixas etárias e grupos de causas de morte eliminados.

\begin{tabular}{|c|c|c|c|c|c|c|c|c|c|c|c|c|c|c|}
\hline \multirow[b]{2}{*}{ Idade } & \multicolumn{2}{|c|}{$\begin{array}{l}\text { Todas as } \\
\text { Causas }\end{array}$} & \multicolumn{2}{|c|}{$\begin{array}{l}\text { Infecciosas e } \\
\text { Parasitárias }\end{array}$} & \multicolumn{2}{|c|}{$\begin{array}{l}\text { Infecciosas } \\
\text { Intestinais }\end{array}$} & \multicolumn{2}{|c|}{$\begin{array}{c}\text { Outras Doencas } \\
\text { Bacterianas }\end{array}$} & \multicolumn{2}{|c|}{$\begin{array}{l}\text { Doenças } \\
\text { Virais }\end{array}$} & \multicolumn{2}{|c|}{ Neoplasias } & \multicolumn{2}{|c|}{$\begin{array}{l}\text { D. Aparelho } \\
\text { Circulatório }\end{array}$} \\
\hline & obito & $Q X$ & $\delta$ & $\mathrm{QX}$ & ito. & QX. & itos & QX. & itos & QX. & obitos & $\mathrm{QX}$ & itos & QX. \\
\hline 0 & 760 & 0,03977 & 111 & 0,03406 & 71 & 0,03612 & 39 & 0,03776 & - & 0,03977 & 3 & 0,03961 & 1 &, 03971 \\
\hline 1 & 54 & 00287 & 8 & 0,00245 & 3 & 0,00271 & 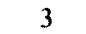 & & $=$ & & 4 & & 3 & 9271 \\
\hline 2 & 31 & 0,00158 & 3 & 0,00142 & 1 & 0,00152 & - & 0,00147 & - & 0,00158 & - & & 2 & 147 \\
\hline 3 & 18 & 0,00093 & 4 & 0,00073 & 1 & 0,00088 & 2 & 0,00083 & - & 0,00093 & 4 & 0,00073 & 1 & 0088 \\
\hline 4 & 13 & 0,00066 & - & 0,00066 & - & 0,00066 & - & 0,00066 & - & 0,00066 & - & & 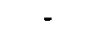 & 0066 \\
\hline $5-9$ & 56 & 0,00279 & 7 & & 2 & & 3 & & - & & 5 & & 3 & 264 \\
\hline $10-14$ & 75 & & 1 & & - & & 1 & & - & & 6 & & 4 & 0285 \\
\hline $15-19$ & 288 & 0,01131 & 12 & 0,01084 & 1 & 0,01127 & 4 & 116 & 4 & 16 & 10 & 92 & 14 & 1077 \\
\hline $20-24$ & 358 & & 19 & & 1 & & 4 & & 8 & & 10 & & 1 & 613 \\
\hline $25-29$ & 311 & 0,01623 & 42 & 36 & 1 & 0,01618 & 5 & 0,0 & 23 & & & & 23 & 1504 \\
\hline $30-34$ & 328 & & 67 & & 2 & & 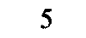 & & 38 & & 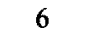 & & & 661 \\
\hline 35-39 & 364 & 0,02 & 75 & 51 & 1 & & 3 & $0, \mathrm{C}$ & 41 & & 23 & & 58 & 959 \\
\hline $40-44$ & 382 & 0,02958 & 70 & 23 & 2 & 43 & 18 & & 18 & & 35 & & 85 & 308 \\
\hline-40 & 382 & & 5 & & 2 & & 3 & & 12 & & 36 & & & 773 \\
\hline $50-54$ & 420 & 010 & 50 & 4 & 3 & 69 & 13 & & 5 & & 6 & & 127 & 232 \\
\hline $55-59$ & 469 & & & & 4 & & 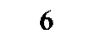 & & 7 & & & & 1 & 828 \\
\hline & 537 & & & & 2 & & $n_{2}$ & & 1 & & 81 & & 7 & 3235 \\
\hline 65-69 & 579 & & & & 3 & & 12 & & - & & & & & \\
\hline $70-74$ & 598 & & 3 & & 1 & & 1 & & - & & & & & 679 \\
\hline $75-79$ & 474 & 305 & 2 & & 3 & & 13 & & - & & 96 & & & 364 \\
\hline 80 et & 774 & & 41 & & 5 & & 18 & & - & & 113 & & 296 & 000 \\
\hline Total & 7.271 & & 743 & & 109 & & 177 & & 157 & & 92 & & 1.776 & \\
\hline$\ldots$ & $\begin{array}{l}\text { D. Is } \\
\text { do }\end{array}$ & 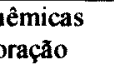 & & & Kes & & & & $\mathrm{Tr}$ & de & & & 9, & 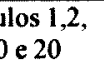 \\
\hline Iuade & óbitos & & & & bitos & & bitos & & & & . & & óbitos & \\
\hline 0 & - & & 1 & & 77 & & & & - & & - & & & 2956 \\
\hline 1 & - & & - & & 8 & & 7 & & - & & - & & 0 & 128 \\
\hline 2 & - & & 1 & & 8 & & 6 & & - & & 2 & & 21 & 051 \\
\hline 3 & - & & - & & 1 & & 2 & & - & & - & & & 031 \\
\hline 4 & - & & - & & 3 & & 9 & & 2 & & - & & 2 & 005 \\
\hline $5-9$ & - & & I & & 1 & & 2 & & 2 & & 3 & & & 0060 \\
\hline & - & & - & & 0 & & 3 & & 0 & & & & & 072 \\
\hline & - & & 1 & & & & & & & & & & & 051 \\
\hline $20-24$ & - & & 2 & & 11 & & & & & & & & & 206 \\
\hline $25-29$ & 3 & & 4 & & 16 & & & & 8 & & & & 277 & 179 \\
\hline & 4 & & - & & 25 & & & & 9 & & & & & 321 \\
\hline 35-39 & 10 & & 2 & & 23 & & & & 13 & & & & & 496 \\
\hline $40-44$ & 13 & & & & 25 & & 7 & & 8 & & 28 & & 294 & 0689 \\
\hline & 22 & & & & & & & & 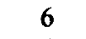 & & 19 & & & 1026 \\
\hline $50-54$ & 27 & 35 & & 26 & 37 & & 3 & & 4 & & 0 & & 316 & 523 \\
\hline $55-59$ & 32 & & & 967 & 40 & & 3 & & 4 & & 8 & & 365 & 2074 \\
\hline & 44 & & 64 & & 67 & & 23 & & 3 & & 4 & & & 3093 \\
\hline $65-69$ & 51 & & 62 & & 66 & & 29 & & 2 & 375 & 2 & & 444 & 0,04914 \\
\hline $70-74$ & 71 & & 68 & & 87 & & 19 & & 1 & & 3 & & 480 & 112 \\
\hline $75-79$ & 44 & 0,35002 & 63 & & 58 & & 16 & & 1 & & 1 & & 374 & 0,09533 \\
\hline 80 et & 67 & 1,00000 & 97 & 1,00000 & 150 & 1,00000 & 25 & 1,00000 & 3 & 000 & 2 & 1,00000 & 625 & 1,00000 \\
\hline Total & 388 & & 540 & & 744 & & 1.344 & & 95 & & 676 & & 5.399 & \\
\hline
\end{tabular}


ANEXO 2 - Número de óbitos corrigidos e probabilidades bruta $\left(q_{\mathrm{X}}\right)$ e líquida (qx.) de morte dos residentes no Município de São Paulo - SP em 1996 (sexo masculino), segundo faixas etárias e grupos de causas de morte eliminados.

\begin{tabular}{|c|c|c|c|c|c|c|c|c|c|c|c|c|c|c|}
\hline \multirow[b]{2}{*}{ Idade } & \multicolumn{2}{|c|}{$\begin{array}{l}\text { Todas as } \\
\text { Causas }\end{array}$} & \multicolumn{2}{|c|}{$\begin{array}{l}\text { Infecciosas e } \\
\text { Parasitárias }\end{array}$} & \multicolumn{2}{|c|}{$\begin{array}{l}\text { Infecciosas } \\
\text { Intestinais }\end{array}$} & \multicolumn{2}{|c|}{$\begin{array}{c}\text { Outras Doencas } \\
\text { Bacterianas }\end{array}$} & \multicolumn{2}{|c|}{$\begin{array}{l}\text { Doenças } \\
\text { Virais }\end{array}$} & \multicolumn{2}{|c|}{ Neoplasias } & \multicolumn{2}{|c|}{$\begin{array}{l}\text { D. Aparelho } \\
\text { Circulatório }\end{array}$} \\
\hline & obitos & $\mathrm{QX}$ & óbitos & QX. & óbitos & $\mathrm{QX}$ & Obitos & $\mathrm{QX}$ & bitos & QX. & óbitos & $\mathrm{QX}$ & óbitos & $\mathrm{QX}$ \\
\hline 0 & 2.571 & 0,03048 & 211 & 0,02802 & 122 & 0,02906 & 62 & 0,02976 & 23 & 0,03021 & 6 & 0,03041 & 25 & 0,03019 \\
\hline 1 & 156 & 0,00196 & 32 & 0,00156 & 10 & 0,00183 & 15 & 0,00177 & 3 & 0,00192 & 4 & 0,00191 & 4 & 0,00191 \\
\hline 2 & 75 & 0,00092 & 19 & 0,00069 & 2 & 0,00090 & 9 & 0,00081 & 8 & 0,00082 & 3 & 0,00089 & 2 & 0,00090 \\
\hline 3 & 59 & 0,00072 & 14 & 0,00055 & 2 & 0,00070 & 8 & 0,00062 & 1 & 0,00071 & 8 & 0,00062 & - & 0,00072 \\
\hline 4 & 36 & 0,00046 & 7 & 0,00037 & 1 & 0,00044 & 5 & 0,00039 & 1 & 0,00044 & 6 & 0,00038 & - & 0,00046 \\
\hline $5 * 9$ & 191 & 0,00225 & 23 & 0,00198 & 1 & 0,00224 & 13 & 0,00210 & 9 & 0,00214 & 28 & 0,00192 & 4 & 0,00220 \\
\hline $10^{*} 14$ & 303 & 0,00328 & 15 & 0,00312 & 1 & 0,00327 & 7 & 0,00320 & 5 & 0,00323 & 34 & 0,00291 & 7 & 0,00320 \\
\hline $15^{*} 19$ & 1.366 & 0,01473 & 24 & 0,01447 & 1 & 0,01472 & 6 & 0,01467 & 13 & 0,01459 & 39 & 0,01431 & 35 & 0,01435 \\
\hline $20 * 24$ & 2.014 & 0,02150 & 123 & 0,02020 & 1 & 0,02149 & 4 & 0,02146 & 102 & 0,02042 & 33 & 0,02115 & 39 & 0,02109 \\
\hline $25^{*} 29$ & 2.385 & 0,02670 & 458 & 0,02163 & 1 & 0,02669 & 13 & 0,02656 & 405 & 0,02222 & 47 & 0,02618 & 77 & 0,02585 \\
\hline $30 * 34$ & 2.416 & 0,02877 & 616 & 0,02151 & 1 & 0,02875 & 12 & 0,02862 & 531 & 0,02251 & 88 & 0,02773 & 126 & 0,02729 \\
\hline $35^{\prime} 39$ & 2.522 & 0,03344 & 572 & 0,02596 & 1 & 0,03343 & 22 & 0,03315 & 471 & 0,02728 & 107 & 0,03204 & 285 & 0,02972 \\
\hline $40{ }^{n} 44$ & 2.506 & 0,03840 & 427 & 0,03196 & 1 & 0,03838 & 14 & 0,03819 & 305 & 0,03380 & 204 & 0,03533 & 480 & 0,03116 \\
\hline $45^{*} 49$ & 2.473 & 0,04757 & 280 & 0,04230 & 3 & 0,04751 & 14 & 0,04731 & 169 & 0,04439 & 341 & 0,04115 & 692 & 0,03449 \\
\hline $50 * 54$ & 2.602 & 0,06493 & 215 & 0,05972 & 1 & 0,06490 & 23 & 0,06437 & 99 & 0,06253 & 419 & 0,05476 & 894 & 0,04311 \\
\hline $55^{\prime} 59$ & 2.768 & 0,08803 & 136 & 0,08389 & 3 & 0,08794 & 16 & 0,08755 & 52 & 0,08645 & 573 & 0,07047 & 1.099 & 0,05405 \\
\hline $60^{2} 64$ & 3.282 & 0,12655 & 135 & 0,12168 & 4 & 0,12641 & 26 & 0,12562 & 34 & 0,12533 & 753 & 0,09901 & 1.406 & 0,07443 \\
\hline $65^{*} 69$ & 3.709 & 0,17379 & 102 & 0,16944 & 5 & 0,17358 & 24 & 0,17277 & 21 & 0,17290 & 782 & 0,13986 & 1.642 & 0,10093 \\
\hline $70 * 74$ & 3.618 & 0,24203 & 86 & 0,23702 & 9 & 0,24150 & 21 & & 12 & & 754 & 0,19696 & 1.636 & 0,14084 \\
\hline $75 * 79$ & 3.035 & 0,34390 & 56 & 0,33878 & 3 & 0,34362 & 19 & 216 & 4 & 0,34353 & 624 & 0,28451 & 1.320 & 0,21191 \\
\hline $80 \mathrm{ct}$ & 4.813 & 1,00000 & 75 & 1,00000 & 8 & 1,00000 & 30 & & 2 & & 713 & 1,00000 & 2.177 & 1,00000 \\
\hline Total & \multicolumn{2}{|c|}{42.900} & \multicolumn{2}{|l|}{3.626} & \multicolumn{2}{|l|}{181} & \multicolumn{2}{|l|}{363} & \multicolumn{2}{|l|}{2.270} & \multicolumn{2}{|l|}{5.566} & \multicolumn{2}{|l|}{11.950} \\
\hline & \multicolumn{2}{|c|}{$\begin{array}{l}\text { D. Isquêmicas } \\
\text { do Coração }\end{array}$} & \multicolumn{2}{|c|}{$\begin{array}{l}\text { Doenças } \\
\text { Cerebrov. }\end{array}$} & \multicolumn{2}{|c|}{$\begin{array}{l}\text { D. Aparelho } \\
\text { Respiratório }\end{array}$} & & is & Aci & $\begin{array}{l}\text { de } \\
\text { te }\end{array}$ & A & & $\begin{array}{r}\text { Capít } \\
9,1\end{array}$ & $\begin{array}{l}\text { los } 1,2 \\
\text { e } 20\end{array}$ \\
\hline Idade & óbitos & $\mathrm{QX}$ & óbitos & QX & óbitos & QX & óbitos & QX. & obitos & QX. & óbitos & $\mathrm{QX}$. & óbitos & QX. \\
\hline 0 & - & 0,03048 & 7 &, 03040 & 355 & 0,02633 & 37 & 0,03005 & 4 & 0,03044 & 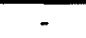 & 0,03048 & 634 & 0,02305 \\
\hline 1 & - & & 1 & & 52 & & 17 & & 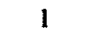 & & 2 & & 109 & 059 \\
\hline 2 & - & 0,00092 & - & 0,00092 & 17 & 0,00071 & 14 & 075 & 1 & 0,00091 & 2 & 0,00090 & 55 & 0,00025 \\
\hline 3 & - & 0,00072 & - & 0,00072 & 7 & 0,00063 & 17 & 051 & 6 & 0,00065 & 1 & 0,00071 & 46 & 0016 \\
\hline 4 & - & 0,00046 & - & 0,00046 & 3 & 0,00042 & 14 & 0,00028 & 9 & 0,00034 & - & 0,00046 & 30 & 0,00008 \\
\hline $5^{*} 9$ & - & 0,00225 & 2 & 0,00223 & 16 & 0,00206 & 89 & 0,00120 & 42 & 0,00176 & 6 & 0,00218 & 160 & 0,00037 \\
\hline $10 * 14$ & 1 & 0,00327 & - & 0,00328 & 20 & 0,00306 & 198 & 0,00114 & 80 & 0,00241 & 34 & 0,00291 & 274 & 0,00031 \\
\hline $15^{*} 19$ & 4 & 0,01469 & 12 & 0,01460 & 34 & 0,01437 & 1.177 & 0,00205 & 177 & 0,01283 & 761 & 0,00655 & 1.309 & 0,00062 \\
\hline $20 \cdot 24$ & 11 & 0,02138 & 6 & 0,02144 & 49 & 0,02098 & 1.678 & 0,00362 & 275 & 0,01859 & 1.129 & 0,00951 & 1.922 & 0,00099 \\
\hline $25^{*} 29$ & 22 & 0,02646 & 19 & 0,02649 & 75 & 0,02587 & 1.568 & 0,00923 & 241 & 0,02404 & 1.053 & 0,01500 & 2.225 & 0,00181 \\
\hline $30 \times 34$ & 44 & 0,02825 & 31 & 0,02840 & 123 & 0,02732 & 1.207 & 0,01450 & 215 & 0,02624 & 750 & 0,01993 & 2.160 & 0,00309 \\
\hline & 122 & 0,03185 & 70 & 0,03253 & 181 & 0,03108 & 975 & 0,02065 & 221 & 0,03055 & 474 & 0,02724 & 2.120 & 0,00541 \\
\hline 44 & 202 & 0,03536 & 140 & 0,03629 & 179 & 0,03571 & 728 & 0,02740 & 152 & 0,03611 & 324 & 0,03352 & 2.018 & 0,00760 \\
\hline $45 * 49$ & 329 & 0,04137 & 193 & 0,04394 & 209 & 0,04364 & 467 & 0,03876 & 111 & 0,04548 & 186 & 0,04407 & 1.989 & 0,00949 \\
\hline $50 * 54$ & 441 & 0,05423 & 224 & 0,05951 & 201 & 0,06006 & 361 & 0,05618 & 98 & 0,06256 & 108 & 0,06232 & 2.090 & 0,01312 \\
\hline $55 * 59$ & 519 & 0,07214 & 252 & 0,08035 & 241 & 0,08068 & 230 & 0,08102 & 53 & 0,08642 & 67 & 0,08599 & 2.279 & 0,01615 \\
\hline $60 * 64$ & 674 & 0,10194 & 352 & 0,11378 & 310 & 0,11532 & 175 & 0,12023 & 49 & 0,12479 & 36 & 0,12525 & 2.779 & 0,02052 \\
\hline & 708 & 0,14313 & 441 & 0,15482 & 476 & 0,15330 & 139 & 0,16786 & 46 & 0,17183 & 17 & 0,17307 & 3.141 & 0,02881 \\
\hline $70 \times 74$ & 735 & 0,19813 & 398 & 0,21856 & 539 & 0,21008 & 113 & 0,23544 & 43 & 0,23953 & 14 & 0,24121 & 3.128 & 0,03683 \\
\hline $75^{* 79}$ & 539 & 0,29291 & 343 & 0,31189 & 528 & 0,29399 & 66 & 0,33786 & 30 & 0,34116 & 1 & 0,34381 & 2.594 & 0,05940 \\
\hline $80 \mathrm{ct}$ & 806 & 1,00000 & 581 & 1,00000 & 1.040 & 1,00000 & 139 & 1,00000 & 40 & 1,00000 & 16 & 1,00000 & 4.144 & 1,00000 \\
\hline Total & 5.157 & & 3.072 & & 4.655 & & 9.409 & & 1.894 & & 4.981 & & 35.206 & \\
\hline
\end{tabular}


ANEXO 3 - Número de óbitos corrigidos e probabilidades bruta $\left(q_{x}\right)$ e líquida $\left(\mathrm{q}_{\mathrm{X} .}\right.$ ) de morte dos residentes no Município de Salvador - BA em 1996 (sexo feminino), segundo faixas etárias e grupos de causas de morte eliminados.

\begin{tabular}{|c|c|c|c|c|c|c|c|c|c|c|c|c|c|c|}
\hline \multirow[b]{2}{*}{ Idade } & \multicolumn{2}{|c|}{$\begin{array}{l}\text { Todas as } \\
\text { Causas }\end{array}$} & \multicolumn{2}{|c|}{$\begin{array}{l}\text { Infecciosas e } \\
\text { Parasitárias }\end{array}$} & \multicolumn{2}{|c|}{$\begin{array}{l}\text { Infecciosas } \\
\text { Intestinais }\end{array}$} & \multicolumn{2}{|c|}{$\begin{array}{c}\text { Outras Doenças } \\
\text { Bacterianas }\end{array}$} & \multicolumn{2}{|c|}{$\begin{array}{c}\text { Doenças } \\
\text { Virais }\end{array}$} & \multicolumn{2}{|c|}{ Neoplasias } & \multicolumn{2}{|c|}{$\begin{array}{l}\text { D. Aparelho } \\
\text { Circulatório }\end{array}$} \\
\hline & óbitc & $Q X$ & itos & $\mathrm{QX}$ & óbitos & $\mathrm{QX}$ & óbitos & QX. & bitos & QX & bitos & QX & bitos & QX \\
\hline 0 & 719 & 03973 & 93 &, 03468 & 67 & 0,03610 & 20 & 0,03865 & 5 & 0,03946 & 3 & 9,03957 & 1 &, 03968 \\
\hline 1 & 56 & 00309 & 7 & 0,00270 & 3 & 0,00292 & 2 & 0,00298 & - & & - & & - & \\
\hline 2 & 29 & 0,00150 & 3 & 0,00135 & 2 & 0,00140 & 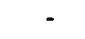 & 0,00150 & 1 & 145 & 1 & & - & 0150 \\
\hline 3 & 19 & & 5 & 074 & - & 0,00101 & 1 & 0096 & 2 & 090 & 3 & 85 & - & 0101 \\
\hline 4 & 10 & .00053 & 1 & 0,00047 & - & 0,00053 & 1 & 0,00047 & - & 0053 & - & 0053 & 1 & 0047 \\
\hline $5^{2} 9$ & 29 & 0,00149 & 7 & 0,00113 & 1 & 0,00144 & 2 & 0,00139 & 2 & 0,00139 & 7 & 113 & 1 & 0144 \\
\hline $10 * 14$ & 70 & 0,00278 & 5 & & - & 0,00278 & 2 & 9270 & - & 0,00278 & 9 & & 9 & 0242 \\
\hline $15^{*} 19$ & 90 & 0,00320 & 10 & 0,00284 & 2 & 0,00313 & 6 & 0,00299 & - & 0,00320 & 9 & 288 & 7 & 0295 \\
\hline $20 * 24$ & 67 & 0,00271 & 3 & 0,00259 & - & 0,00271 & - & 0,00271 & 1 & 267 & 7 & & 11 & 0227 \\
\hline $25^{*} 29$ & 125 & 0,00565 & 30 & 0,00429 & - & 0,00565 & 6 & 0,00538 & 18 & 0,00484 & 11 &, 00515 & 21 & 0470 \\
\hline $30 " 34$ & 154 & 0,0 & 26 & & - & & 1 & & 15 & & 26 & & 32 & 585 \\
\hline $35 * 39$ & 221 & 14 & 32 & 0 & 1 & 208 & 6 & 81 & 14 & & 44 & & 52 & 9929 \\
\hline $40 " 44$ & 269 & 322 & 45 & 0, & 1 & 0,0 & 11 & 748 & 9 & 61 & 62 & 05 & 77 & 1304 \\
\hline $45^{2} 49$ & 305 & & 25 & & 1 & & 9 & & 6 & & 74 & & 104 & 1817 \\
\hline $50 \times 54$ & 331 & 971 & 30 & 0,03618 & 2 & 48 & 7 & 89 & 3 & 936 & 69 & 56 & 134 & 2383 \\
\hline $55 * 59$ & 407 & & 3 & & 3 & & 8 & & 6 & & 88 & & 147 & 3973 \\
\hline 64 & 468 & & 28 & 6 & 2 & & 7 & & 2 & & 91 & & 193 & 5082 \\
\hline $65^{*} 69$ & 600 & & 34 & & - & & 9 & & 1 & & 117 & & 228 & 3414 \\
\hline $70 * 74$ & 596 & & 25 & & 5 & & 6 & & - & & 100 & & 251 & 935 \\
\hline $75^{* 79}$ & 606 & 601 & 32 & 55 & 8 & 0,2 & 12 & & - & 01 & 99 & & 272 & 6306 \\
\hline $80 \mathrm{ct}$ & 1.566 & & 68 & & 18 & & 32 & & 1 & & 154 & & 740 & 0000 \\
\hline Total & 6.737 & & 42 & & 116 & & 148 & & 86 & & 974 & & & \\
\hline & $\begin{array}{l}\text { D. Is } \\
\text { do }\end{array}$ & & & & $\operatorname{Re}$ & & & & $\mathrm{T}$ & & & & & 2 \\
\hline tut & óbitos & QX. & bitos & QX. & Sbitos & & & QX. & & QX. & Wous & QX. & óbitos & $\mathrm{QX}$. \\
\hline 0 & - & & - & & 61 & & 4 & & - & & 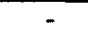 & & & - \\
\hline 1 & - & & - & & 21 & & 3 & & . & & - & & & 138 \\
\hline 2 & - & & - & & 6 & & 3 & & " & & - & & 13 & 083 \\
\hline 3 & - & & - & & 1 & & 4 & & - & & - & & 1 & \\
\hline 4 & - & & - & & 3 & & 2 & & - & & 1 & & 7 & 0016 \\
\hline 529 & - & & - & & - & & 8 & & - & & 2 & & 23 & 0031 \\
\hline $10^{2} 14$ & 1 & & - & & 9 & & 18 & & 3 & & 3 & & 50 & 0080 \\
\hline $15^{*} 19$ & - & 20 & 2 & & 14 & & 26 & & 1 & & 12 & 77 & 66 & 085 \\
\hline & 1 & & 3 & & 3 & & & & - & & 11 & & 46 & 0085 \\
\hline & - & 565 & 9 & & 11 & & & & 2 & & 10 & & 100 & 1113 \\
\hline $30 * 34$ & - & & & & 15 & & 17 & & 2 & & 5 & & 116 & 0183 \\
\hline & 5 & & 23 & & 17 & & & & 3 & & 5 & & 167 & 9298 \\
\hline 44 & 9 & 761 & 26 & & 11 & 48 & 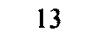 & & 4 & & 1 & & 208 & 0416 \\
\hline $45^{\prime} 49$ & 14 & & & & 19 & & 17 & & 2 & & 2 & & 239 & 0,00600 \\
\hline & 19 & & 38 & & 17 & & 8 & & - & & - & & 258 & 890 \\
\hline 59 & 26 & 0,05768 & 51 & 0,05400 & 26 & 768 & 11 & 988 & - & 149 & 1 & 135 & 305 & 1578 \\
\hline & 39 & & 61 & & 50 & & 1 & & - & & - & & 375 & 1748 \\
\hline 69 & 52 & 0,12144 & 72 & 0,11728 & 66 & & 14 & & 1 & 196 & - & 3216 & 459 & 0,03276 \\
\hline & 53 & 0,16663 & 95 & 0,15479 & 61 & 0,16438 & 17 & 0,17664 & 2 & 0,18077 & - & 0,18132 & 454 & 0,04655 \\
\hline $75^{\wedge} 79$ & 38 & & & & & & 0 & & - & & - & & & 0,06694 \\
\hline $80 \mathrm{et}$ & 119 & 1,00000 & 268 & 1,00000 & 245 & 000 & 23 & 000 & 2 & 000 & $=$ & 000 & 1.230 & 1,00000 \\
\hline Total & 376 & & 803 & & 720 & & 281 & & 23 & & 53 & & 4.798 & \\
\hline
\end{tabular}


ANEXO 4 - Número de óbitos corrigidos e probabilidades bruta $\left(\mathrm{q}_{\mathrm{x}}\right)$ e líquida $\left(q_{X}\right.$.) de morte dos residentes no Município de São Paulo - SP em 1996 (sexo feminino), segundo faixas etárias e grupos de causas de morte eliminados.

\begin{tabular}{|c|c|c|c|c|c|c|c|c|c|c|c|c|c|c|}
\hline \multirow[b]{2}{*}{ Idade } & \multicolumn{2}{|c|}{$\begin{array}{l}\text { Todas as } \\
\text { Causas }\end{array}$} & \multicolumn{2}{|c|}{$\begin{array}{l}\text { Infecciosas e } \\
\text { Parasitárias }\end{array}$} & \multicolumn{2}{|c|}{$\begin{array}{l}\text { Infecciosas } \\
\text { Intestinais }\end{array}$} & \multicolumn{2}{|c|}{$\begin{array}{l}\text { Outras Doenças } \\
\text { Bacterianas }\end{array}$} & \multicolumn{2}{|c|}{$\begin{array}{c}\text { Doenças } \\
\text { Virais }\end{array}$} & \multicolumn{2}{|c|}{ Neoplasias } & \multicolumn{2}{|c|}{$\begin{array}{l}\text { D. Aparelho } \\
\text { Circulatório }\end{array}$} \\
\hline & óbitos & $\mathrm{QX}$ & bitos & QX. & bitos & QX. & bitos & QX. & bitos & QX. & bitos & QX & bitos & $Q X$ \\
\hline 0 & 2.028 & 02504 & 168 & 0,02299 & 72 & 0,02416 & 68 & 0,02421 & 19 & 0,02480 & 9 &, 02493 & 19 &, 02480 \\
\hline 1 & 159 & 0,00206 & 28 & 0,00170 & 7 & & 11 & & 6 & & 3 & & 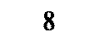 & \\
\hline 2 & 80 & 0,00102 & 23 & & 3 & & 12 & & 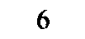 & & 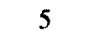 & & & \\
\hline 3 & 46 & 0,00058 & 13 & 0,00042 & 1 & 0,00057 & 9 & 0,00047 & 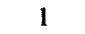 & 0,00057 & 2 & 00056 & 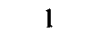 & 0057 \\
\hline 4 & 27 & 0,00035 & 5 & 0,00029 & 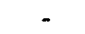 & 0,00035 & 1 & 034 & 8 & 30 & 2 & 33 & 2 & 033 \\
\hline $5 * 9$ & 140 & 0,00169 & 16 & & 1 & & 5 & 163 & 8 & & 20 & & 9 & 158 \\
\hline $10 " 14$ & 187 & 0203 & 6 & 196 & - & 0203 & 4 & 0198 & 2 & & 25 & 76 & 13 & 0189 \\
\hline & 314 & 0,00 & 16 & & - & 25 & 6 & & 8 & & 30 & & 18 & 306 \\
\hline 24 & 428 & & 71 & & - & & 4 & & 57 & & 36 & & 30 & 410 \\
\hline $25^{a} 29$ & 523 & 0,00566 & 168 & 0,00384 & - & 0,00566 & 5 & 0560 & 154 & 400 & 40 & 523 & 47 & 9515 \\
\hline $30 * 34$ & 678 & 0,00749 & & & 1 & & 2 & 747 & 168 & & 99 & & 84 & 657 \\
\hline 39 & 891 & 0,01074 & 4 & & 1 & 0,01073 & 7 & 066 & 147 & & 174 & & 198 & 837 \\
\hline 44 & 944 & & 20 & & 2 & & 8 & & & & & & 268 & \\
\hline $45^{*} 49$ & .211 & 990 & 92 & & 4 & & 5 & 082 & 53 & & 327 & 30 & 407 & 393 \\
\hline $50 * 54$ & 389 & 87 & 70 & & 1 & & 10 & & 29 & & 383 & 245 & 519 & 945 \\
\hline & 648 & & 60 & & 1 & & 10 & & 11 & & & & 650 & 772 \\
\hline & 067 & & 6 & & 3 & & 15 & & 12 & & & & 876 & 798 \\
\hline & 2.571 & & & & 2 & & & & & & & & & \\
\hline & 1 & & 6 & & 9 & & 24 & & 3 & & & & & 375 \\
\hline $75 \bullet 79$ & 3.094 & & 5 & & 11 & & 23 & & 3 & & & & & 800 \\
\hline 80 et & 7.591 & & 119 & & 24 & & 69 & & 5 & & 101 & & 3.928 & 000 \\
\hline Total & 29.027 & & 1.604 & & 143 & & 319 & & 791 & & .972 & & 10073 & \\
\hline$\ldots$ & $\begin{array}{l}\text { D. Is } \\
\text { do } C\end{array}$ & & & & 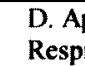 & & & & $T r$ & & & & 9, & , \\
\hline & óbitos & & jtos & & & & itos & & & & ninos & & pitos & \\
\hline $\mathbf{0}$ & - & & 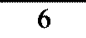 & & & & 38 & & & & 3 & & & \\
\hline 1 & 1 & & 1 & & & & 18 & & 5 & & 1 & & 105 & 70 \\
\hline 2 & - & & 1 & & 1 & & 12 & & 3 & & - & & & 31 \\
\hline 3 & - & & - & & 8 & & 12 & & 6 & & & & & \\
\hline 4 & - & & - & & 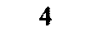 & & 9 & & 6 & & - & & 22 & 007 \\
\hline & - & & 3 & & & & 50 & & & & 7 & & & \\
\hline & - & & 2 & & & & & & & & & & 8 & \\
\hline & 1 & & 2 & & & & & & & & & & 274 & 041 \\
\hline & 8 & & 8 & & 3 & & & & 53 & & & & 345 & 086 \\
\hline 29 & 10 & & 14 & & 4 & & 13 & & 51 & & & & 429 & 102 \\
\hline & & & & & & & & & & & & & & \\
\hline & 49 & & 0 & & 14 & & 117 & & & & & & 747 & \\
\hline & 60 & & & & & & 84 & & & & & 276 & 788 & 217 \\
\hline & & & & & & & & & & & & & 1.007 & \\
\hline 54 & 161 & 34 & & & 12 & & & & 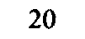 & & & 60 & & \\
\hline & 247 & & & & & & 71 & & 39 & 31 & 12 & 503 & 1.381 & 749 \\
\hline & 332 & & & & & & & & & & 7 & & & \\
\hline & 444 & & & & 267 & & 59 & 221 & 21 & & 4 & & 2.145 & 627 \\
\hline & 537 & & & & & & 5 & & 23 & & 1 & 0,14856 & 2.507 & 657 \\
\hline & 528 & & & & & & & & & & 1 & & & \\
\hline et & 1.340 & 1,00000 & 995 & 1,00000 & 1.435 & & 103 & 00 & 12 & & 3 & 000 & 6.346 & 1,00000 \\
\hline Total & .870 & & 3.031 & & 3.730 & & 1.612 & & 552 & & 402 & & 22.991 & \\
\hline
\end{tabular}


ANEXO 5 - Tábua de vida de múltiplo decremento, eliminando as doenças infecciosas e parasitárias como fator de risco de morte para residentes no Município de Salvador - BA em 1996 (sexo masculino).

\begin{tabular}{|c|c|c|c|c|c|c|}
\hline $\begin{array}{c}\mathbf{X} \\
(1)\end{array}$ & $\begin{array}{l}\mathbf{I}_{\mathbf{X}} \\
(2) \\
\end{array}$ & $\underset{(3)}{\mathbf{n}_{1} \mathbf{q}}$ & $\begin{array}{c}{ }_{n} \mathbf{d}_{\mathbf{X}} \\
(4)\end{array}$ & $\begin{array}{c}{ }_{(5)} \mathbf{L}_{\mathbf{x}} \\
\end{array}$ & $\begin{array}{l}\mathbf{T}_{\mathbf{X}} \\
(6)\end{array}$ & $\begin{array}{l}\mathbf{e x}_{\mathbf{X}} \\
(7) \\
\end{array}$ \\
\hline 0 & 100.000 & 0,03406 & 3.406 & 97.061 & 6.588 .164 & 65,88 \\
\hline 1 & 96.594 & 0,00245 & 236 & 96.429 & 6.491 .103 & 67,20 \\
\hline 2 & 96.358 & 0,00142 & 137 & 96.289 & 6.394 .674 & 66,36 \\
\hline 3 & 96.221 & 0,00073 & 70 & 96.186 & 6.298 .385 & 65,46 \\
\hline 4 & 96.151 & 0,00066 & 63 & 96.119 & 6.202 .199 & 64,50 \\
\hline 5 a 9 & 96.087 & 0,00244 & 235 & 479.850 & 6.106 .080 & 63,55 \\
\hline 10 a 14 & 95.853 & 0,00297 & 284 & 478.552 & 5.626 .230 & 58,70 \\
\hline 15 a 19 & 95.568 & 0,01084 & 1.036 & 475.250 & 5.147 .678 & 53,86 \\
\hline 20 a 24 & 94.532 & 0,01576 & 1.490 & 468.935 & 4.672 .428 & 49,43 \\
\hline 25 a 29 & 93.042 & 0,01406 & 1.308 & 461.941 & 4.203 .493 & 45,18 \\
\hline 30 a 34 & 91.734 & 0,01461 & 1.340 & 455.321 & 3.741 .552 & 40,79 \\
\hline 35 a 39 & 90.394 & 0,01851 & 1.673 & 447.788 & 3.286 .231 & 36,35 \\
\hline 40 a 44 & 88.721 & 0,02423 & 2.150 & 438.232 & 2.838 .443 & 31,99 \\
\hline 45 a 49 & 86.572 & 0,03319 & 2.873 & 425.675 & 2.400 .211 & 27,73 \\
\hline 50 a 54 & 83.699 & 0,05314 & 4.448 & 407.373 & 1.974 .536 & 23,59 \\
\hline 55 a 59 & 79.251 & 0,08170 & 6.475 & 380.065 & 1.567 .163 & 19,77 \\
\hline 60 a 64 & 72.776 & 0,12682 & 9.230 & 340.804 & 1.187 .097 & 16,31 \\
\hline 65 a 69 & 63.546 & 0,18193 & 11.561 & 288.828 & 846.294 & 13,32 \\
\hline 70 a 74 & 51.985 & 0,26024 & 13.528 & 226.104 & 557.466 & 10,72 \\
\hline 75 a 79 & 38.457 & 0,36419 & 14.005 & 157.269 & 331.362 & 8,62 \\
\hline 80 et & 24.451 & 1,00000 & 24.451 & 174.093 & 174.093 & 7,12 \\
\hline
\end{tabular}

ANEXO 6 - Tábua de vida de múltiplo decremento, eliminando as doenças infecciosas e parasitárias como fator de risco de morte para residentes no Município de São Paulo - SP em 1996 (sexo masculino).

\begin{tabular}{|c|c|c|c|c|c|c|}
\hline $\begin{array}{c}\mathbf{X} \\
\text { (1) }\end{array}$ & $\begin{array}{l}\mathbf{l}_{\mathbf{X}} \\
(2)\end{array}$ & $\underset{(3)}{\mathbf{n}_{(3)}}$ & $\begin{array}{l}{ }_{n} \mathbf{d x}_{\mathbf{X}} \\
(4)\end{array}$ & $\begin{array}{c}{ }_{(5)} \mathbf{L}_{\mathbf{x}} \\
\end{array}$ & $\begin{array}{l}T_{\mathbf{X}} \\
(6)\end{array}$ & $\begin{array}{l}\mathbf{e x} \\
\text { (7) }\end{array}$ \\
\hline 0 & 100.000 & 0,02802 & 2.802 & 97.582 & 6.494 .720 & 64,95 \\
\hline 1 & 97.198 & 0,00156 & 151 & 97.093 & 6.397 .138 & 65,82 \\
\hline 2 & 97.047 & 0,00069 & 67 & 97.014 & 6.300 .045 & 64,92 \\
\hline 3 & 96.980 & 0,00055 & 53 & 96.954 & 6.203 .032 & 63,96 \\
\hline 4 & 96.927 & 0,00037 & 36 & 96.909 & 6.106 .078 & 63,00 \\
\hline 5 a 9 & 96.891 & 0,00198 & 192 & 483.977 & 6.009 .169 & 62,02 \\
\hline 10 a 14 & 96.699 & 0,00312 & 301 & 482.744 & 5.525 .192 & 57,14 \\
\hline 15 a 19 & 96.398 & 0,01447 & 1.395 & 478.502 & 5.042 .448 & 52,31 \\
\hline 20 a 24 & 95.003 & 0,02020 & 1.919 & 470.217 & 4.563 .946 & 48,04 \\
\hline 25 a 29 & 93.084 & 0,02163 & 2.013 & 460.385 & 4.093 .729 & 43,98 \\
\hline 30 a 34 & 91.070 & 0,02151 & 1.959 & 450.454 & 3.633 .344 & 39,90 \\
\hline 35 a 39 & 89.111 & 0,02596 & 2.313 & 439.774 & 3.182 .890 & 35,72 \\
\hline 40 a 44 & 86.798 & 0,03196 & 2.774 & 427.057 & 2.743 .116 & 31,60 \\
\hline 45 a 49 & 84.024 & 0,04230 & 3.554 & 411.236 & 2.316 .059 & 27,56 \\
\hline 50 a 54 & 80.470 & 0,05972 & 4.806 & 390.335 & 1.904 .823 & 23,67 \\
\hline 55 a 59 & 75.664 & 0,08389 & 6.348 & 362.451 & 1.514 .488 & 20,02 \\
\hline 60 a 64 & 69.316 & 0,12168 & 8.434 & 325.496 & 1.152 .037 & 16,62 \\
\hline 65 a 69 & 60.882 & 0,16944 & 10.316 & 278.620 & 826.541 & 13,58 \\
\hline 70 a 74 & 50.566 & 0,23702 & 11.985 & 222.868 & 547.920 & 10,84 \\
\hline 75 a 79 & 38.581 & 0,33878 & 13.070 & 160.229 & 325.053 & 8,43 \\
\hline 80 et & 25.511 & 1,00000 & 25.511 & 164.823 & 164.823 & 6,46 \\
\hline
\end{tabular}


ANEXO 7 - Tábua de vida de múltiplo decremento, eliminando as doenças infecciosas e parasitárias como fator de risco de morte para residentes no Município de Salvador - BA em 1996 (sexo feminino).

\begin{tabular}{|c|c|c|c|c|c|c|}
\hline $\begin{array}{c}\mathbf{X} \\
\text { (1) }\end{array}$ & $\begin{array}{l}\mathbf{I}_{\mathbf{X}} \\
(2)\end{array}$ & $\begin{array}{r}\mathbf{n q x} \\
(3) \\
\end{array}$ & 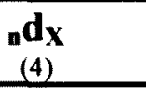 & ${ }^{n} \mathbf{L}_{\mathbf{X}}$ & $\begin{array}{l}T_{\mathbf{X}} \\
(6)\end{array}$ & $\begin{array}{l}\mathbf{e x} \\
\text { (7) }\end{array}$ \\
\hline$\overline{0}$ & 100.000 & 0,03468 & 3.468 & 97.135 & 7.172 .320 & 71,72 \\
\hline 1 & 96.532 & 0,00270 & 261 & 96.349 & 7.075 .185 & 73,29 \\
\hline 2 & 96.271 & 0,00135 & 130 & 96.206 & 6.978 .836 & 72,49 \\
\hline 3 & 96.141 & 0,00074 & 72 & 96.105 & 6.882 .630 & 71,59 \\
\hline 4 & 96.069 & 0,00047 & 45 & 96.047 & 6.786 .525 & 70,64 \\
\hline 5 a 9 & 96.024 & 0,00113 & 109 & 479.848 & 6.690 .478 & 69,68 \\
\hline 10 a 14 & 95.915 & 0,00258 & 248 & 478.957 & 6.210 .631 & 64,75 \\
\hline 15 a 19 & 95.668 & 0,00284 & 272 & 477.658 & 5.731 .674 & 59,91 \\
\hline 20 a 24 & 95.396 & 0,00259 & 247 & 476.360 & 5.254 .016 & 55,08 \\
\hline 25 a 29 & 95.149 & 0,00429 & 409 & 474.722 & 4.777 .655 & 50,21 \\
\hline 30 a 34 & 94.740 & 0,00614 & 581 & 472.247 & 4.302 .934 & 45,42 \\
\hline 35 a 39 & 94.159 & 0,01039 & 978 & 468.348 & 3.830 .687 & 40,68 \\
\hline 40 a 44 & 93.180 & 0,01519 & 1.416 & 462.363 & 3.362 .340 & 36,08 \\
\hline 45 a 49 & 91.765 & 0,02521 & 2.314 & 453.039 & 2.899 .977 & 31,60 \\
\hline 50 a 54 & 89.451 & 0,03618 & 3.236 & 439.164 & 2.446 .938 & 27,36 \\
\hline 55 a 59 & 86.215 & 0,05665 & 4.884 & 418.863 & 2.007 .773 & 23,29 \\
\hline 60 a 64 & 81.331 & 0,08006 & 6.512 & 390.374 & 1.588 .910 & 19,54 \\
\hline 65 a 69 & 74.819 & 0,12517 & 9.365 & 350.683 & 1.198 .536 & 16,02 \\
\hline 70 a 74 & 65.454 & 0,17442 & 11.417 & 298.729 & 847.854 & 12,95 \\
\hline 75 a 79 & 54.038 & 0,26355 & 14.242 & 234.583 & 549.124 & 10,16 \\
\hline 80 et & 39.796 & 1,00000 & 39.796 & 314.541 & 314.541 & 7,90 \\
\hline
\end{tabular}

ANEXO 8 - Tábua de vida de múltiplo decremento, eliminando as doenças infecciosas e parasitárias como fator de risco de morte para residentes no Município de São Paulo - SP em 1996 (sexo feminino).

\begin{tabular}{|c|c|c|c|c|c|c|}
\hline $\begin{array}{c}\mathbf{X} \\
\text { (1) }\end{array}$ & $\begin{array}{l}\mathbf{I}_{\mathbf{X}} \\
(2)\end{array}$ & $\begin{array}{r}\mathbf{n q}_{\mathbf{X}} \\
(3)\end{array}$ & $\begin{array}{l}{ }_{n} \mathbf{d}_{\mathbf{X}} \\
(4)\end{array}$ & $\begin{array}{c}{ }_{n} \mathbf{L}_{\mathbf{X}} \\
(5)\end{array}$ & $\begin{array}{l}T_{\mathbf{X}} \\
(6)\end{array}$ & $\begin{array}{l}\mathbf{e x}_{\mathbf{X}} \\
\text { (7) }\end{array}$ \\
\hline 0 & 100.000 & 0,02299 & 2.299 & 98.101 & 7.481 .974 & 74,82 \\
\hline 1 & 97.701 & 0,00170 & 166 & 97.585 & 7.383 .872 & 75,58 \\
\hline 2 & 97.535 & 0,00072 & 71 & 97.500 & 7.286 .287 & 74,70 \\
\hline 3 & 97.465 & 0,00042 & 41 & 97.444 & 7.188.788 & 73,76 \\
\hline 4 & 97.424 & 0,00029 & 28 & 97.410 & 7.091 .343 & 72,79 \\
\hline 5 a 9 & 97.396 & 0,00150 & 146 & 486.615 & 6.993 .933 & 71,81 \\
\hline 10 a 14 & 97.250 & 0,00196 & 191 & 485.774 & 6.507 .319 & 66,91 \\
\hline 15 a 19 & 97.059 & 0,00308 & 299 & 484.549 & 6.021 .545 & 62,04 \\
\hline 20 a 24 & 96.760 & 0,00367 & 356 & 482.913 & 5.536 .996 & 57,22 \\
\hline 25 a 29 & 96.405 & 0,00384 & 371 & 481.098 & 5.054 .083 & 52,43 \\
\hline 30 a 34 & 96.034 & 0,00532 & 511 & 478.894 & 4.572 .985 & 47,62 \\
\hline 35 a 39 & 95.523 & 0,00853 & 815 & 475.578 & 4.094 .091 & 42,86 \\
\hline 40 a 44 & 94.708 & 0,01142 & 1.082 & 470.836 & 3.618 .513 & 38,21 \\
\hline 45 a 49 & 93.626 & 0,01933 & 1.810 & 463.606 & 3.147 .677 & 33,62 \\
\hline 50 a 54 & 91.816 & 0,02933 & 2.693 & 452.348 & 2.684 .071 & 29,23 \\
\hline 55 a 59 & 89.123 & 0,04374 & 3.898 & 435.869 & 2.231 .723 & 25,04 \\
\hline 60 a 64 & 85.225 & 0,06299 & 5.368 & 412.702 & 1.795 .854 & 21,07 \\
\hline 65 a 69 & 79.856 & 0,09200 & 7.347 & 380.914 & 1.383 .153 & 17,32 \\
\hline 70 a 74 & 72.510 & 0,14569 & 10.564 & 336.139 & 1.002 .239 & 13,82 \\
\hline 75 a 79 & 61.946 & 0,23071 & 14.292 & 274.000 & 666.100 & 10,75 \\
\hline 80 et & 47.654 & 1,00000 & 47.654 & 392.100 & 392.100 & 8,23 \\
\hline
\end{tabular}


ANEXO 9 - Tábua de vida de múltiplo decremento, eliminando as doenças infecciosas intestinais como fator de risco de morte para residentes no Município de Salvador - BA em 1996 (sexo masculino).

\begin{tabular}{|c|c|c|c|c|c|c|}
\hline$\underset{\text { (1) }}{\mathbf{x}}$ & $\begin{array}{l}\mathbf{l}_{\mathbf{X}} \\
(2)\end{array}$ & ${ }_{(3)} \mathbf{9 x}$ & $\begin{array}{l}{ }_{n} d_{x} \\
(4)\end{array}$ & ${ }_{n}{ }_{(5)} \mathbf{L}_{\mathbf{X}}$ & $\underset{(6)}{\mathbf{T}_{\mathbf{X}}}$ & $\begin{array}{l}\mathbf{e x} \\
(7)\end{array}$ \\
\hline$\overline{0}$ & 100.000 & 0,03612 & 3.612 & 96.883 & 6.442 .857 & 64,43 \\
\hline 1 & 96.388 & 0,00271 & 261 & 96.205 & 6.345 .974 & 65,84 \\
\hline 2 & 96.127 & 0,00152 & 147 & 96.054 & 6.249 .769 & 65,02 \\
\hline 3 & 95.980 & 0,00088 & 85 & 95.938 & 6.153 .716 & 64,11 \\
\hline 4 & 95.895 & 0,00066 & 63 & 95.864 & 6.057 .778 & 63,17 \\
\hline 5 a 9 & 95.832 & 0,00269 & 258 & 478.516 & 5.961 .914 & 62,21 \\
\hline 10 a 14 & 95.574 & 0,00301 & 287 & 477.152 & 5.483 .398 & 57,37 \\
\hline 15 a 19 & 95.287 & 0,01127 & 1.074 & 473.748 & 5.006 .246 & 52,54 \\
\hline 20 a 24 & 94.213 & 0,01659 & 1.563 & 467.156 & 4.532 .498 & 48,11 \\
\hline 25 a 29 & 92.650 & 0,01618 & 1.499 & 459.501 & 4.065 .342 & 43,88 \\
\hline 30 a 34 & 91.150 & 0,01822 & 1.660 & 451.602 & 3.605 .842 & 39,56 \\
\hline 35 a 39 & 89.490 & 0,02319 & 2.075 & 442.262 & 3.154 .240 & 35,25 \\
\hline 40 a 44 & 87.415 & 0,02943 & 2.573 & 430.642 & 2.711 .978 & 31,02 \\
\hline 45 a 49 & 84.842 & 0,03881 & 3.293 & 415.979 & 2.281 .335 & 26,89 \\
\hline 50 a 54 & 81.549 & 0,05969 & 4.867 & 395.578 & 1.865 .357 & 22,87 \\
\hline 55 a 59 & 76.682 & 0,08944 & 6.859 & 366.263 & 1.469 .778 & 19,17 \\
\hline 60 a 64 & 69.823 & 0,13383 & 9.344 & 325.756 & 1.103 .515 & 15,80 \\
\hline 65 a 69 & 60.479 & 0,19345 & 11.700 & 273.145 & 777.760 & 12,86 \\
\hline 70 a 74 & 48.779 & 0,27317 & 13.325 & 210.583 & 504.614 & 10,34 \\
\hline 75 a 79 & 35.454 & 0,37618 & 13.337 & 143.928 & 294.031 & 8,29 \\
\hline 80 et & 22.117 & 1,00000 & 22.117 & 150.103 & 150.103 & 6,79 \\
\hline
\end{tabular}

ANEXO 10 - Tábua de vida de múltiplo decremento, eliminando as doenças infecciosas intestinais como fator de risco de morte para residentes no Município de São Paulo - SP em 1996 (sexo masculino).

\begin{tabular}{|c|c|c|c|c|c|c|}
\hline $\begin{array}{c}\mathbf{X} \\
\text { (1) }\end{array}$ & $\begin{array}{l}\mathbf{I X}_{\mathbf{X}} \\
(2)\end{array}$ & 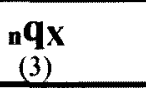 & $\begin{array}{c}{ }_{n} \mathbf{d}_{\mathbf{X}} \\
(4)\end{array}$ & $\begin{array}{c}{ }_{n} \mathbf{L}_{\mathbf{X}} \\
(5)\end{array}$ & $\begin{array}{l}\mathbf{T}_{\mathbf{X}} \\
(6)\end{array}$ & $\begin{array}{l}\mathbf{e x} \\
(7) \\
\end{array}$ \\
\hline 0 & 100.000 & 0,02906 & 2.906 & 97.492 & 6.350 .539 & 63,51 \\
\hline 1 & 97.094 & 0,00183 & 178 & 96.970 & 6.253 .046 & 64,40 \\
\hline 2 & 96.916 & 0,00090 & 87 & 96.873 & 6.156 .077 & 63,52 \\
\hline 3 & 96.829 & 0,00070 & 67 & 96.796 & 6.059 .204 & 62,58 \\
\hline 4 & 96.762 & 0,00044 & 43 & 96.740 & 5.962 .408 & 61,62 \\
\hline 5 a 9 & 96.719 & 0,00224 & 216 & 483.053 & 5.865 .667 & 60,65 \\
\hline 10 a 14 & 96.502 & 0,00327 & 315 & 481.724 & 5.382 .614 & 55,78 \\
\hline 15 a 19 & 96.187 & 0,01472 & 1.416 & 477.396 & 4.900 .890 & 50,95 \\
\hline 20 a 24 & 94.771 & 0,02149 & 2.037 & 468.765 & 4.423 .495 & 46,68 \\
\hline 25 a 29 & 92.735 & 0,02669 & 2.475 & 457.485 & 3.954 .730 & 42,65 \\
\hline 30 a 34 & 90.259 & 0,02875 & 2.595 & 444.809 & 3.497 .245 & 38,75 \\
\hline 35 a 39 & 87.664 & 0,03343 & 2.930 & 430.995 & 3.052 .436 & 34,82 \\
\hline 40 a 44 & 84.734 & 0,03838 & 3.252 & 415.538 & 2.621 .441 & 30,94 \\
\hline 45 a 49 & 81.481 & 0,04751 & 3.871 & 397.729 & 2.205 .903 & 27,07 \\
\hline 50 a 54 & 77.610 & 0,06490 & 5.037 & 375.457 & 1.808 .175 & 23,30 \\
\hline 55 a 59 & 72.573 & 0,08794 & 6.382 & 346.910 & 1.432 .717 & 19,74 \\
\hline 60 a 64 & 66.191 & 0,12641 & 8.367 & 310.037 & 1.085 .808 & 16,40 \\
\hline 65 a 69 & 57.824 & 0,17358 & 10.037 & 264.026 & 775.771 & 13,42 \\
\hline 70 a 74 & 47.787 & 0,24150 & 11.541 & 210.082 & 511.745 & 10,71 \\
\hline 75 a 79 & 36.246 & 0,34362 & 12.455 & 150.093 & 301.662 & 8,32 \\
\hline 80 et & 23.791 & 1,00000 & 23.791 & 151.570 & 151.570 & 6,37 \\
\hline
\end{tabular}


ANEXO 11 - Tábua de vida de múltiplo decremento, eliminando as doenças infecciosas intestinais como fator de risco de morte para residentes no Município de Salvador - BA em 1996 (sexo feminino).

\begin{tabular}{|c|c|c|c|c|c|c|}
\hline $\begin{array}{c}\mathbf{X} \\
\text { (1) }\end{array}$ & $\begin{array}{l}\mathbf{l}_{\mathbf{X}} \\
(2)\end{array}$ & $\underset{(3)}{{ }_{3} \mathbf{q} \mathbf{x}}$ & $\begin{array}{c}{ }_{n} \mathbf{d}_{\mathbf{X}} \\
(4)\end{array}$ & $\begin{array}{c}{ }_{n} \mathbf{L}_{\mathbf{X}} \\
(5)\end{array}$ & $\begin{array}{c}\mathbf{T}_{\mathbf{X}} \\
(6)\end{array}$ & $\begin{array}{l}\mathbf{e x} \\
(7) \\
\end{array}$ \\
\hline$\overline{\mathbf{0}}$ & 100.000 & 0,03610 & 3.610 & 97.018 & 7.070 .557 & 70,71 \\
\hline 1 & 96.390 & 0,00292 & 282 & 96.193 & 6.973 .538 & 72,35 \\
\hline 2 & 96.108 & 0,00140 & 135 & 96.041 & 6.877 .346 & 71,56 \\
\hline 3 & 95.974 & 0,00101 & 97 & 95.925 & 6.781 .304 & 70,66 \\
\hline 4 & 95.877 & 0,00053 & 50 & 95.852 & 6.685 .379 & 69,73 \\
\hline 5 a 9 & 95.826 & 0,00144 & 138 & 478.787 & 6.589 .528 & 68,77 \\
\hline 10 a 14 & 95.689 & 0,00278 & 266 & 477.778 & 6.110 .740 & 63,86 \\
\hline 15 a 19 & 95.423 & 0,00313 & 298 & 476.367 & 5.632 .963 & 59,03 \\
\hline 20 a 24 & 95.124 & 0,00271 & 258 & 474.976 & 5.156 .596 & 54,21 \\
\hline 25 a 29 & 94.866 & 0,00565 & 536 & 472.992 & 4.681 .620 & 49,35 \\
\hline 30 a 34 & 94.331 & 0,00738 & 696 & 469.913 & 4.208 .628 & 44,62 \\
\hline 35 a 39 & 93.635 & 0,01208 & 1.131 & 465.345 & 3.738 .715 & 39,93 \\
\hline 40 a 44 & 92.503 & 0,01815 & 1.679 & 458.319 & 3.273 .370 & 35,39 \\
\hline 45 a 49 & 90.824 & 0,02735 & 2.484 & 447.912 & 2.815 .051 & 30,99 \\
\hline 50 a 54 & 88.341 & 0,03948 & 3.487 & 432.985 & 2.367 .138 & 26,80 \\
\hline 55 a 59 & 84.853 & 0,06106 & 5.181 & 411.315 & 1.934 .153 & 22,79 \\
\hline 60 a 64 & 79.673 & 0,08459 & 6.739 & 381.514 & 1.522 .839 & 19,11 \\
\hline 65 a 69 & 72.933 & 0,13216 & 9.639 & 340.568 & 1.141 .324 & 15,65 \\
\hline 70 a 74 & 63.294 & 0,17995 & 11.389 & 287.996 & 800.756 & 12,65 \\
\hline 75 a 79 & 51.905 & 0,27291 & 14.165 & 224.109 & 512.760 & 9,88 \\
\hline 80 et & 37.739 & 1,00000 & 37.739 & 288.651 & 288.651 & 7,65 \\
\hline
\end{tabular}

ANEXO 12 - Tábua de vida de múltiplo decremento, eliminando as doenças infecciosas intestinais como fator de risco de morte para residentes no Município de São Paulo - SP em 1996 (sexo feminino).

\begin{tabular}{|c|c|c|c|c|c|c|}
\hline $\begin{array}{c}\mathbf{X} \\
\text { (1) }\end{array}$ & $\begin{array}{l}\mathbf{I}_{\mathbf{X}} \\
(2)\end{array}$ & ${ }_{\mathbf{3}} \mathbf{q u}$ & $\begin{array}{r}{ }_{(4)} \mathbf{d}_{\mathbf{X}} \\
\end{array}$ & ${ }_{(5)}{ }_{(5)} \mathbf{L}_{\mathbf{X}}$ & $\begin{array}{c}\mathbf{T}_{\mathbf{X}} \\
(6)\end{array}$ & $\begin{array}{l}\mathbf{e x} \\
\text { (7) }\end{array}$ \\
\hline$\overline{0}$ & 100.000 & 0,02416 & 2.416 & 98.005 & 7.402 .649 & 74,03 \\
\hline 1 & 97.584 & 0,00197 & 193 & 97.449 & 7.304 .644 & 74,85 \\
\hline 2 & 97.392 & 0,00098 & 95 & 97.344 & 7.207 .195 & 74,00 \\
\hline 3 & 97.296 & 0,00057 & 55 & 97.269 & 7.109 .851 & 73,07 \\
\hline 4 & 97.241 & 0,00035 & 34 & 97.224 & 7.012 .582 & 72,12 \\
\hline 5 a 9 & 97.207 & 0,00168 & 163 & 485.626 & 6.915 .359 & 71,14 \\
\hline 10 a 14 & 97.044 & 0,00203 & 197 & 484.726 & 6.429 .733 & 66,26 \\
\hline 15 a 19 & 96.847 & 0,00325 & 314 & 483.449 & 5.945 .007 & 61,39 \\
\hline 20 a 24 & 96.533 & 0,00440 & 425 & 481.600 & 5.461 .558 & 56,58 \\
\hline 25 a 29 & 96.108 & 0,00566 & 544 & 479.178 & 4.979 .957 & 51,82 \\
\hline 30 a 34 & 95.564 & 0,00748 & 715 & 476.032 & 4.500 .779 & 47,10 \\
\hline 35 a 39 & 94.849 & 0,01073 & 1.018 & 471.700 & 4.024 .748 & 42,43 \\
\hline 40 a 44 & 93.831 & 0,01305 & 1.224 & 466.094 & 3.553 .048 & 37,87 \\
\hline 45 a 49 & 92.607 & 0,02084 & 1.929 & 458.210 & 3.086 .953 & 33,33 \\
\hline 50 a 54 & 90.677 & 0,03084 & 2.797 & 446.394 & 2.628 .744 & 28,99 \\
\hline 55 a 59 & 87.880 & 0,04533 & 3.984 & 429.442 & 2.182 .350 & 24,83 \\
\hline 60 a 64 & 83.897 & 0,06491 & 5.446 & 405.869 & 1.752 .908 & 20,89 \\
\hline 65 a 69 & 78.451 & 0,09420 & 7.390 & 373.781 & 1.347 .039 & 17,17 \\
\hline 70 a 74 & 71.061 & 0,14819 & 10.531 & 328.979 & 973.258 & 13,70 \\
\hline 75 a 79 & 60.530 & 0,23350 & 14.134 & 267.318 & 644.280 & 10,64 \\
\hline 80 et & 46.397 & 1,00000 & 46.397 & 376.962 & 376.962 & 8,12 \\
\hline
\end{tabular}


ANEXO 13 - Tábua de vida de múltiplo decremento, eliminando as outras doenças bacterianas como fator de risco de morte para residentes no Município de Salvador - BA em 1996 (sexo masculino).

\begin{tabular}{|c|c|c|c|c|c|c|}
\hline $\begin{array}{c}\mathbf{X} \\
\text { (1) }\end{array}$ & $\begin{array}{l}\mathbf{l X}_{\mathbf{X}} \\
(2)\end{array}$ & $\begin{array}{c}\mathbf{n} \mathbf{q} \mathbf{x} \\
(3) \\
\end{array}$ & $\begin{array}{c}{ }^{n} \mathbf{d}_{\mathbf{X}} \\
(4)\end{array}$ & $\begin{array}{c}\mathbf{n}_{\mathbf{x}} \\
(5)\end{array}$ & $\begin{array}{l}\mathbf{T}_{\mathbf{X}} \\
(6)\end{array}$ & $\begin{array}{l}\mathbf{e x}_{\mathbf{X}} \\
\text { (7) }\end{array}$ \\
\hline$\overline{0}$ & 100.000 & 0,03776 & 3.776 & 96.741 & 6.453 .529 & 64,54 \\
\hline 1 & 96.224 & 0,00271 & 261 & 96.041 & 6.356 .788 & 66,06 \\
\hline 2 & 95.963 & 0,00147 & 141 & 95.892 & 6.260 .747 & 65,24 \\
\hline 3 & 95.821 & 0,00083 & 80 & 95.781 & 6.164 .855 & 64,34 \\
\hline 4 & 95.742 & 0,00066 & 63 & 95.710 & 6.069 .074 & 63,39 \\
\hline 5 a 9 & 95.678 & 0,00264 & 253 & 477.760 & 5.973 .364 & 62,43 \\
\hline 10 a 14 & 95.426 & 0,00297 & 283 & 476.420 & 5.495 .604 & 57,59 \\
\hline 15 a 19 & 95.142 & 0,01116 & 1.061 & 473.058 & 5.019 .184 & 52,75 \\
\hline 20 a 24 & 94.081 & 0,01645 & 1.548 & 466.536 & 4.546 .125 & 48,32 \\
\hline 25 a 29 & 92.533 & 0,01598 & 1.478 & 458.972 & 4.079 .589 & 44,09 \\
\hline 30 a 34 & 91.055 & 0,01805 & 1.643 & 451.167 & 3.620 .618 & 39,76 \\
\hline 35 a 39 & 89.412 & 0,02306 & 2.062 & 441.903 & 3.169 .451 & 35,45 \\
\hline 40 a 44 & 87.349 & 0,02821 & 2.464 & 430.587 & 2.727 .548 & 31,23 \\
\hline 45 a 49 & 84.885 & 0,03871 & 3.286 & 416.212 & 2.296 .961 & 27,06 \\
\hline 50 a 54 & 81.599 & 0,05830 & 4.757 & 396.105 & 1.880 .748 & 23,05 \\
\hline 55 a 59 & 76.842 & 0,08908 & 6.845 & 367.100 & 1.484 .643 & 19,32 \\
\hline 60 a 64 & 69.998 & 0,13266 & 9.286 & 326.772 & 1.117 .543 & 15,97 \\
\hline 65 a 69 & 60.711 & 0,19013 & 11.543 & 274.699 & 790.771 & 13,03 \\
\hline 70 a 74 & 49.168 & 0,26810 & 13.182 & 212.885 & 516.072 & 10,50 \\
\hline 75 a 79 & 35.986 & 0,36990 & 13.311 & 146.652 & 303.187 & 8,43 \\
\hline 80 et & 22.675 & 1,00000 & 22.675 & 156.535 & 156.535 & 6,90 \\
\hline
\end{tabular}

ANEXO 14 - Tábua de vida de múltiplo decremento, eliminando as outras doenças bacterianas como fator de risco de morte para residentes no Município de São Paulo - SP em 1996 (sexo masculino).

\begin{tabular}{|c|c|c|c|c|c|c|}
\hline $\begin{array}{l}\mathbf{X} \\
\text { (1) }\end{array}$ & $\begin{array}{l}\mathbf{I}_{\mathbf{X}} \\
(2)\end{array}$ & $\underset{(3)}{\mathbf{n}^{\mathbf{q}} \mathbf{x}}$ & $\begin{array}{c}{ }_{(4)} \mathbf{d}_{\mathbf{X}} \\
\end{array}$ & $\begin{array}{c}{ }_{n} \mathbf{L}_{\mathbf{x}} \\
(5)\end{array}$ & $\begin{array}{c}\mathbf{T}_{\mathbf{X}} \\
\end{array}$ & $\begin{array}{l}\mathbf{e x} \\
(7) \\
\end{array}$ \\
\hline 0 & 100.000 & 0,02976 & 2.976 & 97.432 & 6.356 .258 & 63,56 \\
\hline 1 & 97.024 & 0,00177 & 172 & 96.904 & 6.258 .826 & 64,51 \\
\hline 2 & 96.853 & 0,00081 & 79 & 96.813 & 6.161 .922 & 63,62 \\
\hline 3 & 96.774 & 0,00062 & 60 & 96.744 & 6.065 .109 & 62,67 \\
\hline 4 & 96.714 & 0,00039 & 38 & 96.695 & 5.968 .365 & 61,71 \\
\hline 5 a 9 & 96.675 & 0,00210 & 203 & 482.871 & 5.871 .671 & 60,74 \\
\hline 10 a 14 & 96.473 & 0,00320 & 309 & 481.591 & 5.388 .800 & 55,86 \\
\hline 15 a 19 & 96.164 & 0,01467 & 1.410 & 477.293 & 4.907 .209 & 51,03 \\
\hline 20 a 24 & 94.753 & 0,02146 & 2.033 & 468.684 & 4.429 .916 & 46,75 \\
\hline 25 a 29 & 92.720 & 0,02656 & 2.463 & 457.444 & 3.961 .232 & 42,72 \\
\hline 30 a 34 & 90.258 & 0,02862 & 2.584 & 444.829 & 3.503 .788 & 38,82 \\
\hline 35 a 39 & 87.674 & 0,03315 & 2.907 & 431.104 & 3.058 .959 & 34,89 \\
\hline 40 a 44 & 84.767 & 0,03819 & 3.237 & 415.744 & 2.627 .855 & 31,00 \\
\hline 45 a 49 & 81.530 & 0,04731 & 3.857 & 398.009 & 2.212 .111 & 27,13 \\
\hline 50 a 54 & 77.673 & 0,06437 & 5.000 & 375.867 & 1.814 .102 & 23,36 \\
\hline 55 a 59 & 72.673 & 0,08755 & 6.362 & 347.462 & 1.438 .235 & 19,79 \\
\hline 60 a 64 & 66.311 & 0,12562 & 8.330 & 310.732 & 1.090 .773 & 16,45 \\
\hline 65 a 69 & 57.982 & 0,17277 & 10.018 & 264.864 & 780.042 & 13,45 \\
\hline 70 a 74 & 47.964 & 0,24081 & 11.550 & 210.945 & 515.178 & 10,74 \\
\hline 75 a 79 & 36.414 & 0,34216 & 12.460 & 150.921 & 304.233 & 8,35 \\
\hline 80 et & 23.954 & 1,00000 & 23.954 & 153.312 & 153.312 & 6,40 \\
\hline
\end{tabular}


ANEXO 15 - Tábua de vida de múltiplo decremento, eliminando as outras doenças bacterianas como fator de risco de morte para residentes no Município de Salvador - BA em 1996 (sexo feminino).

\begin{tabular}{|c|c|c|c|c|c|c|}
\hline $\begin{array}{c}\mathbf{x} \\
(1)\end{array}$ & $\begin{array}{l}\mathbf{I X}_{\mathbf{X}} \\
(2)\end{array}$ & $\begin{array}{r}\mathbf{n} \mathbf{q x}_{(3)} \\
\end{array}$ & $\begin{array}{c}{ }^{n} \mathbf{d}_{(4)} \\
\end{array}$ & ${ }_{(5)} \mathbf{L}_{\mathbf{X}}$ & $\underset{(6)}{T_{\mathbf{X}}}$ & $\begin{array}{l}\mathbf{e x}_{\mathbf{X}} \\
\text { (7) }\end{array}$ \\
\hline$\overline{0}$ & 100.000 & 0,03865 & 3.865 & 96.808 & 7.069 .036 & 70,69 \\
\hline 1 & 96.135 & 0,00298 & 286 & 95.935 & 6.972 .228 & 72,53 \\
\hline 2 & 95.849 & 0,00150 & 144 & 95.777 & 6.876 .293 & 71,74 \\
\hline 3 & 95.705 & 0,00096 & 92 & 95.659 & 6.780 .517 & 70,85 \\
\hline 4 & 95.613 & 0,00047 & 45 & 95.590 & 6.684 .858 & 69,92 \\
\hline 5 a 9 & 95.568 & 0,00139 & 133 & 477.507 & 6.589 .268 & 68,95 \\
\hline 10 a 14 & 95.435 & 0,00270 & 258 & 476.531 & 6.111 .761 & 64,04 \\
\hline 15 a 19 & 95.177 & 0,00299 & 284 & 475.176 & 5.635 .230 & 59,21 \\
\hline 20 a 24 & 94.893 & 0,00271 & 257 & 473.823 & 5.160 .053 & 54,38 \\
\hline 25 a 29 & 94.636 & 0,00538 & 509 & 471.908 & 4.686 .230 & 49,52 \\
\hline 30 a 34 & 94.127 & 0,00733 & 690 & 468.911 & 4.214 .322 & 44,77 \\
\hline 35 a 39 & 93.437 & 0,01181 & 1.103 & 464.428 & 3.745 .411 & 40,08 \\
\hline 40 a 44 & 92.334 & 0,01748 & 1.614 & 457.634 & 3.280 .983 & 35,53 \\
\hline 45 a 49 & 90.720 & 0,02664 & 2.416 & 447.558 & 2.823.349 & 31,12 \\
\hline 50 a 54 & 88.303 & 0,03889 & 3.434 & 432.933 & 2.375 .791 & 26,90 \\
\hline 55 a 59 & 84.870 & 0,06032 & 5.120 & 411.549 & 1.942 .858 & 22,89 \\
\hline 60 a 64 & 79.750 & 0,08372 & 6.677 & 382.058 & 1.531 .309 & 19,20 \\
\hline 65 a 69 & 73.073 & 0,13032 & 9.523 & 341.560 & 1.149 .251 & 15,73 \\
\hline 70 a 74 & 63.551 & 0,17967 & 11.418 & 289.208 & 807.691 & 12,71 \\
\hline 75 a 79 & 52.132 & 0,27136 & 14.147 & 225.295 & 518.484 & 9,95 \\
\hline 80 et & 37.986 & 1,00000 & 37.986 & 293.188 & 293.188 & 7,72 \\
\hline
\end{tabular}

ANEXO 16 - Tábua de vida de múltiplo decremento, eliminando as outras doenças bacterianas como fator de risco de morte para residentes no Município de São Paulo - SP em 1996 (sexo feminino).

\begin{tabular}{|c|c|c|c|c|c|c|}
\hline $\begin{array}{c}\mathbf{X} \\
(1)\end{array}$ & $\begin{array}{l}\mathbf{X}_{\mathbf{X}} \\
(2) \\
\end{array}$ & $\underset{(3)}{\mathbf{n}^{\mathbf{q}} \mathbf{x}}$ & $\begin{array}{c}{ }_{(4)} \mathbf{d}_{\mathbf{x}} \\
\end{array}$ & $\begin{array}{c}\mathbf{n}_{\mathbf{X}} \\
(5)\end{array}$ & $\begin{array}{l}\mathbf{T}_{\mathbf{X}} \\
(6)\end{array}$ & $\begin{array}{l}\mathbf{e x} \\
(7) \\
\end{array}$ \\
\hline$\overline{0}$ & 100.000 & 0,02421 & 2.421 & 98.001 & 7.412 .201 & 74,12 \\
\hline 1 & 97.579 & 0,00192 & 187 & 97.448 & 7.314 .200 & 74,96 \\
\hline 2 & 97.392 & 0,00086 & 84 & 97.350 & 7.216 .752 & 74,10 \\
\hline 3 & 97.308 & 0,00047 & 46 & 97.285 & 7.119 .402 & 73,16 \\
\hline 4 & 97.262 & 0,00034 & 33 & 97.246 & 7.022 .118 & 72,20 \\
\hline 5 a 9 & 97.229 & 0,00163 & 158 & 485.749 & 6.924 .872 & 71,22 \\
\hline 10 a 14 & 97.071 & 0,00198 & 193 & 484.872 & 6.439 .123 & 66,33 \\
\hline 15 a 19 & 96.878 & 0,00318 & 308 & 483.620 & 5.954 .250 & 61,46 \\
\hline 20 a 24 & 96.570 & 0,00436 & 421 & 481.795 & 5.470 .631 & 56,65 \\
\hline 25 a 29 & 96.148 & 0,00560 & 539 & 479.395 & 4.988 .835 & 51,89 \\
\hline 30 a 34 & 95.610 & 0,00747 & 714 & 476.263 & 4.509 .440 & 47,17 \\
\hline 35 a 39 & 94.896 & 0,01066 & 1.012 & 471.949 & 4.033 .177 & 42,50 \\
\hline 40 a 44 & 93.884 & 0,01297 & 1.217 & 466.377 & 3.561 .228 & 37,93 \\
\hline 45 a 49 & 92.667 & 0,02082 & 1.929 & 458.510 & 3.094 .852 & 33,40 \\
\hline 50 a 54 & 90.737 & 0,03065 & 2.781 & 446.735 & 2.636 .341 & 29,05 \\
\hline 55 a 59 & 87.957 & 0,04509 & 3.966 & 429.868 & 2.189 .606 & 24,89 \\
\hline 60 a 64 & 83.991 & 0,06454 & 5.421 & 406.401 & 1.759 .738 & 20,95 \\
\hline 65 a 69 & 78.570 & 0,09354 & 7.349 & 374.476 & 1.353 .336 & 17,22 \\
\hline 70 a 74 & 71.221 & 0,14751 & 10.506 & 329.839 & 978.860 & 13,74 \\
\hline 75 a 79 & 60.715 & 0,23270 & 14.129 & 268.253 & 649.021 & 10,69 \\
\hline 80 et & 46.586 & 1,00000 & 46.586 & 380.767 & 380.767 & 8,17 \\
\hline
\end{tabular}


ANEXO 17 - Tábua de vida de múltiplo decremento, eliminando as doenças virais como fator de risco de morte para residentes no Município de Salvador - BA em 1996 (sexo masculino).

\begin{tabular}{|c|c|c|c|c|c|c|}
\hline $\begin{array}{c}\mathbf{X} \\
\text { (1) }\end{array}$ & $\begin{array}{l}\mathbf{L}_{\mathbf{X}} \\
(2)\end{array}$ & $\begin{array}{l}{ }_{(3)} \\
\mathbf{4}\end{array}$ & $\begin{array}{l}{ }_{n} \mathbf{d}_{X} \\
(4)\end{array}$ & ${ }_{(5)} \mathbf{L}_{\mathbf{X}}$ & $\begin{array}{l}\mathbf{T}_{\mathbf{X}} \\
(6)\end{array}$ & $\begin{array}{l}\mathbf{e x}_{\mathbf{x}} \\
(7)\end{array}$ \\
\hline$\overline{0}$ & 100.000 & 0,03977 & 3.977 & 96.568 & 6.440 .977 & 64,41 \\
\hline 1 & 96.023 & 0,00287 & 276 & 95.830 & 6.344 .409 & 66,07 \\
\hline 2 & 95.748 & 0,00158 & 151 & 95.672 & 6.248 .578 & 65,26 \\
\hline 3 & 95.597 & 0,00093 & 89 & 95.552 & 6.152 .906 & 64,36 \\
\hline 4 & 95.508 & 0,00066 & 63 & 95.476 & 6.057 .354 & 63,42 \\
\hline 5 a 9 & 95.445 & 0,00279 & 266 & 476.556 & 5.961 .878 & 62,46 \\
\hline $10 \times 14$ & 95.178 & 0,00301 & 286 & 475.175 & 5.485 .321 & 57,63 \\
\hline 15 a 19 & 94.892 & 0,01116 & 1.059 & 471.812 & 5.010 .147 & 52,80 \\
\hline 20 a 24 & 93.833 & 0,01626 & 1.526 & 465.350 & 4.538 .334 & 48,37 \\
\hline 25 a 29 & 92.307 & 0,01504 & 1.389 & 458.064 & 4.072 .984 & 44,12 \\
\hline 30 a 34 & 90.918 & 0,01622 & 1.475 & 450.905 & 3.614 .921 & 39,76 \\
\hline 35 a 39 & 89.444 & 0,02066 & 1.848 & 442.598 & 3.164 .015 & 35,37 \\
\hline 40 a 44 & 87.596 & 0,02821 & 2.471 & 431.801 & 2.721 .417 & 31,07 \\
\hline 45 a 49 & 85.125 & 0,03781 & 3.218 & 417.577 & 2.289 .616 & 26,90 \\
\hline 50 a 54 & 81.906 & 0,05941 & 4.866 & 397.366 & 1.872 .039 & 22,86 \\
\hline 55 a 59 & 77.040 & 0,08889 & 6.848 & 368.080 & 1.474 .673 & 19,14 \\
\hline 60 a 64 & 70.192 & 0,13406 & 9.410 & 327.435 & 1.106 .592 & 15,77 \\
\hline 65 a 69 & 60.782 & 0,19435 & 11.813 & 274.377 & 779.157 & 12,82 \\
\hline 70 a 74 & 48.969 & 0,27356 & 13.396 & 211.354 & 504.781 & 10,31 \\
\hline 75 a 79 & 35.573 & 0,37805 & 13.448 & 144.244 & 293.427 & 8,25 \\
\hline 80 et & 22.125 & 1,00000 & 22.125 & 149.183 & 149.183 & 6,74 \\
\hline
\end{tabular}

ANEXO 18 - Tábua de vida de múltiplo decremento, eliminando as doenças virais como fator de risco de morte para residentes no Município de São Paulo - SP em 1996 (sexo masculino).

\begin{tabular}{|c|c|c|c|c|c|c|}
\hline$\underset{\text { (1) }}{\mathbf{x}}$ & $\begin{array}{c}\mathbf{L}_{\mathbf{X}} \\
(2)\end{array}$ & ${ }_{\text {n) }} \mathbf{q x}$ & $\begin{array}{c}{ }_{n} \mathbf{d}_{\mathbf{X}} \\
(4)\end{array}$ & ${ }_{(5)} \mathbf{L}_{\mathbf{X}}$ & $\begin{array}{c}\mathbf{T}_{\mathbf{X}} \\
(6)\end{array}$ & $\begin{array}{l}\mathbf{e x} \\
(7)\end{array}$ \\
\hline$\overline{0}$ & 100.000 & 0,03021 & 3.021 & 97.393 & 6.431 .496 & 64,31 \\
\hline 1 & 96.979 & 0,00192 & 186 & 96.848 & 6.334 .104 & 65,31 \\
\hline 2 & 96.793 & 0,00082 & 80 & 96.753 & 6.237 .256 & 64,44 \\
\hline 3 & 96.713 & 0,00071 & 68 & 96.678 & 6.140 .503 & 63,49 \\
\hline 4 & 96.644 & 0,00044 & 43 & 96.623 & 6.043 .825 & 62,54 \\
\hline 5 a 9 & 96.601 & 0,00214 & 207 & 482.488 & 5.947 .202 & 61,56 \\
\hline 10 a 14 & 96.394 & 0,00323 & 311 & 481.193 & 5.464 .714 & 56,69 \\
\hline 15 a 19 & 96.083 & 0,01459 & 1.402 & 476.911 & 4.983 .521 & 51,87 \\
\hline 20 a 24 & 94.681 & 0,02042 & 1.934 & 468.572 & 4.506 .610 & 47,60 \\
\hline 25 a 29 & 92.748 & 0,02222 & 2.061 & 458.586 & 4.038 .038 & 43,54 \\
\hline 30 a 34 & 90.687 & 0,02251 & 2.042 & 448.330 & 3.579 .451 & 39,47 \\
\hline 35 a 39 & 88.645 & 0,02728 & 2.418 & 437.179 & 3.131 .122 & 35,32 \\
\hline 40 a 44 & 86.227 & 0,03380 & 2.915 & 423.846 & 2.693 .942 & 31,24 \\
\hline 45 a 49 & 83.312 & 0,04439 & 3.698 & 407.313 & 2.270 .096 & 27,25 \\
\hline 50 a 54 & 79.613 & 0,06253 & 4.979 & 385.621 & 1.862 .783 & 23,40 \\
\hline 55 a 59 & 74.635 & 0,08645 & 6.452 & 357.044 & 1.477 .162 & 19,79 \\
\hline 60 a 64 & 68.183 & 0,12533 & 8.545 & 319.550 & 1.120 .118 & 16,43 \\
\hline 65 a 69 & 59.637 & 0,17290 & 10.311 & 272.409 & 800.568 & 13,42 \\
\hline 70 a 74 & 49.326 & 0,24133 & 11.904 & 216.871 & 528.159 & 10,71 \\
\hline 75 a 79 & 37.422 & 0,34353 & 12.856 & 154.972 & 311.287 & 8,32 \\
\hline 80 et & 24.567 & 1,00000 & 24.567 & 156.315 & 156.315 & 6,36 \\
\hline
\end{tabular}


ANEXO 19 - Tábua de vida de múltiplo decremento, eliminando as doenças virais como fator de risco de morte para residentes no Município de Salvador - BA em 1996 (sexo feminino).

\begin{tabular}{|c|c|c|c|c|c|c|}
\hline $\begin{array}{c}\mathbf{x} \\
\text { (1) }\end{array}$ & $\begin{array}{l}\mathbf{I X}_{\mathbf{X}} \\
(2) \\
\end{array}$ & $\begin{array}{l}\mathbf{n}^{\prime} \mathbf{q}_{\mathbf{x}} \\
(3)\end{array}$ & $\begin{array}{l}{ }_{n} \mathbf{d}_{\mathbf{X}} \\
(4)\end{array}$ & $\begin{array}{c}{ }^{n} \mathbf{L}_{\mathbf{X}} \\
(5)\end{array}$ & $\begin{array}{c}\mathbf{T}_{\mathbf{X}} \\
(6)\end{array}$ & $\begin{array}{l}\mathbf{e x} \\
(7) \\
\end{array}$ \\
\hline 0 & 100.000 & 0,03946 & 3.946 & 96.740 & 7.052 .593 & 70,53 \\
\hline 1 & 96.054 & 0,00309 & 297 & 95.846 & 6.955 .852 & 72,42 \\
\hline 2 & 95.757 & 0,00145 & 139 & 95.688 & 6.860 .006 & 71,64 \\
\hline 3 & 95.618 & 0,00090 & 86 & 95.575 & 6.764 .319 & 70,74 \\
\hline 4 & 95.532 & 0,00053 & 50 & 95.506 & 6.668 .744 & 69,81 \\
\hline 5 a 9 & 95.481 & 0,00139 & 132 & 477.076 & 6.573 .238 & 68,84 \\
\hline 10 a 14 & 95.349 & 0,00278 & 265 & 476.082 & 6.096 .162 & 63,94 \\
\hline 15 a 19 & 95.084 & 0,00320 & 304 & 474.659 & 5.620 .081 & 59,11 \\
\hline 20 a 24 & 94.780 & 0,00267 & 253 & 473.266 & 5.145 .422 & 54,29 \\
\hline 25 a 29 & 94.527 & 0,00484 & 457 & 471.491 & 4.672 .156 & 49,43 \\
\hline 30 a 34 & 94.070 & 0,00666 & 627 & 468.781 & 4.200 .665 & 44,65 \\
\hline 35 a 39 & 93.443 & 0,01137 & 1.063 & 464.558 & 3.731 .884 & 39,94 \\
\hline 40 a 44 & 92.380 & 0,01761 & 1.627 & 457.833 & 3.267 .326 & 35,37 \\
\hline 45 a 49 & 90.753 & 0,02690 & 2.441 & 447.662 & 2.809 .493 & 30,96 \\
\hline 50 a 54 & 88.312 & 0,03936 & 3.476 & 432.869 & 2.361 .831 & 26,74 \\
\hline 55 a 59 & 84.836 & 0,06062 & 5.142 & 411.323 & 1.928 .963 & 22,74 \\
\hline 60 a 64 & 79.693 & 0,08459 & 6.741 & 381.614 & 1.517 .639 & 19,04 \\
\hline 65 a 69 & 72.952 & 0,13196 & 9.627 & 340.694 & 1.136 .025 & 15,57 \\
\hline 70 a 74 & 63.326 & 0,18132 & 11.482 & 287.922 & 795.331 & 12,56 \\
\hline 75 a 79 & 51.843 & 0,27601 & 14.309 & 223.444 & 507.409 & 9,79 \\
\hline 80 et & 37.534 & 1,00000 & 37.534 & 283.965 & 283.965 & 7,57 \\
\hline
\end{tabular}

ANEXO 20 - Tábua de vida de múltiplo decremento, eliminando as doenças virais como fator de risco de morte para residentes no Município de São Paulo - SP em 1996 (sexo feminino).

\begin{tabular}{|c|c|c|c|c|c|c|}
\hline $\begin{array}{c}\mathbf{X} \\
(1) \\
\end{array}$ & $\begin{array}{l}\mathbf{l}_{\mathbf{X}} \\
(2) \\
\end{array}$ & $\begin{array}{r}\mathbf{n q x} \\
(3) \\
\end{array}$ & $\begin{array}{c}{ }^{n} \mathbf{d}_{\mathbf{X}} \\
(4) \\
\end{array}$ & $\begin{array}{c}{ }_{n} \mathbf{L}_{\mathbf{X}} \\
(5) \\
\end{array}$ & $\begin{array}{l}\mathbf{T}_{\mathbf{X}} \\
(6) \\
\end{array}$ & $\begin{array}{r}\mathbf{e}_{\mathbf{x}} \\
\text { (7) } \\
\end{array}$ \\
\hline$\overline{0}$ & 100.000 & 0,02480 & 2.480 & 97.951 & 7.432 .780 & 74,33 \\
\hline 1 & 97.520 & 0,00199 & 194 & 97.384 & 7.334 .829 & 75,21 \\
\hline 2 & 97.326 & 0,00094 & 92 & 97.280 & 7.237 .445 & 74,36 \\
\hline 3 & 97.234 & 0,00057 & 55 & 97.207 & 7.140 .165 & 73,43 \\
\hline 4 & 97.179 & 0,00030 & 29 & 97.164 & 7.042 .959 & 72,47 \\
\hline 5 a 9 & 97.150 & 0,00159 & 155 & 485.362 & 6.945 .794 & 71,50 \\
\hline 10 a 14 & 96.995 & 0,00201 & 195 & 484.489 & 6.460 .432 & 66,61 \\
\hline 15 a 19 & 96.801 & 0,00316 & 306 & 483.237 & 5.975 .943 & 61,73 \\
\hline 20 a 24 & 96.494 & 0,00382 & 368 & 481.551 & 5.492 .706 & 56,92 \\
\hline 25 a 29 & 96.126 & 0,00400 & 384 & 479.670 & 5.011 .155 & 52,13 \\
\hline 30 a 34 & 95.742 & 0,00564 & 540 & 477.359 & 4.531 .486 & 47,33 \\
\hline 35 a 39 & 95.202 & 0,00898 & 855 & 473.872 & 4.054 .126 & 42,58 \\
\hline 40 a 44 & 94.347 & 0,01193 & 1.126 & 468.921 & 3.580 .254 & 37,95 \\
\hline 45 a 49 & 93.221 & 0,02000 & 1.864 & 461.445 & 3.111 .333 & 33,38 \\
\hline 50 a 54 & 91.357 & 0,03023 & 2.762 & 449.880 & 2.649 .888 & 29,01 \\
\hline 55 a 59 & 88.595 & 0,04506 & 3.992 & 432.995 & 2.200 .008 & 24,83 \\
\hline 60 a 64 & 84.603 & 0,06463 & 5.468 & 409.344 & 1.767 .014 & 20,89 \\
\hline 65 a 69 & 79.135 & 0,09385 & 7.427 & 377.106 & 1.357 .670 & 17,16 \\
\hline 70 a 74 & 71.708 & 0,14847 & 10.646 & 331.924 & 980.564 & 13,67 \\
\hline 75 a 79 & 61.062 & 0,23403 & 14.290 & 269.583 & 648.640 & 10,62 \\
\hline 80 et & 46.772 & 1,00000 & 46.772 & 379.057 & 379.057 & 8,10 \\
\hline
\end{tabular}


ANEXO 21 - Tábua de vida de múltiplo decremento, eliminando as neoplasias como fator de risco de morte para residentes no Município de Salvador - BA em 1996 (sexo masculino).

\begin{tabular}{|c|c|c|c|c|c|c|}
\hline $\begin{array}{c}\mathbf{X} \\
\text { (1) }\end{array}$ & $\begin{array}{l}\mathbf{I X}_{\mathbf{X}} \\
(2) \\
\end{array}$ & $\underset{(3)}{{ }_{(3)} \mathbf{q}}$ & $\begin{array}{c}{ }_{n} \mathbf{d} \mathbf{d x} \\
(4) \\
\end{array}$ & $\begin{array}{c}{ }_{n} \mathbf{L}_{\mathbf{X}} \\
(5)\end{array}$ & $\begin{array}{l}\mathbf{T}_{\mathbf{X}} \\
\text { (6) }\end{array}$ & $\begin{array}{l}\mathbf{e x} \\
(7) \\
\end{array}$ \\
\hline 0 & 100.000 & 0,03961 & 3.961 & 96.581 & 6.605 .378 & 66,05 \\
\hline 1 & 96.039 & 0,00266 & 255 & 95.860 & 6.508 .797 & 67,77 \\
\hline 2 & 95.784 & 0,00147 & 141 & 95.713 & 6.412 .937 & 66,95 \\
\hline 3 & 95.642 & 0,00073 & 70 & 95.608 & 6.317 .224 & 66,05 \\
\hline 4 & 95.573 & 0,00066 & 63 & 95.541 & 6.221 .616 & 65,10 \\
\hline 5 a 9 & 95.510 & 0,00254 & 243 & 476.941 & 6.126 .075 & 64,14 \\
\hline 10 a 14 & 95.267 & 0,00277 & 264 & 475.675 & 5.649 .134 & 59,30 \\
\hline 15 a 19 & 95.003 & 0,01092 & 1.038 & 472.422 & 5.173 .459 & 54,46 \\
\hline 20 a 24 & 93.966 & 0,01617 & 1.520 & 466.029 & 4.701 .037 & 50,03 \\
\hline 25 a 29 & 92.446 & 0,01592 & 1.472 & 458.549 & 4.235 .008 & 45,81 \\
\hline 30 a 34 & 90.974 & 0,01799 & 1.637 & 450.777 & 3.776 .459 & 41,51 \\
\hline 35 a 39 & 89.337 & 0,02180 & 1.948 & 441.815 & 3.325 .682 & 37,23 \\
\hline 40 a 44 & 87.389 & 0,02691 & 2.352 & 431.067 & 2.883 .866 & 33,00 \\
\hline 45 a 49 & 85.038 & 0,03540 & 3.010 & 417.663 & 2.452 .799 & 28,84 \\
\hline 50 a 54 & 82.027 & 0,05104 & 4.187 & 399.669 & 2.035 .136 & 24,81 \\
\hline 55 a 59 & 77.840 & 0,07651 & 5.955 & 374.313 & 1.635 .467 & 21,01 \\
\hline 60 a 64 & 71.885 & 0,11526 & 8.285 & 338.712 & 1.261 .154 & 17,54 \\
\hline 65 a 69 & 63.600 & 0,16153 & 10.273 & 292.316 & 922.442 & 14,50 \\
\hline 70 a 74 & 53.327 & 0,23122 & 12.330 & 235.808 & 630.126 & 11,82 \\
\hline 75 a 79 & 40.997 & 0,31526 & 12.925 & 172.672 & 394.318 & 9,62 \\
\hline 80 et & 28.072 & 1,00000 & 28.072 & 221.646 & 221.646 & 7,90 \\
\hline
\end{tabular}

ANEXO 22 - Tábua de vida de múltiplo decremento, eliminando as neoplasias como fator de risco de morte para residentes no Município de São Paulo - SP em 1996 (sexo masculino).

\begin{tabular}{|c|c|c|c|c|c|c|}
\hline $\begin{array}{c}\mathbf{x} \\
\text { (1) } \\
\end{array}$ & $\begin{array}{l}\mathbf{l}_{\mathbf{X}} \\
(2)\end{array}$ & $\mathbf{n}_{(3)} \mathbf{q} \mathbf{x}$ & $\begin{array}{c}{ }_{\mathbf{n}} \mathbf{d}_{\mathbf{X}} \\
(4)\end{array}$ & $\begin{array}{c}{ }_{n} \mathbf{L}_{\mathbf{X}} \\
(5)\end{array}$ & $\begin{array}{l}T_{\mathbf{X}} \\
(6)\end{array}$ & $\begin{array}{l}\mathbf{e x}_{\mathbf{X}} \\
(7)\end{array}$ \\
\hline$\overline{0}$ & 100.000 & 0,03041 & 3.041 & 97.375 & 6.561 .868 & 65,62 \\
\hline 1 & 96.959 & 0,00191 & 185 & 96.829 & 6.464 .492 & 66,67 \\
\hline 2 & 96.774 & 0,00089 & 86 & 96.731 & 6.367 .663 & 65,80 \\
\hline 3 & 96.688 & 0,00062 & 60 & 96.658 & 6.270 .932 & 64,86 \\
\hline 4 & 96.628 & 0,00038 & 37 & 96.609 & 6.174 .274 & 63,90 \\
\hline 5 a 9 & 96.591 & 0,00192 & 186 & 482.492 & 6.077 .664 & 62,92 \\
\hline 10 a 14 & 96.406 & 0,00291 & 281 & 481.326 & 5.595 .173 & 58,04 \\
\hline 15 a 19 & 96.125 & 0,01431 & 1.376 & 477.185 & 5.113 .847 & 53,20 \\
\hline 20 a 24 & 94.749 & 0,02115 & 2.004 & 468.735 & 4.636 .662 & 48,94 \\
\hline 25 a 29 & 92.745 & 0,02618 & 2.428 & 457.654 & 4.167 .927 & 44,94 \\
\hline 30 a 34 & 90.317 & 0,02773 & 2.505 & 445.321 & 3.710 .273 & 41,08 \\
\hline 35 a 39 & 87.812 & 0,03204 & 2.814 & 432.025 & 3.264 .951 & 37,18 \\
\hline 40 a 44 & 84.998 & 0,03533 & 3.003 & 417.483 & 2.832 .926 & 33,33 \\
\hline 45 a 49 & 81.995 & 0,04115 & 3.374 & 401.541 & 2.415 .443 & 29,46 \\
\hline 50 a 54 & 78.621 & 0,05476 & 4.306 & 382.343 & 2.013 .902 & 25,62 \\
\hline 55 a 59 & 74.316 & 0,07047 & 5.237 & 358.487 & 1.631 .559 & 21,95 \\
\hline 60 a 64 & 69.079 & 0,09901 & 6.840 & 328.296 & 1.273 .072 & 18,43 \\
\hline 65 a 69 & 62.239 & 0,13986 & 8.705 & 289.435 & 944.777 & 15,18 \\
\hline 70 a 74 & 53.535 & 0,19696 & 10.544 & 241.312 & 655.342 & 12,24 \\
\hline 75 a 79 & 42.990 & 0,28451 & 12.231 & 184.373 & 414.030 & 9,63 \\
\hline $80 \mathrm{e}^{+}$ & 30.759 & 1,00000 & 30.759 & 229.657 & 229.657 & 7,47 \\
\hline
\end{tabular}


ANEXO 23 - Tábua de vida de múltiplo decremento, eliminando as neoplasias como fator de risco de morte para residentes no Município de Salvador - BA em 1996 (sexo feminino).

\begin{tabular}{|c|c|c|c|c|c|c|}
\hline $\begin{array}{c}\mathbf{X} \\
(1)\end{array}$ & $\begin{array}{l}\mathbf{I X} \\
(2) \\
\end{array}$ & $\begin{array}{c}\mathbf{n q x} \\
(3) \\
\end{array}$ & $\begin{array}{c}\mathbf{n}_{(4)} \mathbf{d}_{\mathbf{X}} \\
\end{array}$ & $\begin{array}{c}{ }_{n} \mathbf{L}_{\mathbf{X}} \\
(5)\end{array}$ & $\begin{array}{l}\mathbf{T}_{\mathbf{X}} \\
(6)\end{array}$ & $\begin{array}{l}\text { ex } \\
\text { (7) }\end{array}$ \\
\hline$\overline{0}$ & 100.000 & 0,03957 & 3.957 & 96.731 & 7.266 .426 & 72,66 \\
\hline 1 & 96.043 & 0,00309 & 297 & 95.835 & 7.169 .695 & 74,65 \\
\hline 2 & 95.746 & 0,00145 & 139 & 95.677 & 7.073 .859 & 73,88 \\
\hline 3 & 95.607 & 0,00085 & 81 & 95.567 & 6.978 .183 & 72,99 \\
\hline 4 & 95.526 & 0,00053 & 50 & 95.501 & 6.882 .616 & 72,05 \\
\hline 5 a 9 & 95.476 & 0,00113 & 108 & 477.108 & 6.787 .115 & 71,09 \\
\hline 10 a 14 & 95.368 & 0,00242 & 231 & 476.261 & 6.310 .007 & 66,17 \\
\hline 15 a 19 & 95.137 & 0,00288 & 274 & 474.998 & 5.833 .746 & 61,32 \\
\hline 20 a 24 & 94.863 & 0,00243 & 230 & 473.738 & 5.358 .748 & 56,49 \\
\hline 25 a 29 & 94.632 & 0,00515 & 487 & 471.944 & 4.885 .010 & 51,62 \\
\hline 30 a 34 & 94.145 & 0,00614 & 578 & 469.281 & 4.413 .066 & 46,88 \\
\hline 35 a 39 & 93.567 & 0,00973 & 911 & 465.560 & 3.943 .785 & 42,15 \\
\hline 40 a 44 & 92.657 & 0,01405 & 1.302 & 460.029 & 3.478 .225 & 37,54 \\
\hline 45 a 49 & 91.355 & 0,02085 & 1.905 & 452.014 & 3.018 .196 & 33,04 \\
\hline 50 a 54 & 89.450 & 0,03156 & 2.823 & 440.193 & 2.566 .182 & 28,69 \\
\hline 55 a 59 & 86.627 & 0,04853 & 4.204 & 422.625 & 2.125 .989 & 24,54 \\
\hline 60 a 64 & 82.423 & 0,06901 & 5.688 & 397.897 & 1.703 .363 & 20,67 \\
\hline 65 a 69 & 76.735 & 0,10784 & 8.275 & 362.989 & 1.305 .467 & 17,01 \\
\hline 70 a 74 & 68.460 & 0,15337 & 10.500 & 316.051 & 942.477 & 13,77 \\
\hline 75 a 79 & 57.960 & 0,23678 & 13.724 & 255.492 & 626.426 & 10,81 \\
\hline 80 et & 44.236 & 1,00000 & 44.236 & 370.934 & 370.934 & 8,39 \\
\hline
\end{tabular}

ANEXO 24 - Tábua de vida de múltiplo decremento, eliminando as neoplasias como fator de risco de morte para residentes no Município de São Paulo - SP em 1996 (sexo feminino).

\begin{tabular}{|c|c|c|c|c|c|c|}
\hline $\begin{array}{c}\mathbf{x} \\
\text { (1) }\end{array}$ & $\begin{array}{r}\mathbf{l} \mathbf{x} \\
(2) \\
\end{array}$ & $\begin{array}{c}\mathbf{n} \mathbf{q} \mathbf{x} \\
(3)\end{array}$ & $\begin{array}{c}{ }_{n} \mathbf{d}_{\mathbf{X}} \\
(4)\end{array}$ & $\begin{array}{c}{ }_{n} \mathbf{L}_{\mathbf{X}} \\
(5)\end{array}$ & $\begin{array}{l}\mathbf{T}_{\mathbf{X}} \\
(6) \\
\end{array}$ & $\begin{array}{l}\mathbf{e x} \\
(7) \\
\end{array}$ \\
\hline$\overline{0}$ & 100.000 & 0,02493 & 2.493 & 97.941 & 7.653 .780 & 76,54 \\
\hline 1 & 97.507 & 0,00203 & 197 & 97.369 & 7.555 .839 & 77,49 \\
\hline 2 & 97.310 & 0,00095 & 93 & 97.264 & 7.458 .470 & 76,65 \\
\hline 3 & 97.217 & 0,00056 & 54 & 97.190 & 7.361 .207 & 75,72 \\
\hline 4 & 97.163 & 0,00033 & 32 & 97.147 & 7.264 .016 & 74,76 \\
\hline 5 a 9 & 97.131 & 0,00145 & 141 & 485.305 & 7.166 .869 & 73,79 \\
\hline 10 a 14 & 96.991 & 0,00176 & 170 & 484.527 & 6.681 .565 & 68,89 \\
\hline 15 a 19 & 96.820 & 0,00294 & 284 & 483.391 & 6.197 .037 & 64,01 \\
\hline 20 a 24 & 96.536 & 0,00403 & 389 & 481.707 & 5.713 .646 & 59,19 \\
\hline 25 a 29 & 96.147 & 0,00523 & 502 & 479.477 & 5.231 .939 & 54,42 \\
\hline 30 a 34 & 95.644 & 0,00640 & 612 & 476.690 & 4.752 .462 & 49,69 \\
\hline 35 a 39 & 95.032 & 0,00865 & 822 & 473.104 & 4.275 .772 & 44,99 \\
\hline 40 a 44 & 94.209 & 0,00967 & 911 & 468.770 & 3.802 .669 & 40,36 \\
\hline 45 a 49 & 93.298 & 0,01530 & 1.428 & 462.922 & 3.333 .899 & 35,73 \\
\hline 50 a 54 & 91.871 & 0,02245 & 2.063 & 454.196 & 2.870 .977 & 31,25 \\
\hline 55 a 59 & 89.808 & 0,03258 & 2.926 & 441.725 & 2.416 .780 & 26,91 \\
\hline 60 a 64 & 86.882 & 0,04847 & 4.211 & 423.882 & 1.975 .055 & 22,73 \\
\hline 65 a 69 & 82.671 & 0,07163 & 5.922 & 398.550 & 1.551 .173 & 18,76 \\
\hline 70 a 74 & 76.749 & 0,11833 & 9.081 & 361.042 & 1.152 .623 & 15,02 \\
\hline 75 a 79 & 67.668 & 0,20027 & 13.552 & 304.459 & 791.581 & 11,70 \\
\hline 80 et & 54.116 & 1,00000 & 54.116 & 487.122 & 487.122 & 9,00 \\
\hline
\end{tabular}


ANEXO 25 - Tábua de vida de múltiplo decremento, eliminando as doenças do aparelho circulatório como fator de risco de morte para residentes no Município de Salvador - BA em 1996 (sexo masculino).

\begin{tabular}{|c|c|c|c|c|c|c|}
\hline $\begin{array}{c}\mathbf{X} \\
(1) \\
\end{array}$ & $\begin{array}{l}\mathbf{l} \mathbf{x} \\
(2) \\
\end{array}$ & $\underset{(3)}{{ }_{3} \mathbf{q} \mathbf{x}}$ & $\begin{array}{l}\mathbf{n}^{\mathbf{d}} \mathbf{d x} \\
(4)\end{array}$ & $\begin{array}{c}{ }^{n} \mathbf{L}_{\mathbf{X}} \\
(5) \\
\end{array}$ & $\begin{array}{l}\mathbf{T}_{\mathbf{X}} \\
(6)\end{array}$ & $\begin{array}{l}\mathbf{e x} \\
(7) \\
\end{array}$ \\
\hline 0 & 100.000 & 0,03971 & 3.971 & 96.573 & 6.947 .732 & 69,48 \\
\hline 1 & 96.029 & 0,00271 & 260 & 95.846 & 6.851 .159 & 71,35 \\
\hline 2 & 95.768 & 0,00147 & 141 & 95.698 & 6.755 .313 & 70,54 \\
\hline 3 & 95.627 & 0,00088 & 84 & 95.585 & 6.659 .615 & 69,64 \\
\hline 4 & 95.543 & 0,00066 & 63 & 95.511 & 6.564 .030 & 68,70 \\
\hline 5 a 9 & 95.480 & 0,00264 & 252 & 476.767 & 6.468 .519 & 67,75 \\
\hline 10 a 14 & 95.227 & 0,00285 & 271 & 475.458 & 5.991 .752 & 62,92 \\
\hline 15 a 19 & 94.956 & 0,01077 & 1.022 & 472.225 & 5.516 .294 & 58,09 \\
\hline 20 a 24 & 93.934 & 0,01613 & 1.515 & 465.882 & 5.044 .069 & 53,70 \\
\hline 25 a 29 & 92.419 & 0,01504 & 1.390 & 458.619 & 4.578 .187 & 49,54 \\
\hline 30 a 34 & 91.029 & 0,01661 & 1.512 & 451.364 & 4.119 .568 & 45,26 \\
\hline 35 a 39 & 89.517 & 0,01959 & 1.753 & 443.202 & 3.668.204 & 40,98 \\
\hline 40 a 44 & 87.764 & 0,02308 & 2.025 & 433.755 & 3.225 .002 & 36,75 \\
\hline 45 a 49 & 85.738 & 0,02773 & 2.378 & 422.747 & 2.791 .247 & 32,56 \\
\hline 50 a 54 & 83.361 & 0,04232 & 3.528 & 407.983 & 2.368 .499 & 28,41 \\
\hline 55 a 59 & 79.833 & 0,05828 & 4.653 & 387.532 & 1.960 .516 & 24,56 \\
\hline 60 a 64 & 75.180 & 0,08235 & 6.191 & 360.423 & 1.572 .984 & 20,92 \\
\hline 65 a 69 & 68.989 & 0,13159 & 9.078 & 322.251 & 1.212 .561 & 17,58 \\
\hline 70 a 74 & 59.911 & 0,17679 & 10.591 & 273.077 & 890.310 & 14,86 \\
\hline 75 a 79 & 49.320 & 0,25364 & 12.510 & 215.325 & 617.233 & 12,51 \\
\hline 80 et & 36.810 & 1,00000 & 36.810 & 401.908 & 401.908 & 10,92 \\
\hline
\end{tabular}

ANEXO 26 - Tábua de vida de múltiplo decremento, eliminando as doenças do aparelho circulatório como fator de risco de morte para residentes no Município de São Paulo - SP em 1996 (sexo masculino).

\begin{tabular}{|c|c|c|c|c|c|c|}
\hline $\begin{array}{c}\mathbf{X} \\
\text { (1) }\end{array}$ & $\begin{array}{l}\mathbf{I X}_{\mathbf{X}} \\
(2) \\
\end{array}$ & ${ }_{(3)} \mathbf{q}_{\mathbf{X}}$ & $\begin{array}{c}{ }^{n} \mathbf{d}_{\mathbf{X}} \\
(4)\end{array}$ & $\begin{array}{c}{ }_{(5)} \mathbf{L}_{\mathbf{X}} \\
\end{array}$ & $\begin{array}{l}T_{\mathbf{X}} \\
(6)\end{array}$ & $\begin{array}{l}\mathbf{e x} \\
(7) \\
\end{array}$ \\
\hline 0 & 100.000 & 0,03019 & 3.019 & 97.395 & 6.961 .593 & 69,62 \\
\hline 1 & 96.981 & 0,00191 & 185 & 96.852 & 6.864 .198 & 70,78 \\
\hline 2 & 96.796 & 0,00090 & 87 & 96.753 & 6.767 .347 & 69,91 \\
\hline 3 & 96.709 & 0,00072 & 70 & 96.674 & 6.670 .594 & 68,98 \\
\hline 4 & 96.639 & 0,00046 & 44 & 96.617 & 6.573 .920 & 68,03 \\
\hline 5 a 9 & 96.595 & 0,00220 & 213 & 482.444 & 6.477 .302 & 67,06 \\
\hline 10 a 14 & 96.382 & 0,00320 & 309 & 481.140 & 5.994 .859 & 62,20 \\
\hline 15 a 19 & 96.074 & 0,01435 & 1.379 & 476.920 & 5.513 .719 & 57,39 \\
\hline 20 a 24 & 94.694 & 0,02109 & 1.997 & 468.480 & 5.036 .799 & 53,19 \\
\hline 25 a 29 & 92.698 & 0,02585 & 2.396 & 457.497 & 4.568 .319 & 49,28 \\
\hline 30 a 34 & 90.301 & 0,02729 & 2.464 & 445.346 & 4.110 .822 & 45,52 \\
\hline 35 a 39 & 87.837 & 0,02972 & 2.610 & 432.660 & 3.665 .476 & 41,73 \\
\hline 40 a 44 & 85.227 & 0,03116 & 2.656 & 419.495 & 3.232 .816 & 37,93 \\
\hline 45 a 49 & 82.571 & 0,03449 & 2.848 & 405.736 & 2.813 .321 & 34,07 \\
\hline 50 a 54 & 79.723 & 0,04311 & 3.437 & 390.024 & 2.407 .585 & 30,20 \\
\hline 55 a 59 & 76.287 & 0,05405 & 4.123 & 371.125 & 2.017 .561 & 26,45 \\
\hline 60 a 64 & 72.163 & 0,07443 & 5.371 & 347.390 & 1.646 .436 & 22,82 \\
\hline 65 a 69 & 66.793 & 0,10093 & 6.741 & 317.110 & 1.299 .046 & 19,45 \\
\hline 70 a 74 & 60.051 & 0,14084 & 8.458 & 279.112 & 981.936 & 16,35 \\
\hline 75 a 79 & 51.593 & 0,21191 & 10.933 & 230.634 & 702.824 & 13,62 \\
\hline $80 \mathrm{e}+$ & 40.660 & 1,00000 & 40.660 & 472.190 & 472.190 & $\cdot 11,61$ \\
\hline
\end{tabular}


ANEXO 27 - Tábua de vida de múltiplo decremento, eliminando as doenças do aparelho circulatório como fator de risco de morte para residentes no Município de Salvador - BA em 1996 (sexo feminino).

\begin{tabular}{|c|c|c|c|c|c|c|}
\hline $\begin{array}{c}\mathbf{x} \\
\text { (1) }\end{array}$ & $\begin{array}{l}\mathbf{I}_{\mathbf{X}} \\
(2) \\
\end{array}$ & $\begin{array}{c}{ }^{n} \mathbf{q}_{\mathbf{X}} \\
(3)\end{array}$ & $\begin{array}{r}{ }_{n} \mathbf{d}_{\mathbf{X}} \\
(4) \\
\end{array}$ & $\begin{array}{c}{ }_{n} \mathbf{L}_{\mathbf{X}} \\
(5)\end{array}$ & $\begin{array}{l}\mathbf{T}_{\mathbf{X}} \\
\text { (6) }\end{array}$ & $\begin{array}{r}\mathbf{e x} \\
(7) \\
\end{array}$ \\
\hline 0 & 100.000 & 0,03968 & 3.968 & 96.723 & 7.796 .123 & 77,96 \\
\hline 1 & 96.032 & 0,00309 & 297 & 95.824 & 7.699 .400 & 80,18 \\
\hline 2 & 95.735 & 0,00150 & 144 & 95.663 & 7.603 .576 & 79,42 \\
\hline 3 & 95.592 & 0,00101 & 97 & 95.543 & 7.507 .912 & 78,54 \\
\hline 4 & 95.495 & 0,00047 & 45 & 95.472 & 7.412 .369 & 77,62 \\
\hline 5 a 9 & 95.450 & 0,00144 & 137 & 476.905 & 7.316 .897 & 76,66 \\
\hline 10 a 14 & 95.312 & 0,00242 & 231 & 475.985 & 6.839 .991 & 71,76 \\
\hline 15 a 19 & 95.081 & 0,00295 & 280 & 474.706 & 6.364 .007 & 66,93 \\
\hline 20 a 24 & 94.801 & 0,00227 & 215 & 473.468 & 5.889 .301 & 62,12 \\
\hline 25 a 29 & 94.586 & 0,00470 & 445 & 471.819 & 5.415 .833 & 57,26 \\
\hline 30 a 34 & 94.142 & 0,00585 & 551 & 469.331 & 4.944 .013 & 52,52 \\
\hline 35 a 39 & 93.591 & 0,00929 & 870 & 465.780 & 4.474 .682 & 47,81 \\
\hline 40 a 44 & 92.721 & 0,01304 & 1.209 & 460.583 & 4.008 .902 & 43,24 \\
\hline 45 a 49 & 91.512 & 0,01817 & 1.662 & 453.405 & 3.548.319 & 38,77 \\
\hline 50 a 54 & 89.850 & 0,02383 & 2.141 & 443.897 & 3.094 .914 & 34,45 \\
\hline 55 a 59 & 87.709 & 0,03973 & 3.485 & 429.832 & 2.651 .017 & 30,23 \\
\hline 60 a 64 & 84.224 & 0,05082 & 4.280 & 410.419 & 2.221 .185 & 26,37 \\
\hline 65 a 69 & 79.944 & 0,08414 & 6.726 & 382.903 & 1.810 .766 & 22,65 \\
\hline 70 a 74 & 73.218 & 0,10935 & 8.007 & 346.071 & 1.427 .862 & 19,50 \\
\hline 75 a 79 & 65.211 & 0,16306 & 10.634 & 299.471 & 1.081 .791 & 16,59 \\
\hline 80 et & 54.577 & 1,00000 & 54.577 & 782.320 & 782.320 & 14,33 \\
\hline
\end{tabular}

ANEXO 28 - Tábua de vida de múltiplo decremento, eliminando as doenças do aparelho circulatório como fator de risco de morte para residentes no Município de São Paulo - SP em 1996 (sexo feminino).

\begin{tabular}{|c|c|c|c|c|c|c|}
\hline $\begin{array}{l}\mathbf{X} \\
\text { (1) }\end{array}$ & $\begin{array}{l}\mathbf{l}_{\mathbf{X}} \\
\text { (2) }\end{array}$ & $\underset{(3)}{\mathbf{n q}^{2} \mathbf{q}}$ & $\underset{(4)}{{ }_{\mathbf{n}} \mathbf{d}_{\mathbf{X}}}$ & $\underset{\text { (5) }}{{ }^{n} \mathbf{L}_{\mathbf{X}}}$ & $\begin{array}{c}\mathbf{T}_{\mathbf{6}} \\
\mathbf{T}\end{array}$ & $\begin{array}{l}\mathbf{e}_{\mathbf{x}} \\
(7)\end{array}$ \\
\hline$\overline{0}$ & 100.000 & 0,02480 & 2.480 & 97.951 & 8.318 .270 & 83,18 \\
\hline 1 & 97.520 & 0,00196 & 191 & 97.386 & 8.220 .319 & 84,29 \\
\hline 2 & 97.328 & 0,00098 & 95 & 97.281 & 8.122 .933 & 83,46 \\
\hline 3 & 97.233 & 0,00057 & 55 & 97.205 & 8.025 .652 & 82,54 \\
\hline 4 & 97.178 & 0,00033 & 32 & 97.162 & 7.928 .447 & 81,59 \\
\hline 5 a 9 & 97.146 & 0,00158 & 153 & 485.346 & 7.831 .285 & 80,61 \\
\hline 10 a 14 & 96.993 & 0,00189 & 183 & 484.505 & 7.345 .938 & 75,74 \\
\hline 15 a 19 & 96.810 & 0,00306 & 296 & 483.307 & 6.861 .433 & 70,88 \\
\hline 20 a 24 & 96.513 & 0,00410 & 395 & 481.579 & 6.378 .126 & 66,09 \\
\hline 25 a 29 & 96.118 & 0,00515 & 495 & 479.353 & 5.896 .547 & 61,35 \\
\hline 30 a 34 & 95.623 & 0,00657 & 628 & 476.545 & 5.417 .195 & 56,65 \\
\hline 35 a 39 & 94.995 & 0,00837 & 795 & 472.989 & 4.940 .650 & 52,01 \\
\hline 40 a 44 & 94.200 & 0,00938 & 884 & 468.793 & 4.467 .661 & 47,43 \\
\hline 45 a 49 & 93.317 & 0,01393 & 1.300 & 463.334 & 3.998 .868 & 42,85 \\
\hline 50 a 54 & 92.017 & 0,01945 & 1.789 & 455.611 & 3.535 .534 & 38,42 \\
\hline 55 a 59 & 90.228 & 0,02772 & 2.501 & 444.886 & 3.079 .923 & 34,14 \\
\hline 60 a 64 & 87.727 & 0,03798 & 3.332 & 430.302 & 2.635 .037 & 30,04 \\
\hline 65 a 69 & 84.394 & 0,05460 & 4.608 & 410.452 & 2.204 .735 & 26,12 \\
\hline 70 a 74 & 79.786 & 0,08375 & 6.682 & 382.226 & 1.794 .283 & 22,49 \\
\hline 75 a 79 & 73.104 & 0,12800 & 9.358 & 342.128 & 1.412 .057 & 19,32 \\
\hline $80 \mathrm{e}+$ & 63.747 & 1,00000 & 63.747 & 1.069 .929 & 1.069 .929 & $\cdot 16,78$ \\
\hline
\end{tabular}


ANEXO 29 - Tábua de vida de múltiplo decremento, eliminando as doenças isquêmicas do coração como fator de risco de morte para residentes no Município de Salvador - BA em 1996 (sexo masculino).

\begin{tabular}{|c|c|c|c|c|c|c|}
\hline $\begin{array}{c}\mathbf{x} \\
\text { (1) }\end{array}$ & $\begin{array}{l}\mathbf{l}_{\mathbf{X}} \\
(2) \\
\end{array}$ & $\underset{(3)}{\mathbf{n q x}}$ & $\begin{array}{l}{ }_{n} \mathbf{d}_{\mathbf{X}} \\
(4)\end{array}$ & $\begin{array}{l}{ }_{n} \mathbf{L}_{\mathbf{x}} \\
(5)\end{array}$ & $\begin{array}{l}\mathbf{T}_{\mathbf{X}} \\
(6)\end{array}$ & $\begin{array}{l}\mathbf{e x} \\
(7)\end{array}$ \\
\hline$\overline{0}$ & 100.000 & 0,03977 & 3.977 & 96.568 & 6.499 .428 & 64,99 \\
\hline 1 & 96.023 & 0,00287 & 276 & 95.830 & 6.402 .859 & 66,68 \\
\hline 2 & 95.748 & 0,00158 & 151 & 95.672 & 6.307 .029 & 65,87 \\
\hline 3 & 95.597 & 0,00093 & 89 & 95.552 & 6.211 .357 & 64,97 \\
\hline 4 & 95.508 & 0,00066 & 63 & 95.476 & 6.115 .804 & 64,03 \\
\hline 5 a 9 & 95.445 & 0,00279 & 266 & 476.556 & 6.020 .328 & 63,08 \\
\hline 10 a 14 & 95.178 & 0,00301 & 286 & 475.175 & 5.543 .772 & 58,25 \\
\hline 15 a 19 & 94.892 & 0,01131 & 1.073 & 471.775 & 5.068 .597 & 53,41 \\
\hline 20 a 24 & 93.818 & 0,01663 & 1.561 & 465.190 & 4.596 .822 & 49,00 \\
\hline 25 a 29 & 92.258 & 0,01608 & 1.483 & 457.581 & 4.131 .632 & 44,78 \\
\hline 30 a 34 & 90.774 & 0,01810 & 1.643 & 449.763 & 3.674 .051 & 40,47 \\
\hline 35 a 39 & 89.131 & 0,02262 & 2.016 & 440.614 & 3.224 .288 & 36,17 \\
\hline 40 a 44 & 87.115 & 0,02859 & 2.491 & 429.346 & 2.783 .674 & 31,95 \\
\hline 45 a 49 & 84.624 & 0,03681 & 3.115 & 415.333 & 2.354 .327 & 27,82 \\
\hline 50 a 54 & 81.509 & 0,05635 & 4.593 & 396.064 & 1.938 .994 & 23,79 \\
\hline 55 a 59 & 76.916 & 0,08429 & 6.483 & 368.373 & 1.542 .930 & 20,06 \\
\hline 60 a 64 & 70.433 & 0,12400 & 8.734 & 330.329 & 1.174 .558 & 16,68 \\
\hline 65 a 69 & 61.699 & 0,17887 & 11.036 & 280.904 & 844.228 & 13,68 \\
\hline 70 a 74 & 50.663 & 0,24546 & 12.436 & 222.224 & 563.324 & 11,12 \\
\hline 75 a 79 & 38.227 & 0,35002 & 13.380 & 157.684 & 341.100 & 8,92 \\
\hline 80 et & 24.847 & 1,00000 & 24.847 & 183.416 & 183.416 & 7,38 \\
\hline
\end{tabular}

ANEXO 30 - Tábua de vida de múltiplo decremento, eliminando as doenças isquêmicas do coração como fator de risco de morte para residentes no Município de São Paulo - SP em 1996 (sexo masculino).

\begin{tabular}{|c|c|c|c|c|c|c|}
\hline$\underset{\text { (1) }}{\mathbf{x}}$ & $\begin{array}{c}\mathbf{X}_{\mathbf{X}} \\
(2)\end{array}$ & $\underset{(3)}{\mathbf{n q}}$ & $\begin{array}{l}{ }^{n} \mathbf{d}_{\mathbf{X}} \\
\text { (4) }\end{array}$ & $\begin{array}{c}{ }_{n} \mathbf{L}_{\mathbf{X}} \\
(5)\end{array}$ & $\begin{array}{l}T_{X} \\
(6)\end{array}$ & $\begin{array}{l}\mathbf{e}_{\mathbf{X}} \\
(7)\end{array}$ \\
\hline$\overline{0}$ & 100.000 & 0,03048 & 3.048 & 97.369 & 6.542 .871 & 65,43 \\
\hline 1 & 96.952 & 0,00196 & 190 & 96.819 & 6.445 .502 & 66,48 \\
\hline 2 & 96.762 & 0,00092 & 89 & 96.717 & 6.348 .683 & 65,61 \\
\hline 3 & 96.673 & 0,00072 & 70 & 96.638 & 6.251 .965 & 64,67 \\
\hline 4 & 96.603 & 0,00046 & 44 & 96.581 & 6.155 .328 & 63,72 \\
\hline 5 a 9 & 96.559 & 0,00225 & 217 & 482.251 & 6.058 .747 & 62,75 \\
\hline 10 a 14 & 96.342 & 0,00327 & 315 & 480.921 & 5.576 .495 & 57,88 \\
\hline 15 a 19 & 96.027 & 0,01469 & 1.410 & 476.608 & 5.095 .575 & 53,06 \\
\hline 20 a 24 & 94.616 & 0,02138 & 2.023 & 468.024 & 4.618 .967 & 48,82 \\
\hline 25 a 29 & 92.593 & 0,02646 & 2.450 & 456.841 & 4.150 .943 & 44,83 \\
\hline 30 a 34 & 90.143 & 0,02825 & 2.546 & 444.349 & 3.694 .103 & 40,98 \\
\hline 35 a 39 & 87.597 & 0,03185 & 2.790 & 431.009 & 3.249 .753 & 37,10 \\
\hline 40 a 44 & 84.807 & 0,03536 & 2.999 & 416.538 & 2.818 .744 & 33,24 \\
\hline 45 a 49 & 81.808 & 0,04137 & 3.385 & 400.579 & 2.402 .207 & 29,36 \\
\hline 50 a 54 & 78.423 & 0,05423 & 4.253 & 381.486 & 2.001 .627 & 25,52 \\
\hline 55 a 59 & 74.171 & 0,07214 & 5.350 & 357.478 & 1.620 .141 & 21,84 \\
\hline 60 a 64 & 68.820 & 0,10194 & 7.016 & 326.563 & 1.262 .663 & 18,35 \\
\hline 65 a 69 & 61.805 & 0,14313 & 8.846 & 286.909 & 936.101 & 15,15 \\
\hline 70 a 74 & 52.959 & 0,19813 & 10.493 & 238.561 & 649.192 & 12,26 \\
\hline 75 a 79 & 42.466 & 0,29291 & 12.439 & 181.233 & 410.631 & 9,67 \\
\hline 80 et & 30.027 & 1,00000 & 30.027 & 229.398 & 229.398 & 7,64 \\
\hline
\end{tabular}


ANEXO 31 - Tábua de vida de múltiplo decremento, eliminando as doenças isquêmicas do coração como fator de risco de morte para residentes no Município de Salvador - BA em 1996 (sexo feminino).

\begin{tabular}{|c|c|c|c|c|c|c|}
\hline $\begin{array}{c}\mathbf{X} \\
\text { (I) }\end{array}$ & $\begin{array}{l}\mathbf{X} \\
(2)\end{array}$ & (3) & $\begin{array}{l}{ }_{(4)} \mathbf{d x}_{\mathbf{x}} \\
\end{array}$ & ${ }_{(5)} \mathbf{L}_{\mathbf{x}}$ & $\underset{(6)}{\mathbf{T}_{\mathbf{X}}}$ & $\begin{array}{c}\mathbf{e x} \\
(7)\end{array}$ \\
\hline 0 & 100.000 & 0,03973 & 3.973 & 96.718 & 7.117 .683 & 71,18 \\
\hline 1 & 96.027 & 0,00309 & 297 & 95.819 & 7.020 .965 & 73,11 \\
\hline 2 & 95.730 & 0,00150 & 144 & 95.658 & 6.925 .146 & 72,34 \\
\hline 3 & 95.586 & 0,00101 & 97 & 95.538 & 6.829 .488 & 71,45 \\
\hline 4 & 95.489 & 0,00053 & 50 & 95.464 & 6.733 .950 & 70,52 \\
\hline 5 a 9 & 95.439 & 0,00149 & 142 & 476.841 & 6.638 .486 & 69,56 \\
\hline 10 a 14 & 95.297 & 0,00274 & 261 & 475.833 & 6.161 .645 & 64,66 \\
\hline 15 a 19 & 95.036 & 0,00320 & 304 & 474.420 & 5.685 .812 & 59,83 \\
\hline 20 a 24 & 94.732 & 0,00267 & 253 & 473.028 & 5.211 .393 & 55,01 \\
\hline 25 a 29 & 94.479 & 0,00565 & 533 & 471.062 & 4.738 .365 & 50,15 \\
\hline 30 a 34 & 93.946 & 0,00738 & 693 & 467.995 & 4.267 .303 & 45,42 \\
\hline 35 a 39 & 93.252 & 0,01186 & 1.106 & 463.496 & 3.799 .308 & 40,74 \\
\hline 40 a 44 & 92.146 & 0,01761 & 1.623 & 456.673 & 3.335 .811 & 36,20 \\
\hline 45 a 49 & 90.523 & 0,02619 & 2.371 & 446.688 & 2.879 .138 & 31,81 \\
\hline 50 a 54 & 88.152 & 0,03747 & 3.303 & 432.502 & 2.432 .450 & 27,59 \\
\hline 55 a 59 & 84.849 & 0,05768 & 4.894 & 412.008 & 1.999 .949 & 23,57 \\
\hline $60 a 64$ & 79.954 & 0,07814 & 6.248 & 384.153 & 1.587 .941 & 19,86 \\
\hline 65 a 69 & 73.707 & 0,12144 & 8.951 & 346.156 & 1.203 .788 & 16,33 \\
\hline 70 a 74 & 64.756 & 0,16663 & 10.790 & 296.805 & 857.632 & 13,24 \\
\hline 75 a 79 & 53.966 & 0,26119 & 14.096 & 234.591 & 560.827 & 10,39 \\
\hline 80 et & 39.870 & 1,00000 & 39.870 & 326.237 & 326.237 & 8,18 \\
\hline
\end{tabular}

ANEXO 32 - Tábua de vida de múltiplo decremento, eliminando as doenças isquêmicas do coração como fator de risco de morte para residentes no Município de São Paulo - SP em 1996 (sexo feminino).

\begin{tabular}{|c|c|c|c|c|c|c|}
\hline $\begin{array}{c}\mathbf{X} \\
\text { (1) }\end{array}$ & $\begin{array}{l}\mathbf{l}_{\mathbf{X}} \\
(2)\end{array}$ & ${ }_{(3)} \mathbf{q x}$ & $\begin{array}{l}{ }_{n} \mathbf{d}_{\mathbf{x}} \\
(4)\end{array}$ & $\begin{array}{l}{ }_{n} \mathbf{L}_{\mathbf{X}} \\
\text { (5) }\end{array}$ & $\begin{array}{c}T_{\mathbf{X}} \\
\end{array}$ & $\begin{array}{l}\mathbf{e x} \\
(7) \\
\end{array}$ \\
\hline$\overline{0}$ & 100.000 & 0,02504 & 2.504 & 97.932 & 7.604 .442 & 76,04 \\
\hline 1 & 97.496 & 0,00205 & 200 & 97.356 & 7.506 .510 & 76,99 \\
\hline 2 & 97.296 & 0,00102 & 99 & 97.247 & 7.409 .154 & 76,15 \\
\hline 3 & 97.198 & 0,00058 & 57 & 97.169 & 7.311 .907 & 75,23 \\
\hline 4 & 97.141 & 0,00035 & 34 & 97.124 & 7.214 .738 & 74,27 \\
\hline 5 a 9 & 97.107 & 0,00169 & 164 & 485.123 & 7.117 .614 & 73,30 \\
\hline 10 a 14 & 96.943 & 0,00203 & 197 & 484.222 & 6.632 .491 & 68,42 \\
\hline 15 a 19 & 96.746 & 0,00324 & 313 & 482.948 & 6.148 .269 & 63,55 \\
\hline $20 a 24$ & 96.433 & 0,00432 & 417 & 481.124 & 5.665 .320 & 58,75 \\
\hline 25 a 29 & 96.016 & 0,00555 & 533 & 478.750 & 5.184 .197 & 53,99 \\
\hline 30 a 34 & 95.484 & 0,00723 & 690 & 475.693 & 4.705 .447 & 49,28 \\
\hline 35 a 39 & 94.793 & 0,01016 & 963 & 471.561 & 4.229 .754 & 44,62 \\
\hline 40 a 44 & 93.831 & 0,01225 & 1.149 & 466.280 & 3.758 .193 & 40,05 \\
\hline 45 a 49 & 92.681 & 0,01871 & 1.735 & 459.070 & 3.291 .913 & 35,52 \\
\hline 50 a 54 & 90.947 & 0,02734 & 2.486 & 448.518 & 2.832 .843 & 31,15 \\
\hline 55 a 59 & 88.460 & 0,03869 & 3.423 & 433.746 & 2.384 .325 & 26,95 \\
\hline 60 a 64 & 85.038 & 0,05485 & 4.664 & 413.528 & 1.950 .579 & 22,94 \\
\hline 65 a 69 & 80.373 & 0,07865 & 6.321 & 386.064 & 1.537 .051 & 19,12 \\
\hline 70 a 74 & 74.052 & 0,12382 & 9.169 & 347.338 & 1.150 .988 & 15,54 \\
\hline 75 a 79 & 64.883 & 0,19854 & 12.882 & 292.210 & 803.650 & 12,39 \\
\hline 80 et & 52.001 & 1,00000 & 52.001 & 511.441 & 511.441 & 9,84 \\
\hline
\end{tabular}


ANEXO 33 - Tábua de vida de múltiplo decremento, eliminando as doenças cerebrovasculares como fator de risco de morte para residentes no Município de Salvador - BA em 1996 (sexo masculino).

\begin{tabular}{|c|c|c|c|c|c|c|}
\hline $\begin{array}{c}\mathbf{x} \\
(1) \\
\end{array}$ & $\begin{array}{l}\mathbf{l} \mathbf{x} \\
(2) \\
\end{array}$ & $\begin{array}{c}\mathbf{n} \mathbf{9 x} \\
\text { (3) }\end{array}$ & $\begin{array}{l}{ }_{n} \mathbf{d}_{\mathbf{x}} \\
(4)\end{array}$ & $\begin{array}{c}n \mathbf{n} \mathbf{x} \\
(5) \\
\end{array}$ & $\begin{array}{l}\mathbf{T}_{\mathbf{X}} \\
(6)\end{array}$ & $\begin{array}{l}\mathbf{e x} \\
(7)\end{array}$ \\
\hline$\overline{0}$ & 100.000 & 0,03971 & 3.971 & 96.573 & 6.538 .665 & 65,39 \\
\hline 1 & 96.029 & 0,00287 & 276 & 95.836 & 6.442 .092 & 67,09 \\
\hline 2 & 95.753 & 0,00152 & 146 & 95.680 & 6.346 .257 & 66,28 \\
\hline 3 & 95.607 & 0,00093 & 89 & 95.562 & 6.250 .577 & 65,38 \\
\hline 4 & 95.518 & 0,00066 & 63 & 95.486 & 6.155 .015 & 64,44 \\
\hline 5 a 9 & 95.454 & 0,00274 & 262 & 476.618 & 6.059 .529 & 63,48 \\
\hline 10 a 14 & 95.193 & 0,00301 & 286 & 475.248 & 5.582 .911 & 58,65 \\
\hline 15 a 19 & 94.906 & 0,01127 & 1.070 & 471.857 & 5.107 .663 & 53,82 \\
\hline 20 a 24 & 93.837 & 0,01654 & 1.552 & 465.302 & 4.635 .806 & 49,40 \\
\hline 25 a 29 & 92.284 & 0,01603 & 1.479 & 457.724 & 4.170 .504 & 45,19 \\
\hline 30 a 34 & 90.805 & 0,01805 & 1.639 & 449.929 & 3.712 .780 & 40,89 \\
\hline 35 a 39 & 89.166 & 0,02243 & 2.000 & 440.831 & 3.262 .851 & 36,59 \\
\hline 40 a 44 & 87.166 & 0,02783 & 2.426 & 429.766 & 2.822 .020 & 32,38 \\
\hline 45 a 49 & 84.741 & 0,03540 & 3.000 & 416.203 & 2.392 .253 & 28,23 \\
\hline 50 a 54 & 81.741 & 0,05426 & 4.435 & 397.615 & 1.976 .050 & 24,17 \\
\hline 55 a 59 & 77.306 & 0,07967 & 6.159 & 371.131 & 1.578 .435 & 20,42 \\
\hline 60 a 64 & 71.147 & 0,11929 & 8.487 & 334.517 & 1.207 .304 & 16,97 \\
\hline 65 a 69 & 62.660 & 0,17549 & 10.996 & 285.809 & 872.787 & 13,93 \\
\hline 70 a 74 & 51.664 & 0,24667 & 12.744 & 226.458 & 586.978 & 11,36 \\
\hline 75 a 79 & 38.920 & 0,33753 & 13.136 & 161.757 & 360.519 & 9,26 \\
\hline 80 et & 25.783 & 1,00000 & 25.783 & 198.762 & 198.762 & 7,71 \\
\hline
\end{tabular}

ANEXO 34 - Tábua de vida de múltiplo decremento, eliminando as doenças cerebrovasculares como fator de risco de morte para residentes no Município de São Paulo - SP em 1996 (sexo masculino).

\begin{tabular}{|c|c|c|c|c|c|c|}
\hline $\begin{array}{c}\mathbf{X} \\
\text { (1) }\end{array}$ & $\begin{array}{l}\mathbf{I}_{\mathbf{X}} \\
(2) \\
\end{array}$ & $\begin{array}{c}\mathbf{n q x} \\
\text { (3) }\end{array}$ & $\begin{array}{l}{ }_{n} \mathbf{d}_{\mathbf{X}} \\
(4)\end{array}$ & $\begin{array}{c}{ }_{(5)} \mathbf{L}_{\mathbf{X}} \\
\end{array}$ & $\begin{array}{l}\mathbf{T}_{\mathbf{X}} \\
(6)\end{array}$ & $\begin{array}{l}\mathbf{e x} \\
(7) \\
\end{array}$ \\
\hline$\overline{0}$ & 100.000 & 0,03040 & 3.040 & 97.376 & 6.454 .286 & 64,54 \\
\hline 1 & 96.960 & 0,00194 & 188 & 96.828 & 6.356 .910 & 65,56 \\
\hline 2 & 96.771 & 0,00092 & 89 & 96.727 & 6.260 .082 & 64,69 \\
\hline 3 & 96.682 & 0,00072 & 70 & 96.647 & 6.163 .355 & 63,75 \\
\hline 4 & 96.612 & 0,00046 & 44 & 96.590 & 6.066 .708 & 62,79 \\
\hline 5 a 9 & 96.568 & 0,00223 & 215 & 482.304 & 5.970 .118 & 61,82 \\
\hline 10 a 14 & 96.353 & 0,00328 & 316 & 480.976 & 5.487 .814 & 56,96 \\
\hline 15 a 19 & 96.037 & 0,01460 & 1.402 & 476.680 & 5.006 .838 & 52,13 \\
\hline 20 a 24 & 94.635 & 0,02144 & 2.029 & 468.103 & 4.530 .157 & 47,87 \\
\hline 25 a 29 & 92.606 & 0,02649 & 2.453 & 456.898 & 4.062 .054 & 43,86 \\
\hline 30 a 34 & 90.153 & 0,02840 & 2.560 & 444.363 & 3.605 .156 & 39,99 \\
\hline 35 a 39 & 87.592 & 0,03253 & 2.849 & 430.839 & 3.160 .793 & 36,09 \\
\hline 40 a 44 & 84.743 & 0,03629 & 3.076 & 416.028 & 2.729 .954 & 32,21 \\
\hline 45 a 49 & 81.668 & 0,04394 & 3.588 & 399.368 & 2.313 .926 & 28,33 \\
\hline 50 a 54 & 78.079 & 0,05951 & 4.646 & 378.781 & 1.914 .559 & 24,52 \\
\hline 55 a 59 & 73.433 & 0,08035 & 5.900 & 352.415 & 1.535 .778 & 20,91 \\
\hline 60 a 64 & 67.533 & 0,11378 & 7.684 & 318.454 & 1.183 .363 & 17,52 \\
\hline 65 a 69 & 59.849 & 0,15482 & 9.266 & 276.078 & 864.909 & 14,45 \\
\hline 70 a 74 & 50.583 & 0,21856 & 11.056 & 225.274 & 588.831 & 11,64 \\
\hline 75 a 79 & 39.527 & 0,31189 & 12.328 & 166.815 & 363.557 & 9,20 \\
\hline $80 \mathrm{et}$ & 27.199 & 1,00000 & 27.199 & 196.742 & 196.742 & 7,23 \\
\hline
\end{tabular}


ANEXO 35 - Tábua de vida de múltiplo decremento, eliminando as doenças cerebrovasculares como fator de risco de morte para residentes no Município de Salvador - BA em 1996 (sexo feminino).

\begin{tabular}{|c|c|c|c|c|c|c|}
\hline $\begin{array}{c}\mathbf{X} \\
\text { (1) }\end{array}$ & $\begin{array}{l}\mathbf{l} \\
(2) \\
\end{array}$ & $\underset{(3)}{\mathbf{n}^{\mathbf{q}} \mathbf{x}}$ & $\begin{array}{r}{ }^{n} \mathbf{d X}_{\mathbf{X}} \\
(4)\end{array}$ & $\begin{array}{c}{ }_{n} \mathbf{L}_{\mathbf{X}} \\
(5)\end{array}$ & $\begin{array}{l}\mathbf{T}_{\mathbf{X}} \\
(6)\end{array}$ & $\begin{array}{l}\mathbf{e x}_{\mathbf{X}} \\
(7)\end{array}$ \\
\hline$\overline{\mathbf{0}}$ & 100.000 & 0,03973 & 3.973 & 96.718 & 7.224 .896 & 72,25 \\
\hline 1 & 96.027 & 0,00309 & 297 & 95.819 & 7.128 .178 & 74,23 \\
\hline 2 & 95.730 & 0,00150 & 144 & 95.658 & 7.032 .359 & 73,46 \\
\hline 3 & 95.586 & 0,00101 & 97 & 95.538 & 6.936 .701 & 72,57 \\
\hline 4 & 95.489 & 0,00053 & 50 & 95.464 & 6.841 .163 & 71,64 \\
\hline 5 a 9 & 95.439 & 0,00149 & 142 & 476.841 & 6.745 .699 & 70,68 \\
\hline 10 a 14 & 95.297 & 0,00278 & 265 & 475.823 & 6.268 .858 & 65,78 \\
\hline 15 a 19 & 95.032 & 0,00313 & 297 & 474.418 & 5.793 .035 & 60,96 \\
\hline 20 a 24 & 94.735 & 0,00259 & 245 & 473.062 & 5.318 .617 & 56,14 \\
\hline 25 a 29 & 94.490 & 0,00524 & 495 & 471.211 & 4.845 .555 & 51,28 \\
\hline 30 a 34 & 93.995 & 0,00690 & 649 & 468.351 & 4.374 .344 & 46,54 \\
\hline 35 a 39 & 93.346 & 0,01088 & 1.016 & 464.190 & 3.905 .994 & 41,84 \\
\hline 40 a 44 & 92.330 & 0,01647 & 1.521 & 457.849 & 3.441 .804 & 37,28 \\
\hline 45 a 49 & 90.809 & 0,02450 & 2.225 & 448.484 & 2.983 .955 & 32,86 \\
\hline 50 a 54 & 88.584 & 0,03523 & 3.121 & 435.119 & 2.535 .471 & 28,62 \\
\hline 55 a 59 & 85.463 & 0,05400 & 4.615 & 415.778 & 2.100 .352 & 24,58 \\
\hline 60 a 64 & 80.848 & 0,07429 & 6.006 & 389.225 & 1.684 .574 & 20,84 \\
\hline 65 a 69 & 74.842 & 0,11728 & 8.777 & 352.267 & 1.295 .349 & 17,31 \\
\hline 70 a 74 & 66.065 & 0,15479 & 10.226 & 304.758 & 943.081 & 14,28 \\
\hline 75 a 79 & 55.839 & 0,23147 & 12.925 & 246.880 & 638.323 & 11,43 \\
\hline 80 et & 42.913 & 1,00000 & 42.913 & 391.443 & 391.443 & 9,12 \\
\hline
\end{tabular}

ANEXO 36 - Tábua de vida de múltiplo decremento, eliminando as doenças cerebrovasculares como fator de risco de morte para residentes no Município de São Paulo - SP em 1996 (sexo feminino).

\begin{tabular}{|c|c|c|c|c|c|c|}
\hline $\begin{array}{c}\mathbf{X} \\
(1)\end{array}$ & $\begin{array}{l}\mathbf{l}_{\mathbf{X}} \\
(2)\end{array}$ & ${ }_{\text {(3) }} \mathbf{q}_{\mathbf{X}}$ & $\begin{array}{c}{ }^{n} \mathbf{d}_{\mathbf{X}} \\
(4)\end{array}$ & $\begin{array}{c}{ }_{(5)} \mathbf{L}_{\mathbf{x}} \\
{ }^{2}\end{array}$ & $\begin{array}{l}\mathbf{T}_{\mathbf{X}} \\
(6)\end{array}$ & $\begin{array}{l}\mathbf{e x} \\
\text { (7) }\end{array}$ \\
\hline$\overline{0}$ & 100.000 & 0,02496 & 2.496 & 97.938 & 7.552 .057 & 75,52 \\
\hline 1 & 97.504 & 0,00205 & 200 & 97.364 & 7.454 .119 & 76,45 \\
\hline 2 & 97.304 & 0,00100 & 98 & 97.255 & 7.356 .755 & 75,61 \\
\hline 3 & 97.206 & 0,00058 & 57 & 97.178 & 7.259 .500 & 74,68 \\
\hline 4 & 97.149 & 0,00035 & 34 & 97.132 & 7.162 .323 & 73,72 \\
\hline 5 a 9 & 97.115 & 0,00165 & 160 & 485.175 & 7.065 .190 & 72,75 \\
\hline 10 a 14 & 96.955 & 0,00201 & 194 & 484.287 & 6.580 .016 & 67,87 \\
\hline 15 a 19 & 96.760 & 0,00322 & 312 & 483.021 & 6.095 .728 & 63,00 \\
\hline 20 a 24 & 96.448 & 0,00432 & 417 & 481.199 & 5.612 .707 & 58,19 \\
\hline $25: 29$ & 96.031 & 0,00551 & 529 & 478.835 & 5.131 .508 & 53,44 \\
\hline 30 a 34 & 95.503 & 0,00726 & 693 & 475.780 & 4.652 .673 & 48,72 \\
\hline 35 a 39 & 94.809 & 0,00976 & 925 & 471.733 & 4.176 .894 & 44,06 \\
\hline 40 a 44 & 93.884 & 0,01127 & 1.058 & 466.774 & 3.705 .161 & 39,47 \\
\hline 45 a 49 & 92.826 & 0,01837 & 1.705 & 459.865 & 3.238 .387 & 34,89 \\
\hline $50 \cong 54$ & 91.120 & 0,02707 & 2.467 & 449.433 & 2.778 .522 & 30,49 \\
\hline 55 a 59 & 88.653 & 0,04053 & 3.593 & 434.283 & 2.329 .089 & 26,27 \\
\hline 60 a 64 & 85.060 & 0,05816 & 4.947 & 412.931 & 1.894 .806 & 22,28 \\
\hline 65 a 69 & 80.112 & 0,08459 & 6.777 & 383.621 & 1.481 .875 & 18,50 \\
\hline 70 a 74 & 73.336 & 0,13225 & 9.699 & 342.432 & 1.098 .254 & 14,98 \\
\hline 75 a 79 & 63.637 & 0,20673 & 13.155 & 285.296 & 755.823 & 11,88 \\
\hline 80 et & 50.481 & 1,00000 & 50.481 & 470.527 & 470.527 & 9,32 \\
\hline
\end{tabular}


ANEXO 37 - Tábua de vida de múltiplo decremento, eliminando as doenças do aparelho respiratório como fator de risco de morte para residentes no Município de Salvador - BA em 1996 (sexo masculino).

\begin{tabular}{|c|c|c|c|c|c|c|}
\hline $\begin{array}{c}\mathbf{X} \\
\text { (1) }\end{array}$ & $\begin{array}{l}\mathbf{I}_{\mathbf{X}} \\
(2) \\
\end{array}$ & $\begin{array}{c}{ }_{n} \mathbf{q}_{\mathbf{X}} \\
(3)\end{array}$ & $\begin{array}{l}{ }_{n} \mathbf{d}_{\mathbf{X}} \\
(4)\end{array}$ & $\begin{array}{l}{ }_{n} \mathbf{L}_{\mathbf{X}} \\
(5)\end{array}$ & $\begin{array}{c}\mathbf{T}_{\mathbf{X}} \\
(6)\end{array}$ & $\begin{array}{l}\mathbf{e x}_{\mathbf{x}} \\
(7) \\
\end{array}$ \\
\hline 0 & 100.000 & 0,03581 & 3.581 & 96.910 & 6.598 .770 & 65,99 \\
\hline 1 & 96.419 & 0,00245 & 236 & 96.254 & 6.501 .860 & 67,43 \\
\hline 2 & 96.183 & 0,00117 & 112 & 96.127 & 6.405 .607 & 66,60 \\
\hline 3 & 96.071 & 0,00088 & 85 & 96.028 & 6.309 .480 & 65,68 \\
\hline 4 & 95.986 & 0,00051 & 49 & 95.962 & 6.213 .451 & 64,73 \\
\hline 5 a 9 & 95.937 & 0,00274 & 263 & 479.028 & 6.117 .490 & 63,77 \\
\hline 10 a 14 & 95.674 & 0,00269 & 257 & 477.728 & 5.638 .462 & 58,93 \\
\hline 15 a 19 & 95.417 & 0,01077 & 1.027 & 474.517 & 5.160 .734 & 54,09 \\
\hline 20 a 24 & 94.390 & 0,01613 & 1.522 & 468.144 & 4.686 .217 & 49,65 \\
\hline 25 a 29 & 92.868 & 0,01541 & 1.431 & 460.761 & 4.218 .073 & 45,42 \\
\hline 30 a 34 & 91.437 & 0,01694 & 1.549 & 453.312 & 3.757 .312 & 41,09 \\
\hline 35 a 39 & 89.888 & 0,02180 & 1.960 & 444.540 & 3.304 .000 & 36,76 \\
\hline 40 a 44 & 87.928 & 0,02767 & 2.433 & 433.558 & 2.859 .460 & 32,52 \\
\hline 45 a 49 & 85.495 & 0,03711 & 3.172 & 419.544 & 2.425 .902 & 28,37 \\
\hline 50 a 54 & 82.323 & 0,05496 & 4.524 & 400.302 & 2.006 .358 & 24,37 \\
\hline 55 a 59 & 77.798 & 0,08281 & 6.443 & 372.885 & 1.606 .056 & 20,64 \\
\hline 60 a 64 & 71.356 & 0,11858 & 8.461 & 335.625 & 1.233 .171 & 17,28 \\
\hline 65 a 69 & 62.894 & 0,17426 & 10.960 & 287.072 & 897.546 & 14,27 \\
\hline 70 a 74 & 51.934 & 0,23898 & 12.412 & 228.643 & 610.474 & 11,75 \\
\hline 75 a 79 & 39.523 & 0,34084 & 13.471 & 163.937 & 381.830 & 9,66 \\
\hline 80 et & 26.052 & 1,00000 & 26.052 & 217.893 & 217.893 & 8,36 \\
\hline
\end{tabular}

ANEXO 38 - Tábua de vida de múltiplo decremento, eliminando as doenças do aparelho respiratório como fator de risco de morte para residentes no Município de São Paulo - SP em 1996 (sexo masculino).

\begin{tabular}{|c|c|c|c|c|c|c|}
\hline $\begin{array}{c}\mathbf{X} \\
(1)\end{array}$ & $\begin{array}{l}\mathbf{l}_{\mathbf{X}} \\
(2)\end{array}$ & $\begin{array}{c}\mathbf{n}_{(3)} \mathbf{q} \\
\end{array}$ & $\begin{array}{c}{ }^{n} \mathbf{d}_{\mathbf{X}} \\
(4)\end{array}$ & ${ }_{(5)} \mathbf{n}_{\mathbf{X}}$ & $\begin{array}{c}T_{\mathbf{X}} \\
(6)\end{array}$ & $\begin{array}{l}\mathbf{e x}_{\mathbf{X}} \\
(7) \\
\end{array}$ \\
\hline 0 & 100.000 & 0,02633 & 2.633 & 97.728 & 6.540 .765 & 65,41 \\
\hline 1 & 97.367 & 0,00130 & 127 & 97.278 & 6.443 .037 & 66,17 \\
\hline 2 & 97.240 & 0,00071 & 69 & 97.205 & 6.345 .759 & 65,26 \\
\hline 3 & 97.171 & 0,00063 & 62 & 97.140 & 6.248 .553 & 64,30 \\
\hline 4 & 97.109 & 0,00042 & 41 & 97.089 & 6.151 .414 & 63,35 \\
\hline 5 a 9 & 97.068 & 0,00206 & 200 & 484.840 & 6.054 .325 & 62,37 \\
\hline 10 a 14 & 96.868 & 0,00306 & 297 & 483.598 & 5.569 .485 & 57,50 \\
\hline 15 a 19 & 96.571 & 0,01437 & 1.387 & 479.388 & 5.085 .887 & 52,66 \\
\hline 20 a 24 & 95.184 & 0,02098 & 1.997 & 470.927 & 4.606 .499 & 48,40 \\
\hline 25 a 29 & 93.187 & 0,02587 & 2.411 & 459.906 & 4.135 .572 & 44,38 \\
\hline 30 a 34 & 90.776 & 0,02732 & 2.480 & 447.678 & 3.675 .666 & 40,49 \\
\hline 35 a 39 & 88.296 & 0,03108 & 2.744 & 434.618 & 3.227 .988 & 36,56 \\
\hline 40 a 44 & 85.552 & 0,03571 & 3.055 & 420.121 & 2.793 .370 & 32,65 \\
\hline 45 a 49 & 82.497 & 0,04364 & 3.600 & 403.484 & 2.373.249 & 28,77 \\
\hline 50 a 54 & 78.897 & 0,06006 & 4.739 & 382.637 & 1.969 .764 & 24,97 \\
\hline 55 a 59 & 74.158 & 0,08068 & 5.983 & 355.831 & 1.587 .127 & 21,40 \\
\hline 60 a 64 & 68.175 & 0,11532 & 7.862 & 321.218 & 1.231 .296 & 18,06 \\
\hline 65 a 69 & 60.313 & 0,15330 & 9.246 & 278.449 & 910.078 & 15,09 \\
\hline 70 a 74 & 51.067 & 0,21008 & 10.728 & 228.514 & 631.628 & 12,37 \\
\hline 75 a 79 & 40.339 & 0,29399 & 11.859 & 172.046 & 403.114 & 9,99 \\
\hline 80 et & 28.480 & 1,00000 & 28.480 & 231.068 & 231.068 & 8,11 \\
\hline
\end{tabular}


ANEXO 39 - Tábua de vida de múltiplo decremento, eliminando as doenças do aparelho respiratório como fator de risco de morte para residentes no Município de Salvador - BA em 1996 (sexo feminino).

\begin{tabular}{|c|c|c|c|c|c|c|}
\hline $\begin{array}{c}\mathbf{X} \\
\text { (1) }\end{array}$ & $\begin{array}{l}\mathbf{l}_{\mathbf{X}} \\
(2)\end{array}$ & $\underset{(3)}{\mathbf{n}^{\mathbf{q}} \mathbf{x}}$ & $\underset{(4)}{{ }^{n} \mathbf{d}_{\mathbf{X}}}$ & $\begin{array}{c}{ }_{n} \mathbf{L}_{\mathbf{X}} \\
(5)\end{array}$ & $\begin{array}{c}\mathbf{T}_{\mathbf{X}} \\
(6)\end{array}$ & $\begin{array}{l}\mathbf{e x} \\
(7) \\
\end{array}$ \\
\hline$\overline{0}$ & 100.000 & 0,03642 & 3.642 & 96.991 & 7.213 .913 & 72,14 \\
\hline 1 & 96.358 & 0,00193 & 186 & 96.227 & 7.116 .922 & 73,86 \\
\hline 2 & 96.171 & 0,00119 & 115 & 96.114 & 7.020 .695 & 73,00 \\
\hline 3 & 96.057 & 0,00096 & 92 & 96.011 & 6.924 .580 & 72,09 \\
\hline 4 & 95.965 & 0,00037 & 35 & 95.947 & 6.828 .570 & 71,16 \\
\hline 5 a 9 & 95.929 & 0,00149 & 143 & 479.290 & 6.732 .623 & 70,18 \\
\hline 10 a 14 & 95.786 & 0,00242 & 232 & 478.352 & 6.253 .333 & 65,28 \\
\hline 15 a 19 & 95.554 & 0,00270 & 258 & 477.127 & 5.774 .981 & 60,44 \\
\hline 20 a 24 & 95.296 & 0,00259 & 247 & 475.865 & 5.297 .854 & 55,59 \\
\hline 25 a 29 & 95.050 & 0,00515 & 490 & 474.024 & 4.821 .989 & 50,73 \\
\hline 30 a 34 & 94.560 & 0,00666 & 630 & 471.225 & 4.347 .965 & 45,98 \\
\hline 35 a 39 & 93.930 & 0,01121 & 1.053 & 467.018 & 3.876 .741 & 41,27 \\
\hline 40 a 44 & 92.877 & 0,01748 & 1.623 & 460.327 & 3.409 .723 & 36,71 \\
\hline 45 a 49 & 91.254 & 0,02575 & 2.350 & 450.395 & 2.949.395 & 32,32 \\
\hline 50 a 54 & 88.904 & 0,03771 & 3.353 & 436.139 & 2.499 .000 & 28,11 \\
\hline 55 a 59 & 85.552 & 0,05768 & 4.935 & 415.421 & 2.062 .861 & 24,11 \\
\hline 60 a 64 & 80.617 & 0,07622 & 6.144 & 387.723 & 1.647 .440 & 20,44 \\
\hline 65 a 69 & 74.472 & 0,11853 & 8.827 & 350.295 & 1.259 .717 & 16,92 \\
\hline 70 a 74 & 65.645 & 0,16438 & 10.791 & 301.250 & 909.422 & 13,85 \\
\hline 75 a 79 & 54.854 & 0,25089 & 13.762 & 239.867 & 608.172 & 11,09 \\
\hline 80 et & 41.092 & 1,00000 & 41.092 & 368.306 & 368.306 & 8,96 \\
\hline
\end{tabular}

ANEXO 40 - Tábua de vida de múltiplo decremento, eliminando as doenças do aparelho respiratório como fator de risco de morte para residentes no Município de São Paulo - SP em 1996 (sexo feminino).

\begin{tabular}{|c|c|c|c|c|c|c|}
\hline$\underset{\text { (1) }}{\mathbf{x}}$ & $\begin{array}{l}\mathbf{l}_{\mathbf{X}} \\
(2)\end{array}$ & $\underset{(3)}{{ }_{(3)}}$ & $\begin{array}{l}{ }_{n} \mathbf{d}_{\mathbf{X}} \\
(4)\end{array}$ & ${ }_{(5)} \mathbf{L}_{\mathbf{X}}$ & $\begin{array}{l}T_{\mathbf{X}} \\
(6)\end{array}$ & $\begin{array}{l}\mathbf{e x} \\
(7)\end{array}$ \\
\hline 0 & 100.000 & 0,02162 & 2.162 & 98.214 & 7.614 .380 & 76,14 \\
\hline 1 & 97.838 & 0,00144 & 141 & 97.740 & 7.516 .165 & 76,82 \\
\hline 2 & 97.697 & 0,00085 & 83 & 97.656 & 7.418 .426 & 75,93 \\
\hline 3 & 97.614 & 0,00048 & 47 & 97.591 & 7.320 .770 & 75,00 \\
\hline 4 & 97.567 & 0,00030 & 29 & 97.552 & 7.223 .179 & 74,03 \\
\hline 5 a 9 & 97.538 & 0,00150 & 146 & 487.324 & 7.125 .627 & 73,06 \\
\hline 10 a 14 & 97.392 & 0,00181 & 176 & 486.519 & 6.638 .303 & 68,16 \\
\hline 15 a 19 & 97.216 & 0,00293 & 284 & 485.367 & 6.151 .784 & 63,28 \\
\hline 20 a 24 & 96.931 & 0,00409 & 396 & 483.666 & 5.666 .417 & 58,46 \\
\hline 25 a 29 & 96.535 & 0,00523 & 505 & 481.415 & 5.182 .751 & 53,69 \\
\hline 30 a 34 & 96.031 & 0,00689 & 661 & 478.500 & 4.701 .337 & 48,96 \\
\hline 35 a 39 & 95.369 & 0,00986 & 940 & 474.497 & 4.222 .836 & 44,28 \\
\hline 40 a 44 & 94.430 & 0,01213 & 1.145 & 469.285 & 3.748 .339 & 39,69 \\
\hline 45 a 49 & 93.284 & 0,01935 & 1.805 & 461.910 & 3.279 .054 & 35,15 \\
\hline 50 a 54 & 91.480 & 0,02815 & 2.575 & 450.960 & 2.817 .144 & 30,80 \\
\hline 55 a 59 & 88.904 & 0,04191 & 3.726 & 435.207 & 2.366 .184 & 26,61 \\
\hline 60 a 64 & 85.178 & 0,05930 & 5.051 & 413.265 & 1.930 .977 & 22,67 \\
\hline 65 a 69 & 80.128 & 0,08491 & 6.803 & 383.630 & 1.517 .712 & 18,94 \\
\hline 70 a 74 & 73.324 & 0,13197 & 9.677 & 342.429 & 1.134 .082 & 15,47 \\
\hline 75 a 79 & 63.647 & 0,20412 & 12.992 & 285.757 & 791.653 & 12,44 \\
\hline 80 et & 50.655 & 1,00000 & 50.655 & 505.896 & 505.896 & 9,99 \\
\hline
\end{tabular}


ANEXO 41 - Tábua de vida de múltiplo decremento, eliminando as causas externas como fator de risco de morte para residentes no Município de Salvador - BA em 1996 (sexo masculino).

\begin{tabular}{|c|c|c|c|c|c|c|}
\hline$\underset{\text { (1) }}{\mathbf{x}}$ & $\begin{array}{l}\mathbf{I}_{\mathbf{X}} \\
(2)\end{array}$ & $\begin{array}{r}\mathbf{n}_{(3)} \mathbf{q x} \\
\end{array}$ & $\begin{array}{c}{ }_{n} \mathbf{d}_{\mathbf{X}} \\
(4)\end{array}$ & ${ }_{(5)} \mathbf{L}_{\mathbf{X}}$ & $\underset{(6)}{\mathbf{T}_{\mathbf{X}}}$ & $\begin{array}{l}\mathbf{e x}_{(7)} \\
\text { (7) }\end{array}$ \\
\hline$\overline{0}$ & 100.000 & 0,03946 & 3.946 & 96.595 & 6.695 .239 & 66,95 \\
\hline 1 & 96.054 & 0,00250 & 240 & 95.886 & 6.598 .644 & 68,70 \\
\hline 2 & 95.814 & 0,00127 & 122 & 95.753 & 6.502 .758 & 67,87 \\
\hline 3 & 95.692 & 0,00083 & 80 & 95.653 & 6.407 .005 & 66,95 \\
\hline 4 & 95.613 & 0,00020 & 19 & 95.603 & 6.311 .352 & 66,01 \\
\hline 5 a 9 & 95.593 & 0,00140 & 134 & 477.633 & 6.215 .749 & 65,02 \\
\hline 10 a 14 & 95.460 & 0,00148 & 142 & 476.945 & 5.738 .116 & 60,11 \\
\hline 15 a 19 & 95.318 & 0,00249 & 237 & 475.999 & 5.261 .171 & 55,20 \\
\hline 20 a 24 & 95.081 & 0,00444 & 422 & 474.351 & 4.785 .172 & 50,33 \\
\hline 25 a 29 & 94.659 & 0,00635 & 601 & 471.793 & 4.310 .821 & 45,54 \\
\hline 30 a 34 & 94.058 & 0,01043 & 981 & 467.837 & 3.839 .029 & 40,82 \\
\hline 35 a 39 & 93.077 & 0,01641 & 1.528 & 461.565 & 3.371 .191 & 36,22 \\
\hline 40 a 44 & 91.549 & 0,02354 & 2.155 & 452.359 & 2.909 .627 & 31,78 \\
\hline 45 a 49 & 89.394 & 0,03319 & 2.967 & 439.555 & 2.457 .268 & 27,49 \\
\hline 50 a 54 & 86.428 & 0,05496 & 4.750 & 420.264 & 2.017 .713 & 23,35 \\
\hline 55 a 59 & 81.678 & 0,08392 & 6.855 & 391.253 & 1.597 .449 & 19,56 \\
\hline 60 a 64 & 74.823 & 0,12893 & 9.647 & 349.999 & 1.206 .196 & 16,12 \\
\hline 65 a 69 & 65.176 & 0,18559 & 12.096 & 295.642 & 856.197 & 13,14 \\
\hline 70 a 74 & 53.080 & 0,26614 & 14.127 & 230.085 & 560.555 & 10,56 \\
\hline 75 a 79 & 38.953 & 0,36800 & 14.335 & 158.930 & 330.471 & 8,48 \\
\hline 80 et & 24.619 & 1,00000 & 24.619 & 171.541 & 171.541 & 6,97 \\
\hline
\end{tabular}

ANEXO 42 - Tábua de vida de múltiplo decremento, eliminando as causas externas como fator de risco de morte para residentes no Município de São Paulo - SP em 1996 (sexo masculino).

\begin{tabular}{|c|c|c|c|c|c|c|}
\hline $\begin{array}{c}\mathbf{X} \\
(1)\end{array}$ & $\begin{array}{l}\mathbf{I}_{\mathbf{X}} \\
(2) \\
\end{array}$ & $\underset{(3)}{\mathbf{n}^{\mathbf{q}} \mathbf{x}}$ & $\begin{array}{c}{ }^{n} \mathbf{d}_{\mathbf{X}} \\
(4)\end{array}$ & $\begin{array}{c}{ }_{(5)} \mathbf{L}_{\mathbf{X}} \\
\end{array}$ & $\begin{array}{l}\mathbf{T}_{\mathbf{X}} \\
(6)\end{array}$ & $\begin{array}{l}\mathbf{e x}_{\mathbf{x}} \\
\text { (7) }\end{array}$ \\
\hline 0 & 100.000 & 0,03005 & 3.005 & 97.407 & 6.761 .828 & 67,62 \\
\hline 1 & 96.995 & 0,00174 & 169 & 96.877 & 6.664 .421 & 68,71 \\
\hline 2 & 96.826 & 0,00075 & 73 & 96.789 & 6.567 .544 & 67,83 \\
\hline 3 & 96.753 & 0,00051 & 50 & 96.728 & 6.470 .755 & 66,88 \\
\hline 4 & 96.704 & 0,00028 & 27 & 96.690 & 6.374 .027 & 65,91 \\
\hline 5 a 9 & 96.676 & 0,00120 & 116 & 483.092 & 6.277 .337 & 64,93 \\
\hline 10 a 14 & 96.560 & 0,00114 & 110 & 482.527 & 5.794 .245 & 60,01 \\
\hline 15 a 19 & 96.450 & 0,00205 & 198 & 481.757 & 5.311 .718 & 55,07 \\
\hline 20 a 24 & 96.253 & 0,00362 & 348 & 480.392 & 4.829 .961 & 50,18 \\
\hline 25 a 29 & 95.904 & 0,00923 & 885 & 477.308 & 4.349 .569 & 45,35 \\
\hline 30 a 34 & 95.019 & 0,01450 & 1.378 & 471.651 & 3.872 .261 & 40,75 \\
\hline 35 a 39 & 93.641 & 0,02065 & 1.933 & 463.373 & 3.400 .610 & 36,32 \\
\hline 40 a 44 & 91.708 & 0,02740 & 2.513 & 452.258 & 2.937 .237 & 32,03 \\
\hline 45 a 49 & 89.195 & 0,03876 & 3.457 & 437.333 & 2.484 .978 & 27,86 \\
\hline 50 a 54 & 85.738 & 0,05618 & 4.816 & 416.648 & 2.047 .645 & 23,88 \\
\hline 55 a 59 & 80.921 & 0,08102 & 6.556 & 388.216 & 1.630 .997 & 20,16 \\
\hline 60 a 64 & 74.365 & 0,12023 & 8.941 & 349.473 & 1.242 .781 & 16,71 \\
\hline 65 a 69 & 65.424 & 0,16786 & 10.982 & 299.666 & 893.308 & 13,65 \\
\hline 70 a 74 & 54.442 & 0,23544 & 12.818 & 240.166 & 593.642 & 10,90 \\
\hline 75 a 79 & 41.624 & 0,33786 & 14.063 & 172.964 & 353.475 & 8,49 \\
\hline 80 et & 27.561 & 1,00000 & 27.561 & 180.511 & 180.511 & 6,55 \\
\hline
\end{tabular}


ANEXO 43 - Tábua de vida de múltiplo decremento, eliminando as causas externas como fator de risco de morte para residentes no Município de Salvador - BA em 1996 (sexo feminino).

\begin{tabular}{|c|c|c|c|c|c|c|}
\hline $\begin{array}{c}\mathbf{X} \\
(1) \\
\end{array}$ & $\begin{array}{l}\mathbf{l}_{\mathbf{X}} \\
\text { (2) } \\
\end{array}$ & ${ }_{(3)} \mathbf{q}_{\mathbf{X}}$ & $\begin{array}{r}{ }_{(4)} \mathbf{d}_{\mathbf{X}} \\
\end{array}$ & $\underset{(5)}{{ }_{(5)} \mathbf{L}_{\mathbf{X}}}$ & $\begin{array}{l}\mathbf{T}_{\mathbf{X}} \\
(6)\end{array}$ & $\begin{array}{l}\mathbf{e x} \\
\text { (7) } \\
\end{array}$ \\
\hline 0 & 100.000 & 0,03952 & 3.952 & 96.736 & 7.096 .058 & 70,96 \\
\hline 1 & 96.048 & 0,00292 & 281 & 95.852 & 6.999.322 & 72,87 \\
\hline 2 & 95.767 & 0,00135 & 129 & 95.703 & 6.903 .470 & 72,09 \\
\hline 3 & 95.638 & 0,00080 & 76 & 95.600 & 6.807 .767 & 71,18 \\
\hline 4 & 95.562 & 0,00042 & 40 & 95.542 & 6.712 .167 & 70,24 \\
\hline 5 a 9 & 95.522 & 0,00108 & 103 & 477.352 & 6.616 .625 & 69,27 \\
\hline 10 a 14 & 95.419 & 0,00207 & 197 & 476.601 & 6.139 .273 & 64,34 \\
\hline 15 a 19 & 95.222 & 0,00228 & 217 & 475.567 & 5.662 .672 & 59,47 \\
\hline 20 a 24 & 95.005 & 0,00182 & 173 & 474.593 & 5.187 .105 & 54,60 \\
\hline 25 a 29 & 94.832 & 0,00443 & 420 & 473.110 & 4.712 .513 & 49,69 \\
\hline 30 a 34 & 94.412 & 0,00657 & 620 & 470.510 & 4.239 .403 & 44,90 \\
\hline 35 a 39 & 93.792 & 0,01093 & 1.026 & 466.396 & 3.768 .893 & 40,18 \\
\hline 40 a 44 & 92.766 & 0,01734 & 1.609 & 459.809 & 3.302 .497 & 35,60 \\
\hline 45 a 49 & 91.157 & 0,02593 & 2.363 & 449.878 & 2.842 .688 & 31,18 \\
\hline 50 a 54 & 88.794 & 0,03877 & 3.443 & 435.364 & 2.392 .810 & 26,95 \\
\hline 55 a 59 & 85.351 & 0,05988 & 5.111 & 413.980 & 1.957 .446 & 22,93 \\
\hline 60 a 64 & 80.240 & 0,08268 & 6.634 & 384.617 & 1.543 .466 & 19,24 \\
\hline 65 a 69 & 73.606 & 0,12929 & 9.517 & 344.240 & 1.158 .850 & 15,74 \\
\hline 70 a 74 & 64.090 & 0,17664 & 11.321 & 292.148 & 814.609 & 12,71 \\
\hline 75 a 79 & 52.769 & 0,27253 & 14.381 & 227.894 & 522.461 & 9,90 \\
\hline 80 et & 38.388 & 1,00000 & 38.388 & 294.567 & 294.567 & 7,67 \\
\hline
\end{tabular}

ANEXO 44 - Tábua de vida de múltiplo decremento, eliminando as causas externas como fator de risco de morte para residentes no Município de São Paulo - SP em 1996 (sexo feminino).

\begin{tabular}{|c|c|c|c|c|c|c|}
\hline $\begin{array}{c}\mathbf{X} \\
\text { (1) }\end{array}$ & $\begin{array}{c}\mathbf{L}_{\mathbf{X}} \\
(2)\end{array}$ & $\mathbf{n}_{(3)}$ & $\begin{array}{c}{ }_{n} \mathbf{d}_{\mathbf{X}} \\
(4)\end{array}$ & $\begin{array}{c}{ }_{n} \mathbf{L}_{\mathbf{X}} \\
(5)\end{array}$ & $\begin{array}{l}T_{\mathbf{X}} \\
(6)\end{array}$ & $\begin{array}{l}\mathbf{e x} \\
(7) \\
\end{array}$ \\
\hline$\overline{0}$ & 100.000 & 0,02457 & 2.457 & 97.970 & 7.480 .894 & $\overline{74,81}$ \\
\hline 1 & 97.543 & 0,00183 & 179 & 97.418 & 7.382 .924 & 75,69 \\
\hline 2 & 97.364 & 0,00086 & 84 & 97.322 & 7.285 .506 & 74,83 \\
\hline 3 & 97.280 & 0,00043 & 42 & 97.259 & 7.188 .184 & 73,89 \\
\hline 4 & 97.238 & 0,00024 & 23 & 97.227 & 7.090 .925 & 72,92 \\
\hline 5 a 9 & 97.215 & 0,00109 & 106 & 485.812 & 6.993 .699 & 71,94 \\
\hline 10 a 14 & 97.110 & 0,00112 & 108 & 485.277 & 6.507 .886 & 67,02 \\
\hline 15 a 19 & 97.001 & 0,00140 & 135 & 484.668 & 6.022 .609 & 62,09 \\
\hline 20 a 24 & 96.866 & 0,00258 & 250 & 483.703 & 5.537 .941 & 57,17 \\
\hline 25 a 29 & 96.615 & 0,00421 & 407 & 482.060 & 5.054 .238 & 52,31 \\
\hline 30 a 34 & 96.209 & 0,00594 & 571 & 479.614 & 4.572 .178 & 47,52 \\
\hline 35 a 39 & 95.637 & 0,00934 & 893 & 475.953 & 4.092 .564 & 42,79 \\
\hline 40 a 44 & 94.744 & 0,01192 & 1.129 & 470.897 & 3.616 .611 & 38,17 \\
\hline 45 a 49 & 93.615 & 0,01937 & 1.813 & 463.541 & 3.145 .714 & 33,60 \\
\hline 50 a 54 & 91.802 & 0,02949 & 2.707 & 452.242 & 2.682 .173 & 29,22 \\
\hline 55 a 59 & 89.095 & 0,04345 & 3.871 & 435.797 & 2.229 .931 & 25,03 \\
\hline 60 a 64 & 85.224 & 0,06330 & 5.394 & 412.635 & 1.794 .134 & 21,05 \\
\hline 65 a 69 & 79.830 & 0,09221 & 7.361 & 380.746 & 1.381 .499 & 17,31 \\
\hline 70 a 74 & 72.469 & 0,14619 & 10.594 & 335.859 & 1.000 .753 & 13,81 \\
\hline 75 a 79 & 61.875 & 0,23012 & 14.238 & 273.778 & 664.894 & 10,75 \\
\hline 80 et & 47.636 & 1,00000 & 47.636 & 391.116 & 391.116 & 8,21 \\
\hline
\end{tabular}


ANEXO 45 - Tábua de vida de múltiplo decremento, eliminando os acidentes de transporte como fator de risco de morte para residentes no Município de Salvador - BA em 1996 (sexo masculino).

\begin{tabular}{|c|c|c|c|c|c|c|}
\hline $\begin{array}{c}\mathbf{X} \\
\text { (1) }\end{array}$ & $\begin{array}{r}\mathbf{L}_{\mathbf{X}} \\
(2)\end{array}$ & $\underset{(3)}{\mathbf{n q}}$ & $\begin{array}{c}{ }_{(4)} \mathbf{d}_{\mathbf{x}} \\
\end{array}$ & $\begin{array}{c}{ }_{(5)} \mathbf{L}_{\mathbf{X}} \\
\end{array}$ & $\begin{array}{l}\mathbf{T}_{\mathbf{X}} \\
(6)\end{array}$ & $\begin{array}{l}\mathbf{e x} \\
\text { (7) }\end{array}$ \\
\hline 0 & 100.000 & 0,03977 & 3.977 & 96.568 & 6.429 .318 & 64,29 \\
\hline 1 & 96.023 & 0,00287 & 276 & 95.830 & 6.332 .750 & 65,95 \\
\hline 2 & 95.748 & 0,00158 & 151 & 95.672 & 6.236 .919 & 65,14 \\
\hline 3 & 95.597 & 0,00093 & 89 & 95.552 & 6.141 .247 & 64,24 \\
\hline 4 & 95.508 & 0,00056 & 53 & 95.481 & 6.045 .695 & 63,30 \\
\hline 5 a 9 & 95.454 & 0,00269 & 257 & 476.629 & 5.950 .214 & 62,34 \\
\hline 10 a 14 & 95.197 & 0,00293 & 279 & 475.289 & 5.473 .585 & 57,50 \\
\hline 15 a 19 & 94.919 & 0,01088 & 1.033 & 472.010 & 4.998 .296 & 52,66 \\
\hline 20 a 24 & 93.886 & 0,01590 & 1.492 & 465.697 & 4.526 .286 & 48,21 \\
\hline 25 a 29 & 92.393 & 0,01582 & 1.462 & 458.312 & 4.060 .589 & 43,95 \\
\hline 30 a 34 & 90.932 & 0,01783 & 1.621 & 450.605 & 3.602 .277 & 39,62 \\
\hline 35 a 39 & 89.310 & 0,02243 & 2.003 & 441.543 & 3.151 .672 & 35,29 \\
\hline 40 a 44 & 87.307 & 0,02897 & 2.530 & 430.211 & 2.710 .129 & 31,04 \\
\hline 45 a 49 & 84.777 & 0,03841 & 3.256 & 415.746 & 2.279 .918 & 26,89 \\
\hline 50 a 54 & 81.521 & 0,05955 & 4.854 & 395.470 & 1.864 .172 & 22,87 \\
\hline 55 a 59 & 76.667 & 0,08944 & 6.857 & 366.190 & 1.468 .702 & 19,16 \\
\hline 60 a 64 & 69.809 & 0,13360 & 9.326 & 325.731 & 1.102 .512 & 15,79 \\
\hline 65 a 69 & 60.483 & 0,19375 & 11.719 & 273.119 & 776.780 & 12,84 \\
\hline 70 a 74 & 48.764 & 0,27317 & 13.321 & 210.519 & 503.661 & 10,33 \\
\hline 75 a 79 & 35.443 & 0,37743 & 13.377 & 143.774 & 293.142 & 8,27 \\
\hline 80 et & 22.066 & 1,00000 & 22.066 & 149.368 & 149.368 & 6,77 \\
\hline
\end{tabular}

ANEXO 46 - Tábua de vida de múltiplo decremento, eliminando os acidentes de transporte como fator de risco de morte para residentes no município de São Paulo - SP em 1996 (sexo masculino).

\begin{tabular}{|c|c|c|c|c|c|c|}
\hline $\begin{array}{c}\mathbf{X} \\
(1)\end{array}$ & $\begin{array}{l}\mathbf{l}_{\mathbf{X}} \\
(2)\end{array}$ & $\begin{array}{r}{ }_{\mathbf{n}} \mathbf{q X}_{\mathbf{X}} \\
(3)\end{array}$ & $\begin{array}{c}{ }^{n} \mathbf{d}_{\mathbf{X}} \\
(4)\end{array}$ & ${ }_{(5)} \mathbf{L}_{\mathbf{X}}$ & $\begin{array}{l}T_{\mathbf{X}} \\
(6)\end{array}$ & $\begin{array}{l}\mathbf{e}_{\mathbf{X}} \\
(7)\end{array}$ \\
\hline$\overline{0}$ & 100.000 & 0,03044 & 3.044 & 97.373 & 6.419 .723 & 64,20 \\
\hline 1 & 96.956 & 0,00194 & 188 & 96.824 & 6.322 .350 & 65,21 \\
\hline 2 & 96.768 & 0,00091 & 88 & 96.724 & 6.225 .526 & 64,33 \\
\hline 3 & 96.680 & 0,00065 & 63 & 96.649 & 6.128 .802 & 63,39 \\
\hline 4 & 96.617 & 0,00034 & 33 & 96.601 & 6.032 .153 & 62,43 \\
\hline 5 a 9 & 96.584 & 0,00176 & 170 & 482.496 & 5.935 .553 & 61,45 \\
\hline 10 a 14 & 96.414 & 0,00241 & 233 & 481.490 & 5.453 .056 & 56,56 \\
\hline 15 a 19 & 96.182 & 0,01283 & 1.234 & 477.823 & 4.971 .566 & 51,69 \\
\hline 20 a 24 & 94.947 & 0,01859 & 1.765 & 470.324 & 4.493 .743 & 47,33 \\
\hline 25 a 29 & 93.182 & 0,02404 & 2.240 & 460.311 & 4.023 .420 & 43,18 \\
\hline 30 a 34 & 90.942 & 0,02624 & 2.386 & 448.746 & 3.563 .109 & 39,18 \\
\hline 35 a 39 & 88.556 & 0,03055 & 2.706 & 436.015 & 3.114 .363 & 35,17 \\
\hline 40 a 44 & 85.850 & 0,03611 & 3.100 & 421.500 & 2.678 .348 & 31,20 \\
\hline 45 a 49 & 82.750 & 0,04548 & 3.764 & 404.340 & 2.256 .847 & 27,27 \\
\hline 50 a 54 & 78.986 & 0,06256 & 4.941 & 382.578 & 1.852 .507 & 23,45 \\
\hline 55 a 59 & 74.045 & 0,08642 & 6.399 & 354.227 & 1.469 .929 & 19,85 \\
\hline 60 a 64 & 67.646 & 0,12479 & 8.441 & 317.126 & 1.115 .702 & 16,49 \\
\hline 65 a 69 & 59.205 & 0,17183 & 10.173 & 270.590 & 798.576 & 13,49 \\
\hline 70 a 74 & 49.031 & 0,23953 & 11.744 & 215.796 & 527.986 & 10,77 \\
\hline 75 a 79 & 37.287 & 0,34116 & 12.721 & 154.633 & 312.190 & 8,37 \\
\hline 80 et & 24.566 & 1,00000 & 24.566 & 157.557 & 157.557 & 6,41 \\
\hline
\end{tabular}


ANEXO 47 - Tábua de vida de múltiplo decremento, eliminando os acidentes de transporte como fator de risco de morte para residentes no Município de Salvador - BA em 1996 (sexo feminino).

\begin{tabular}{|c|c|c|c|c|c|c|}
\hline $\begin{array}{c}\mathbf{x} \\
\text { (1) }\end{array}$ & $\begin{array}{l}\mathbf{I X}_{\mathbf{X}} \\
(2)\end{array}$ & $\begin{array}{c}\mathbf{n}_{(3)} \\
(3 \mathbf{x}\end{array}$ & $\begin{array}{c}{ }_{n} \mathbf{n}_{\mathbf{X}} \\
(4)\end{array}$ & ${ }_{(5)} \mathbf{L}_{\mathbf{X}}$ & $\begin{array}{l}\mathbf{T}_{\mathbf{X}} \\
(6)\end{array}$ & $\begin{array}{l}\mathbf{e x} \\
(7)\end{array}$ \\
\hline$\overline{0}$ & 100.000 & 0,03973 & 3.973 & 96.718 & 7.037 .875 & 70,38 \\
\hline 1 & 96.027 & 0,00309 & 297 & 95.819 & 6.941 .157 & 72,28 \\
\hline 2 & 95.730 & 0,00145 & 139 & 95.661 & 6.845 .338 & 71,51 \\
\hline 3 & 95.591 & 0,00101 & 97 & 95.543 & 6.749 .677 & 70,61 \\
\hline 4 & 95.494 & 0,00053 & 50 & 95.469 & 6.654 .135 & 69,68 \\
\hline 5 a 9 & 95.444 & 0,00149 & 142 & 476.866 & 6.558 .665 & 68,72 \\
\hline 10 a 14 & 95.302 & 0,00266 & 254 & 475.876 & 6.081 .800 & 63,82 \\
\hline 15 a 19 & 95.048 & 0,00316 & 301 & 474.491 & 5.605 .923 & 58,98 \\
\hline 20 a 24 & 94.748 & 0,00271 & 257 & 473.097 & 5.131 .433 & 54,16 \\
\hline 25 a 29 & 94.491 & 0,00556 & 525 & 471.143 & 4.658 .335 & 49,30 \\
\hline 30 a 34 & 93.966 & 0,00728 & 684 & 468.119 & 4.187 .193 & 44,56 \\
\hline 35 a 39 & 93.282 & 0,01197 & 1.117 & 463.616 & 3.719 .074 & 39,87 \\
\hline 40 a 44 & 92.165 & 0,01795 & 1.654 & 456.688 & 3.255 .458 & 35,32 \\
\hline 45 a 49 & 90.511 & 0,02726 & 2.467 & 446.385 & 2.798 .769 & 30,92 \\
\hline 50 a 54 & 88.043 & 0,03971 & 3.496 & 431.477 & 2.352 .384 & 26,72 \\
\hline 55 a 59 & 84.547 & 0,06149 & 5.199 & 409.738 & 1.920 .908 & 22,72 \\
\hline 60 a 64 & 79.348 & 0,08494 & 6.740 & 379.891 & 1.511 .170 & 19,04 \\
\hline 65 a 69 & 72.608 & 0,13196 & 9.581 & 339.089 & 1.131 .279 & 15,58 \\
\hline 70 a 74 & 63.027 & 0,18077 & 11.393 & 286.652 & 792.190 & 12,57 \\
\hline 75 a 79 & 51.634 & 0,27601 & 14.251 & 222.540 & 505.538 & 9,79 \\
\hline 80 et & 37.382 & 1,00000 & 37.382 & 282.997 & 282.997 & 7,57 \\
\hline
\end{tabular}

ANEXO 48 - Tábua de vida de múltiplo decremento, eliminando os acidentes de transporte como fator de risco de morte para residentes no Município de São Paulo - SP em 1996 (sexo feminino).

\begin{tabular}{|c|c|c|c|c|c|c|}
\hline $\begin{array}{c}\mathbf{X} \\
\text { (1) }\end{array}$ & $\begin{array}{l}\mathbf{l X}_{\mathbf{X}} \\
(2)\end{array}$ & $\begin{array}{r}\mathbf{n}_{(3)} \\
(3)\end{array}$ & $\begin{array}{c}{ }^{n} \mathbf{d}_{\mathbf{X}} \\
(4)\end{array}$ & $\begin{array}{c}{ }_{n} \mathbf{L}_{\mathbf{X}} \\
(5)\end{array}$ & $\begin{array}{l}T_{X} \\
(6)\end{array}$ & $\begin{array}{l}\mathbf{e x}_{\mathbf{X}} \\
\text { (7) }\end{array}$ \\
\hline$\overline{0}$ & 100.000 & 0,02498 & 2.498 & 97.937 & 7.422 .415 & 74,22 \\
\hline 1 & 97.502 & 0,00200 & 195 & 97.366 & 7.324 .478 & 75,12 \\
\hline 2 & 97.308 & 0,00098 & 95 & 97.260 & 7.227 .112 & 74,27 \\
\hline 3 & 97.212 & 0,00051 & 49 & 97.188 & 7.129 .852 & 73,34 \\
\hline 4 & 97.163 & 0,00027 & 27 & 97.150 & 7.032 .665 & 72,38 \\
\hline 5 a 9 & 97.136 & 0,00134 & 130 & 485.357 & 6.935 .515 & 71,40 \\
\hline 10 a 14 & 97.006 & 0,00167 & 162 & 484.627 & 6.450 .158 & 66,49 \\
\hline 15 a 19 & 96.844 & 0,00270 & 261 & 483.569 & 5.965 .531 & 61,60 \\
\hline 20 a 24 & 96.583 & 0,00386 & 373 & 481.984 & 5.481 .962 & 56,76 \\
\hline 25 a 29 & 96.210 & 0,00511 & 491 & 479.823 & 4.999 .978 & 51,97 \\
\hline 30 a 34 & 95.719 & 0,00698 & 669 & 476.923 & 4.520 .155 & 47,22 \\
\hline 35 a 39 & 95.050 & 0,01022 & 971 & 472.824 & 4.043 .232 & 42,54 \\
\hline 40 a 44 & 94.079 & 0,01275 & 1.199 & 467.399 & 3.570 .408 & 37,95 \\
\hline 45 a 49 & 92.880 & 0,02027 & 1.883 & 459.694 & 3.103 .009 & 33,41 \\
\hline 50 a 54 & 90.997 & 0,03043 & 2.769 & 448.065 & 2.643 .314 & 29,05 \\
\hline 55 a 59 & 88.228 & 0,04431 & 3.909 & 431.369 & 2.195 .250 & 24,88 \\
\hline 60 a 64 & 84.319 & 0,06451 & 5.440 & 407.997 & 1.763 .881 & 20,92 \\
\hline 65 a 69 & 78.880 & 0,09354 & 7.378 & 375.953 & 1.355 .883 & 17,19 \\
\hline 70 a 74 & 71.502 & 0,14756 & 10.550 & 331.132 & 979.931 & 13,71 \\
\hline 75 a 79 & 60.951 & 0,23250 & 14.171 & 269.327 & 648.799 & 10,64 \\
\hline $80 e^{+}$ & 46.780 & 1,00000 & 46.780 & 379.472 & 379.472 & 8,11 \\
\hline
\end{tabular}


ANEXO 49 - Tábua de vida de múltiplo decremento, eliminando as agressões como fator de risco de morte para residentes no Município de Salvador - BA em 1996 (sexo masculino).

\begin{tabular}{|c|c|c|c|c|c|c|}
\hline $\begin{array}{c}\mathbf{x} \\
\text { (1) }\end{array}$ & $\begin{array}{l}\mathbf{I} \\
(2)\end{array}$ & $\begin{array}{l}\text { nqx } \\
\text { (3) }\end{array}$ & $\begin{array}{l}{ }_{n} \mathbf{d}_{\mathbf{X}} \\
(4)\end{array}$ & $\begin{array}{l}{ }_{(5)} \mathbf{L}_{\mathbf{X}} \\
\end{array}$ & $\begin{array}{c}\mathbf{T}_{\mathbf{X}} \\
(6)\end{array}$ & $\begin{array}{l}\mathbf{e x} \\
(7)\end{array}$ \\
\hline$\overline{0}$ & 100.000 & 0,03977 & 3.977 & 96.568 & 6.545 .544 & 65,46 \\
\hline 1 & 96.023 & 0,00287 & 276 & 95.830 & 6.448 .975 & 67,16 \\
\hline 2 & 95.748 & 0,00152 & 146 & 95.675 & 6.353 .145 & 66,35 \\
\hline 3 & 95.602 & 0,00093 & 89 & 95.557 & 6.257 .470 & 65,45 \\
\hline 4 & 95.512 & 0,00066 & 63 & 95.481 & 6.161 .913 & 64,51 \\
\hline 5 a 9 & 95.449 & 0,00264 & 252 & 476.616 & 6.066 .432 & 63,56 \\
\hline 10 a 14 & 95.197 & 0,00257 & 244 & 475.375 & 5.589 .816 & 58,72 \\
\hline 15 a 19 & 94.953 & 0,00528 & 501 & 473.511 & 5.114 .441 & 53,86 \\
\hline 20 a 24 & 94.451 & 0,00803 & 758 & 470.362 & 4.640 .931 & 49,14 \\
\hline 25 a 29 & 93.693 & 0,00932 & 874 & 466.283 & 4.170 .568 & 44,51 \\
\hline 30 a 34 & 92.820 & 0,01433 & 1.330 & 460.773 & 3.704 .286 & 39,91 \\
\hline 35 a 39 & 91.489 & 0,02073 & 1.896 & 452.707 & 3.243 .512 & 35,45 \\
\hline 40 a 44 & 89.593 & 0,02744 & 2.459 & 441.819 & 2.790 .806 & 31,15 \\
\hline 45 a 49 & 87.134 & 0,03711 & 3.233 & 427.589 & 2.348 .986 & 26,96 \\
\hline 50 a 54 & 83.901 & 0,05885 & 4.938 & 407.161 & 1.921 .397 & 22,90 \\
\hline 55 a 59 & 78.963 & 0,08871 & 7.005 & 377.305 & 1.514 .236 & 19,18 \\
\hline 60 a 64 & 71.959 & 0,13336 & 9.597 & 335.801 & 1.136 .931 & 15,80 \\
\hline 65 a 69 & 62.362 & 0,19375 & 12.083 & 281.603 & 801.130 & 12,85 \\
\hline 70 a 74 & 50.279 & 0,27239 & 13.696 & 217.156 & 519.528 & 10,33 \\
\hline 75 a 79 & 36.583 & 0,37743 & 13.808 & 148.398 & 302.371 & 8,27 \\
\hline 80 et & 22.776 & 1,00000 & 22.776 & 153.973 & 153.973 & 6,76 \\
\hline
\end{tabular}

ANEXO 50 - Tábua de vida de múltiplo decremento, eliminando as agressões como fator de risco de morte para residentes no Município de São Paulo SP em 1996 (sexo masculino).

\begin{tabular}{|c|c|c|c|c|c|c|}
\hline $\begin{array}{c}\mathbf{X} \\
\text { (1) }\end{array}$ & $\begin{array}{l}\mathbf{I X}_{\mathbf{X}} \\
(2)\end{array}$ & $\underset{(3)}{\mathbf{n}^{\prime} \mathbf{q}}$ & $\begin{array}{l}\mathbf{n} \mathbf{d}_{\mathbf{X}} \\
\text { (4) }\end{array}$ & $\begin{array}{c}{ }_{n} \mathbf{L}_{\mathbf{X}} \\
(5)\end{array}$ & $\begin{array}{l}\mathbf{T}_{\mathbf{X}} \\
(6)\end{array}$ & $\begin{array}{l}\mathbf{e x} \\
(7) \\
\end{array}$ \\
\hline$\overline{0}$ & 100.000 & 0,03048 & 3.048 & 97.369 & 6.558 .004 & 65,58 \\
\hline 1 & 96.952 & 0,00193 & 187 & 96.821 & 6.460 .635 & 66,64 \\
\hline 2 & 96.765 & 0,00090 & 87 & 96.721 & 6.363 .814 & 65,77 \\
\hline 3 & 96.678 & 0,00071 & 68 & 96.643 & 6.267 .093 & 64,82 \\
\hline 4 & 96.609 & 0,00046 & 44 & 96.587 & 6.170 .450 & 63,87 \\
\hline 5 a 9 & 96.565 & 0,00218 & 210 & 482.298 & 6.073 .863 & 62,90 \\
\hline 10 a 14 & 96.354 & 0,00291 & 281 & 481.070 & 5.591 .564 & 58,03 \\
\hline 15 a 19 & 96.074 & 0,00655 & 629 & 478.796 & 5.110 .494 & 53,19 \\
\hline 20 a 24 & 95.444 & 0,00951 & 907 & 474.954 & 4.631 .698 & 48,53 \\
\hline 25 a 29 & 94.537 & 0,01500 & 1.418 & 469.140 & 4.156 .744 & 43,97 \\
\hline 30 a 34 & 93.119 & 0,01993 & 1.855 & 460.956 & 3.687 .604 & 39,60 \\
\hline 35 a 39 & 91.264 & 0,02724 & 2.486 & 450.102 & 3.226 .647 & 35,36 \\
\hline 40 a 44 & 88.777 & 0,03352 & 2.976 & 436.448 & 2.776 .545 & 31,28 \\
\hline 45 a 49 & 85.802 & 0,04407 & 3.781 & 419.555 & 2.340 .097 & 27,27 \\
\hline 50 a 54 & 82.020 & 0,06232 & 5.111 & 397.323 & 1.920 .542 & 23,42 \\
\hline 55 a 59 & 76.909 & 0,08599 & 6.614 & 368.011 & 1.523 .219 & 19,81 \\
\hline 60 a 64 & 70.295 & 0,12525 & 8.805 & 329.464 & 1.155 .208 & 16,43 \\
\hline 65 a 69 & 61.490 & 0,17307 & 10.642 & 280.847 & 825.744 & 13,43 \\
\hline 70 a 74 & 50.848 & 0,24121 & 12.265 & 223.578 & 544.897 & 10,72 \\
\hline 75 a 79 & 38.583 & 0,34381 & 13.265 & 159.752 & 321.319 & 8,33 \\
\hline 80 et & 25.318 & 1,00000 & 25.318 & 161.566 & 161.566 & 6,38 \\
\hline
\end{tabular}


ANEXO 51 - Tábua de vida de múltiplo decremento, eliminando as agressões como fator de risco de morte para residentes no Município de Salvador - BA em 1996 (sexo feminino).

\begin{tabular}{|c|c|c|c|c|c|c|}
\hline $\begin{array}{c}\mathbf{X} \\
\text { (1) }\end{array}$ & $\begin{array}{l}\mathbf{I}_{\mathbf{X}} \\
(2)\end{array}$ & $\begin{array}{c}\mathbf{n q x} \\
(3)\end{array}$ & $\begin{array}{c}\mathbf{n}_{\mathbf{n}} \mathbf{d}_{\mathbf{x}} \\
(4)\end{array}$ & ${ }_{(5)} \mathbf{L}_{\mathbf{X}}$ & $\begin{array}{l}T_{\mathbf{X}} \\
(6)\end{array}$ & $\begin{array}{l}\mathbf{e x} \\
(7) \\
\end{array}$ \\
\hline 0 & 100.000 & 0,03973 & 3.973 & 96.718 & 7.043 .999 & $\overline{70,44}$ \\
\hline 1 & 96.027 & 0,00309 & 297 & 95.819 & 6.947 .281 & 72,35 \\
\hline 2 & 95.730 & 0,00150 & 144 & 95.658 & 6.851 .462 & 71,57 \\
\hline 3 & 95.586 & 0,00101 & 97 & 95.538 & 6.755 .803 & 70,68 \\
\hline 4 & 95.489 & 0,00047 & 45 & 95.467 & 6.660 .266 & 69,75 \\
\hline 5 a 9 & 95.444 & 0,00139 & 132 & 476.891 & 6.564 .799 & 68,78 \\
\hline 10 a 14 & 95.312 & 0,00266 & 254 & 475.925 & 6.087 .908 & 63,87 \\
\hline 15 a 19 & 95.058 & 0,00277 & 264 & 474.633 & 5.611 .983 & 59,04 \\
\hline 20 a 24 & 94.795 & 0,00227 & 215 & 473.437 & 5.137 .350 & 54,19 \\
\hline 25 a 29 & 94.580 & 0,00520 & 491 & 471.671 & 4.663 .913 & 49,31 \\
\hline 30 a 34 & 94.089 & 0,00714 & 672 & 468.763 & 4.192 .242 & 44,56 \\
\hline 35 a 39 & 93.417 & 0,01186 & 1.108 & 464.313 & 3.723 .479 & 39,86 \\
\hline 40 a 44 & 92.308 & 0,01815 & 1.675 & 457.354 & 3.259 .166 & 35,31 \\
\hline 45 a 49 & 90.633 & 0,02726 & 2.470 & 446.989 & 2.801 .812 & 30,91 \\
\hline 50 a 54 & 88.163 & 0,03971 & 3.501 & 432.061 & 2.354 .823 & 26,71 \\
\hline 55 a 59 & 84.662 & 0,06135 & 5.194 & 410.324 & 1.922 .762 & 22,71 \\
\hline 60 a 64 & 79.468 & 0,08494 & 6.750 & 380.465 & 1.512 .439 & 19,03 \\
\hline 65 a 69 & 72.718 & 0,13216 & 9.611 & 339.564 & 1.131 .974 & 15,57 \\
\hline 70 a 74 & 63.107 & 0,18132 & 11.443 & 286.930 & 792.410 & 12,56 \\
\hline 75 a 79 & 51.665 & 0,27601 & 14.260 & 222.674 & 505.480 & 9,78 \\
\hline 80 et & 37.405 & 1,00000 & 37.405 & 282.806 & 282.806 & 7,56 \\
\hline
\end{tabular}

ANEXO 52 - Tábua de vida de múltiplo decremento, eliminando as agressões como fator de risco de morte para residentes no Município de São Paulo SP em 1996 (sexo feminino).

\begin{tabular}{|c|c|c|c|c|c|c|}
\hline $\begin{array}{c}\mathbf{X} \\
\text { (1) }\end{array}$ & $\begin{array}{l}\mathbf{I X}_{\mathbf{X}} \\
(2)\end{array}$ & ${ }_{(3)} \mathbf{q u}_{(3)}$ & $\begin{array}{l}{ }_{n} \mathbf{d x}_{(4)} \\
\end{array}$ & ${ }_{(5)} \mathbf{L}_{\mathbf{X}}$ & $\begin{array}{l}\mathbf{T}_{\mathbf{X}} \\
(6)\end{array}$ & $\begin{array}{l}\mathbf{e x} \\
\text { (7) }\end{array}$ \\
\hline 0 & 100.000 & 0,02501 & 2.501 & 97.934 & 7.413 .821 & 74,14 \\
\hline 1 & 97.499 & 0,00205 & 200 & 97.359 & 7.315 .887 & 75,04 \\
\hline 2 & 97.299 & 0,00102 & 99 & 97.249 & 7.218 .528 & 74,19 \\
\hline 3 & 97.200 & 0,00056 & 54 & 97.173 & 7.121 .278 & 73,26 \\
\hline 4 & 97.146 & 0,00035 & 34 & 97.129 & 7.024.106 & 72,30 \\
\hline 5 a 9 & 97.112 & 0,00160 & 156 & 485.168 & 6.926 .977 & 71,33 \\
\hline $10 \cong 14$ & 96.956 & 0,00178 & 172 & 484.348 & 6.441 .809 & 66,44 \\
\hline 15 a 19 & 96.783 & 0,00247 & 239 & 483.319 & 5.957 .461 & 61,55 \\
\hline 20 a 24 & 96.544 & 0,00354 & 342 & 481.866 & 5.474 .142 & 56,70 \\
\hline 25 a 29 & 96.202 & 0,00520 & 501 & 479.760 & 4.992 .276 & 51,89 \\
\hline 30 a 34 & 95.702 & 0,00694 & 664 & 476.848 & 4.512 .516 & 47,15 \\
\hline 35 a 39 & 95.037 & 0,01032 & 981 & 472.734 & 4.035 .669 & 42,46 \\
\hline 40 a 44 & 94.056 & 0,01276 & 1.200 & 467.281 & 3.562 .934 & 37,88 \\
\hline 45 a 49 & 92.856 & 0,02060 & 1.912 & 459.499 & 3.095 .654 & 33,34 \\
\hline $50 \geq 54$ & 90.944 & 0,03060 & 2.783 & 447.760 & 2.636 .154 & 28,99 \\
\hline 55 a 59 & 88.160 & 0,04503 & 3.970 & 430.876 & 2.188 .394 & 24,82 \\
\hline 60 a 64 & 84.190 & 0,06479 & 5.454 & 407.315 & 1.757 .518 & 20,88 \\
\hline 65 a 69 & 78.736 & 0,09413 & 7.411 & 375.151 & 1.350 .203 & 17,15 \\
\hline 70 a 74 & 71.325 & 0,14856 & 10.596 & 330.133 & 975.052 & 13,67 \\
\hline 75 a 79 & 60.729 & 0,23416 & 14.220 & 268.093 & 644.919 & 10.62 \\
\hline 80 et & 46.509 & 1,00000 & 46.509 & 376.825 & 376.825 & 8,10 \\
\hline
\end{tabular}

